\title{
Expression screen for Wnt signaling-like phenotypes identifies Fam132b as a novel inhibitor of BMP signaling in Xenopus
}

\author{
Doctoral Thesis
}

\begin{abstract}
Dissertation for the award of the degree "Doctor rerum naturalium (Dr.rer.nat)" at the Georg-August-University Göttingen Faculty of Biology
\end{abstract}

\author{
submitted by \\ Juliane Melchert \\ born in Neubrandenburg, Germany
}

Göttingen 2013 
Members of the Thesis Committee

Prof. Dr. Tomas Pieler

Developmental Biochemistry, Georg-August-University, Göttingen

Prof. Dr. Ernst A. Wimmer

Developmental Biology, Georg-August-University, Göttingen

Members of the Examination Board

Referee: Prof. Dr. Tomas Pieler

Developmental Biochemistry, Georg-August-University, Göttingen

Co-referee: Prof. Dr. Ernst A. Wimmer

Developmental Biology, Georg-August-University, Göttingen

Further members of the Examination Board

Prof. Dr. Annette Borchers

Molecular Embryology, Philipps University, Marburg

Prof. Dr. Detlef Doenecke

Molecular Biology, Georg-August-University, Göttingen

Prof. Dr. Sigrid Hoyer-Fender

Developmental Biology, Georg-August-University, Göttingen

Prof. Dr. Ahmed Mansouri

Molecular Cell differentiation, Max Planck Institute for Biophysical Chemistry 


\begin{abstract}
Affidavit
Herewith I declare that I prepared the PhD thesis "Expression screen for Wnt signaling-like phenotypes identifies Fam132b as a novel inhibitor of BMP signaling in Xenopus" on my own and with no other sources and aids than quoted.
\end{abstract}

01.02.2013

Submission date

Juliane Melchert 
Abstract

List of Figures VII

List of Tables X

Abbreviations XI

1. Introduction 1

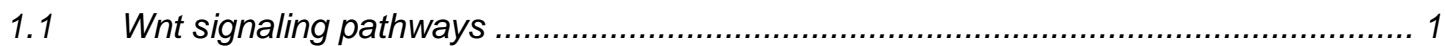

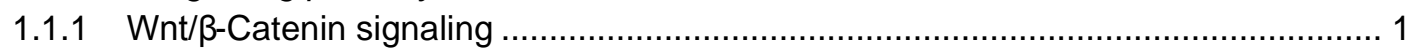

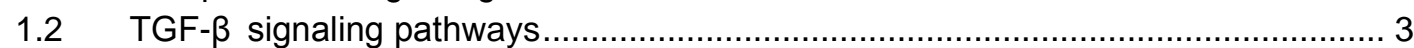

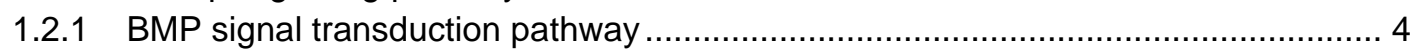

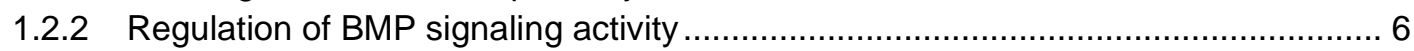

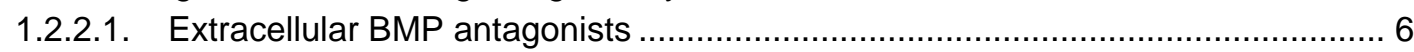

1.2.2.2. BMP regulation on the receptor or cytoplasmic level ................................. 9

1.3 Development of the blood circulatory system in vertebrates .............................. 11

1.3.1 Development of blood and vessels during Xenopus embryogenesis .................. 11

1.3.2 Blood and vascular development from the hemangioblast and the hemogenic

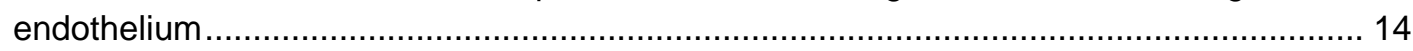

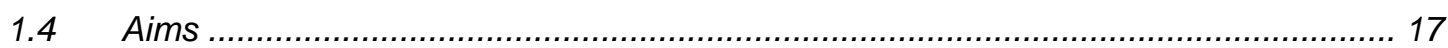

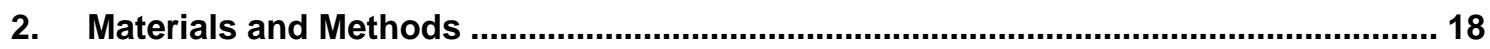

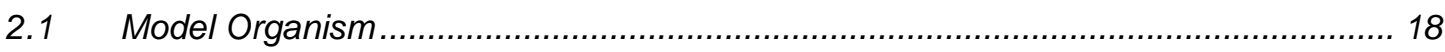

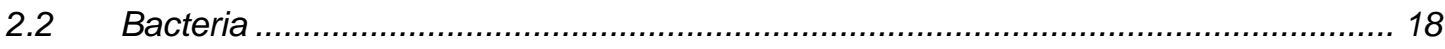

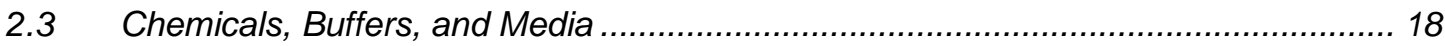

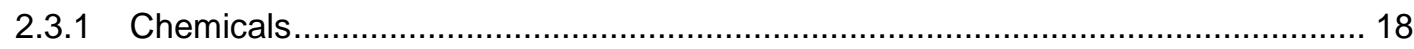

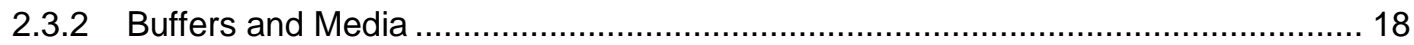

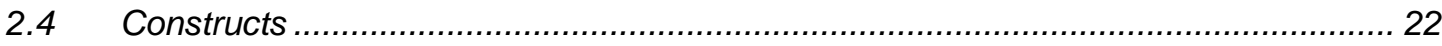

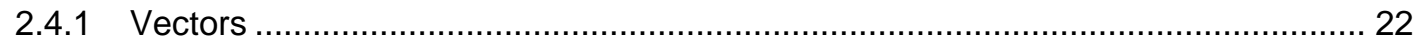

2.4.2 Expression constructs and luciferase reporters ........................................ 24

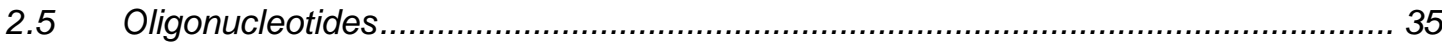

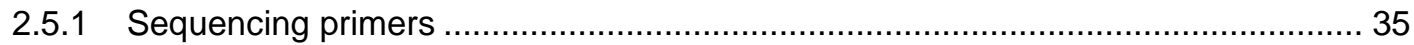

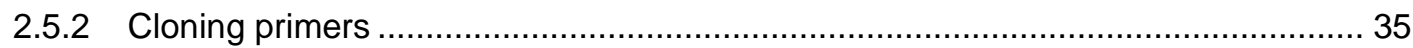

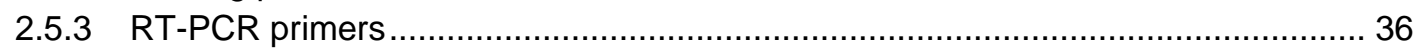

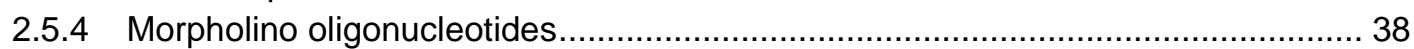

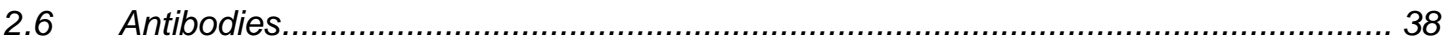

2.7 Chemical transformation and cultivation of bacterial cells .................................... 39

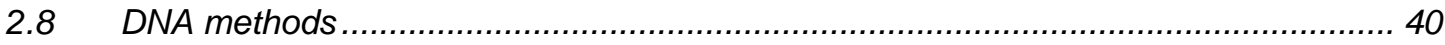

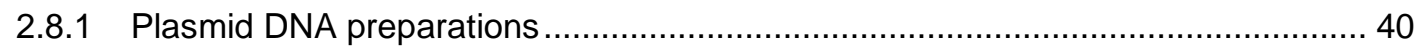

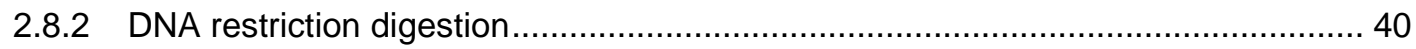

2.8.3 Agarose gel electrophoresis.............................................................. 40

2.8.4 Purification of DNA fragments from agarose gel or restriction digestion mixture ... 41

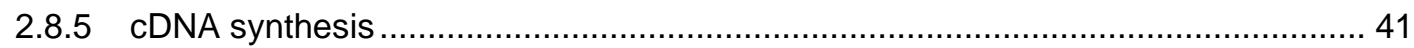

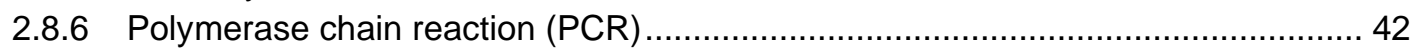

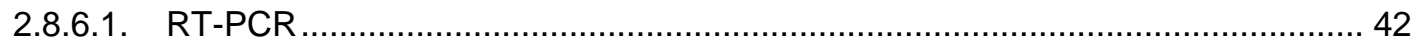




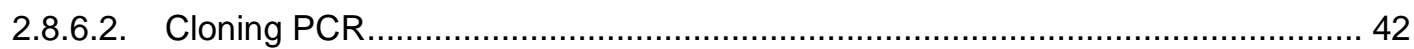

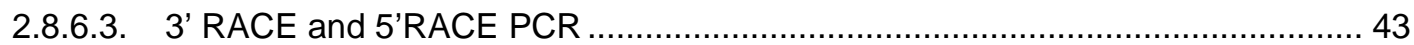

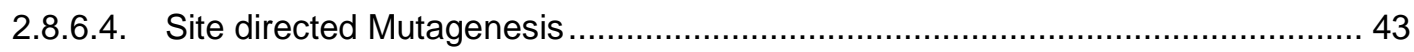

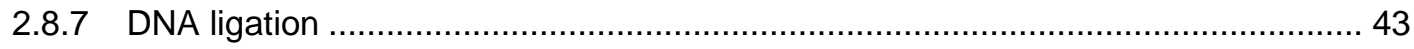

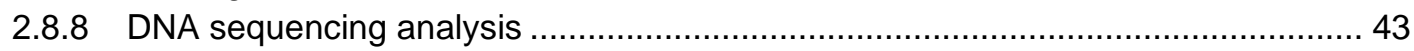

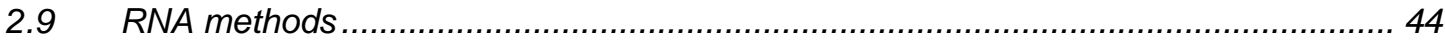

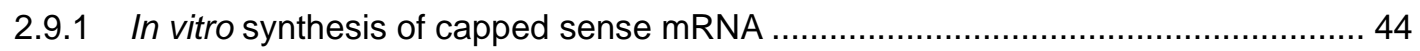

2.9.2 In vitro synthesis of labeled antisense RNA ....................................................... 45

2.9.3 Total RNA extraction from whole embryos and embryonic explants .......................46 46

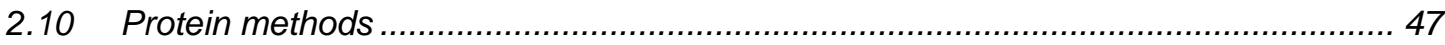

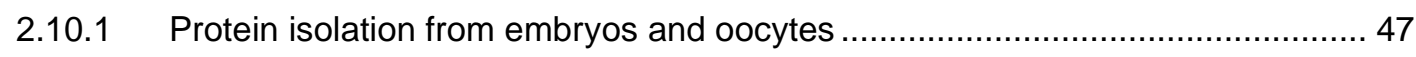

2.10.2 Protein isolation from oocyte culture medium ............................................ 47

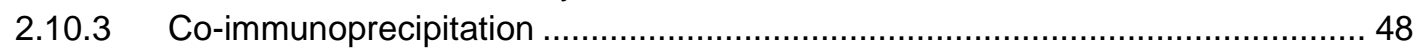

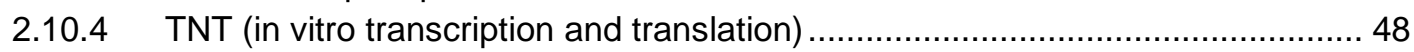

2.10.5 Protein electrophoresis under denaturing conditions (SDS-PAGE) ................... 48

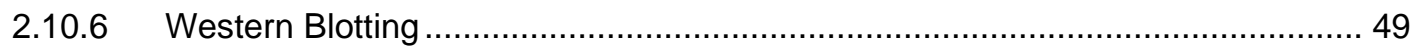

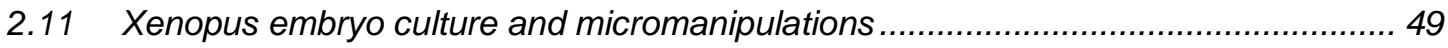

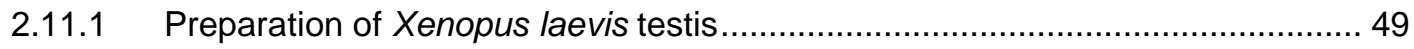

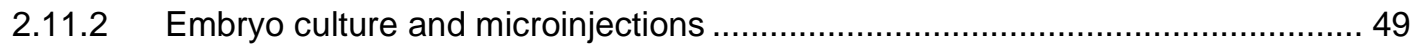

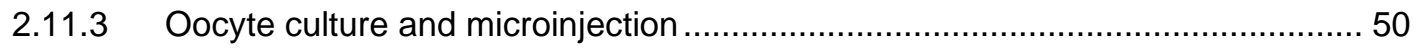

2.11.4 Xenopus ectodermal and ventral mesodermal explants ................................. 50

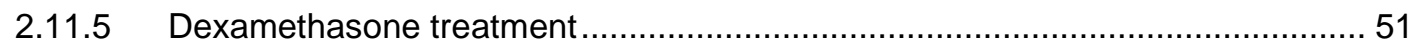

2.12 Xenopus tropicalis "Full-Length" Library Expression Screen ................................... 51

2.13 Whole mount in situ hybridization (WMISH) ....................................................... 52

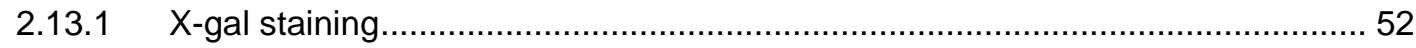

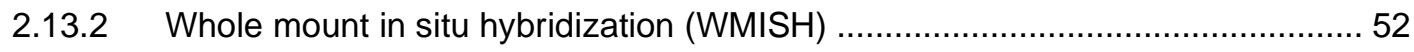

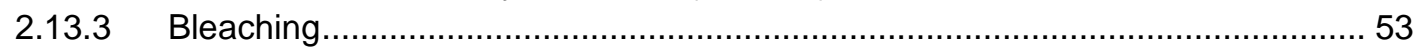

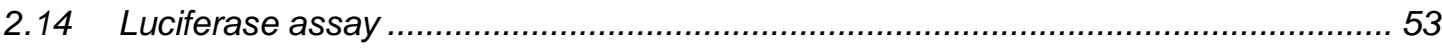

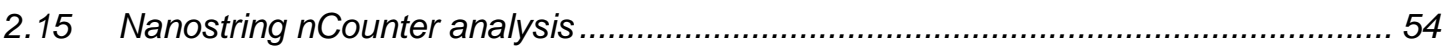

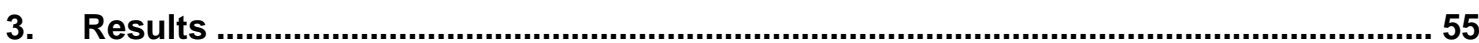

3.1 Temporally controlled modulation of canonical Wnt signaling activity in Xenopus

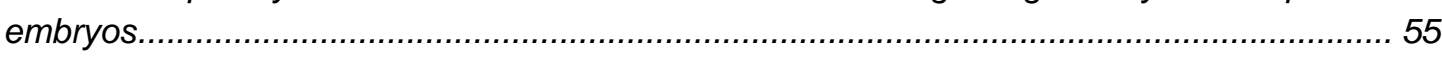

3.2 Modulation of canonical Wnt signaling activity interferes with pancreas specification and differentiation.

3.3 Ectopic Fam132b induces formation of a secondary body axis in Xenopus embryos 64

3.4 Fam132b does not activate Wnt/ $\beta$-Catenin signaling ............................................. 67

3.5 BMP signaling activity is repressed by ectopic Fam132b expression ........................ 69

3.6 Fam132b selectively inhibits BMP signaling ......................................................... 72

3.7 The BMP antagonizing activity of Fam132b is mediated on the extracellular level.... 74

3.8 Fam132b physically interacts with BMP specific type I receptors ............................. 76

3.9 The conserved C1qTNF-like domain is dispensable for the BMP antagonizing activity

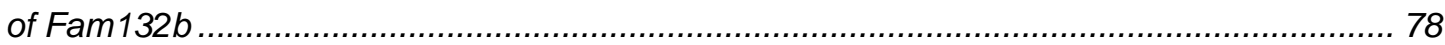

3.10 The BMP antagonizing activity of Fam132b is not highly conserved........................ 80

3.11 Fam132b is expressed in ventral blood islands and circulating blood cells .............. 83 
3.12 Etv2 induces Fam132b expression ..................................................... 85

3.13 Fam132b promotes vascular and suppresses hematopoietic development............. 87

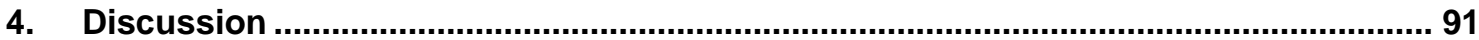

4.1 Modification of canonical Wnt signaling using GR-fusion constructs...................... 91

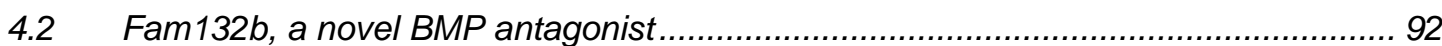

4.3 Fam132b, a member of the secreted C1q domain containing protein family ............ 94

4.4 The role of Fam132b during development of blood and vasculature........................ 97

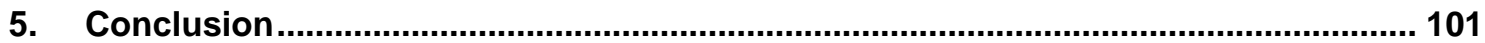

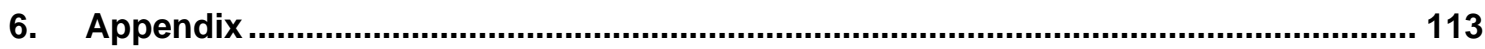

6.1 Genes analyzed by Nanostring $n$ Counter ............................................ 113

6.2 Primary gene expression data ...................................................... 115

6.3 Processed data from Nanostring $n$ Counter analysis...................................... 122 


\section{Acknowledgements}

First of all, I would like to thank my supervisor Prof. Pieler for giving me the opportunity to do my PhD thesis in his laboratory and to work on a very interesting project. I am grateful for all the guidance and help.

Additionally, I thank Prof. Wimmer, who kindly agreed to be second examiner of my thesis and Prof. Borchers, Prof. Doenecke, Prof. Hoyer-Fender and Prof. Mansouri who agreed to be member of my extended examination Board.

I would like to thank Kris Henningfeld, who supported me a lot with her knowledge and experience when I entered a new scientific field.

Furthermore, I want to thank the former Neuro people for welcoming me and even start the era of Norgano-group, when I moved into their laboratory.

I want to thank all my colleagues in the Dept. of Developmental Biochemistry, especially Katja Ditter, Ilona Wunderlich, Marie Hedderich, Patrick Berndt, Maja Gere,Kris Henningfeld, Juliane Wellner, and Diana Obermann for the great atmosphere, team spirit and encouragement.

I want to thank my friends, who were happy for me when I was fine and who encouraged me when I was not at my best.

Finally, I want to thank my family, especially my parents, for their love and their patience. I also want to thank my sister for taking care of me when I was in need of comfort. 


\section{Abstract}

The canonical Wnt signaling pathway is known to regulate multiple developmental events, including development of the digestive tract. In this study, we wanted to systematically analyze the role of the $\mathrm{Wnt} / \beta$-Catenin signaling pathway during early and late phases of endodermal organogenesis. We generated a set of putative hormone-inducible activators or repressors of the canonical Wnt signaling pathway. Analysis of Wnt target gene expression and axis formation assays revealed that only a subset of these GR-fusion proteins is indeed inducible. These constructs were overexpressed in the endoderm of Xenopus embryos and protein activity was induced before or after specification of endodermal precursor cells. Analysis of pancreatic marker gene expression revealed that activation as well as repression of canonical Wnt signaling, early and late, inhibit exocrine pancreatic development.

Expression cloning was used to identify novel regulators of early embryonic patterning.We indentified Fam132b as a factor that induces hyperdorsalization and secondary axis formation in Xenopus embryos. Analysis of Wnt and BMP target gene expression as well as luciferase reporter experiments revealed that Fam132b does not regulate Wnt signaling activity, but antagonizes the BMP signaling pathway. Fam132b contains a conserved C-terminal C1q domain and an N-terminal signal peptide. Overexpression studies in oocytes demonstrate that Fam132b is indeed a secreted factor. Analysis of endogenous target gene expression and promoter reporter studies indicated that Fam132b selectively inhibits BMP and not activin or FGF induced signaling, and that inhibition occurs at the extracellular level. Fam132b strongly interacts with BMP type I receptors, and weakly with BMP4 itself, as demonstrated by ColP experiments. Fam132b deletion analysis demonstrated that the $\mathrm{C} 1 \mathrm{q}$ domain is dispensable for the BMP antagonizing activity. Sequence analysis and axis duplication assays revealed that Fam132b protein sequence and protein function are only weakly conserved in a comparison of Xenopus and other vertebrate species.

Fam132b is expressed in the ventral blood islands and later in circulating blood cells. In animal cap explants Fam132b is induced by Etv2/er71, which is known to activate expression of endothelial and hematopoietic genes in this system.Analysis of hematopoietic and vascular marker gene expression in 
Etv2/er71 expressing animal cap explants using multiplex Nanostring nCounter analysis revealed that Fam132b can enhance endothelial development at the expense of blood cell lineages. 


\section{List of Figures}

Figure 1 Overview of the $\mathrm{Wnt} / \beta$-Catenin-mediated signaling pathway

Figure 2 BMP signal transduction pathway

Figure 3 Extracellular mechanisms for modulation of BMP signaling activity

Figure 4 Intracellular regulation of BMP signaling activity

Figure 5 The VBI and the DLP contribute to the formation of primitive and definitive blood as well as to the vascular system

Figure 6 Ontogeny of the anterior and the posterior portion of the VBI and the DLP

Figure 7 Overlapping expression pattern of Xfli-1 and SCL marks hemangioblast formation in the VBI and the DLP

Figure 8 Development of hematopoietic and vascular cell types from the hemangioblast

Figure 9 Schematic representation of GR-fusion constructs employed for modulation of Wnt signaling

GR-fusion constructs were tested for canonical Wnt

Figure 10 signaling modulating activity and DEX-inducibility using axis duplication or ventralization assay

Figure 11 Activity and DEX-inducibilty of GR-fusion constructs as tested by gene expression analysis in animal cap explants

Stimulation and Inhibition of canonical Wnt signaling before

Figure 12 and after pancreatic specification result in a reduced expression of the exocrine pancreatic marker XPDIp

Figure 13 Schematic illustration of expression cloning

Figure 14 Expression cloning identifies Fam132b a dorsalizing factor

Figure 15

Fam132b induces secondary axis formation upon ventral overexpression 
Overexpression of Fam132b does not modulate

Figure 16 endogenous or ectopicaly activated canonical Wnt signaling 68 activity

Figure 17 Overexpression of Fam132b antagonizes BMP-mediated target gene transcription

Fam132b represses BMP4- and BMP2-mediated BMP

Figure $18 \begin{array}{ll}\text { Fam132b represses } \\ \text { signaling activity }\end{array}$

Fam132b selectively antagonizes BMP induced target gene transcription

Figure 19

Figure 20 Fam132b is a secreted protein

Figure 21 Fam132b inhibits BMP signaling activity on the extracellular level

Figure 22 Fam132b strongly interacts with BMP type I receptors, and weakly with BMP4

Figure 23 The Fam132b C1q domain is dispensable for Fam132b-

Figure 24 Fam132b amino-terminal domain is sufficient to block BMP signaling in animal cap cells

Figure 25 Sequence comparison of vertebrate Fam132b

Figure 26 Xenopus but not mouse or zebrafish Fam123 can induce secondary axis formation

Figure 27 Fam132b is expressed in the VBI and in circulating blood cells

Figure 28 Fam132b is expressed in differentiated blood cells

Figure 29

Figure 30

Figure 31
Overexpression of Etv2/er71 in animal caps induces expression of Fam132b

Fam132b MO1 and MO2 efficiently block reporter protein synthesis

Fam132b enhances expression of vascular genes at the expense of blood markers 
Figure 32 Model for Fam132b mediated BMP antagonism via receptor interaction Figure 33 Cartoon depicting the structural motifs of the C1q family
members

Figure 34 Model for Fam132b activity in the context of cell fate determination in Etv2/er71 expressing animal cap cells 


\section{List of Tables}

Table 1 Expression constructs and luciferase preporters

Table 2 Linearization of DNA constructs and in vitro transcription

Table 3 RT-PCR primers

Table 4 Anisense Morpholino oligonucleotides

Table 5 Antibodies

Table 6 Total amounts of injected RNAs with respect to pool size

Table 7 Summary of canonical Wnt signaling modulating activity and DEX inducibility of GR-fusion constructs used in this study

Table 8 Summary of Gene symbols, Accession numbers, Target regions and Target sequences for all genes analyzed by Nanostring nCounter

Table 9 Primary gene expression data from Nanostring nCounter analysis for experiment 1

Table 10 Primary gene expression data from Nanostring nCounter analysis for experiment 2

Table 11 Averaged fold changes over Etv2 of two independent experiments

Table 12 Standard errors of the fold change over Etv2 shown in Table 


\section{Abbreviations}

\begin{tabular}{|c|c|}
\hline A & Alanin \\
\hline AP & alkaline phosphatase \\
\hline AA & amino acid \\
\hline $\mathrm{BCIP}$ & 5-bromo-4-chloro-3-indolyl-phosphate \\
\hline BMB & Bohringer Mannheim blocking reagent \\
\hline BMP & bone morphogenetic protein \\
\hline bp & base pairs \\
\hline BSA & bovine serum albumin \\
\hline${ }^{\circ} \mathrm{C}$ & Celsius degree \\
\hline cDNA & complementary DNA \\
\hline DEX & dexamethasone \\
\hline Dig & dioxigenine \\
\hline DNA & desoxyribonucleic acid \\
\hline DNAse & desoxyribonuclease \\
\hline DTT & 1,4-dithiothreitol \\
\hline EDTA & ethylendiaminetetraacetic acid \\
\hline EGTA & ethylenglycolel-bis(2-aminoethylether)-N,N'- tetraacetate \\
\hline et al. & et alii \\
\hline $\mathrm{EtOH}$ & ethanol \\
\hline Fam132b & Family with sequence similarity, member B \\
\hline Gad1 & glutamatic acid decarboxylase \\
\hline hrs & hours \\
\hline HCG & human chorionic gondaotropin \\
\hline $\mathrm{H}_{2} \mathrm{O}$ & water \\
\hline $\mathrm{k}$ & kilo \\
\hline $\mathrm{kb}$ & kilobase \\
\hline $\mathrm{L}$ & liter \\
\hline LB & Luria-Bertani \\
\hline$\mu$ & Micro \\
\hline $\mathrm{m}$ & milli \\
\hline M & molar \\
\hline MAB & maleic acid buffer \\
\hline
\end{tabular}




\begin{tabular}{|c|c|}
\hline MEM & MOPS-EGTA-MgSo4 buffer \\
\hline MEMFA & MOPS-EGTA-MgSo4 formaldehyde buffer \\
\hline $\min$ & minutes \\
\hline mRNA & messenger RNA \\
\hline $\mathrm{n}$ & Nano \\
\hline $\mathrm{NaAC}$ & sodium acetate \\
\hline NBT & nitro-blue-tetrazolium \\
\hline OD & optic density \\
\hline PAGE & polyacrylamid gel elektrophoresis \\
\hline PBS & phosphate buffered saline \\
\hline PCR & polymerase chain reaction \\
\hline $\mathrm{pH}$ & negative decade logarithm of hydrogen ion concentration \\
\hline$\%$ & percentage \\
\hline RNA & ribnucleic acid \\
\hline RNase & ribonuclease \\
\hline rpm & rounds per minute \\
\hline RT & room temperature, reverse transcriptase \\
\hline RT-PCR & reverse transcriptase PCR \\
\hline SDS & sodium dodecyl sulfate \\
\hline sec & second \\
\hline SSC & standard saline citrate buffer \\
\hline st & stage \\
\hline TA & annealing temperature \\
\hline Taq & Thermus aquaticus \\
\hline Tm & melting temperature \\
\hline$U$ & units \\
\hline $\mathrm{V}$ & voltage \\
\hline Vol & volume \\
\hline W & Tryptophan \\
\hline WMISH & "Whole Mount" in situ hybridization \\
\hline X-Gal & 5-bromo-4-chloro-3-indolyl- $\beta$-d-galactoside \\
\hline
\end{tabular}




\section{Introduction}

\subsection{Wnt signaling pathways}

The wnt genes encode a large family of secreted glycoproteins with a highly conserved cysteine-rich domain (Angers and Moon, 2009; Croce and McClay, 2008). The term Wnt is composed of the Drosophila segment polarity gene wingless $(\mathrm{wg})$ and the mouse proto-oncogene int-1, two genes that have independently been discovered and later shown to encode homologous proteins (Baker, 1987; Nusse and Varmus, 1982; Rijsewijk et al., 1987; Sharma and Chopra, 1976; van Ooyen and Nusse, 1984).

The Wnt family of proteins can be subdivided into canonical and non-canonical ones, depending on their ability to induce specific Wnt dependent signaling pathways. Non-canonical Wnt signaling pathways include different types of cellcell communication that are mediated via a Wnt signal, but independent of the transcriptional co-activator $\beta$-Catenin(Habas and Dawid, 2005). The two most intensely studied of the non-canonical Wnt signaling pathways are the planar cell polarity (PCP) pathway and the Wnt/calcium (Wnt/Ca2+) pathway. The PCP pathway plays an important role in establishing cell polarity and in the control of convergent extension movements of cells, while the $\mathrm{Wnt} / \mathrm{Ca}^{2+}$ pathway mediates cytoskeletal dynamics and cell adhesion through the regulation of intracellular calcium levels (Kohn and Moon, 2005; Seifert and Mlodzik, 2007; Semenov et al., 2007).

\subsubsection{Wnt/ $\beta$-Catenin signaling}

The first Wnt pathway discovered is also referred to as the canonical Wnt signaling pathway and it has been shown to be involved in cell fate decisions, proliferation and regeneration. Canonical Wnt signal transduction is mediated by the activity of the transcriptional co-activator $\beta$-Catenin(Clevers and Nusse, 2012; MacDonald et al., 2009). In the absence of a Wnt signal, cytoplasmic $\beta$ Catenin is recruited into a destruction complex containingthe scaffoldprotein 
Axin1/2, adenomatous polyposis coli (APC), glycogen synthase kinase 3

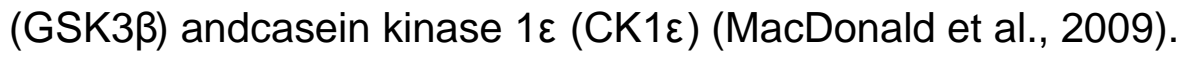

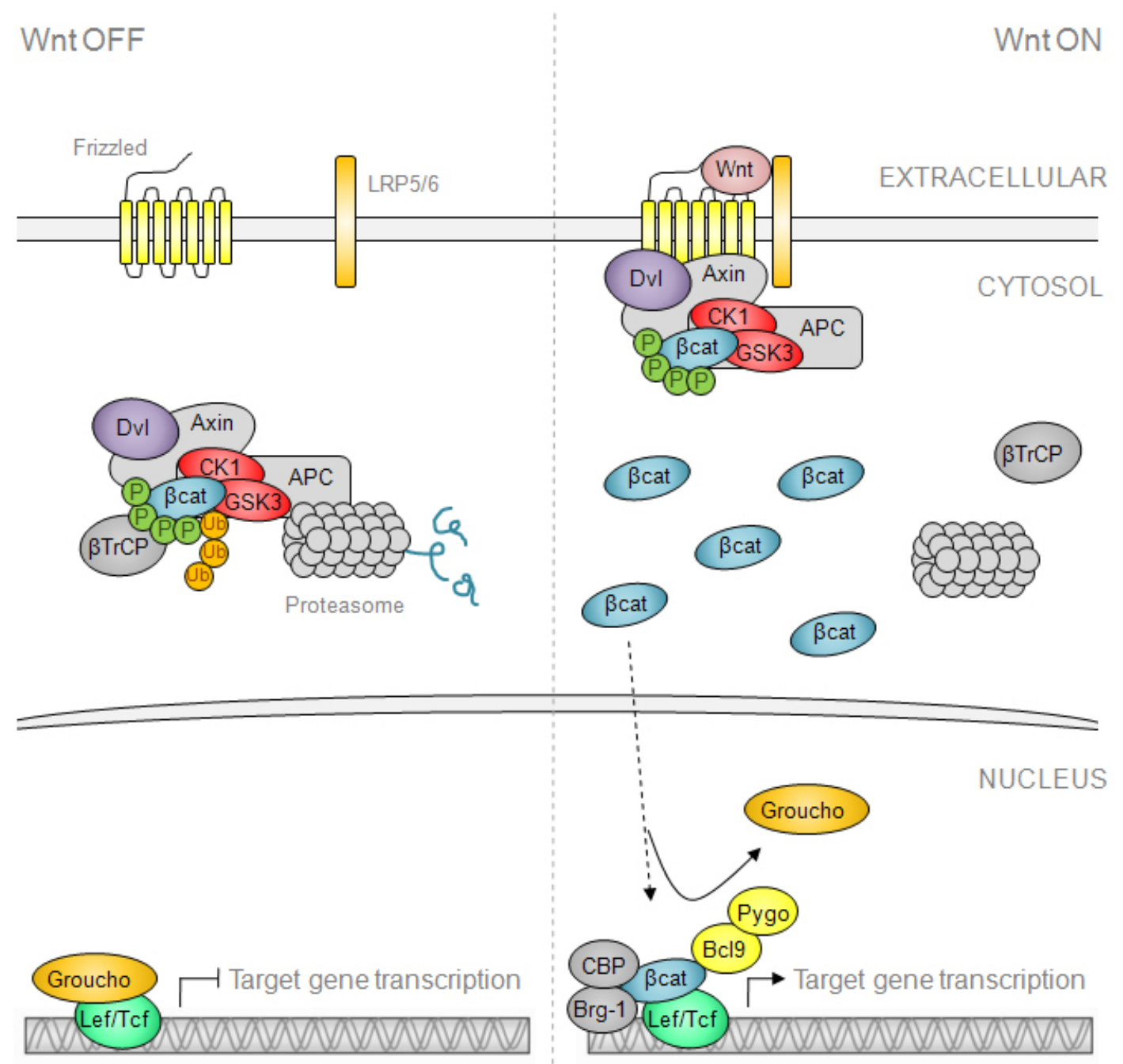

Figure 1. Overview of the $W n t / \beta$-Catenin-mediated signaling pathway. In the absence of Wnt, a destruction complex is formed in the cytoplasm, which binds, phosphorylates and ubiquitinates cytosolic $\beta$-Catenin, leading to its proteasomal degradation. Lef/Tcf transcription factors interact with transcriptional corepressors and suppress target gene transcription. Wnt binding to the Frizzled receptor recruits the destruction complex to the membrane. $\beta$-Catenin is not further ubiquitinated, and newly synthesizesed $\beta$-Catenin accumulates in the cytoplasm, transfers to the nucleus and replaces corepressors from Lef/Tcf. Transcriptional coactivators are recruited and target gene transcription is induced (after Clevers and Nusse, 2012).

In this way, initial $\mathrm{N}$-terminal phosphorylation of $\beta$-Catenin mediated by CK1عand GSK3 $\beta$ can occur(Amit et al., 2002; Liu et al., 2002; Yost et al., 1996). Consequently, $\beta$-Catenin is ubiquitinated by $\beta$ transducing repeat-containing protein ( $\beta \operatorname{TrCP}$ ) and thereby marked for proteasomal degradation (Aberle et al., 1997; Yanagawa et al., 2002). In the nucleus, transcription factors of 
thelymphoid enhancer-binding protein (Lef)/ T-cell factor (Tcf) family associate with transcriptional co-repressors, such as Groucho, and prevent prospective Wnt/ $\beta$-Catenin target gene expression (Figure 1), (Cavallo et al., 1998; Roose et al., 1998).

The canonical Wnt signaling pathway can be stimulated by binding of a Wnt protein to the extracellular cysteine-rich domain of the seven-transmembrane Frizzled receptor(Bhanot et al., 1996; Dann et al., 2001). As a result, Frizzled forms a complex with the single-pass transmembrane protein LDL-receptorrelated proteins 5 and 6 (LRP5/6) (Pinson et al., 2000; Tamai et al., 2000). Furthermore, the intracellular domain of Frizzled interacts with Dvl, causing the recruitment of the destruction complex to the plasma membrane, where Axin binds Dvl as well as the cytoplasmic domain of LRP5/6(Chen et al., 2003; Fiedler et al., 2011; Mao et al., 2001). The complex becomes saturated by phosphorylated $\beta$-Catenin and newly synthesized $\beta$-Catenin is no longer degraded and can accumulate in the cytoplasm(Li et al., 2012). Finally, $\beta-$ Catenin transfers into the nucleus, where it displaces Groucho andrecruits other transcriptional co-activators, such as histone modifiers CBP and Brg-1 (Stadeli et al., 2006). Additionally, BCL9 binds $\beta$-Catenin N-terminally and recruits the transcriptional co-activator Pygopus 1 and 2, resulting in transcriptional activation of Wnt/ $\beta$-Catenin target genes (Figure 1), (Brack et al., 2009; Schwab et al., 2007).

\subsection{TGF- $\beta$ signaling pathways}

The transforming growth factor-beta (TGF- $\beta$ ) superfamily of signaling pathways is involved in regulation of many developmental processes, such as proliferation, differentiation, and apoptosis (Massague, 1998). More than 40 signaling proteins, including TGF-ßs, Nodal, Activin and bone morphogenetic proteins (BMPs), are known to induce canonical Smad-dependent TGF- $\beta$ signaling pathways (Chen et al., 2012; Guo and Wang, 2009). Additionally, TGF- $\beta$ signals can be transmitted Smad-independently by activating the ERK MAP kinase (MAPK) signaling pathway (Lee et al., 2007).

Among the members of the TGF- $\beta$ family, more than 20 proteins isolated in vertebrates and invertebrates have been classified as members of the BMP 
subfamily (Chen et al., 2004). Except for BMP1 and BMP3, which function as signaling regulators, BMP proteins activate the BMP signal transduction pathway (Gamer et al., 2005; Ge and Greenspan, 2006).

\subsubsection{BMP signal transduction pathway}

BMP ligands are synthesized as large precursor proteins consisting of an amino-terminal prodomain and a C-terminal mature ligand domain. In the endoplasmatic reticulum, these precursors associate as homo- or hetero-dimers that are processed in the Golgi compartment allowing the release of mature dimers of the ligand domains into the extracellular space (Constam and Robertson, 1999; Cui et al., 1998).

The secreted BMP ligand forms heterohexameric complexes with type I and type II BMP receptors at the cell surface (Ehrlich et al., 2011). The BMP type II receptor has an intrinsic kinase activity and it phosphorylates serine and threonine residues in the intracellular GS domain of the BMP type I receptor(Miyazono et al., 2010);in consequence, the kinase activity of the BMP type I receptor is stimulated (Figure 2). Sma and Mad related proteins (Smad) 1, 5, and 8 are substrates for the BMP type I receptor kinase and are called receptor-regulated Smads (R-Smads), accordingly. These R-Smads are phosphorylated at the SSVS motif in the C-terminal Mad homology $2(\mathrm{MH} 2)$ domain(Qin et al., 2001). Phosphorylated R-Smads can complex with the cooperating Smad 4 (Co-Smad) via their MH2 domain (Figure 2).

The complex of R-Smads and Co-Smad can then translocate to the nucleus and bind BMP-responsive regulatory DNA regions via their $\mathrm{MH} 1$ domain(Ramel and Hill, 2012). Depending on the availability of additional transcriptional regulators, DNA bound Smad complexes regulate target gene expression positively or negatively (Blitz and Cho, 2009).

Similar to BMP proteins, also other members of the TGF- $\beta$ family can induce signal transduction via activation of serine/threonine receptor kinases and Smad proteins. In the classical view the type I activin receptor-like kinases Alk1/2/3/6 specifically phosphorylate the BMP-specific R-Smads 1/5/8, while TGF- $\beta$, Nodal, and Activin ligands bind and activate Alk4/5/7, causing a selective 
phosphorylation of R-Smads 2/3 (Massague et al., 2005). However, it has been shown that also members of the BMP family have the potential to activate Alk 4/5/7 (Schmierer and Hill, 2007). Conversely, other studies revealed that TGF- $\beta$ activates both Smad 2/3 and Smad1/5/8 in various cell types (Bharathy et al., 2008; Daly et al., 2008; Liu et al., 2009). Furthermore, there are 5 known TGF- $\beta$ type II receptors. BMP receptor II (BMPRII) is a receptor that only recognizes BMPs, while Activin receptor II (ActRII) and ActRIIb are bound by activin and BMPs (Moustakas and Heldin, 2009). Both BMP-mediated and BMPindependent branches of Smad dependent signaling operate via the common Co-Smad 4 (Chen et al., 1997; Liu et al., 1997).

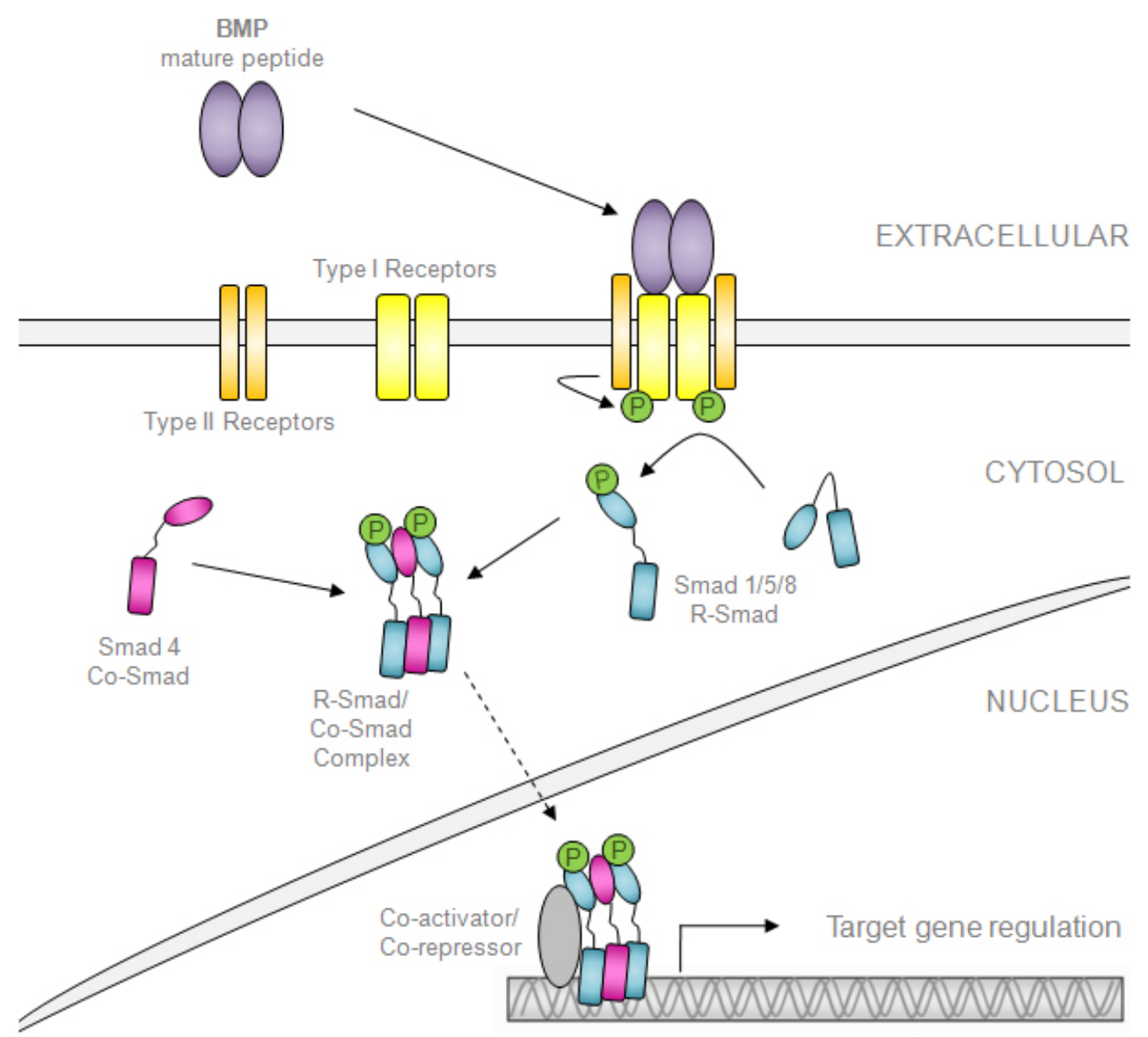

Figure 2. BMP signal transduction pathway. The BMP dimer complexes with type I and type II BMP receptors. This leads to autophosphorylation of the type I receptor. The activated type I receptor phosphorylates BMP receptor-Smad proteins (R-Smads; Smad 1, 5, and 8), which then interact with Co-Smad 4 proteins. The Smad complex transfers to the nucleus and regulates target gene transcription (after Miyazono et al., 2010and Walsh et al., 2010). 


\subsubsection{Regulation of BMP signaling activity}

BMPs were originally identified as molecules with the potential to induce bone and cartilage formation when implanted at ectopic sites in rats (Urist, 1965). In addition to their role in bone formation, BMPs have been shown to regulate tooth, kidney, skin, hair, muscle, hematopoietic and neural development (Botchkarev and Sharov, 2004; Bracken et al., 2008; Rogers et al., 2009; Sadlon et al., 2004; Thesleff, 2003; Wang et al., 2010). To ensure appropriate levels of BMP signaling activity spatially and temporally, this pathway has to be tightly regulated during development. Several mechanisms are known to regulate BMP signaling on the intracellular as well as on the extracellular level (Ramel and Hill, 2012; Walsh et al., 2010).

\subsubsection{Extracellular BMP antagonists}

Secreted BMP-binding proteins exhibit several functions, including initial activation and release of BMPs, transport of BMP proteins through tissues, and reception of the BMP signal (Umulis et al., 2009). Active BMP proteins are generated via cleavage of the pre-protein into the prodomain and the mature ligand domain. In vitro studies have shown that the cysteine-rich transmembrane BMP regulator 1 (CRIM 1) binds and reduces cleavage of the BMP pre-protein (Wilkinson et al., 2003). The cleaved prodomain itself can also act as a BMP binding protein. Correspondingly, Ge and colleagues could show that BMP11 forms a noncovalent latent complex with its cleaved prodomain that can be reactivated by the secreted zinc metalloproteinase BMP1/Tolloid (Figure 3 A), (Ge et al., 2005).

Extracellular BMP antagonists represent several secreted peptides, which bind BMP proteins and prevent their interaction with their specific receptors (Figure 3 $B)$. The protein sequence of these factors is characterized by conserved cysteine-rich (CR) domains that are involved in the formation of characteristic cystine knot structures, similar to those of the BMP proteins. There are three classes of secreted inhibitory proteins: Noggin, the DAN family, and Chordin (Gazzerro and Canalis, 2006). Noggin was found to bind several BMP proteins 
and vegetally localized protein $(\mathrm{Vg})-1$, but no other members of the TGF- $\beta$ family of proteins (Smith and Harland, 1992; Zimmerman et al., 1996). Similar to Noggin, also Chordin Chd, the vertebrate homologue of Drosophila Short Gastrulation Sog, specifically binds and inhibits BMP proteins (Gazzerro and Canalis, 2006; Piccolo et al., 1996).

A

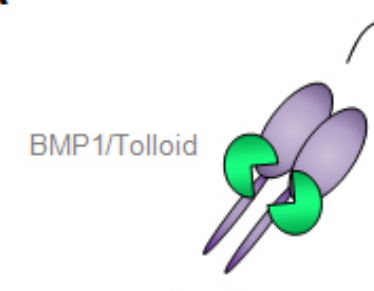

inactive

BMP propeptide
B
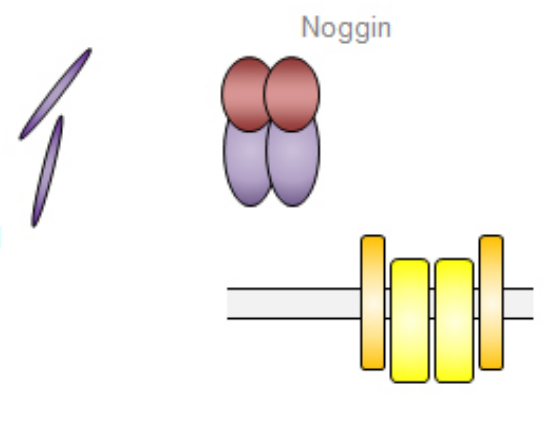

C

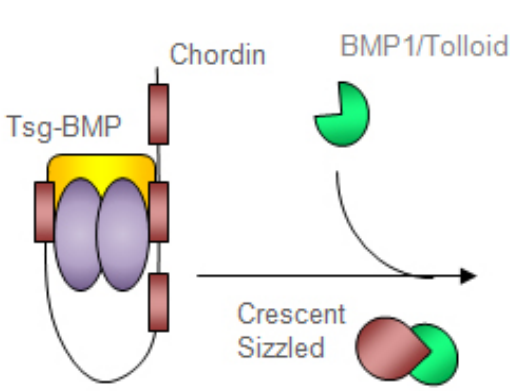

inactive

D

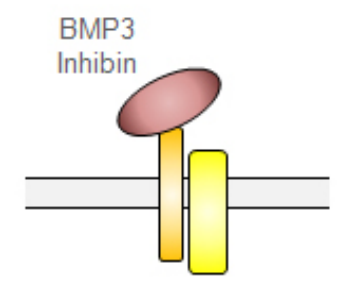

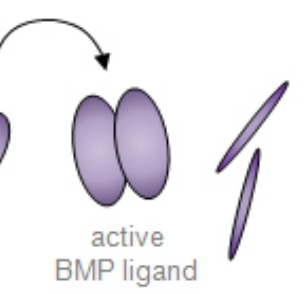

BMP ligand

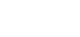

$\mathbf{F}$

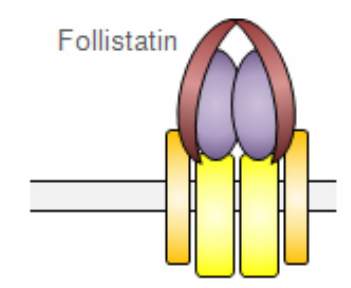

Figure 3. Extracellular mechanisms for modulation of BMP signaling activity. (A) The BMP ligand is inactivated by binding to the BMP prodomain and can be reactivated by metalloprotease activity of BMP1/Tolloid. (B) Secreted BMP antagonists bind the BMP protein and prevent ligand/receptor interaction. (C) Chordin forms a trimeric complex with Tsg and BMP and thereby inhibits BMP/receptor interaction. The metalloproteaseTolloid cleaves Chordin, resulting in a release of the BMP protein.Tolloid can be bound by Sizzled or Crescent, preventing Tolloid activity. Tsg antagonizes BMP signaling by enhancing the formation of the Chordin/BMP complex. But it also acts as BMP activator by facilitating Tolloid-mediated cleavage of Chordin. (D) BMP3 and Inhibin bind type II TGF- $\beta$ receptors inhibit signal transduction into the cytoplasm. (E) Follistatin antagonizes BMP signaling by binding the BMP/receptor complex. 
Furthermore, Chd-mediated BMP antagonism is regulated by additional secreted factors within a complex network (Figure $3 \mathrm{C}$ ). The Twisted gastrulation protein can regulate Chordin activity positively as well as negatively. On the one hand, it promotes the binding of chordin to the BMP protein and thereby the formation of a stable BMP inhibitory complex (Plouhinec et al., 2011). But on the other hand, it facilitates BMP1/Tolloid mediated proteolysis of Chordin, followed by the release of BMP proteins (Gazzerro and Canalis, 2006; Oelgeschlager et al., 2000). In contrast, the secreted Frizzled related protein (SFRP) Sizzled as well as Crescent, which both are known to antagonize Wnt signaling, can bind and inhibit activity of BMP1 and thereby enhance Chordin activity (Lee et al., 2006; Misra and Matise, 2010; Muraoka et al., 2006; Ploper et al., 2011; Yabe et al., 2003).

Another group of extracellular BMP antagonist is the DAN family, including Gremelin, Sclerostin, Dan, uterine sensitization associated gene (USAG-1), Cerberus, Caronte, Coco, protein related to Dan and Cerberus (PRDC) and Dante. In contrast to Noggin or Chordin, these factors antagonize BMP signaling as well as Activin-, Nodal-, TGf- $\beta$ or Wnt signaling (Gazzerro and Canalis, 2006; Hsu et al., 1998).

In addition to BMP interacting proteins, BMP signaling can be modulated by receptor interacting factors as well. Inhibin and BMP3 have shown to compete with BMP or activin for binding to the corresponding TGF- $\beta$ type II receptor (Figure $3 \mathrm{D}$ ). While Inhibin can bind ActRII, ActRIIB, and BMPRII, BMP3 was shown to antagonize signaling by complex formation with ActRIIB (Gamer et al., 2005; Wiater and Vale, 2003). In contrast to Inhibin and BMP3, Follistatin and Follistatin-like proteins inhibit BMP and activin signaling via direct interaction with the complex of ligand and receptor (Figure $3 \mathrm{E}$ ). Follistatin was first identiefied as a potent inhibitor of activin, but later was shown also to interact with several BMP proteins and myostatin (Geng et al., 2011; lemura et al., 1998). Additionally, Thompson and colleagues could show that Follistatin interacts with both type I and type II TGF- $\beta$ receptors (Thompson et al., 2005). 


\subsubsection{BMP regulation on the receptor or cytoplasmic level}

BMP regulation can occur on the receptor level, involving the activity of pseudoreceptors. BMP and activin bound protein (BAMBI) is such a pseudoreceptor that is structurally related to type I TGF- $\beta$ and BMP receptors, but it lacks the intracellular kinase domain (Figure $4 \mathrm{~A}$ ). BAMBI associates with type I and type II receptors and inhibits activin as well as BMP signaling mediated by these receptor kinases (Miyazono et al., 2010; Onichtchouk et al., 1999). Additionally, some tyrosine kinases, such as TrkC and Ror2 can bind type II or type I BMP receptors and inhibit signal transduction(Jin et al., 2007; Sammar et al., 2004). In contrast, cytoplasmic cGMP-dependent kinase I (cGKI) causes the stimulation of BMP signaling activity by binding and phosphorylation of BMPRII (Figure 4 B), (Schwappacher et al., 2009).

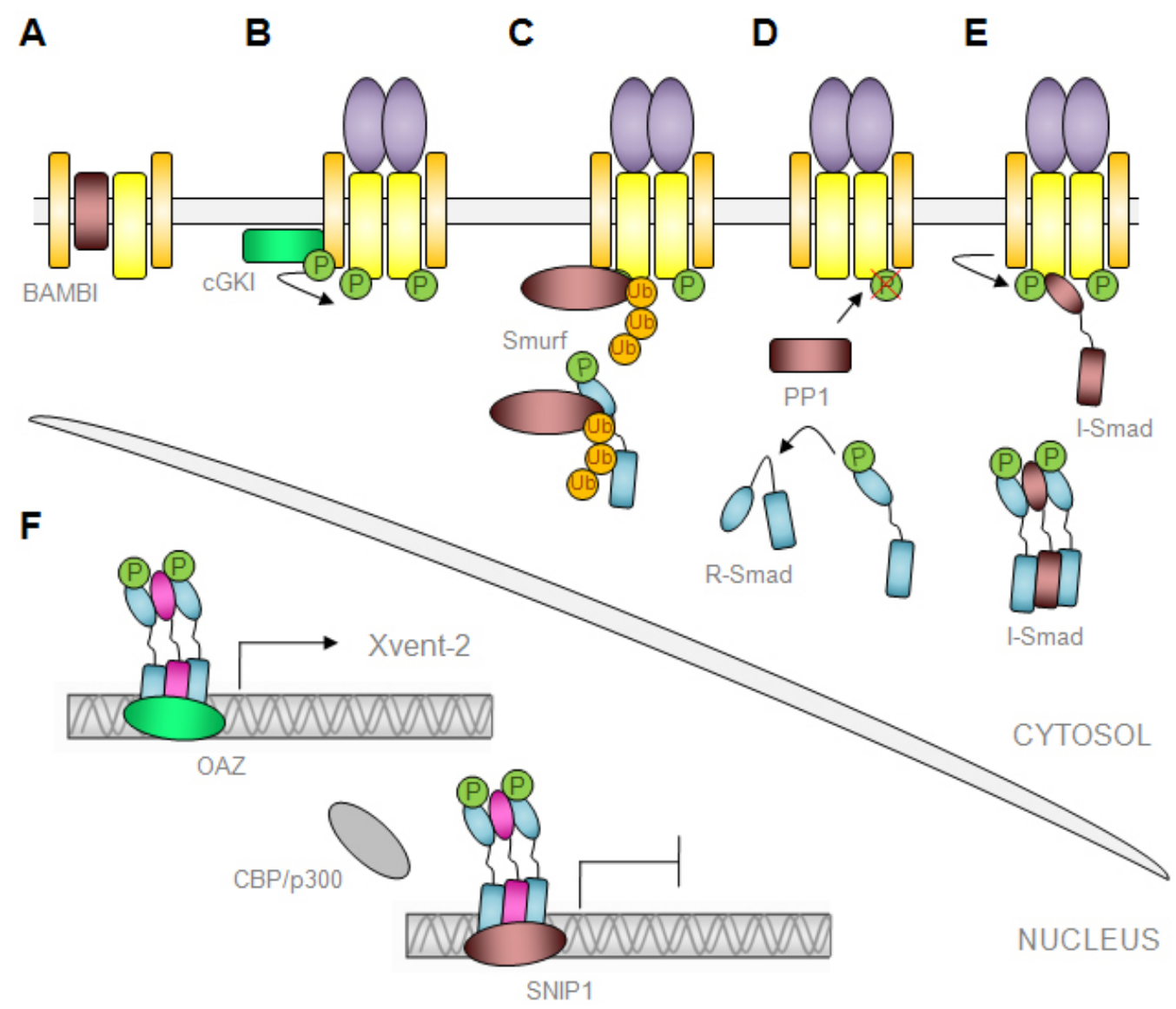

Figure 4. Intracellular regulation of BMP signaling activity. (A) The pseudoreceptor BAMBI interacts with TGF- $\beta$ receptors and inhibits signal transduction. (B) $c G K I$ binds and phosphorylates BMP type II receptors and thereby enhances BMP signaling. (C) Smurfs ubiquitinate BMP receptors and R-Smads, leading to their proteasomal degradation. (F) Phosphatases such as PP1 dephosphorylate activated TGF- 
Breceptors and R-Smads. (E) I-Smads bind to activated type I receptors and prevent R-Smad phosphorylation. Additionally, I-Smads antagonize BMP signaling by the formation of transcriptionally inactive complexes with R-Smads . (F) Transcriptional cofactors positively or negatively regulate Smad-mediated transcription of target genes. While OAZ stimulates expression of Xvent-2, SNIP1 binds the Smad complex in inhibits transcriptional activation by CBP/p300. (A-F) Negative regulators are indicated in green; positive regulators are indicated in red.

Intracellularly, BMP signaling can be modulated by inhibitory Smads (I-Smads), phophatases, E3 ubiquitin-ligases, and transcriptional cofactors. Thel-Smad family consists of Smad 6 and 7 in vertebrates (Figure 4 E). These factors stably bind to the intracellular domain of activated BMP or TGF- $\beta$ type I receptors and thereby prevent phosphorylation of R-Smads by the receptor (Imamura et al., 1997; Souchelnytskyi et al., 1998). Additionally, Smad 6 can compete with Smad 4 for Smad 1 binding, leading to the formation of a transcriptionally inactive Smad 6/ Smad 1 complex (Hata et al., 1998).

Smad ubiquitination regulatory factors (Smurfs) are E3 ubiquitin-ligases that cause proteasomal degradation of R-Smads or BMP receptors (Figure $4 \mathrm{C}$ ). Smurf1 has been shown to specifically target Smads 1 and 5 (Zhu et al., 1999). Kavsak and colleagues reported that human Smurf 2 mediates proteasomal degradation of activated TGF- $\beta$ and BMP receptors (Kavsak et al., 2000). Furthermore several phosphatases, such as PP1 or PP2a inhibit BMP signaling by dephosphorylation of both the receptor and R-Smads (Figure $4 \mathrm{D})$, (Wrighton et al., 2009).

The biological output of BMP signaling can be further modulated by interaction of nuclear SMAD complexes with different transcriptional co-activators or corepressors (Figure $4 \mathrm{~F}$ ). Apart from general transcriptional coactivators, such as p300 and CBP, also Olf-1/EBF associated zinc fingerOAZ was identified as DNA binding cofactor that stimulates expression of the direct BMP target gene Xvent-2(Hata et al., 2000; Liu et al., 2008; Pouponnot et al., 1998). In contrast, some transcriptional co-repressors, such as SNIP1 or E1A are known to inhibit TGF- $\beta$ signaling by inhibiting the interaction between Smads and CBP/p300 (Kim et al., 2000; Nishihara et al., 1999). 


\subsection{Development of the blood circulatory system in vertebrates}

Vertebrate blood can be classified into three main cell lineages: erythrocytes, thrombocytes and leukocytes. These blood cells require a functional vascular system in such a way as to enable them to circulate through the body and to fulfill their cell-type-specific functions, such as gas transport, blood clotting, and immune response, respectively (Hartenstein, 2006). During embryogenesis the blood circulatory system is one of the first organ systems to develop. In this process blood cells and vessels develop simultaneously in close association with each other(Risau, 1995).

\subsubsection{Development of blood and vessels during Xenopus embryogenesis}

Vertebrate blood development occurs in 2 waves, termed primitive and definitive hematopoiesis. Early primitive blood cell formation produces primarily primitive red blood cells that provide the developing embryo with oxygen. In contrast, within the second definitive hematopoietic wave hematopoietic stem cells (HSCs) give rise to blood cells of all lineages that are required throughout the whole life span of the organism (Kau and Turpen, 1983; Tsiftsoglou et al., 2009). Ciau-Uitz and colleagues obtained evidence that embryonic and adult blood cells have distinct origins in Xenopus (Ciau-Uitz et al., 2000).

Primitive (embryonic) hematopoiesis occurs first in the ventral blood islands (VBI) that are located at the ventral side of the embryo and resemble the analogous structure of the mammalian extra-embryonic blood islands on the yolk sac (Figure $5 \mathrm{~A}$ ). In contrast, definitive hematopoiesis originates from the dorsal lateral plate(DLP) that resembles the analog of the para-aortic slanchnopleura or AGM (aorta, gonads, mesonephros) region in other vertebrates (Figure $5 \mathrm{~A}$ ).

In addition to blood cell formation, the VBI as well as the DLP contribute to the development of vascular structures (Figure 5 B). In a process, termed vasculogenesis, blood vessels develop de novo by differentiation of mesodermal progenitor cells into endothelial cells, which form a primitive 
capillary network. Vasculogenesis is followed by angiogenesis, the formation of new blood vessels from these pre-existing calillaries(Levine et al., 2003; Pardali et al., 2010; Risau, 1995). While the VBI mainly contribute to the development of embryonic vitelline vein network, the main body vessels, such as dorsal aorta and posterior cardinal vein derive from the DLP(Cleaver and Krieg, 1998; Walmsley et al., 2002).

A

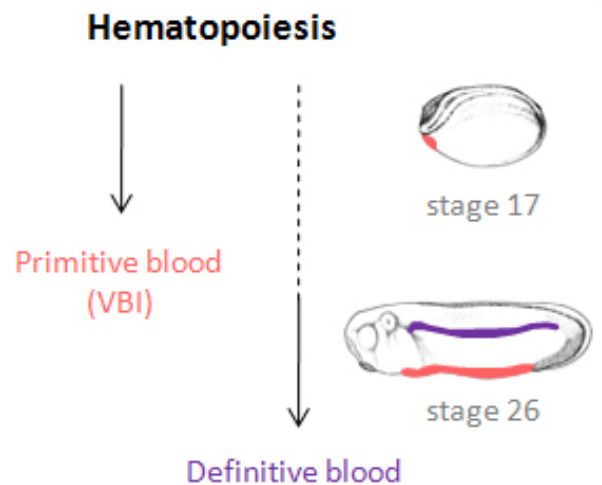

(DLP)
B

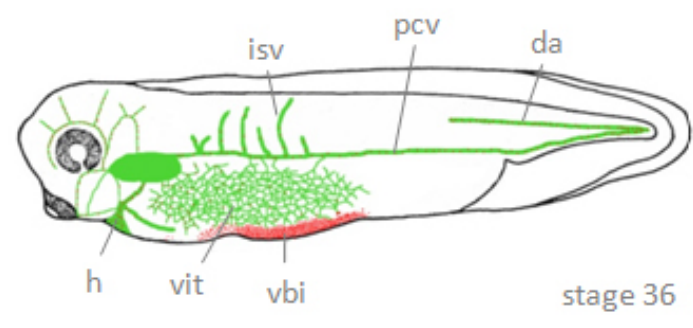

Figure 5. The $\mathrm{VBI}$ and the DLP contribute to the formation of primitive and definitive blood as well as to the vascular system. (A) The formation of embryonic and defintive blood cells occurs spatially and temporally separated. While primitive hematopoiesis is initiated in the $\mathrm{VBI}$ at the end of neurulation, definitive hematopoiesis in the DLP is induced later, at late tailbud stage. (B) At stage 36 the the vitelline vein network and the main body vessels (green) have formed and the first differentiated embryonic erythrocytes (red) have started to circulate within the vascular network (after Levine et al., 2003). da: dorsal aorta; h: heart; isv: intersomitic veins; pcv posterior cardinal vein; vbi: ventral blood islands; vit: vitelline veins.

Lineage tracing studies in Xenopus have shown that both, ventral $(\mathrm{V})$ and dorsal (D) mesoderm (M) contribute to the future ventral blood islands(Ciau-Uitz et al., 2010; Tracey et al., 1998). While the DM contributes to the most anterior portion of the $\mathrm{VBI}$, the aVBI, the $\mathrm{VM}$ gives rise to the posterior portion, the $\mathrm{pVBI}$ (Figure $6 \mathrm{~A}$ and $\mathrm{C}$ ). As gastrulation proceeds, involuting mesoderm at the dorsal blastopore lip migrates under the roof of the blastocoel and finally meets up with the ventral mesodermal leading edge (Figure $6 \mathrm{~B}$ ). At the end of neurulation, a colony of precursor cells is located immediately posterior to the cement gland (Figure $6 \mathrm{~A}$ ), where they differentiate into either the endothelial or the hematopoietic lineage, as development proceeds (Ciau-Uitz et al., 2010; Kumano et al., 1999; Walmsley et al., 2002). 
While cells of the aVBI give rise to a minority of erythrocytes and a large number of myeloid cells, the pVBI produces the main portion of embryonic erythrocytes, but also leukocytes and a few short term lymphocytes(Ciau-Uitz et al., 2010; Costa et al., 2008; Maeno et al., 2012; Tashiro et al., 2006). Terminal differentiation of myeloid cells in the aVBI occurs as early as stage 20 and these cells start to migrate throughout the embryo by stage 24 , long before the circulatory system is established(Maeno et al., 2012; Smith et al., 2002). In contrast, first erythrocytes differentiate and express embryonic globin genes in the $\mathrm{VBI}$ at around stage 30 in ananterior to posterior wave (Tsiftsoglou et al., 2009). The heart starts beating at stage 33/34 and differentiated erythrocytes enter the circulatory system by stage 35/36 (Figure 5 B); (Zon, 1995).

A

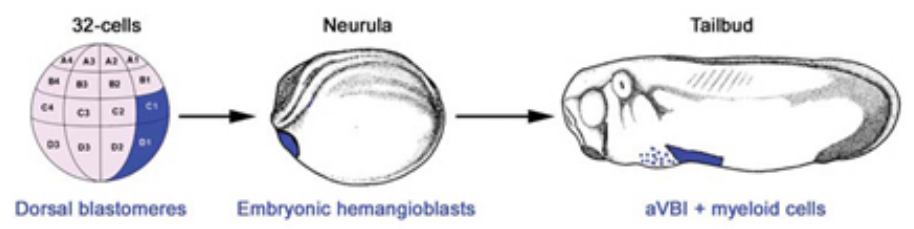

B

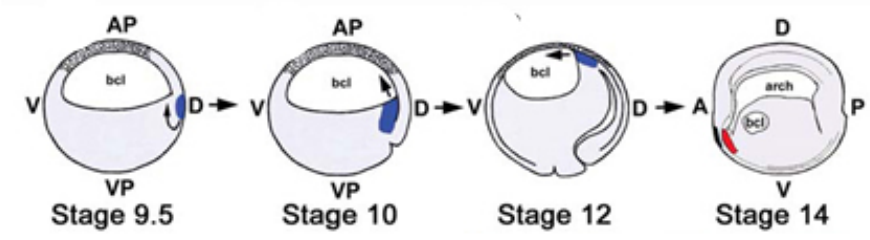

C

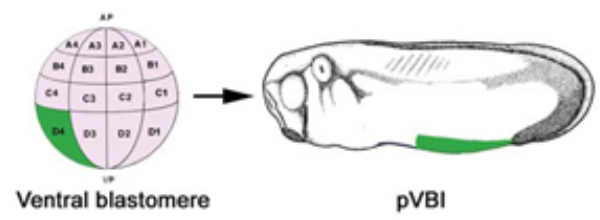

D

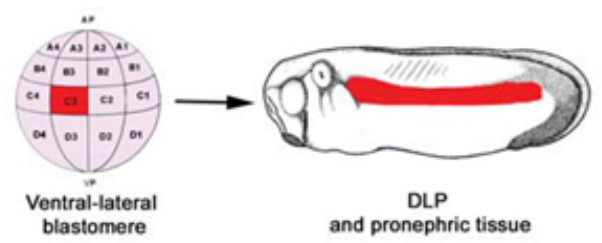

Figure 6. Ontogeny of the anterior and the posterior portion of the VBI and the DLP . (A) The aVBI derive from the dorsal C1 and D1 blastomeres of the 32-cell stage embryo. (B) During gastrulation, mesodermal cells, that will form the aVBI, migrate along the blastocoel roof from dorsal to ventral. (C) The ventral D4 blastomere gives rise to the $\mathrm{pVBI}$. (D) Cells contributing to the DLP and pronephric tissue derive from the C3 blastomere of the 32-cell stage embryo. (A-D) modified after Ciau-Uitz et al., 2010).

The DLP is a derivative of the C3 blastomere of the 32 cell-stage Xenopus embryo (Figure $6 \mathrm{D}$ ). During tailbud stages this mesodermal compartment is 
populated by progenitor cells for definitive blood and the main body vessels that coexpress endothelial and hematopoietic marker genes (Ciau-Uitz et al., 2000). At stage 27, a subpopulation of cells from the DLP that does not express blood genes migrates to the midline towards the hypochord where they form the dorsal aorta (Cleaver and Krieg, 1998). Later, blood gene expression is again detected in cells associated with the floor of the dorsal aorta (Ciau-Uitz et al., 2000). These hematopoietic cells are thought to be the first adult blood stem cells(Ciau-Uitz et al., 2000; Huber and Zon, 1998).

\subsubsection{Blood and vascular development from the hemangioblast and thehemogenic endothelium}

In 1917, Florence Sabin observed that hematopoietic and vascular cells develop in close spatial and temporal association with each other in the avian model sytem(Sabin, 2002). In 1932, his finding was confirmed by Murray, who proposed a model for a common progenitor for both endothelial and hematopoietic cell lineages and termed it the hemangioblast(Murray, 1932).

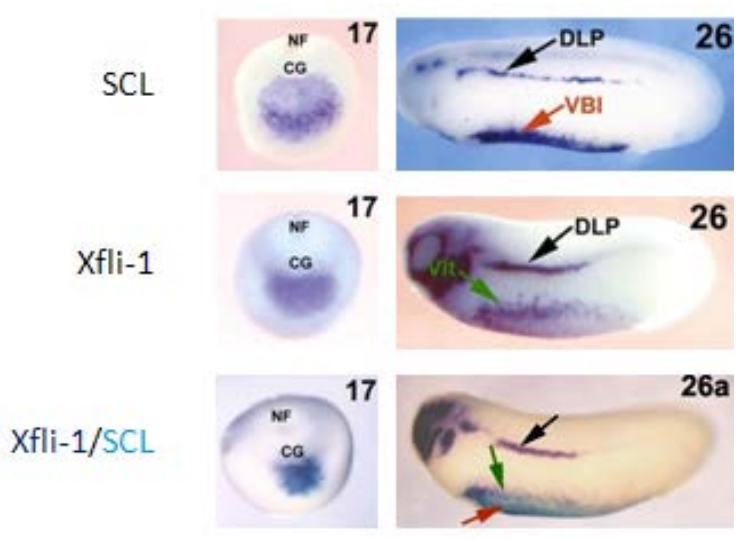

Figure 7. Overlapping expression pattern of Xfli-1 and SCL marks hemangioblast formation in the VBI and the DLP. At stage $17 \mathrm{SCL}$ and Xfli-1 are coexpressed by a cell population immediately posterior to the cement gland (left panel). At stage 26, expression of these genes has become mutually exclusivein the VBI, while overlapping in the DLP (right panel). Spatial distribution of SCL and Xfli-1 transcripts was determined by whole-mount in situ hybridization of stage 17 or stage 26 Xenopus embryos, as indicated. Black arrows indicate DLP; red arrows indicate VBI; Green arrows indicate vitelline veins (Vit); (modified after Walmsley et al., 2002). 
Further evidence for the existence of such a bipotential precursor came from studies in mouse, showing that endothelial and hematopoietic cells express a similar set of genes, includingFlk1, SCL/tal-1, Cbfa2/Runx1/AML1 and CD34(Baron, 2001; Walmsley et al., 2002). Consitent with these data, Walmsley and colleagues reported that in Xenopusthe endothelial marker Xfli1 and the hematopoietic marker SCL are coexpressed at the end of neurulation in a restricted region posterior to the cement gland, while getting expressed mutually exclusive as differentiation into vascular or blood fate proceeds(Figure 7). At tailbud stage when definitive hematopoiesis gets initiated these factors are coexpressed in the DLP (Walmsley et al., 2002).

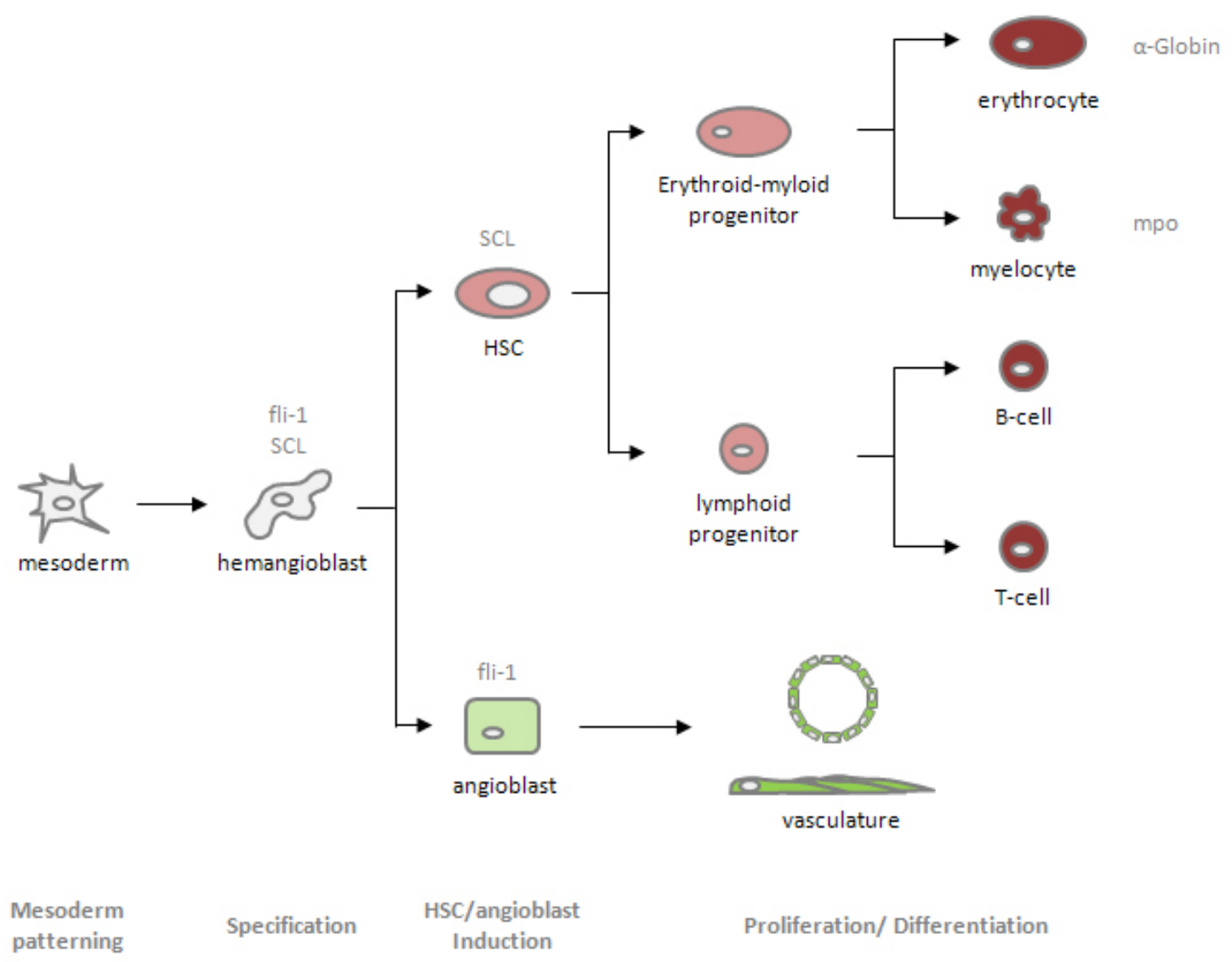

Figure 8. Development of hematopoietic and vascular cell types from the hemangioblast. The hemangioblast, specified from mesoderm, is the common precursor of both hematopoietic stem cells (HSC) and the angioblast. HSCs differentiate into mature blood cell types expressing cell-type specific genes, while angioblasts give rise to vascular structures. During further specification of the hemangioblast growth factors, receptors, or transcription factors, that are originally coexpressed in the hemangioblast like fli-1 and SCL get restricted to either the hematopoietic or the angiogenic fate, as indicated (after Crosier et al., 2002 and Martin et al., 2011). 
Transient mouse embryonic stem cell (ESC)-derived blast colony forming cells (BL-CFCs), give rise to both hematopoietic and vascular cell lineages. Therefore it was considered that these cells are the in vitro equivalent of the hemangioblast(Choi et al., 1998; Kennedy et al., 2007).

Furthermore, loss of function studies in mouse revealed that targeted disruption of either the endothelial gene Flk1 or the hematopoietic marker SCL in mouse caused severe defects in hematopoiesis as well as in vasculogenesis(Robb et al., 1995; Shalaby et al., 1995; Visvader et al., 1998).

Based on these data, a model has been proposed in which the hemangioblast is specified from the mesoderm, followed by angiogenic or hematopoietic fatedecision. Factors that are expressed by the hemangioblast become restricted to either the hematopoietic stem cell (HSC) or the angioblast, such as fli-1 or SCL, respectively (Figure 8), (Walmsley et al., 2002). While the angioblast contributes to the formation of the vascular system, hematopoietic stem cells can develop into either lymphoid or erythroid-myeloid precursor cells, followed by terminal differentiation into the different mature blood cell types, such as B-cells, T-cells, myeloperoxidase (mpo) expressing myeloid cells, or globin gene expressing erythrocytes (Figure 8), (Crosier et al., 2002; Martin et al., 2011).

While the development of blood cell lineages and vascular cells from the common precursor cell, the hemangioblast, appears to be relevant for at least primitive hematopoietic events, it is now generally accepted that during definitive hematopoiesis HSCs arise from a hemogenic endothelium. The term hemogenic endothelium defines specialized vascular endothelial cells that aquire blood forming potential (Hirschi, 2012). Using lineage tracing studies in mouse, Zovein and colleagues could show that an epithelial VE-cadherin expressing cell population in the AGM region gave rise to all blood cell lineages in vivo (Zovein et al., 2008). Further evidence came from in vivo dynamic imaging studies in mouse and zebrafish that demonstrated the generation hematopoietic cells from the aortic endothelium (Boisset et al., 2010; Kissa and Herbomel, 2010). 


\subsection{Aims}

Wnt and BMP signaling pathways play important roles in multiple aspects of embryogenesis. The first aim of this study was to investigate Wnt signaling in the context of gut tube patterning in Xenopus. The second goal of this study was to analyze biochemical and biological activities of a novel regulator of BMP signaling, identified by expression cloning. 


\section{Materials and Methods}

\subsection{Model Organism}

The African clawed frog Xenopus laevis (X. laevis) was used as a model organism during this study. Adult frogs were purchased from NASCO (Ft. Atkinson, USA).

\subsection{Bacteria}

E. coli strain XL1-Blue (RecA1, endA1, gyrA96, thi-1, hsdR17, supE44, relA1, lac[F'proAB, ZMM15, Tn10(Tetr) $]^{c}$ (Stratagene)) was used during this study.

\subsection{Chemicals, Buffers, and Media}

\subsubsection{Chemicals}

The Chemicals were purchased from the following companies: Roth (Karlsruhe), Sigma (Munich), Biomol (Hamburg), Applichem (Darmstadt), and Biochrom (Berlin).

\subsubsection{Buffers and Media}

Buffers were prepared using deionized water (MiliQ).

\section{Alkaline phosphatase buffer (APB)}

100 mM Tris, 50 mM MgCl2, 100 mM NaCl, 0.1 \% TWEEN-20; pH 9.0

\section{Bleaching solution}

$50 \%$ Formamide, $1 \%-2 \% \mathrm{H}_{2} \mathrm{O}_{2}$, in $5 \times \mathrm{SSC}$

\section{Blocking solution}

1 x TBST; $5 \%$ non fat dry milk 


\section{ColP buffer}

50 mM Tris- $\mathrm{HCl}$ (pH 7.5), 100 mM NaCl, 2 mM EDTA, 1 mM EGTA, $0.5 \%$ (v/v) NP-40, 10 \% (v/v) glycerol, 1 mM NaF, 1 mM $\beta$-glycerolphosphate, 1 mM

Sodium orthovanadate, Complete Protease inhibitor mix EDTA free (1 tablet per $50 \mathrm{ml}$ of buffer, Roche)

color reaction solution (WMISH)

$80 \mu \mathrm{g} / \mathrm{ml} \mathrm{NBT}, 175 \mu \mathrm{g} / \mathrm{ml}$ BCIP in APB; $\mathrm{pH} 9.0$

\section{Collagenase-buffer}

$82.5 \mathrm{mM} \mathrm{NaCl}, 2$ mM KCl, 1 mM MgCl2, 5 mM HEPES; pH 7.5

\section{Cystein solution}

2 \% L-Cystein hydrochloride; $\mathrm{pH} 7.8$

\section{0x Dexamethasone (Dex)}

$20 \mathrm{mM}$ dexamethasone in ethanol, stored in the dark, stable for up to 3 month

\section{Hybridization Mix (Hyb Mix)}

50\% (v/v) Formamide (deionized), 1 mg/ml Torula-RNA (Sigma), $100 \mu \mathrm{g} / \mathrm{ml}$ Heparin, 1 x Denhardt's, 0.1\% (v/v) Tween-20, 0.1\% (w/v) CHAPS (Sigma), 10 mM EDTA, 5X SSC

\section{Injection Buffer}

1 x MBS, $1 \%$ Ficoll (Sigma)

\section{Laemmli loading buffer $(2 \mathrm{x})$}

$10 \mathrm{ml} 1.5 \mathrm{M}$ Tris (pH 6.8), $12 \mathrm{ml} 10 \%$ SDS, $30 \mathrm{ml}$ glycerol, $15 \mathrm{ml} \beta$ mercaptoethanol, $1.8 \mathrm{mg}$ bromphenol blue

\section{Laemmli running buffer (1 x)}

25 mM Tris, 192 mM Glycine, $0.1 \%$ SDS 


\section{LB-Agar}

$1.5 \%(w / v)$ agar (DIFCO) in liquid LB-medium

\section{Luria-Bertani (LB)-Medium}

$1 \%(\mathrm{w} / \mathrm{v})$ Bacto-Trypton (DIFCO), $0.5 \%$ (w/v) yeast extract (DIFCO), $1 \%(\mathrm{w} / \mathrm{v})$ $\mathrm{NaCl}, \mathrm{pH} 7.5$

\section{MAB (5 x)}

$500 \mathrm{mM}$ maleic acid, $750 \mathrm{mM} \mathrm{NaCl}$; pH 7.5

\section{MBS buffer Salts (10 x)}

$880 \mathrm{mM} \mathrm{NaCl}, 10 \mathrm{mM} \mathrm{KCl}, 10 \mathrm{mM} \mathrm{MgSO}_{4}, 50$ mM Hepes, 25 mM NaHCO$;$; pH 7.8

\section{MBS buffer AC (5 x)}

$440 \mathrm{mM} \mathrm{NaCl}, 5 \mathrm{mM} \mathrm{KCl}, 4.1 \mathrm{mM} \mathrm{MgSO}_{4}, 50$ mM Hepes, 12 mM NaHCO $3,2.05$ $\mathrm{mM} \mathrm{CaCl} 2,1.65$ mM Ca(NO 3$)_{2} ; \mathrm{pH} 7.4$

\section{MBS buffer (1 $x)$}

$1 \times$ MBS buffer Salts, $0.7 \mathrm{mM} \mathrm{CaCl}_{2}$

\section{MEM (10 x)}

$1 \mathrm{M}$ MOPS, 20 mM EGTA, 10 mM MgSO $4 ;$ pH 7.4

\section{MEMFA (1 x)}

1 x MEM, $4 \%$ formaldehyde

\section{Nile Blue Solution}

$0.01 \%$ (w/v) Nile Blue chloride, 89.6 mM Na $2 \mathrm{HPO}_{4}, 10.4$ mM NaH $2 \mathrm{PO}_{4} ; \mathrm{pH} 7.8$

\section{Oocyte culture medium (OCM)}

8.4 mg/ml Leibovitz's L-15 powder (Gibco®), 0.4 mg/ml BSA, 1 mM Lglutamine, $0.1 \mathrm{mg} / \mathrm{ml}$ Penicillin/Streptomycin (Biochrom) in autoclaved $\mathrm{H}_{2} \mathrm{O}$ 
PBS (10 x)

1.75 M NaCl, $1 \mathrm{M} \mathrm{KCl,} 65 \mathrm{mM} \mathrm{Na}_{2} \mathrm{HPO}_{4}, 18 \mathrm{mM} \mathrm{KH}_{2} \mathrm{PO}_{4} ; \mathrm{pH} 7.4$

\section{Ponceau S Solution}

$2 \mathrm{~g}$ Ponceau S, $30 \mathrm{~g}$ trichloracetic acid, $30 \mathrm{~g}$ sulfosalicylic acid acid per $100 \mathrm{ml}$

\section{Ptw buffer}

$0.1 \%$ Tween-20 in $1 \times$ PBS

\section{$\operatorname{SSC}(20 x)$}

$3 \mathrm{M} \mathrm{NaCl}, 0.3 \mathrm{M}$ Sodium citrate, $\mathrm{pH} 7.4$

\section{TAE (Tris/Acetate/EDTA)}

$40 \mathrm{mM}$ Tris-Acetate (pH 8.5), 2 mM EDTA

\section{TE-Buffer}

$10 \mathrm{mM}$ Tris- $\mathrm{HCl}$ (pH 8.8), 1 mM EDTA)

TBST (1 x)

50 mM Tris, 150 mM NaCl, 0.1 \% TWEEN-20; pH 7.5

\section{Transfer Buffer}

$2.9 \mathrm{~g}$ Glycine, $5.8 \mathrm{~g}$ Tris, $0.37 \mathrm{~g}$ SDS, $200 \mathrm{~mL}$ Methanol per $1 \mathrm{~L}$

\section{X-gal}

$40 \mathrm{mg} / \mathrm{ml}$ 5-Bromo-4-chloro-3-indolyl-b-D-galactosidase (X-gal) in formamide; stored in the dark at $-20^{\circ} \mathrm{C}$

\section{$X$-gal staining solution}

$1 \times$ PBS, $1 \mathrm{mg} / \mathrm{ml}$ X-gal, $5 \mathrm{mM} \mathrm{K}_{3} \mathrm{Fe}(\mathrm{CN})_{6}, 5 \mathrm{mM} \mathrm{K}_{4} \mathrm{Fe}(\mathrm{CN})_{6}, 2 \mathrm{mM} \mathrm{MgCl}$ 


\subsection{Constructs}

\subsubsection{Vectors}

\section{pCS2+}

The multipurpose expression vector pCS2+ contains the simian cytomegalovirus IE94 enhancer/promoter sequence, which is suitable for overexpression experiments in Xenopus. The viral SP6 promoter, polylinker sequence, and SV40 viral polyadenylation signal allow the in vitro transcription of sense polyadenylated mRNA for microinjection(Rupp et al., 1994).

\section{MT/pCS2+}

pCS2+/MT is a derivative of the pCS2+ vector, that contains a hexameric repeat of the Myc epitope tag at the 5'-end of the first polylinker(Rupp et al., 1994). This vector allows the expression of myc-tagged proteins.

\section{HA/pCS2+}

pCS2+/HA is a derivative of the pCS2+ vector, that contains the Human influenza hemagglutinin (HA) epitope tag inserted via the Xbal site(Damianitsch et al., 2009). This vector allows the expression of HA-tagged proteins.

\section{MT-GFP/pCS2+}

pCS2+/MT-GFP is a derivative of the pCS2+/MT vector, that contains the S65A mutant form of GFP, in-frame with the Myc epitope tags. This vector is a suitable system for cloning of $\mathrm{N}$ - and/or C-terminally tagged constructs, as well as for the analysis of promoter and enhancer sequences (Rubenstein et al., 1997).

\section{MT-GR/pCS2+}

MT-GR/pCS2+ is a derivative of the MT/pCS2+ vector, that contains the human glucocorticoid receptor domain (GR), in-frame with the Myc epitope tags. This vector is a suitable system for cloning of $\mathrm{N}$ - and/or C-terminally tagged hormone-inducible constructs (Yonglong Chen, unpublished). 


\section{GR/pCS2+}

$\mathrm{GR} / \mathrm{pCS} 2+$ is a derivative of the pCS2+ vector, that contains the human glucocorticoid receptor domain (GR). This vector is a suitable system for cloning of hormone-inducible constructs (Yonglong Chen, unpublished).

\section{5'GR/pCS2+}

$\mathrm{GR} / \mathrm{pCS} 2+$ is a derivative of the pCS2+ vector, that contains the human glucocorticoid receptor domain (GR). This vector is a suitable system for cloning of N-terminally fused hormone-inducible constructs(Damianitsch, 2008).

\section{pCS107}

The pCS107 vector is a modification of the pCS105 vector. The major modification is the functional T7 promoterwhich now reads: $5^{\prime}$ gcctctcgagcctctcgccctatagtgagtcg $3^{\prime}$ the only difference from pCS105 is the change of cgcc (optimal bluescript motif) from agaa (Grammer et al., 2000).

\section{pGEM®-T Easy}

pGEM®-T Easy vector is a suitable system for the cloning of PCR products. It contains single $3^{\prime}-\mathrm{T}$ overhangs at the insertion site within the multiple cloning region. This cloning region is located within the alpha-peptide coding region of the enzyme beta-galactosidase, what allows blue/white screening on indicator plates. The pGEM®-T Easy vector contains T7 and SP6 RNA polymerase promoters (Promega).

\section{pBluescript KS/SK}

pBluescript KS/SK phagemids (plasmids with a phage origin) are a cloning vectors that contain the beta-galctosidase coding region, which is interrupted by a polylinker and flanked by T7 and T3 RNA polymerase promoters (Stratagene).

\section{pGL3}

The pGL3 vector contains a modified coding region of the firefly luciferase gene and was designed for the analysis of promoter and enhancer sequences or DNA-binding proteins in the context of transcriptional regulation (Promega). 


\section{pRL-TK}

The pRL-TK vector contains cDNA encoding Renilla luciferase under control of the herpes simplex virus thymidine kinase (HSV-TK) promoter. It is intended for use as an internal control reporter in combination with any experimental reporter vector (Promega).

\section{pRL-CMV}

The PRL-CMV vector contains CDNA encoding Renilla luciferase under control of the cytomegalovirus (CMV) promoter. It is intended for use as an internal control reporter in combination with any experimental reporter vector (Promega).

\subsubsection{Expression constructs and luciferase reporters}

The expression construct and luciferase reporters used in this study are presented in Table 1. The constructs were linearized and in vitro transcribed as indicated in Table 2.

Table 1.Expression constructs and luciferase preporters

\begin{tabular}{|c|c|c|c|}
\hline Name & Vector & Insert & Cloning strategy \\
\hline BcatS33A -GR & GR/pCS2+ & $\begin{array}{l}\text { Human } \beta \text { catS33A } \\
\text { fused to human } \\
\text { GR-LBD }\end{array}$ & $\begin{array}{l}\text { (Aberle et al., 1997; } \\
\text { Damianitsch, 2008) }\end{array}$ \\
\hline $\begin{array}{l}\text { ßcatS33A } \triangle T A- \\
\text { GR }\end{array}$ & GR/pCS2+ & $\begin{array}{l}\text { Human } \beta \text { catS33A } \\
\text { lacking Trans- } \\
\text { activation domain } \\
\text { fused to human } \\
\text { GR-LBD }\end{array}$ & 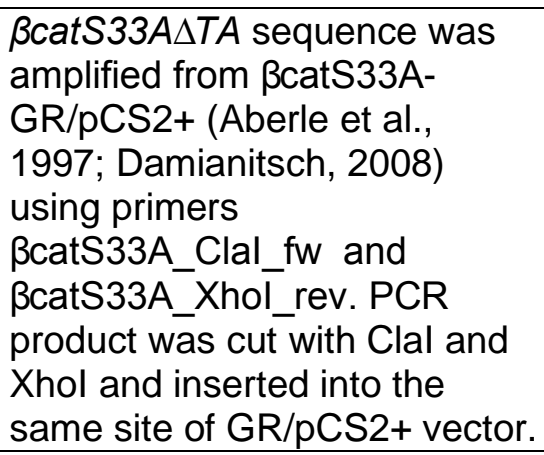 \\
\hline $\begin{array}{l}\beta c \text { catS33A } \triangle T A- \\
\text { VP16-GR }\end{array}$ & GR/pCS2+ & $\begin{array}{l}\text { Human ßcatS33A } \\
\text { lacking Trans- } \\
\text { activation domain } \\
\text { fused to Herpes } \\
\text { simplex virus } \\
\text { VP16 and human } \\
\text { GR-LBD }\end{array}$ & $\begin{array}{l}\text { VP16 sequence was amplified } \\
\text { from VP16/pCS2+ using } \\
\text { primers VP16_Xhol_fw and } \\
\text { VP16_Xhol_rev. PCR product } \\
\text { was cut with Xhol and inserted } \\
\text { into the same site of } \\
\text { BcatS33A } \triangle T A-G R \text { vector. }\end{array}$ \\
\hline
\end{tabular}




\begin{tabular}{|c|c|c|c|}
\hline Name & Vector & Insert & Cloning strategy \\
\hline $\begin{array}{l}\text { GR- } \\
\text { ßcatS33Y } \triangle T A\end{array}$ & 5'GR/pCS2+ & $\begin{array}{l}\text { Human } \beta \text {-Catenin } \\
\text { with a mutation at } \\
\text { serine } 33 \text { site } \\
\text { lacking Trans- } \\
\text { activation domain } \\
\text { fused to the } \\
\text { human GR-LBD. }\end{array}$ & 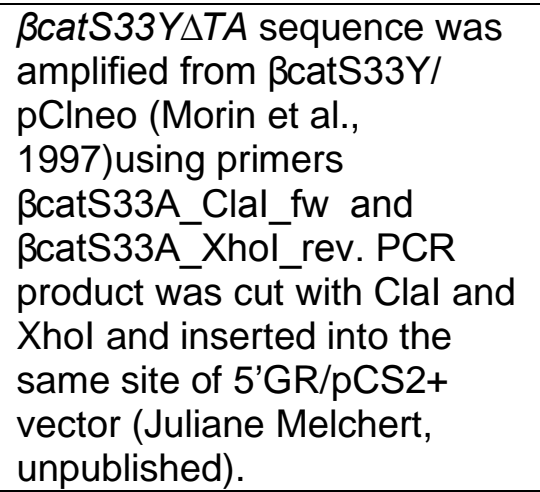 \\
\hline $\begin{array}{l}\text { ßcatS33A } \triangle T A- \\
\text { EnR-GR }\end{array}$ & GR/pCS2+ & $\begin{array}{l}\text { Human } \beta \text { catS33A } \\
\text { lacking Trans- } \\
\text { activation domain } \\
\text { fused to } \\
\text { Drosophila EnR } \\
\text { and human GR- } \\
\text { LBD }\end{array}$ & $\begin{array}{l}\text { EnR sequence was amplified } \\
\text { from EnR/pCS2+ (Tiemo } \\
\text { Klisch, unpublished) using } \\
\text { primers EnR_Xhol_fw and } \\
\text { EnR_Xhol_rev. PCR product } \\
\text { was cut with Xhol and inserted } \\
\text { into the same site of } \\
\text { ßcatS33A } \triangle T A-G R \text { vector. }\end{array}$ \\
\hline GR- $\Delta N T c f 3$ & 5'GR/pCS2+ & $\begin{array}{l}\text { Xenopus Tcf3 } \\
\text { lacking the } \beta- \\
\text { Catenin binding } \\
\text { domain fused to } \\
\text { human GR-LBD. }\end{array}$ & $\begin{array}{l}\Delta \text { NTcf3 sequence was } \\
\text { amplified from } \Delta \text { NTcf3/pT7T } \\
\text { (Molenaar et al., 1996) using } \\
\text { primers dNTCF3_EcoRI_fw } \\
\text { and dNTCF3_Xhol_rev. PCR } \\
\text { product was cut with EcoRI } \\
\text { and Xhol and inserted into the } \\
\text { same site of 5'GR/pCS2+ } \\
\text { vector (Juliane Melchert, } \\
\text { unpublished). }\end{array}$ \\
\hline Tcf3 $\Delta C-G R$ & GR/pCS2+ & $\begin{array}{l}\text { Xenopus Tcf3 } \\
\text { lacking the CtBP } \\
\text { binding domain } \\
\text { fused to human } \\
\text { GR-LBD. }\end{array}$ & $\begin{array}{l}\text { Tcf3 } \Delta \text { C sequence was } \\
\text { amplified from Tcf3 } \Delta \text { C/ pCS2+ } \\
\text { (Pukrop et al., 2001) using } \\
\text { primers TCF3AdC_EcoRI_fw } \\
\text { and TCF3-AdC_Xhol_rev. } \\
\text { PCR product was cut with } \\
\text { EcoRI/Xhol and inserted into } \\
\text { the same site of GR/pCS2+ } \\
\text { vector. }\end{array}$ \\
\hline GR-Tcf3 $\Delta H M G$ & 5'GR/pCS2+ & $\begin{array}{l}\text { Xenopus Tcf3 } \\
\text { lacking the C- } \\
\text { terminus } \\
\text { including DNA } \\
\text { binding domain } \\
\text { fused to human } \\
\text { GR-LBD. }\end{array}$ & $\begin{array}{l}\text { Tcf3 } 3 H M G \text { sequence was cut } \\
\text { off from Tcf } 3 \Delta H M G / p C S 2+ \\
\text { (Pukrop, unpublished) using } \\
\text { EcoRI/Xhol and inserted into } \\
\text { the same site of } 5 \text { 'GR/pCS2+ } \\
\text { vector. }\end{array}$ \\
\hline Tcf3 3 HMG-GR & GR/pCS2+ & $\begin{array}{l}\text { Xenopus Tcf3 } \\
\text { lacking the C- } \\
\text { terminus } \\
\text { including DNA } \\
\text { binding domain } \\
\text { fused to human } \\
\text { GR-LBD. }\end{array}$ & $\begin{array}{l}\text { Tcf3 } 3 H M G \text { sequence was cut } \\
\text { off from Tcf } 3 \Delta H M G / p C S 2+ \\
\text { (Pukrop, unpublished) using } \\
\text { EcoRI/Xhol and inserted into } \\
\text { the same site of GR/pCS2+ } \\
\text { vector. }\end{array}$ \\
\hline Lef1-GR & GR/pCS2+ & mouse full-length & (Behrens et al., 1996; \\
\hline
\end{tabular}




\begin{tabular}{|c|c|c|c|}
\hline Name & Vector & Insert & Cloning strategy \\
\hline & & $\begin{array}{l}\text { Lef1 fused to } \\
\text { human GR-LBD. }\end{array}$ & Damianitsch, 2008) \\
\hline Lef $\triangle B D-G R$ & GR/pCS2+ & $\begin{array}{l}\text { Mouse Lef1 } \\
\text { lacking the } \beta \text { - } \\
\text { Catenin binding } \\
\text { domain fused to } \\
\text { human GR-LBD. }\end{array}$ & $\begin{array}{l}\text { (Behrens et al., 1996; } \\
\text { Katharina Damianitsch, } \\
\text { unpublished) }\end{array}$ \\
\hline Lef $\Delta \mathrm{N}-\mathrm{VP} 16-\mathrm{GR}$ & GR/pCS2+ & $\begin{array}{l}\text { Chimeric fusion of } \\
\text { the Lef1 DNA } \\
\text { binding domain } \\
\text { fused to Herpes } \\
\text { simplex virus } \\
\text { VP16 and human } \\
\text { GR.LBD }\end{array}$ & (Denayer et al., 2008) \\
\hline EnR-Lef1-GR & GR/pCS2+ & $\begin{array}{l}\text { Full-length Lef1 } \\
\text { fused to } \\
\text { Drosophila EnR } \\
\text { and human GR- } \\
\text { LBD. }\end{array}$ & (Lyons et al., 2009) \\
\hline MT-Dvl & $\mathrm{MT} / \mathrm{pCS} 2+$ & $\begin{array}{l}\text { Full-length } \\
\text { Xenopus laevis } \\
\text { disheveled fused } \\
\text { to MT }\end{array}$ & (Sokol, 1996) \\
\hline MT- $\beta$-Catenin & $\mathrm{MT} / \mathrm{pCS} 2+$ & $\begin{array}{l}\text { Full-length human } \\
\beta \text {-Catenin fused } \\
\text { to MT }\end{array}$ & (Behrens et al., 1996) \\
\hline $\operatorname{lac} Z$ & pCS2+ & $\begin{array}{l}\text { Bacterial } \beta- \\
\text { galactosidase }\end{array}$ & (Smith and Harland, 1991) \\
\hline PDIp & pBK-CMV & $\begin{array}{l}\text { Xenopus laevis } \\
\text { fulllength } \\
\text { pancreatic protein } \\
\text { disulfide } \\
\text { isomerase }\end{array}$ & (Afelik et al., 2004) \\
\hline TTpA072o12 & pCS107 & $\begin{array}{l}\text { Xenopus } \\
\text { tropicalis cDNA } \\
\text { clone } \\
\text { TTpA072012 }\end{array}$ & (Gilchrist et al., 2004) \\
\hline TTpA074b10 & pCS107 & $\begin{array}{l}\text { Xenopus } \\
\text { tropicalis cDNA } \\
\text { clone } \\
\text { TTpA074b10 } \\
\end{array}$ & (Gilchrist et al., 2004) \\
\hline TTpA074h13 & pCS107 & $\begin{array}{l}\text { Xenopus } \\
\text { tropicalis cDNA } \\
\text { clone } \\
\text { TTpA074h13 }\end{array}$ & (Gilchrist et al., 2004) \\
\hline TTpA075c05 & pCS107 & $\begin{array}{l}\text { Xenopus } \\
\text { tropicalis cDNA } \\
\text { clone } \\
\text { TTpA075c05 }\end{array}$ & (Gilchrist et al., 2004) \\
\hline TTpA075j02 & pCS107 & $\begin{array}{l}\text { Xenopus } \\
\text { tropicalis cDNA } \\
\text { clone } \\
\text { TTpA075j02 }\end{array}$ & (Gilchrist et al., 2004) \\
\hline
\end{tabular}




\begin{tabular}{|c|c|c|c|}
\hline Name & Vector & Insert & Cloning strategy \\
\hline TTpA075o18 & pCS107 & $\begin{array}{l}\text { Xenopus } \\
\text { tropicalis cDNA } \\
\text { clone } \\
\text { TTpA075o18 }\end{array}$ & (Gilchrist et al., 2004) \\
\hline TTpA076d05 & pCS107 & $\begin{array}{l}\text { Xenopus } \\
\text { tropicalis cDNA } \\
\text { clone } \\
\text { TTpA076d05 }\end{array}$ & (Gilchrist et al., 2004) \\
\hline TTpA076k21 & pCS107 & $\begin{array}{l}\text { Xenopus } \\
\text { tropicalis cDNA } \\
\text { clone } \\
\text { TTpA076k21 }\end{array}$ & (Gilchrist et al., 2004) \\
\hline TTpA077b02 & pCS107 & $\begin{array}{l}\text { Xenopus } \\
\text { tropicalis cDNA } \\
\text { clone } \\
\text { TTpA077b02 } \\
\end{array}$ & (Gilchrist et al., 2004) \\
\hline TTpA078d11 & pCS107 & $\begin{array}{l}\text { Xenopus } \\
\text { tropicalis cDNA } \\
\text { clone } \\
\text { TTpA078d11 }\end{array}$ & (Gilchrist et al., 2004) \\
\hline TTpA078h06 & pCS107 & $\begin{array}{l}\text { Xenopus } \\
\text { tropicalis cDNA } \\
\text { clone } \\
\text { TTpA078h06 }\end{array}$ & (Gilchrist et al., 2004) \\
\hline TTpA078I11 & pCS107 & $\begin{array}{l}\text { Xenopus } \\
\text { tropicalis cDNA } \\
\text { clone } \\
\text { TTpA078I11 } \\
\end{array}$ & (Gilchrist et al., 2004) \\
\hline TТрА073i18 & pCS107 & $\begin{array}{l}\text { Xenopus } \\
\text { tropicalis cDNA } \\
\text { clone } \\
\text { TTpA073i18 }\end{array}$ & (Gilchrist et al., 2004) \\
\hline TTpA074b19 & pCS107 & $\begin{array}{l}\text { Xenopus } \\
\text { tropicalis cDNA } \\
\text { clone } \\
\text { TTpA074b19 }\end{array}$ & (Gilchrist et al., 2004) \\
\hline TTpA074l15 & pCS107 & $\begin{array}{l}\text { Xenopus } \\
\text { tropicalis cDNA } \\
\text { clone } \\
\text { TTpA074I15 }\end{array}$ & (Gilchrist et al., 2004) \\
\hline TTpA075f20 & pCS107 & $\begin{array}{l}\text { Xenopus } \\
\text { tropicalis cDNA } \\
\text { clone } \\
\text { TTpA075f20 }\end{array}$ & (Gilchrist et al., 2004) \\
\hline TTpA075I15 & pCS107 & $\begin{array}{l}\text { Xenopus } \\
\text { tropicalis cDNA } \\
\text { clone } \\
\text { TTpA075I15 }\end{array}$ & (Gilchrist et al., 2004) \\
\hline TTpA076b06 & pCS107 & $\begin{array}{l}\text { Xenopus } \\
\text { tropicalis cDNA } \\
\text { clone } \\
\text { TTpA076b06 }\end{array}$ & (Gilchrist et al., 2004) \\
\hline
\end{tabular}




\begin{tabular}{|c|c|c|c|}
\hline Name & Vector & Insert & Cloning strategy \\
\hline TTрА076j03 & pCS107 & $\begin{array}{l}\text { Xenopus } \\
\text { tropicalis cDNA } \\
\text { clone } \\
\text { TTpA076j03 } \\
\end{array}$ & (Gilchrist et al., 2004) \\
\hline TTpA076I10 & pCS107 & $\begin{array}{l}\text { Xenopus } \\
\text { tropicalis cDNA } \\
\text { clone } \\
\text { TTpA076I10 }\end{array}$ & (Gilchrist et al., 2004) \\
\hline TTpA077e08 & pCS107 & $\begin{array}{l}\text { Xenopus } \\
\text { tropicalis cDNA } \\
\text { clone } \\
\text { TTpA077e08 } \\
\end{array}$ & (Gilchrist et al., 2004) \\
\hline TTpA078f11 & pCS107 & $\begin{array}{l}\text { Xenopus } \\
\text { tropicalis cDNA } \\
\text { clone } \\
\text { TTpA078f11 }\end{array}$ & (Gilchrist et al., 2004) \\
\hline TTpA078k07 & pCS107 & $\begin{array}{l}\text { Xenopus } \\
\text { tropicalis cDNA } \\
\text { clone } \\
\text { TTpA078k07 }\end{array}$ & (Gilchrist et al., 2004) \\
\hline TTpA078m10 & pCS107 & $\begin{array}{l}\text { Xenopus } \\
\text { tropicalis cDNA } \\
\text { clone } \\
\text { TTpA078m10 } \\
\end{array}$ & (Gilchrist et al., 2004) \\
\hline XtFam132b & pCS2+ & $\begin{array}{l}\text { Xenopus } \\
\text { tropicalis } \\
\text { fam132bcoding } \\
\text { sequence }\end{array}$ & $\begin{array}{l}\text { XtFam132b sequence was } \\
\text { amplified from } \\
\text { TTpA078f11/pCS107(Gilchrist } \\
\text { et al., 2004) using primers } \\
\text { fam132b_BamHI_fw and } \\
\text { fam132b_Xhol_rev. PCR } \\
\text { product was cut with } \\
\text { BamHI/Xhol and inserted into } \\
\text { the same site of pCS2+ vector. }\end{array}$ \\
\hline tBR & pSP64T & $\begin{array}{l}\text { Xenopus laevis } \\
\text { dominant } \\
\text { negative BMP } \\
\text { receptor }\end{array}$ & (Graff et al., 1994) \\
\hline MT-Wnt8 & $\mathrm{MT} / \mathrm{pCS} 2+$ & $\begin{array}{l}\text { Full-length } \\
\text { Xenopus laevis } \\
\text { Wnt8 fused to MT }\end{array}$ & (Damianitsch et al., 2009) \\
\hline Siamois-Luc & pGL3 & $\begin{array}{l}\text { contains Xenopus } \\
\text { laevis Siamois } \\
\text { promoter } \\
\text { upstream of } \\
\text { Firefly luciferase } \\
\text { ATG }\end{array}$ & (Brannon et al., 1997) \\
\hline Renilla-Luc & pRL-CMV & $\begin{array}{l}\text { Contains Renilla } \\
\text { luciferase under } \\
\text { control of CMV } \\
\text { promoter }\end{array}$ & promega \\
\hline Noggin & pGEM5ZF & $\begin{array}{l}\text { 5'truncated } \\
\text { version of } \\
\text { Xenopus laevis }\end{array}$ & (Smith and Harland, 1992) \\
\hline
\end{tabular}




\begin{tabular}{|c|c|c|c|}
\hline Name & Vector & Insert & Cloning strategy \\
\hline & & Noggin & \\
\hline BMP4 & pSP64T & $\begin{array}{l}\text { Xenopus laevis } \\
\text { bone } \\
\text { morphogenetic } \\
\text { protein } 4\end{array}$ & (Nishimatsu et al., 1992) \\
\hline BMP2 & pSP64T & $\begin{array}{l}\text { Xenopus laevis } \\
\text { bone } \\
\text { morphogenetic } \\
\text { protein } 2\end{array}$ & (Clement et al., 1995) \\
\hline $\begin{array}{l}\text { Vent2b-BRE- } \\
\text { Luc }\end{array}$ & pGL3 & $\begin{array}{l}\text { contains Xenopus } \\
\text { laevis }-275 /+52- \\
\text { Vent2b promoter } \\
\text { upstream of } \\
\text { Firefly luciferase } \\
\text { ATG }\end{array}$ & (Henningfeld et al., 2000) \\
\hline Renilla-Luc & pRL-TK & $\begin{array}{l}\text { Contains Renilla } \\
\text { luciferase under } \\
\text { control of HSV- } \\
\text { TK promoter }\end{array}$ & promega \\
\hline eFGF & pSP64T & $\begin{array}{l}\text { Xenopus laevis } \\
\text { embryonic } \\
\text { fibroblast growth } \\
\text { factor }\end{array}$ & (Isaacs et al., 1994) \\
\hline Activin & pSP64T & $\begin{array}{l}\text { Zebrafish } \\
\text { activin } \beta B\end{array}$ & (Wittbrodt and Rosa, 1994) \\
\hline Fam132b-HA & $\mathrm{HA} / \mathrm{pCS} 2+$ & $\begin{array}{l}\text { Xenopus } \\
\text { tropicalis } \\
\text { fam132bcoding } \\
\text { sequence fused } \\
\text { to HA tag }\end{array}$ & $\begin{array}{l}\text { XtFam132b sequence was } \\
\text { amplified from } \\
\text { XtFam132b/pCS2+ using } \\
\text { primers fam132b_EcoRI_fw } \\
\text { and fam132b_stop_Xhol_rev. } \\
\text { PCR product was cut with } \\
\text { EcoRI/Xhol and inserted into } \\
\text { the same site of HA/pCS2+ } \\
\text { vector. }\end{array}$ \\
\hline $\mathrm{Su}(\mathrm{H})-\mathrm{HA}$ & $\mathrm{HA} / \mathrm{pCS} 2+$ & $\begin{array}{l}\text { Xenopus laevis } \\
\text { Suppressor of } \\
\text { Hairless fused to } \\
\text { HA tag }\end{array}$ & $\begin{array}{l}\text { (Marie Hedderich, } \\
\text { unpublished) }\end{array}$ \\
\hline sFRP5-HA & $\mathrm{HA} / \mathrm{pCS} 2+$ & $\begin{array}{l}\text { Xenopus laevis } \\
\text { secreted Frizzled- } \\
\text { related protein } 5 \\
\text { fused to HA tag }\end{array}$ & (Damianitsch et al., 2009) \\
\hline caBMPR & pSP64T & $\begin{array}{l}\text { Constitutively } \\
\text { active Xenopus } \\
\text { laevis Alk3 BMP } \\
\text { type I receptor } \\
\text { with the mutation } \\
\text { Glu228Asp }\end{array}$ & (Candia et al., 1997) \\
\hline XtFam132b-MT & $\mathrm{MT} / \mathrm{pCS} 2+$ & $\begin{array}{l}\text { Xenopus } \\
\text { tropicalis } \\
\text { fam132bcoding } \\
\text { sequence fused } \\
\text { to MT }\end{array}$ & $\begin{array}{l}\text { XtFam132b sequence was } \\
\text { amplified from } \\
\text { XtFam132b/pCS2+ using } \\
\text { primers } \\
\text { famSP_BamHI_fw and }\end{array}$ \\
\hline
\end{tabular}




\begin{tabular}{|c|c|c|c|}
\hline Name & Vector & Insert & Cloning strategy \\
\hline & & & $\begin{array}{l}\text { fam132b_Stop_Clal_rev. PCR } \\
\text { product was cut with } \\
\text { BamHI/Clal and inserted into } \\
\text { the same site of MT/pCS2+ } \\
\text { vector. }\end{array}$ \\
\hline $\begin{array}{l}\text { XtFam132b- } \\
\text { MT-GR }\end{array}$ & $\begin{array}{l}\text { MT- } \\
\text { GR/pCS2+ }\end{array}$ & $\begin{array}{l}\text { Xenopus } \\
\text { tropicalis } \\
\text { fam132bcoding } \\
\text { sequence fused } \\
\text { to MT and GR- } \\
\text { LBD }\end{array}$ & $\begin{array}{l}\text { XtFam132b sequence was cut } \\
\text { off from XtFam132b- } \\
\text { MT/pCS2+ using BamHII/Clal } \\
\text { and inserted into the same site } \\
\text { of MT-GR/pCS2+ vector. }\end{array}$ \\
\hline Alk2-HA & $\mathrm{HA} / \mathrm{pCS} 2+$ & $\begin{array}{l}\text { Xenopus laevis } \\
\text { Alk2 BMP type I } \\
\text { receptor fused to } \\
\text { HA tag }\end{array}$ & (Aramaki et al., 2010) \\
\hline Alk3-HA & $\mathrm{HA} / \mathrm{pCS} 2+$ & $\begin{array}{l}\text { Xenopus laevis } \\
\text { Alk3 BMP type I } \\
\text { receptor fused to } \\
\text { HA tag }\end{array}$ & (Aramaki et al., 2010) \\
\hline Noggin-MT & $\mathrm{MT} / \mathrm{pCS} 2+$ & $\begin{array}{l}\text { Xenopus laevis } \\
\text { Noggin fused to } \\
\text { MT tag }\end{array}$ & $\begin{array}{l}\text { Noggin sequence was } \\
\text { amplified from } \\
\text { Noggin/pGEM5ZF using } \\
\text { primers } \\
\text { Noggin_Clal_fw and } \\
\text { Noggin_Clal_rev. PCR product } \\
\text { was cut with Clal and inserted } \\
\text { into the same site of } \\
\text { MT/pCS2+ vector. }\end{array}$ \\
\hline BMP4-HA & pCS2+ & $\begin{array}{l}\text { Xenopus laevis } \\
\text { bone } \\
\text { morphogenetic } \\
\text { protein } 4 \text { fused to } \\
\text { HA tag }\end{array}$ & (Haramoto et al., 2004) \\
\hline $\begin{array}{l}\text { XtFam132b- } \\
\Delta C 1 \mathrm{q}\end{array}$ & pCS2+ & $\begin{array}{l}\text { Xenopus } \\
\text { tropicalis } \\
\text { Fam132blacking } \\
\text { the C1q/TNF-like } \\
\text { domain }\end{array}$ & $\begin{array}{l}\text { XtFam132b_C1q sequence } \\
\text { was amplified from } \\
\text { XtFam132b/pCS2+ using } \\
\text { primers famSP_BamHI_fw and } \\
\text { intfam_Xhol_rev. PCR product } \\
\text { was cut with EcoRI/Xhol and } \\
\text { inserted into the same site of } \\
\text { pCS2+ vector. }\end{array}$ \\
\hline XtFam132b- $\Delta$ int & pCS2+ & $\begin{array}{l}\text { Xenopus } \\
\text { tropicalis } \\
\text { Fam132blacking } \\
\text { the internal } \\
\text { sequence }\end{array}$ & $\begin{array}{l}\text { XtFam132b_vintern sequence } \\
\text { was amplified from } \\
\text { XtFam132b/pCS2+. N-terminal } \\
\text { signal sequence was amplified } \\
\text { using primers } \\
\text { famSP_BamHI_fw and } \\
\text { famSP_EcoRI_rev. PCR } \\
\text { product was cut with } \\
\text { BamHI/EcoRI. C-terminal C1q } \\
\text { domain was ampliefied using } \\
\text { primers C1q_EcoRI_fw and } \\
\text { fam132b_Xhol_rev. PCR }\end{array}$ \\
\hline
\end{tabular}




\begin{tabular}{|c|c|c|c|}
\hline Name & Vector & Insert & Cloning strategy \\
\hline & & & $\begin{array}{l}\text { product was cut with } \\
\text { EcoRI/Xhol. Both fragments } \\
\text { were inserted into the } \\
\text { BamHI/Xhol site of the pCS2+ } \\
\text { vector. }\end{array}$ \\
\hline XtFam132a & pCS2+ & $\begin{array}{l}\text { Xenopus } \\
\text { tropicalis } \\
\text { fam132acoding } \\
\text { sequence }\end{array}$ & $\begin{array}{l}\text { XtFam132a sequence was } \\
\text { ampliefied from } \\
\text { XtFam132a/pCS108 (Source } \\
\text { Bioscience Life Science; } \\
\text { IMAGE ID: 7603110) using } \\
\text { primers Xtfam132a_EcoRI_fw } \\
\text { and Xtfam132a_Xhol_rev. } \\
\text { PCR product was cut with } \\
\text { EcoRI/Xhol and inserted into } \\
\text { the same site of pCS2+ vector. }\end{array}$ \\
\hline MmFam132b & pCS2+ & $\begin{array}{l}\text { mouse } \\
\text { fam132bcoding } \\
\text { sequence }\end{array}$ & $\begin{array}{l}\text { MmFam132b sequence was } \\
\text { ampliefied from } \\
\text { MmFam132b/pYX-Asc } \\
\text { (Source Bioscience Life } \\
\text { Science; IMAGE ID: } 5716432 \text { ) } \\
\text { using primers } \\
\text { Mmfam132b_EcoRI_fw and } \\
\text { Mmfam132b_Xhol_rev. PCR } \\
\text { product was cut with } \\
\text { EcoRI/Xhol and inserted into } \\
\text { the same site of pCS2+ vector. }\end{array}$ \\
\hline DrFam132b & pCS2+ & $\begin{array}{l}\text { zebrafish } \\
\text { fam132bcoding } \\
\text { sequence }\end{array}$ & $\begin{array}{l}\text { (AN: XM_002660704; Biomatik } \\
\text { gene synthesis) }\end{array}$ \\
\hline XIFam132b & pCS2+ & $\begin{array}{l}\text { Xenopus laevis } \\
\text { fam132bcoding } \\
\text { sequence }\end{array}$ & $\begin{array}{l}\text { Partial XIFam132b sequence } \\
\text { was cloned from X. laevis st } \\
37 / 38 \text { cDNA using primers } \\
\text { fam132b_E3_fw and } \\
\text { fam132b_E5_rev. PCR } \\
\text { product was cloned into } \\
\text { pGEM-T®Easy vector. Based } \\
\text { on sequence analysis of the } \\
\text { PCR fragment gene specific } \\
\text { primers 5'RACE_fam132b and } \\
\text { 3'RACE_fam132b were } \\
\text { generated and used for RACE- } \\
\text { PCR using X. laevis st } 37 / 38 \\
\text { CDNA. 3' and 5'RACE } \\
\text { fragments were inserted into } \\
\text { pGEM-T@Easy vector. Based } \\
\text { on sequence analysis of these } \\
\text { fragments, cloning primers } \\
\text { fam132b_CDS_EcoRI_fw and } \\
\text { fam132b_CDS_Xbal_rev were } \\
\text { generated and used for cloning } \\
\text { of the XIFam132b coding } \\
\text { sequence from X. laevis st } \\
37 / 38 \text { cDNA. PCR product was }\end{array}$ \\
\hline
\end{tabular}




\begin{tabular}{|c|c|c|c|}
\hline Name & Vector & Insert & Cloning strategy \\
\hline & & & $\begin{array}{l}\text { cutwith EcoRI/Xbal and } \\
\text { inserted into the same site of } \\
\text { pCS2+ vector. }\end{array}$ \\
\hline XIFam132b & pBluskript SK & $\begin{array}{l}\text { Xenopus laevis } \\
\text { fam132bcoding } \\
\text { sequence }\end{array}$ & $\begin{array}{l}\text { XIFam132b sequence was cut } \\
\text { off from XIFam132b/pCS2+ } \\
\text { using EcoRI/Xbal and inserted } \\
\text { into the same site of pBluskript } \\
\text { SK vector. }\end{array}$ \\
\hline SCL & pGEM-T & $\begin{array}{l}\text { Xenopus laevis } \\
\text { SCL }\end{array}$ & (Neuhaus et al., 2010) \\
\hline mpo & pCMV-Sport6 & $\begin{array}{l}\text { Xenopus laevis } \\
\text { myeloperoxidase }\end{array}$ & (Smith et al., 2002) \\
\hline LMO-2A & pCMV-Sport6 & $\begin{array}{l}\text { Xenopus laevis } \\
\text { LIM domain only } \\
2\end{array}$ & (Mead et al., 2001) \\
\hline a-Globin & pSPT18 & $\begin{array}{l}\text { Xenopus laevis } \\
\text { a-Globin }\end{array}$ & (Neuhaus et al., 2010) \\
\hline ami & pBluskript SK & $\begin{array}{l}\text { Xenopus laevis } \\
\text { Serine protease } \\
\text { ami }\end{array}$ & (Inui and Asashima, 2006) \\
\hline $\begin{array}{l}\text { 5'UTR- } \\
\text { XIFam132b- } \\
\text { MT-GFP }\end{array}$ & $\begin{array}{l}\text { MT- } \\
\text { GFP/pCS2+ }\end{array}$ & $\begin{array}{l}\text { Xenopus laevis } \\
\text { Fam132b 5'UTR } \\
\text { with } 27 \\
\text { nucleotides of the } \\
\text { Fam132b CDS }\end{array}$ & $\begin{array}{l}\text { 5'UTR-XIFam132b sequence } \\
\text { was amplified from 5'UTR- } \\
\text { XIFam132b/pGEM-T®Easy } \\
\text { using primers 5'UTR- } \\
\text { XIfam132b_fw_BamHI and } \\
\text { 5'UTR-XIfam132b_- } \\
\text { BamHI_rev. PCR product was } \\
\text { cut with BamHI and inserted } \\
\text { into the same site of MT- } \\
\text { GFP/pCS2+ vector. }\end{array}$ \\
\hline Etv2/er71 & pCS2+ & $\begin{array}{l}\text { Xenopus laevis } \\
\text { Etv2/er71 }\end{array}$ & $\begin{array}{l}\text { etv2/er71sequence was cloned } \\
\text { from Etv2/pBlueskript SK } \\
\text { (Salanga et al., 2010)using } \\
\text { primers etv2_Clal_fw and } \\
\text { etv2_Xhol_rev. PCR product } \\
\text { was cut with Clal/Xhol and } \\
\text { inserted into the same site of } \\
\text { pCS2+ vector. }\end{array}$ \\
\hline
\end{tabular}

Table 2.Linearization of DNA constructs and in vitro transcription

\begin{tabular}{|c|c|c|c|c|}
\hline \multirow{2}{*}{ Name } & \multicolumn{2}{|c|}{ sense RNA } & \multicolumn{2}{|c|}{ antisense RNA } \\
\hline & cut & polymerize & cut & polymerize \\
\hline$\beta$ catS33A- $\triangle T A-G R$ & Notl & SP6 & & \\
\hline $\begin{array}{l}\text { BcatS33A } \triangle \text { TA-VP16- } \\
\text { GR }\end{array}$ & Apal & SP6 & & \\
\hline GR- $\beta$ catS33AY & Notl & SP6 & & \\
\hline $\begin{array}{l}\text { BcatS33A } \Delta T A-E n R- \\
\text { GR }\end{array}$ & Apal & SP6 & & \\
\hline
\end{tabular}


Materials and Methods

\begin{tabular}{|c|c|c|c|c|}
\hline \multirow{2}{*}{ Name } & \multicolumn{2}{|c|}{ sense RNA } & \multicolumn{2}{|c|}{ antisense RNA } \\
\hline & cut & polymerize & cut & polymerize \\
\hline GR- $\Delta$ NTcf3 & Notl & SP6 & & \\
\hline $\operatorname{Tcf} 3 \Delta \mathrm{C}-\mathrm{GR}$ & Notl & SP6 & & \\
\hline GR-Tcf3 $\Delta \mathrm{HMG}$ & Notl & SP6 & & \\
\hline Tcf3 $\Delta$ HMG-GR & Notl & SP6 & & \\
\hline Lef1-GR & Notl & SP6 & & \\
\hline Lef $\triangle B D-G R$ & Notl & SP6 & & \\
\hline Lef $\Delta N-V P 16-G R$ & Xhol & SP6 & & \\
\hline EnR-Lef1-GR & EcoRV & SP6 & & \\
\hline PDIp & & & BamHI & T7 \\
\hline TTpA072o12 & Notl & SP6 & & \\
\hline TTpA074b10 & Notl & SP6 & & \\
\hline TTpA074h13 & Notl & SP6 & & \\
\hline ТTрА075c05 & Notl & SP6 & & \\
\hline TTрА075j02 & Notl & SP6 & & \\
\hline TTpA075o18 & Notl & SP6 & & \\
\hline TTpA076d05 & Notl & SP6 & & \\
\hline TTpA076k21 & Notl & SP6 & & \\
\hline TTpA077b02 & Notl & SP6 & & \\
\hline TTpA078d11 & Notl & SP6 & & \\
\hline TTpA078h06 & Notl & SP6 & & \\
\hline TTpA078|11 & Notl & SP6 & & \\
\hline TTpA073i18 & Notl & SP6 & & \\
\hline TTpA074b19 & Notl & SP6 & & \\
\hline TTpA074|15 & Notl & SP6 & & \\
\hline TTpA075f20 & Notl & SP6 & & \\
\hline TTpA075I15 & Notl & SP6 & & \\
\hline TTpA076b06 & Notl & SP6 & & \\
\hline ТTрА076j03 & Notl & SP6 & & \\
\hline TTpA076|10 & Notl & SP6 & & \\
\hline TTpA077e08 & Notl & SP6 & & \\
\hline TTpA078f11 & Notl & SP6 & & \\
\hline TTpA078k07 & Notl & SP6 & & \\
\hline
\end{tabular}


Materials and Methods

\begin{tabular}{|c|c|c|c|c|}
\hline \multirow{2}{*}{ Name } & \multicolumn{2}{|c|}{ sense RNA } & \multicolumn{2}{|c|}{ antisense RNA } \\
\hline & cut & polymerize & cut & polymerize \\
\hline TTpA078m10 & Notl & SP6 & & \\
\hline XtFam132b & Notl & SP6 & & \\
\hline tBR & EcoRI & SP6 & & \\
\hline MT-Wnt8 & Notl & SP6 & & \\
\hline Noggin & Notl & SP6 & & \\
\hline BMP4 & BamHI & SP6 & & \\
\hline BMP2 & EcoRI & SP6 & & \\
\hline eFGF & $\mathrm{Accl}$ & SP6 & & \\
\hline Activin & Xbal & SP6 & & \\
\hline Fam132b-HA & Notl & SP6 & & \\
\hline $\mathrm{Su}(\mathrm{H})-\mathrm{HA}$ & Notl & SP6 & & \\
\hline sFRP5-HA & Notl & SP6 & & \\
\hline caBMPR & Notl & SP6 & & \\
\hline XtFam132b-MT & Notl & SP6 & & \\
\hline XtFam132b-MT-GR & Notl & SP6 & & \\
\hline Alk2-HA & Notl & SP6 & & \\
\hline Alk3-HA & Notl & SP6 & & \\
\hline Noggin-MT & Notl & SP6 & & \\
\hline BMP4-HA & Asp718 & SP6 & & \\
\hline $\mathrm{XtFam} 132 \mathrm{~b}-\Delta \mathrm{C} 1 \mathrm{q}$ & Notl & SP6 & & \\
\hline XtFam132b- $\Delta$ int & Notl & SP6 & & \\
\hline DrFam132b & Notl & SP6 & & \\
\hline MmFam132b & Notl & SP6 & & \\
\hline XtFam132a & Notl & SP6 & & \\
\hline XIFam132b & Notl & SP6 & & \\
\hline SCL & & & Xhol & SP6 \\
\hline mpo & & & Sall & $\mathrm{T} 7$ \\
\hline LMO-2A & & & Sall & $\mathrm{T} 7$ \\
\hline a-Globin & & & Pstl & $\mathrm{T} 7$ \\
\hline ami & & & EcoRI & $\mathrm{T} 7$ \\
\hline $\begin{array}{l}\text { 5'UTR-XIFam132b - } \\
\text { MT-GFP }\end{array}$ & Notl & SP6 & & \\
\hline Etv2/er71 & Notl & SP6 & & \\
\hline
\end{tabular}




\subsection{Oligonucleotides}

The oligonucleotides (primers) were purchased from Sigma-Aldrich Chemie.

\subsubsection{Sequencing primers}

The sequences of sequencing primers used in this study are indicated in 5' 3 ' direction.

SP6

T3

T7 (pCS2+)

T7 (pGEM-T)

SP6 (pCMV-Sport6)

T7 (pCMV-Sport6)

5'RACE_fam132b_1

5'RACE_fam132b_2
TTAGGTGACACTATAGAATAC

AATTAACCCTCACTAAAGGG

TCTACGTAATACGACTCACTATAG

TAATACGACTCACTATAGGGCGA

CTATTTAGGTGACACTATAG

TAATACGACTCACGTATAGGG

GACTGTAACTGTGATGTGTAGCAGGTGC

GCAACTGCAGGAAATGATGGA

\subsubsection{Cloning primers}

The sequences of cloning primers are indicated in 5' 3 ' direction (the digestion enzyme site is underlined).

$\begin{array}{ll}\text { EnR_Xhol_fw } & \text { CACTCGAGATGGCCCTGGAG } \\ \text { EnR_Xhol_rev } & \text { CTCTCGAGTATGTCGCTTTCCTCCTC } \\ \text { BcatS33A_Clal_fw } & \text { CATCGATATGGCTACTCAAGCTGACC } \\ \text { ßcatS33A_Xhol_rev } & \text { GACTCGAGCTGAGCAAGTTCACAG } \\ \text { VP16_Xhol_fw } & \text { GACTCGAGTTAGCCCCCCCGAC } \\ \text { VP16_Xhol_rev } & \text { CACTCGAGCCCACCGTACTCGTC } \\ \text { dNTCF3_EcoRI_fw } & \text { CTGAATTCATGGCCATCGATG } \\ \text { dNTCF3_Xhol_rev } & \text { CTTCTCGAGGTCACTGGATTTG } \\ \text { TCF3-AdC_EcoRI_fw } & \text { ACGAATTCATGCCTCAGCTCAA }\end{array}$


TCF3-AdC_Xhol_rev

fam132b_BamHI_fw

fam132b_Xhol_rev

fam132b_EcoRI_fw

fam132b $\Delta$ stop_Xhol_rev

famSP_BamHI_fw

fam132b $\Delta$ Stop_Clal_rev

Noggin_Clal_fw

Noggin_Clal_rev

intfam_Xhol_rev

famSP_EcoRI_rev

C1q_EcoRI_fw

fam132b_E3_fw

fam132b_E5_rev

5'RACE_fam132b

3'RACE fam132b

fam132b_CDS_EcoRI_fw

fam132b_CDS_Xbal_rev

Xtfam132a_EcoRI_fw

Xtfam132a_Xhol_rev

Mmfam132b_EcoRI_fw

Mmfam132b_Xhol_rev

5'UTR-XIfam132b fw BamHI

5'UTR-XIfam132b BamHI rev

etv2_Clal_fw

etv2_Xhol_rev
GTCTCGAGGTTTTCCATCTCAGG

GTGGATCCATGGATGCAGAGTACAAG

GTCTCGAGTCATTGTCCAAGAAGCAC

GTGAATTCATGGATGCAGAGTACAAGC

GTCTCGAGTTGTCCAAGAAGCAC

TTGGATCCATGGATGCAGAGTA

GTATCGATGTTGTCCAAGAAGCAC

GCATCGATATGGATCATTCCCAGT

TTATCGATTGCATGAGCATTTGC

TTCTCGAGCTATCTGTTGAATGAGC

TTGAATTCGTTCTTGTGGGTACAG

TTGAATTCTCATTCAACAGAGGAGCAG

ATGTCGCCGTGGCCCTAT

CAATATTCAGTCTTGAATTGAAAGC

GACTGTAACTGTGATGTGTAGCAGGTGC

ACTTGTCTCTGCAACAAACCAGCCAG

TAGAATTCATGGATGCCGAATACA

TATCTAGATCATTGTCCGAGCAGC

CTGAATTCATGAGGTGTTGGGTA

CTCTCGAGTTAAAGACCCATAAG

CTGAATTCATGGCCTCGACCC

CTCTCGAGTCACAGGCCCAGG

GTGGATCCAGGGAAAGTAATTGG

TTGGATCCAGGGATCGGCTTG

CTATCGATATGGATCCCAGTATCTACTACT

CCCTCGAGTTATTGAATCCTGG

\subsubsection{RT-PCR primers}

The RT-PCR primers used in this study are listed in Table 3. 
Table 3.RT-PCR primers

\begin{tabular}{|c|c|c|c|c|}
\hline $\begin{array}{l}\text { Target } \\
\text { gene }\end{array}$ & Primer name & Primer sequence $5^{\prime}-\mathbf{3}^{\prime}$ & $\mathrm{T}_{\text {an }}\left[{ }^{\circ} \mathrm{C}\right]$ & cycles \\
\hline \multirow{2}{*}{ Histone H4 } & $\mathrm{H} 4$ fw & CGGGATAACATTCAGGGTATCACT & \multirow{2}{*}{56} & \multirow{2}{*}{25} \\
\hline & H4_rev & ATCCATGGCGGTAACTGTCTTCCT & & \\
\hline \multirow{2}{*}{ Xnr3 } & Xnr3_fw & GACCAGGGGAAAGAGGTT & \multirow{2}{*}{59} & \multirow{2}{*}{30} \\
\hline & Xnr3_rev & GGGATCAGGTTTAGCATGAG & & \\
\hline \multirow{2}{*}{ Siamois } & Siamois_fw & CTCCAGCCACCAGTACCAGAT & \multirow{2}{*}{61} & \multirow{2}{*}{34} \\
\hline & Siamois_rev & GGGGAGAGTGGAAAGTGGTT & & \\
\hline \multirow{2}{*}{ Fam132b } & Fam132b_fw & ATGTCGCCGTGGCCCTAT & \multirow{2}{*}{57} & \multirow{2}{*}{$32-34$} \\
\hline & Fam132b_rev & CAATATTCAGTCTTGAATTGAAAGC & & \\
\hline \multirow{2}{*}{ Vent1 } & Vent1_fw & GCATCTCCTTGGCATATTTGG & \multirow{2}{*}{55} & \multirow{2}{*}{36} \\
\hline & Vent1_rev & TTCCCTTCAGCATGGTTCAAC & & \\
\hline \multirow{2}{*}{ Vent2 } & Vent2_fw & ССTCTGTTGAATGGCTTGCT & \multirow{2}{*}{57} & \multirow{2}{*}{24} \\
\hline & Vent2_rev & TGAGACTTGGGCACTGTCTG & & \\
\hline \multirow{2}{*}{ Msx1 } & Msx1_fw & GCAGGAACATCACACAGTCC & \multirow{2}{*}{57} & \multirow{2}{*}{30} \\
\hline & Msx1_rev & GGGTGGGCTCATCCTTCT & & \\
\hline \multirow{2}{*}{ Msx2 } & Msx2_fw & AGAGACCGGGACCTGTCTA & \multirow{2}{*}{57} & \multirow{2}{*}{30} \\
\hline & Msx2_rev & TTGAGCAGCGTCTCCTCT & & \\
\hline \multirow{2}{*}{ egr-1 } & egr_fw & GAGATGTTAGCCTTGTATCTGC & \multirow{2}{*}{58} & \multirow{2}{*}{29} \\
\hline & egr_rev & GTACTGTTGATAGTCTTGAGGTCC & & \\
\hline \multirow{2}{*}{ Xbra } & Xbra_fw & GGATCGTTATCACCTCTG & \multirow{2}{*}{56} & \multirow{2}{*}{30} \\
\hline & Xbra_rev & GTGTAGTCTGTAGCA & & \\
\hline Neng & N-CAM_fw & GCCССTCTTGTGGATCTTAGTGA & רז & 01 \\
\hline IV-CAIVI & N-CAM_rev & ACAGCGGCAGGAGTAGCAGTTC & 51 & 31 \\
\hline Normin & Noggin_fw & AGTTGCAGATGTGGCTCT & $c 0$ & 21 \\
\hline INoggin! & Noggin_rev & AGTCCAAGAGTCTCAGCA & 00 & 31 \\
\hline Chordin & Chordin_fw & CTAAGGGCCCATGGTTCACGAT & 56 & 32 \\
\hline entoram & Chordin_rev & ATTGGCACGGATTGGGTTGGTA & 56 & 33 \\
\hline- & Follistatin_fw & CAGTGCAGCGCTGGAAAGAA & & \\
\hline romilatur! & Follistatin_rev & GCATACACCTATTTACAGTA & 57 & 30 \\
\hline Clabin & aGlobin_fw & TCССТCAGACCAAAACCTAC & 51 & 21 \\
\hline aGIODIn & aGlobin_rev & GACAGCAGTTTGAAGTTTCC & 54 & 31 \\
\hline & SCL_fw & АСТСАСССТССAGACAAGAA & & \\
\hline SCL & SCL_rev & ATTTAATCACCGCTGCCCAC & 56 & 32 \\
\hline
\end{tabular}




\begin{tabular}{|l|l|l|l|l|}
\hline $\begin{array}{c}\text { Target } \\
\text { gene }\end{array}$ & Primer name & \multicolumn{1}{|c|}{ Primer sequence 5'-3' } & Tan [ $^{\circ} \mathbf{C}$ ] & cycles \\
\hline \multirow{2}{*}{ msr } & msr_fw & AACTTCGCTCTCGCTCCTCCATAC & \multirow{2}{*}{63} & \multirow{2}{*}{31} \\
\cline { 2 - 5 } & msr_rev & GCCAGCAGATAGCAAACACCAC & & \multirow{2}{*}{59} \\
\hline \multirow{2}{*}{ ami } & ami_fw & TAAATGGGTGCTGAGTGCAG & 29 \\
\cline { 2 - 5 } & ami_rev & GTTCCGGCGATTACAGACAT & & \\
\hline
\end{tabular}

\subsubsection{Morpholino oligonucleotides}

Antisense Morpholino oligonucleotides (Morpholinos, MO) were purchased from Gene Tools, LLC (Philomath, USA). Morpholinos were dissolved in RNAse-free water to a $1 \mu \mathrm{M}$ concentration. The sequences of the antisense Morpholinos used in this study are presented in Table 4.

Table 4. Anisense Morpholino oligonucleotides

\begin{tabular}{|c|c|c|c|}
\hline Morpholino name & Target gene & Sequence $5^{\prime} \rightarrow 3^{\prime}$ & $\begin{array}{l}\text { Working } \\
\text { conc. }\end{array}$ \\
\hline Fam132bMO1 & $\begin{array}{l}\text { Xenopus laevis } \\
\text { Fam132b }\end{array}$ & $\begin{array}{l}\text { GGATCGGCTTGTAT } \\
\text { TCGGCATCCAT }\end{array}$ & \\
\hline Fam132bMO2 & $\begin{array}{l}\text { Xenopus laevis } \\
\text { Fam132b }\end{array}$ & $\begin{array}{l}\text { GTCTGACTGGCCCA } \\
\text { ACAAAACAAGT }\end{array}$ & $\begin{array}{l}\text { 5-20 ng/ } \\
\text { embryo }\end{array}$ \\
\hline Fam132bmmMO1 & $\begin{array}{l}\text { Mutated } \\
\text { Fam132bMO1, } \\
\text { which does not bind } \\
\text { target sequence }\end{array}$ & $\begin{array}{l}\text { GGATCGcCTTcTATT } \\
\text { CcGCtTgCAT }\end{array}$ & $\begin{array}{l}5-20 \mathrm{ng} / \\
\text { embryo }\end{array}$ \\
\hline Fam132bmmMO2 & $\begin{array}{l}\text { Mutated } \\
\text { Fam132bMO2, } \\
\text { which does not bind } \\
\text { target sequence }\end{array}$ & $\begin{array}{l}\text { GTgTcACTGcCCCAA } \\
\text { CAAAAgAAcT }\end{array}$ & $\begin{array}{l}5-20 \mathrm{ng} / \\
\text { embryo }\end{array}$ \\
\hline cMO & no target & $\begin{array}{l}\text { CCTCTTACCTCAGTT } \\
\text { ACAATTTATA }\end{array}$ & $\begin{array}{l}5-20 \mathrm{ng} / \\
\text { embryo }\end{array}$ \\
\hline
\end{tabular}

\subsection{Antibodies}

The antibodies used during this study are presented in Table 5. 
Table 5. Antibodies

\begin{tabular}{|c|c|c|c|c|}
\hline \multirow{2}{*}{ Name } & \multirow{2}{*}{$\begin{array}{c}\text { Company, } \\
\text { catalogue } \\
\text { number }\end{array}$} & \multirow{2}{*}{ Description } & \multicolumn{2}{|c|}{ Dilution } \\
\hline & & & WB & IP \\
\hline HA.11 & $\begin{array}{l}\text { Covance, } \\
\text { MMS-101P }\end{array}$ & $\begin{array}{l}\text { Primary mouse } \\
\text { monoclonal } \\
\text { antibody, } \\
\text { recognizes HA } \\
\text { tag (peptide } \\
\text { CYPYDVPDYASL). }\end{array}$ & 1:1000 & $1: 150$ \\
\hline MT & $\begin{array}{l}\text { Abcam } \\
\text { ab19234 }\end{array}$ & $\begin{array}{l}\text { Primary goat } \\
\text { polyclonal antibody } \\
\text { recognizes myc tag } \\
\text { (peptide } \\
\text { EQKLISEEDL). }\end{array}$ & $1: 10000$ & $1: 250$ \\
\hline $\begin{array}{l}\text { a-mouse- } \\
\text { HRP }\end{array}$ & $\begin{array}{l}\text { Santa Cruz, } \\
\text { sc-2005 }\end{array}$ & $\begin{array}{l}\text { Secondary goat } \\
\text { anti mouse } \\
\text { IgG coupled with } \\
\text { HRP. }\end{array}$ & $1: 5000$ & \\
\hline $\begin{array}{l}\text { a-goat- } \\
\text { HRP }\end{array}$ & $\begin{array}{l}\text { Santa Cruz, } \\
\text { SC-2020 }\end{array}$ & $\begin{array}{l}\text { Secondary donkey } \\
\text { anti goat } \\
\text { IgG coupled with } \\
\text { HRP. }\end{array}$ & $1: 10000$ & \\
\hline $\begin{array}{l}\text { a-goat- } \\
\text { IRDye } \\
\text { 800CW }\end{array}$ & $\begin{array}{l}\text { LI-COR } \\
926-32214\end{array}$ & $\begin{array}{l}\text { Secondary donkey } \\
\text { anti goat IgG }(\mathrm{H}+ \\
\text { L) coupled with } \\
\text { IRDye } 800 \mathrm{CW}\end{array}$ & $1: 20000$ & \\
\hline $\begin{array}{l}\text { a-mouse- } \\
\text { IRDye } 680\end{array}$ & $\begin{array}{l}\text { LI-COR } \\
926-32222\end{array}$ & $\begin{array}{l}\text { Secondary donkey } \\
\text { anti mouse IgG (H } \\
+ \text { L) coupled with } \\
\text { IRDye } 680\end{array}$ & $1: 15000$ & \\
\hline
\end{tabular}

\subsection{Chemical transformation and cultivation of bacterial cells}

For chemical transformation $200 \mu$ of chemically competent E.coli XL1blue cells were thawed on ice, mixed with $10 \mu$ of the ligation mix or $100 \mathrm{ng}$ of plasmid DNA, incubated for 30 min on ice and heat-shocked for $90 \mathrm{sec}$ at $42^{\circ} \mathrm{C}$, then left for $3 \mathrm{~min}$ on ice. $800 \mu \mathrm{l}$ of LB-medium were added to the cells and the culture was incubated at $37^{\circ} \mathrm{C}$ for 30 to $45 \mathrm{~h}$ min. Bacterial pellets were seeded on LB 
agar plates supplemented with $0.1 \mathrm{mg} / \mathrm{ml}$ ampicillin (Biomol) for the selection of transformed cells. LB-agar plates were incubated overnight at $37^{\circ} \mathrm{C}($ Sambrook, 2001).

For preparation of a liquid bacterial culture one single bacterial colony was isolated from a bacterial plate and transferred into a sterile Erlenmeyer flask filled with $100 \mathrm{ml}$ of LB-medium supplemented with ampicillin. The liquid culture was incubated overnight in a $37^{\circ} \mathrm{C}$ shaker at $220 \mathrm{rpm}($ Sambrook, 2001).

\subsection{DNA methods}

\subsubsection{Plasmid DNA preparations}

Isolation of plasmid DNA in analytical amounts was performed using IllustraTM Plasmid Prep Mini Spin Kit (GE Healthcare). For the isolation of plasmid DNA in preparative amounts IllustraTM Plasmid Prep Midi Flow Kit (GE Healthcare) was used. The DNA isolation was performed according to the manufacturer's instructions. DNA concentrations were measured using the ND-1000 Spectrophotometer, Coleman Technologies Inc.

\subsubsection{DNA restriction digestion}

DNA restriction digestion was performed using restriction endonucleases purchased from MBI Fermentas according to manufacturer's instructions.

\subsubsection{Agarose gel electrophoresis}

DNA or RNA fragments were separated in a horizontal electrical field into agarose gel(Sharp et al., 1973). Depending on the expected sizes of DNA/RNA fragments, 0.8 to $2 \%(\mathrm{w} / \mathrm{v})$ agarose gels were prepared in TAE buffer. $0.5 \mu \mathrm{g} / \mathrm{ml}$ ethidium bromine was added for visualization of nucleic acids. Before loading the gel slots, nucleic acid samples were mixed with DNA loading dye (6x, 
Ambion). The electrophoresis was run in the standard TAE-running buffer at $100 \mathrm{~V}$ in horizontal electrophoresis chamber. After electrophoresis, DNA/RNA bands were visualized using the UV-transilluminator (Herolab) and documented with the ChemiDoc video documentation system (EASY view). Standard DNA ladders were used to determine the sizes of DNA fragments (High, Middle, or Low Range, Fermentas).

\subsubsection{Purification of DNA fragments from agarose gel or restriction digestion mixture}

The purification of DNA fragments from agarose gels or restriction digestion mixture was performed with the Illustra ${ }^{\mathrm{TM}}$ GFX PCR DNA and Gel Band Purification Kit (GE Healthcare) according to manufacturer's instructions.

\subsection{5 cDNA synthesis}

MuLV Reverse Transcriptase (Roche) was used to synthesize complementary DNA (cDNA) from total RNA, extracted from whole embryos or embryonic explants.

$\begin{array}{lll}1 \mathrm{x} & \text { Go Taq® Flexi Buffer (Promega) } \\ 5 \mathrm{mM} & \mathrm{MgCl}_{2} \text { (Fermentas) } \\ 1 \mathrm{mM} & \text { dNTP mix (Thermo Scientific) } \\ 5 \mathrm{ng} / \mu \mathrm{l} & \text { Random primers (Invitrogen) } \\ 15 \mathrm{ng} / \mu \mathrm{l} & \text { total RNA } \\ 0.8 \mathrm{U} / \mu \mathrm{l} & \text { Ribolock RNase Inhibitor (Fermentas) } \\ 2 \mathrm{U} / \mu \mathrm{l} & \text { MulV Reverse transcriptase (Roche) }\end{array}$

After an initial incubation for $10 \mathrm{~min}$ at $20^{\circ} \mathrm{C}$ to anneal the Random primers, cDNA synthesis was carried out for 1 hour at $42^{\circ} \mathrm{C}$ and terminated by heating to $95^{\circ} \mathrm{C}$ for $5 \mathrm{~min}$. 


\subsubsection{Polymerase chain reaction (PCR)}

\subsubsection{RT-PCR}

For semi-quantative RT-PCR, $5 \mu$ cDNA were used in a total volume of $25 \mu \mathrm{l}$ containing $0.2 \mu \mathrm{M} R \mathrm{RT}$ primers each, $1.5 \mathrm{mM} \mathrm{MgCl}$, $0.5 \cup \mathrm{Go}$ Taq ${ }^{\circledR}$ polymerase in $1 \times$ Green Go Taq ${ }^{\circledR}$ Flexi Buffer (Promega). To test for DNA contaminations H4 RT-PCR was carried out using total RNA. H4 RT-PCR on cDNA templates served as a control for equal cDNA concentrations.

\subsubsection{Cloning PCR}

The High Fidelity PCR enzyme Mix (Fermentas) was used for PCR followed by molecular cloning of the amplified fragments

PCR reaction mixture:
$1 \mathrm{x}$
High Fidelity PCR Buffer with $15 \mathrm{mM} \mathrm{MgCl}_{2}$
$0.2 \mathrm{mM}$
dNTP mix (Thermo Scientific)
$0.75 \mu \mathrm{M} \quad$ primers each
$0.1 \mathrm{ng} / \mu \mathrm{l} \quad$ matrix DNA
$0.1 \mathrm{U} / \mu \mathrm{l} \quad$ High Fidelity PCR enzyme Mix (Fermentas)
add HPLC-water (ROTH)

The following cycling conditions were used for DNA fragments amplification:

\begin{tabular}{lll|l} 
Initial denaturation & $95^{\circ} \mathrm{C}$ & $5 \mathrm{~min}$ & \\
Denaturation & $95^{\circ} \mathrm{C}$ & $45 \mathrm{sec}$ & 30 cycles \\
Primer annealing & $\mathrm{x}^{\circ} \mathrm{C}$ & $45 \mathrm{sec}$ & \\
Elongation & $72^{\circ} \mathrm{C}$ & $1 \mathrm{~min} / 1 \mathrm{~kb}$ & \\
Final elongation & $72^{\circ} \mathrm{C}$ & $5 \mathrm{~min}$ &
\end{tabular}




\subsubsection{3' RACE and 5'RACE PCR}

For the isolation of 5'- and 3'sequences of target transcripts first-strand CDNA synthesis and RACE PCRs were performed using the SMART RACE CDNA Amplification Kit (Clontech) according to manufacturer's instructions.

\subsubsection{Site directed Mutagenesis}

To introduce specific mutations at a target site within one sequence the QuikChange ${ }^{\circledR}$ XL Site-Directed Mutagenesis Kit (Stratagene) was used. Design of mutagenic primers, mutagenesis reaction, and digest of methylated, nonmutated DNA template were performed according to manufacturer's instructions. Afterwards E.coli XL1blue cells were transformed with $20 \mu$ of the reaction mix (described in paragraph 2.7).

\subsubsection{DNA ligation}

To ligate DNA fragments T4 DNA ligase (Fermentas) was used according to manufacturer's instructions. For the ligation a vector and an insert were taken in 1 to 3 molar ratio. The total amount of vector DNA was $50 \mathrm{ng}$. For $10 \mu \mathrm{l}$ of a single reaction mixture $5 \cup$ T4 DNA ligase were used. The ligation was performed overnight at $16^{\circ} \mathrm{C}$. E.coli XL1blue cells were transformed with $10 \mu \mathrm{l}$ of the ligation mixture (described in paragraph 2.7).

\subsubsection{DNA sequencing analysis}

The Dye-termination sequencing method, which is the modification of Sanger chain-termination sequencing, was used (Sanger et al. 1977). For preparation of the sequencing PCR mixture the Big DyeTM Terminator Kit (Applied Biosystems) was used according to the manufacturer's instructions. 
Sequencing PCR mixture: $\quad 200$ - 400 ng DNA matrix

$\begin{array}{ll}1.5 \mu \mathrm{l} & \text { Seq mix } \\ 1.5 \mu \mathrm{l} & \text { Seq buffer } \\ 8 \mathrm{pmol} & \text { Seq. primer } \\ \text { add HPLC water to } 10 \mu \mathrm{l}\end{array}$

Sequencing PCR conditions: $\quad 95^{\circ} \mathrm{C} \quad 2 \mathrm{~min}$

\begin{tabular}{ll|l}
$95^{\circ} \mathrm{C}$ & $30 \mathrm{sec}$ & \\
$56^{\circ} \mathrm{C}$ & $20 \mathrm{sec}$ & 25 cycles \\
$60^{\circ} \mathrm{C}$ & $4 \mathrm{~min}$ &
\end{tabular}

To purify the DNA fragments from the sequencing reaction the following components were added to $10 \mu$ of the reaction mixture:

$\begin{array}{ll}1 \mu \mathrm{l} & 125 \mathrm{mM} \text { EDTA }(\mathrm{pH} 8.0) \\ 1 \mu \mathrm{l} & 3 \mathrm{M} \text { sodium acetate }(\mathrm{pH} 5.4) \\ 50 \mu \mathrm{l} & 100 \% \text { ethanol }\end{array}$

The samples were incubated for $5 \mathrm{~min}$ at room temperature, then centrifuged for $15 \mathrm{~min}$ at $14000 \mathrm{rpm}$. The DNA pellets were washed with $70 \mu \mathrm{l}$ of $70 \%$ ethanol, air-dried and dissolved in $15 \mu \mathrm{l}$ of $\mathrm{HiDi}^{\mathrm{TM}}$ buffer (Applied Biosystems). Automated sequencing was carried out by the ABI 3100 Automated Capillary DNA Sequencer (Applied Biosystems).

\subsection{RNA methods}

\subsubsection{In vitro synthesis of capped sense mRNA}

In vitro synthesis of capped sense mRNAs for microinjections into Xenopus embryos and oocytes was performed with using the SP6 or T7 mMessage mMachine Kits ${ }^{\mathrm{TM}}$ (Ambion) according to the manufacturer's protocol. $20 \mu \mathrm{l}$ of reaction mixture containing 0.5 - $1 \mu \mathrm{g}$ of linearized DNA template was incubated 
for 3 hours at $37^{\circ} \mathrm{C}$, followed by template DNA digestion for 30 min at $37^{\circ} \mathrm{C}$ using $5 \mathrm{U}$ of Turbo DNasel (Ambion). Synthesized RNA was purified using the Illustra $^{\mathrm{TM}}$ RNAspin Mini RNA Isolation Kit (GE Healthcare). RNA concentrations were determined using the ND-1000 Spectrophotometer (Coleman Technologies Inc.).

\subsubsection{In vitro synthesis of labeled antisense RNA}

The following reaction mixture was used for the synthesis of digoxgenin-labeled antisense RNA for whole mount in situ hybridization:

$\begin{array}{ll}1 \mathrm{x} & \text { transcription buffer (Fermentas) } \\ 1 \mathrm{mM} & \text { rATP (Boehringer) } \\ 1 \mathrm{mM} & \text { rCTP (Boehringer) } \\ 1 \mathrm{mM} & \text { rGTP (Boehringer) } \\ 0.64 \mathrm{mM} & \text { rUTP (Boehringer) } \\ 0.36 \mathrm{mM} & \text { digoxigenin-rUTP (Boehringer) } \\ 0.03 \mu \mathrm{M} & \text { DTT } \\ 1.6 \mathrm{U} / \mu \mathrm{l} & \text { Ribolock RNase Inhibitor (Fermentas) } \\ 2 \mu \mathrm{g} & \text { linearized DNA template } \\ 1.2 \mathrm{U} / \mu \mathrm{l} & \text { T3, T7 or Sp6 polymerase (Fermentas) } \\ \text { add RNase-free water }\end{array}$

The reaction mixture was incubated for 3 hours at $37^{\circ} \mathrm{C}$, followed by template DNA digestion for $30 \mathrm{~min}$ at $37^{\circ} \mathrm{C}$ using $0.2 \mathrm{U} / \mu \mathrm{l}$ Turbo DNasel (Ambion). Synthesized digoxgenin-labeled RNA was purified with the RNeasy ${ }^{\mathrm{TM}}$ Mini Kit (Quiagen) according to manufacturer's instructions. The RNA was eluted twice with $50 \mu \mathrm{R}$ Rase-free $\mathrm{H} 2 \mathrm{O}$ and stored in Hybridization Mix (see whole mount in situ hybridization) at $-20^{\circ} \mathrm{C}$. 


\subsubsection{Total RNA extraction from whole embryos and embryonic explants}

For extraction of total RNA used for cDNA synthesis and RT-PCR 5 whole embryos, 10 mesodermal explants, or 50 - 100 ectodermal explants were fixed in $\mathrm{N}_{2 \text { liq }}$ and macerated in $400 \mu \mathrm{l}$ peqGOLD TriFast reagent (peQlab) using a sterile Omnican ${ }^{\circledR} 40$ syringe (Braun). After $30 \mathrm{sec}$ of vortexing $80 \mu \mathrm{l}$ of Chloroform (Roth) were added and the sample was vortexed for $30 \mathrm{sec}$, followed by 10 min of centrifugation. The upper phase was transferred into a new tube and mixed with another $200 \mu$ of Chloroform (Roth) by vortexing for $30 \mathrm{sec}$. After a second centrifugation step of $5 \mathrm{~min}$ the upper phase was transferred into a new tube and precipitation of nucleic acids was carried out by the addition of $200 \mu$ of 2-Propanol (Roth), vortexing and overnight incubation at $-20^{\circ} \mathrm{C}$. After $30 \mathrm{~min}$ of centrifugation the nucleic acid pellet was washed using $400 \mu \mathrm{l}$ of $70 \%$ ethanol. The air-dried pellet was dissolved in $12.5 \mu \mathrm{l}$ of RNasefree water. For DNA digestion and purification of RNA the RNAqueous-Micro Kit (Ambion) was used according to manufacturer's instructions. After a final incubation of the extracted RNA at $70^{\circ} \mathrm{C}$, RNA concentrations were determined using the ND-1000 Spectrophotometer (Coleman Technologies Inc.) and RNA samples were stored at $-80^{\circ} \mathrm{C}$.

For extraction of total RNA used for 3' RACE and 5'RACE PCR 5 embryos were fixed in $\mathrm{N}_{2}$ liq and homogenized in $500 \mu \mathrm{l} 0.2 \mathrm{mg} / \mathrm{ml}$ proteinase $\mathrm{K} / 1 \times$ extraction buffer using a sterile Omnican ${ }^{\circledR} 40$ syringe (Braun). After 45 min of incubation at $45^{\circ} \mathrm{C}$ RNA extraction was carried by addition of the following reagents:

\section{1 vol Roti®-Aqua-Phenol/C/l (Roth) \\ 1 vol Roti®-Aqua-Phenol/C/l (Roth) \\ 1 vol 24/1 Chloroform/Isoamoyl alcohol}

Every extraction step was followed by vortexing, centrifugation for $10 \mathrm{~min}$, and transfer of the upper aqueous phase into a new tube. 1 vol of $8 \mathrm{M} \mathrm{LiCL}$ was added to precipitate RNA by vortexing and overnight incubation at $-20^{\circ} \mathrm{C}$. After 30 min of centrifugation the pellet was air-dried and dissolved in $100 \mu$ of RNase-free water. Another precipitation step was carried out by addition of 0.2 vol $5 \mathrm{M}$ ammonium acetate and 5 vol of $100 \%$ ethanol, followed by $30 \mathrm{~min}$ 
incubation at $-20^{\circ} \mathrm{C}$. After 30 min of centrifugation the pellet was washed in 80 $\%$ ethanol, air-dried and dissolved in $40 \mu \mathrm{l}$ of RNase-free water. To completely remove residual genomic DNA $5 \mu \mathrm{l} 10$ x DNase buffer (Fermentas), $1 \mu \mathrm{l} 1 \mathrm{U} / \mu \mathrm{l}$ RNase-free DNase I (Fermentas) and $4 \mu$ RNase-free water were added and incubated for $30 \mathrm{~min}$ at $37^{\circ} \mathrm{C}$. After addition of $50 \mu \mathrm{l}$ RNase-free water 3 RNA precipitation steps followed using 1 vol Roti®-Aqua-Phenol/C/l (Roth), 1 vol 24/1 Chloroform/Isoamoyl alcohol, and 0.2 vol $5 \mathrm{M}$ ammonium acetate and 5 vol of $100 \%$ ethanol, as described above. After another washing step using $80 \%$ ethanol the air-dried RNA pellet was dissolved in $50 \mu$ RNase-free water. Every centrifugation step was carried out at $4^{\circ} \mathrm{C}$ and $13000 \mathrm{rpm}$. RNA concentrations were determined using the ND-1000 Spectrophotometer (Coleman Technologies Inc.) and RNA samples were stored at $-80^{\circ} \mathrm{C}$.

\subsection{Protein methods}

\subsubsection{Protein isolation from embryos and oocytes}

For protein isolation 20 embryos or oocytes were fixed in $\mathrm{N}_{2}$ liq and macerated in $500 \mu \mathrm{l}$ ColP buffer using a sterile Omnican ${ }^{\circledR} 40$ syringe (Braun). Lysates were centrifuged for $15 \mathrm{~min}$ at $4^{\circ} \mathrm{C}$ and $13000 \mathrm{rpm}$ and the supernatant was either used for Co-immunoprecipitation, or samles were prepared for SDS-PAGE.

\subsubsection{Protein isolation from oocyte culture medium}

$5 \mathrm{vol}$ of ice cold Aceton were added to the oocyte culture medium and protein precipitation was carried out on ice. After centrifugation for $15 \mathrm{~min}$ at $4^{\circ} \mathrm{C}$ and $13000 \mathrm{rpm}$ the protein pellet was washed in $1 \mathrm{ml}$ ice cold Aceton and dried at $40^{\circ} \mathrm{C}$ to $50^{\circ} \mathrm{C}$. The pellet was then dissolved in $30 \mu \mathrm{l}$ of ColP buffer and the protein sample was prepared for SDS-PAGE. 


\subsubsection{Co-immunoprecipitation}

Co-immunoprecipitation (CoIP) in Xenopus embryos was performed as described. Xenopus embryos were injected with mRNAs coding for tagged proteins animally into both blastomeres at the two cell stage and cultured until stage 10.5 to 11.5. After protein isolation, described in paragraph 2.10.1, an input aliquot was taken from each sample and prepared for SDS-PAGE. Protein containing supernatants were incubated for $30 \mathrm{~min}$ with $15 \mu \mathrm{l}$ Protein $\mathrm{A}$ Sepharose (Amersham) for pre-clearing. After centrifugation supernatants were transferred into fresh tubes, antibodies were added, and the samples were incubated for two hours, followed by two hours incubation with $15 \mu$ Protein $A$ Sepharose (Amersham). Preclearing- and ColP-pellets were washed 5 times for 5 min with ColP buffer, resuspended in $10 \mu \mathrm{l}$ ColP buffer, and prepared for SDS-PAGE. Every incubation and centrifugation step was carried out at $4^{\circ} \mathrm{C}$.

\subsubsection{TNT (in vitro transcription and translation)}

The In vitro transcription and translation-assay and protein detection were performed, using the TNT® Coupled Reticulocyte Lysate System (promega) and the Transcend ${ }^{\mathrm{TM}}$ Chemiluminescent Non-Radioactive Translation Detection System (promega). TNT reactions were carried out in volumes of $12.5 \mu \mathrm{l}$ according the manufacturer's user manual.

\subsubsection{Protein electrophoresis under denaturing conditions (SDS-PAGE)}

The proteins were separated by SDS polyacrylamid gel electrophoresis (Harlow, 1988; Laemmli, 1970). $10 \%$ - 12 \% SDS polyacrylamid gels were used for the analysis of proteins with distinct molecular weights. Protein samples were diluted 1:1 with 2x Laemmli loading buffer and boiled for 3 min at $95^{\circ} \mathrm{C}$, then applied on the gel. The gel running was performed in $1 \mathrm{x}$ Laemmli running buffer. At first voltage of $70 \mathrm{~V}$ was applied, and once the bromphenol-blue front reached the separating gel, the voltage was raised to $120 \mathrm{~V}$. 


\subsubsection{Western Blotting}

After SDS-PAGE proteins were transferred to a nitrocellulose membrane $(0.45$ $\mu \mathrm{m}$, Schleicher \& Schuell) using semi-dry blotting system(Harlow, 1988). Protein transfer was carried out in transfer buffer for $1 \mathrm{~h}$ using a voltage of $40 \mathrm{~V}$. After transfer, the membrane was blocked with a blocking solution for 1 hour at room temperature. Incubation with primary antibody solution was carried out overnight at $4{ }^{\circ} \mathrm{C}$ in blocking solution. Next day the membrane was washed 3 times for 10 min in blocking solution and the secondary antibodies coupled with horse reddish peroxidase (HRP) or fluorescent IRDyes (LI-COR) were applied in blocking solution for $1 \mathrm{~h}$ at room temperature. The membrane was washed again with blocking solution 2 times for $10 \mathrm{~min}$ and 1 time in TBST for $10 \mathrm{~min}$. The HRP signals were detected with the ECL Kit Super Signal DuraTM West Kit (Pierce) on X-raydetection film (Amersham). Fluorescent signals were detetected using LI-COR Odyssey Infrared Imaging system.

\subsection{Xenopus embryo culture and micromanipulations}

\subsubsection{Preparation of Xenopus laevis testis}

The Xenopus male frog was sacrificed by submerging it in $0.05 \%$ benzocaine for $30 \mathrm{~min}$ at room temperature. The frog was decapitated, the skin flap was removed from the belly and an incision into the muscle was performed. The testes were removed through the incision together with fat body and detached from it. The testes were washed 3 times with $1 \times$ MBS and stored in the 1x MBS buffer at $4^{\circ} \mathrm{C}$.

\subsubsection{Embryo culture and microinjections}

Xenopus laevis female frogs were induced to lay eggs by injection of 1000 units human chorionic gonadotropin (hCG, Sigma Aldrich) into the dorsal lymph sac, approximately 12 hours before desired egg-laying. Laid eggs were in vitro 
fertilized with minced testis in $0.1 \times$ MBS. Fertilized eggs were treated with $2 \%$ cyteine hydrochloride, $\mathrm{pH} 8.0$, to remove the jelly coat.The embryos were cultured in $0.1 \times \mathrm{MBS}$ at $12.5-18^{\circ} \mathrm{C}$. Albino embryos were stained with Nile Blue vital dye for 10 min prior to injection to allow to distinguish animal and vegetal poles, as well as different stages of development. Injections were performed in injection buffer on a cooling plate $\left(12.5^{\circ} \mathrm{C}\right)$. The solutions for microinjections were loaded into the glass needles prepared on Leitz Needle puller. The Microinjector 5242 (Eppendorf) was used during this study. For different purposes injections at 2-, 4- or 8-cell stages were performed. The injection volume was $4 \mathrm{nl}$ of injection mixture per blastomere. Injected embryos were kept for at least 1 hour in the injection buffer to allow the heeling of injection opening and embryos were then transferred into $0.1 \mathrm{x}$ MBS. The developmental stages were defined according to Nieuwkoop and Faber Normal Table of Xenopus laevis (Daudin).

\subsubsection{Oocyte culture and microinjection}

To isolate oocytes, adult, female Xenopus laevis were operated on ice under anesthesia with 0.25\% 3-aminobenzoic acid ethyl ester solution (20 min anesthesia). Oocytes were separated by treatment with $1 \mathrm{mg} / \mathrm{ml}$ liberase blendzyme (Roche) in collagenase-buffer and agitation up to $120 \mathrm{~min}$. Oocytes were extensively washed using $1 \mathrm{x} \mathrm{MBS}$, incubated at $18^{\circ} \mathrm{C}$ and staged according to Dumont, 1972. Stage VI oocytes were injected in in $1 \times$ MBS into the vegetal pole, as described for embryo microinjections (2.11.2). Injected oocytes were cultivated for 24 hours in oocyte culture medium (OCM) at $18^{\circ} \mathrm{C}$. After separation of oocyte and OCM fraction, samples were fixed in liquid nitrogen for protein isolation.

\subsubsection{Xenopus ectodermal and ventral mesodermal explants}

For explantation of embryonic tissues the vitteline membrane of Xenopus embryos was removed using forceps. And animal caps were explanted at stage 8 using a 'gastromaster tip'. Ventral mesodermal tissue was dissected from 
stage 10.25 embryos using forceps. Embryonic explants were dissected and cultivated on 1\% agarose-coated Petri dishes in 0,8 $\times$ MBS buffer until control sibling embryos reached the desired stage of development, fixed in liquid Nitrogen, and stored at $-80^{\circ} \mathrm{C}$ (Sive et al., 2000).

\subsubsection{Dexamethasone treatment}

Embryos were injected with inducible mRNA constructs. Animal caps and embryos were treated with fresh $1 \times$ Dexamethasone (DEX)/0.1 x MBS at various stages and continuously kept in solution until fixation.

\subsection{Xenopus tropicalis "Full-Length" Library Expression Screen}

For the Expression-cloning RNA pools of 24 individual RNAs derived from a Xenopus tropicalis "Full-Length" cDNA Library were injected animally into both cells of Xenopus laevis two-cell stage embryos (Gilchrist et al., 2004). Embryos were cultivated to tadpole stage and scored for axis formation defects. To identify the active clone within one pool, RNA mixtures containing 12,6 , or 1 individual mRNA of the original pool of 24 were injected and scored for the corresponding phenotype. Depending on the number of individual RNA clones contributing to the mixture, different RNA concentrations were injected, as indicated in Table 6.

Table 6. Total amounts of injected RNAs with respect to pool size

\begin{tabular}{|c|c|}
\hline number of individual RNAs/injection & RNA conc. [pg total RNA/embryo) \\
\hline 24 & 1600 \\
\hline 12 & 800 \\
\hline 6 & 400 \\
\hline 1 & 60 and 120 \\
\hline
\end{tabular}




\subsection{Whole mount in situ hybridization (WMISH)}

\subsubsection{X-gal staining}

Embryos were grown to the desired stage and fixed for 20 min in MEMFA. After washing three times for $10 \mathrm{~min}$ in $1 \mathrm{x}$ PBS, embryos were transferred to $\mathrm{X}$-gal staining solution until staining was sufficient, typically 10 to $20 \mathrm{~min}$. The reaction was stopped by washing the embryos three times in 1x PBS and afterwards fixed in MEMFA for 25 min. For whole mount in situ embryos were dehydrated with absolute ethanol and stored at $-20^{\circ} \mathrm{C}$.

\subsubsection{Whole mount in situ hybridization (WMISH)}

Whole mount in situ hybridization (WMISH) was performed essentially, as described (Harland, 1991; Hollemann and Pieler, 1999)using antisense RNA labeled with digoxigenin-11-UTP. All steps were performed at ambient temperature with mild shaking. Embryos were rehydrated with the EtOH series to PTw, washed three times in PTw for $10 \mathrm{~min}$ and subjected to Proteinase $\mathrm{K}$ treatment to allow better penetration of the RNA probe. Stage 15 embryos were incubated for 6 min, later stage embryos were incubated for no longer than 15 min in Proteinase K. Embryos were washed twice in $0.1 \mathrm{M}$ triethanolamine, pH 7.5 , to stop Proteinase $\mathrm{K}$ digestion and acetylated by adding $25 \mu \mathrm{l}$ acetic anhydrite to fresh triethanolamine. After $5 \mathrm{~min}$, another $25 \mu \mathrm{l}$ acetic anhydrite was added. Then embryos were fixed in PTw/MEMFA for $25 \mathrm{~min}$, washed five times in PTw, transferred to Hyb Mix and incubated for $5 \mathrm{hr}$ at $65^{\circ} \mathrm{C}$ in a water bath. Hyb Mix was exchanged for the antisense RNA probe and incubated overnight at $65^{\circ} \mathrm{C}$ in a water bath. The next day, the RNA probe was collected and stored $-20^{\circ} \mathrm{C}$ for reuse. After washes in $\mathrm{Hyb}$ Mix for $10 \mathrm{~min}$ at $65^{\circ} \mathrm{C}$, three times in $2 \times \mathrm{SSC}$ for $15 \mathrm{~min}$ at $65^{\circ} \mathrm{C}$, non-hybridized RNA probe was removed by RNase digestion for 1 hour at $37^{\circ} \mathrm{C}$ in RNase solution. The digested probe removed by washing once in $2 \times \mathrm{SSC}$ at $37^{\circ} \mathrm{C}$ and twice $0.2 \times \mathrm{SSC}$ at $65^{\circ} \mathrm{C}$. After exchanging the buffer to $M A B$, embryos were blocked in MAB/BMB for 20 
min and $\mathrm{MAB} / \mathrm{BMB} / \mathrm{HS}$ for $40 \mathrm{~min}$ to minimize unspecific binding of the antibody. The solution was replaced with antibody solution and incubated for 5 hours. The embryos were washed three times for 10 min with MAB and then overnight in MAB. After three rinses with $M A B$ for 5 min, the caps were exchanged and the embryos transferred to APB. After three washes in APB for 5 min each, alkaline phosphatase was detected in color reaction solution. Embryos were kept at $4^{\circ} \mathrm{C}$ in the dark until staining was sufficient. The embryos were transferred to $100 \%$ Methanol to stop the reaction and to minimize background staining. Then embryos were rehydrated with the $\mathrm{MeOH}$ series to MEMFA and incubated in MEMFA for $30 \mathrm{~min}$ followed by bleaching of the embryos.

\subsubsection{Bleaching}

Embryos were washed twice in $5 \times$ SSC and transferred into bleaching solution to remove pigmentation of the embryos. Bleached embryos were washed twice in $5 \times$ SSC and fixed over night in MEMFA.

\subsection{Luciferase assay}

Embryos were injected with either 50 pg Siamois-Luc (Brannon et al., 1997) and 10 pg pRL-TK (Promega) or 8 pg Vent2b-BRE-Luc (Henningfeld et al., 2000) and 4 pg pRL-CMV (Promega) reporter DNA in combination with respective mRNAs. Gastrula stage embryos were fixed in liquid $\mathrm{N}_{2}$ and stored at $-80^{\circ} \mathrm{C}$. For each sample triplicates of 15 embryos each were analyzed within 1 independent experiment. The Dual Luciferase Assay Kit (Promega) was used for preparation of embryonic lysates and measurement of Firefly and Renilla luciferase activity according to the manufacturer's instructions. Measurements were performed on a Centro LB 960 luminometer (Berthold Technologies). 


\subsection{Nanostring nCounter analysis}

The quantitative multiplexed gene expression analysis using Nanostring nCounter was used according to the manufacturer's instructions;500 ng of total RNA from Xenopus embryos or ectodermal explants was applied in $5 \mu \mathrm{l}$ for a total volume of $30 \mu \mathrm{l}$. The genes analyzed by Nanostring nCounter, accession numbers, target regions and the reporter probe sequences are shown in Appendix 6.1. Primary gene expression data from Nanostring nCounter analysis are shown in Appendix 6.2. To process the data, the counts were first normalized with respect to the geometric mean of the positive control counts using the nSolver software program provided by Nanostring nCounter. In a second step, the counts were normalized with respect to the geometric mean of ornithine decarboxylase (ODC). Even though additional housekeeping genes were present in the Nanostring set, only ODC was chosen for normalization as the other genes show developmental regulatory effects. Finally, a stringent background correction was performed by subtracting the mean and two standard deviations of the eight negative control counts for each lane. Values less than 1 were set to 1 as background level. Two independent experiments were analyzed. 


\section{Results}

\subsection{Temporally controlled modulation of canonical Wnt signaling activity in Xenopus embryos}

Wnt/ $\beta$-Catenin signalinghas been shown to play important roles during embryonic development and deregulation of thissignalingpathway has been implicated in tumor development. In order to study the function of canonical Wnt signaling during specific developmental processes, tools have to be developed that modulate canonical Wnt signaling activity under tight temporal control. For this issue, we wanted to generate hormone-inducible constructs that have the potential to either stimulate or repress canonical Wnt signaling activity in Xenopus embryos. We used modified versions of the transcriptional coactivator $\beta$-Catenin and the transcription factors Tcf3 and Lef1 (Figure 9 A-C). Wildtype $\beta$-Catenin protein contains an amino-terminal domain that is responsible for protein instability.Mutation of the serine residue 33 in the $\mathrm{N}$-terminal domain of $\beta$-Catenin results in a stabilized protein that is no longer vulnerable to initial phosphorylations leading to $\beta$-Catenin destruction(Aberle et al., 1997; Morin et al., 1997).This stabilized form of $\beta$-Catenin was further modified by substitution of the trans-activation domain with either the Herpes simplex virus VP16 transcriptional activation domain (VP16) or the Drosophila melanogaster Engrailed repression domain (EnR), resulting in the predicted constitutively active and dominant negative versions of $\beta$-Catenin (Figure 9 A).Trancriptionfactors of the Lef/Tcf family have a similar organization regarding their protein domain structure. These proteins contain an amino-terminal $\beta$ Catenin binding domain, a central domain for groucho/TLE interaction, a DNA binding HMG box, and a C-terminal tail (Figure 9 B, C). We used an aminoterminal deletion mutant of Tcf3 that is predicted to interact with $\beta$-Catenin, while still binding to the target DNA sequence and masking it from binding to other transcriptional activating complexes (Molenaar et al., 1996).Additionally, another Tcf3 deletion mutant lacking the HMG DNA binding domain was employed. This protein should bind and therefore block $\beta$-Catenin from 
interaction with endogenous transcription factors (Figure $9 \mathrm{~B}$ ). $\operatorname{Tcf} 3 \Delta \mathrm{C}$ is a mutant version of Tcf3 lacking the C-terminal domain that is important for CtBP binding. CtBP is a transcriptional co-repressor that mediates histone modification(Shi et al., 2003). However, this mutant had previously been shown to efficiently block Wnt/ $\beta$-Catenin-mediated signaling activity (Pukrop et al., 2001).

A

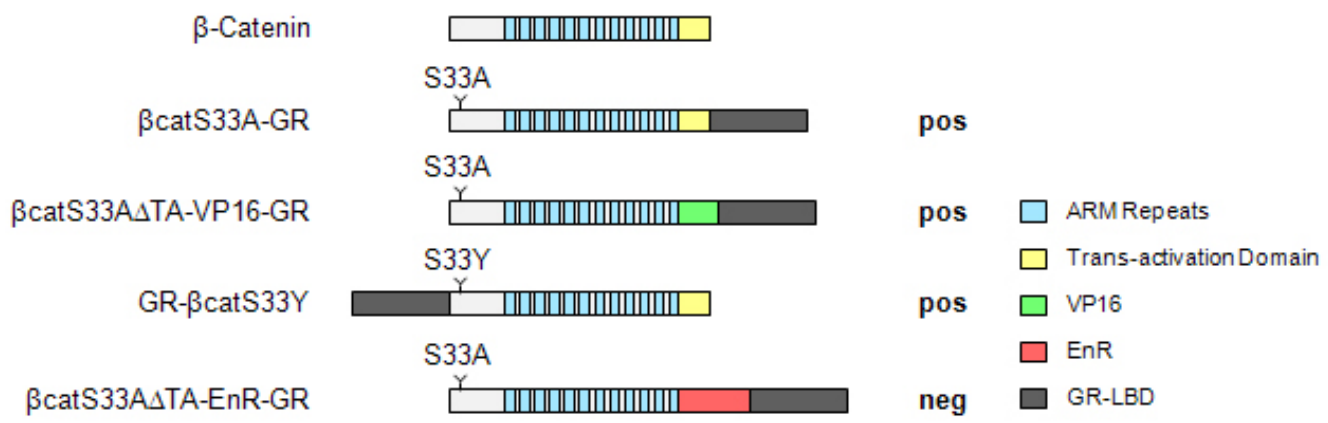

B

Tcf3

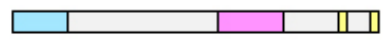

GR- $\Delta N-T c f 3$

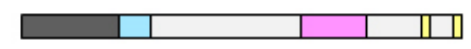

neg

Tcf3 3 C-GR

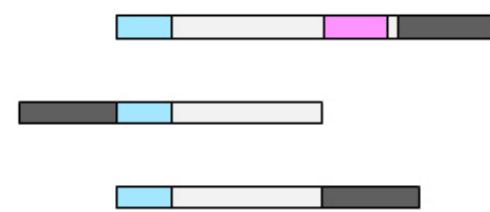

neg

GR-Tcf $3 \Delta \mathrm{HMG}$

neg

$\beta$-Catenin binding domain

$\square$ HMG box

Tcf3 $\Delta$ HMG-GR

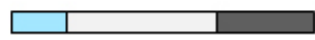

neg

CtBP binding domain

$\square$ GR-LBD

C

Lef1-GR
Lef $\Delta$ BD-GR
Lef $\Delta N-V P 16-G R$
EnR-Lef1-GR

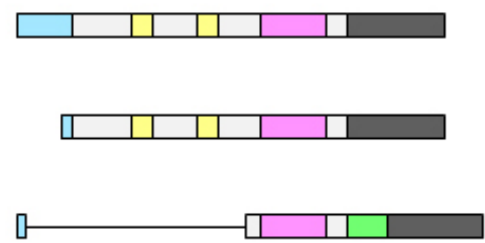

pos
neg
$\square$-Catenin binding domain

$\square$ Trans-activation domain

$\square$ HMG box

pos

$\square$ VP16

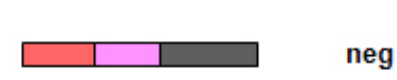

$\square$ EnR

neg

GR-LBD

Figure 9. Schematic representation of GR-fusion constructsemployed for modulation of Wnt signaling. (A) Overview of wildtype and modified versions of human $\beta$-Catenin. Mutations in the nucleotide sequence leading to a single amino acid exchange and stabilization of mutant $\beta$-Catenin are indicated. (B) Scheme of Xenopus Tcf3 and corresponding GR-fused deletion mutants of XTcf3. (C) Overview of GRfused wildtype or mutant versions of mouse Lef1. (A-C) Mutant versions of $\beta$-Catenin, Tcf3, and Lef1 lacking specific protein domains or chimeric constructs containing endogenous protein domains and VP16 transcriptional activation or EnR transcriptional repression domain. All construct were fused to the human GR ligand binding domain. Protein domains are indicated in the corresponding legends. Predicted activities of 
depicted factors concerning modulation of canonical Wnt signaling are specified: pos, positive regulation; neg, negative regulation.

Behrens and colleagues had shown that the full-length transcription factor Lef1 induces secondary axis formation upon ventral overexpression in Xenopus embryos (Behrens et al., 1996). Therefore, this construct was used as canonical Wnt signaling stimulating factor in this study (Figure $9 \mathrm{C}$ ). In addition a deletion mutant of Lef1 lacking the $\beta$-Catenin binding domain was included into our set of putative canonical Wnt signaling regulating factors (Figure $9 \mathrm{C}$ ).

To gain temporal control of protein activity, one can make use of fusion proteins that contain the ligand binding domain (LBD) of steroid-hormone receptors, such as the glucocorticoid receptor (GR). GR-fusion proteins are bound and inactivated by heat shock proteins in the cytoplasm immediately after translation. To induce protein activity, cells are treated with the steroid hormone Dexamethasone (DEX), which binds the GR-LBD and causes a release fromheat shock proteins. Consequently, the activated GR-fusion protein can translocate to the nucleus and modulate target gene transcription.All constructs, described above, were fused to the hormone-inducible GR-LBD (Figure 9 A-C). Apart from the factors described above, we included2additional GR-fusion constructs that had already been described to modulate canonical Wnt signaling activity dependent on DEX treatment. EnR-Lef1-GR consists of the Drosophila Engrailed repression domain and the mouse Lef1-DNA binding domain fused to the human GR-LBD and acts as repressor of canonical Wnt signaling activity (Lyons et al., 2009). In contrast, Lef $\Delta$ N-VP16-GR containing mouse Lef1-DNA binding domain, the VP16 transcriptional activation domain, and GR-LBD, was shown to activate Wnt/ß-Catenin signaling(Denayer et al., 2008).

Formation of the dorsal-ventral body axis in Xenopus embryos is initiated via high levels of nuclear $\beta$-Catenin in the dorsal endoderm of early cleavage stage embryos.As a result, the Spemann organizer is induced in the dorsal mesoderm and allows the development of dorsal structures. Ectopic activation of Wnt signaling on the ventral side induces the formation of a secondary body axis. This system was used to test Wntsignalingpromoting activities and hormone inducibilitiy of the generated GR-fusion constructsdescribed above.mRNAs coding for predicted canonical Wnt signaling stimulating factors were injected marginally into 1 ventral blastomere at the 4-cell stage and, subsequently, 
treated with DEX to induce protein activity. At late tailbud stages embryos were scored for secondary axis formation (Figure $10 \mathrm{~A}$ ). All those factors that were predicted to stimulate canonical Wnt signaling efficiently induced secondary axis formation upon treatment with DEX (Figure $10 \mathrm{C}$, D; Table 7). Full-length Lef $\Delta$ N-VP16-GR and Lef1-GR induced canonical Wnt signaling activity upon DEX-mediated activation (Figure $10 \mathrm{C}$; Table 7). In contrast, GR-fused mutant versions of $\beta$-Catenin showed secondary axis induction also in the absence of DEX (Figure 10 D, Table 7).

A

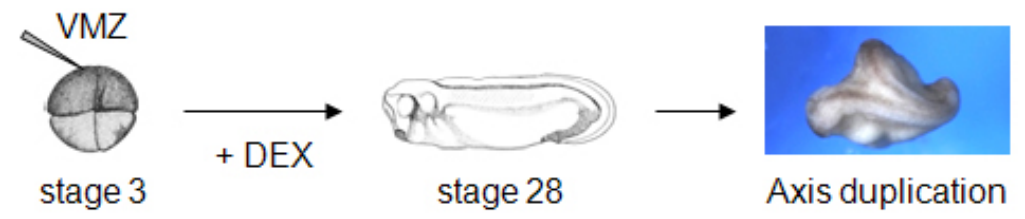

B

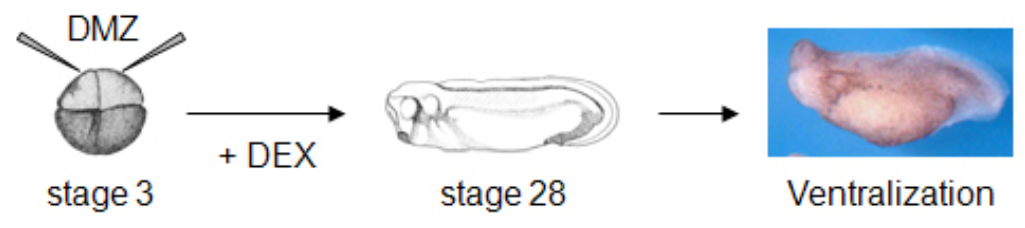

C

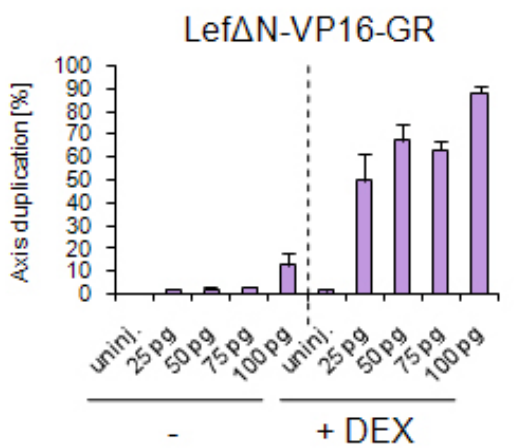

D

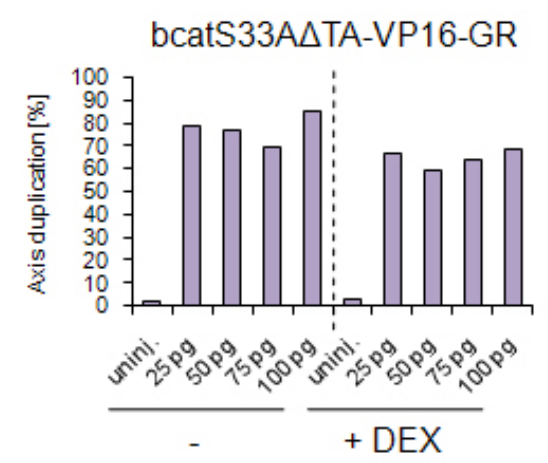

E

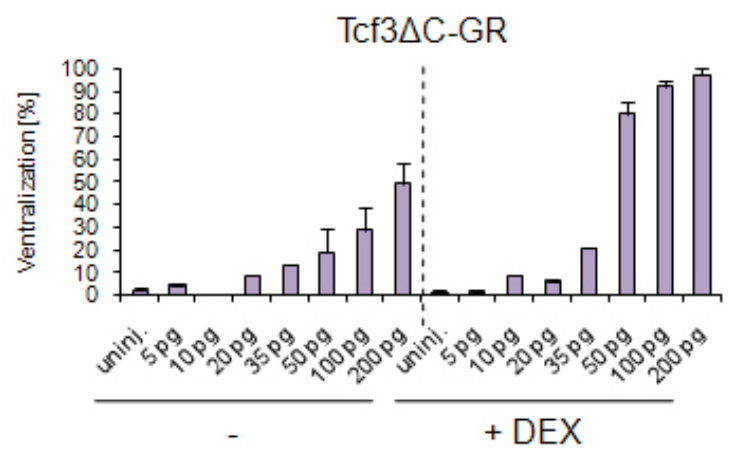

$\mathbf{F}$

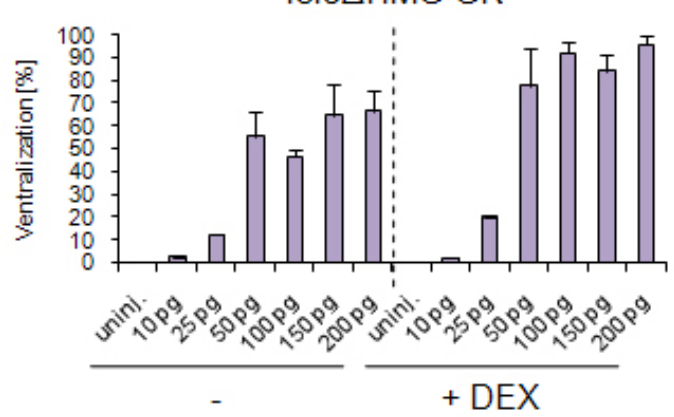

Figure 10. GR-fusion constructs were tested for canonical Wnt signaling modulating activity and DEX-inducibility using axis duplication or ventralization assay. (A) Xenopus embryos were injected into the marginal zone of one ventral blastomere, DEX-treated until early tailbud stages and scored for the formation of a secondary body axis (C-D). (B) Xenopus embryos were injected into the marginal zone of both dorsal blastomeres, DEX-treated until early tailbud stages and scored for a 
ventralized phenotype (E-F). (C-F) Embryos were injected with different amounts of Lef $\Delta$ N-VP16-GR, Tcf3 $\Delta$ C-GR, $\beta$ catS33A $\Delta$ TA-VP16-GR, or Tcf $\Delta H M G-G R$ mRNA and treated with DEX as inicated. (C-D) Lef1-GR and ßcatS33A $\triangle T A-V P 16-G R$ both stimulate secondary axis formation. (C) Lef $\Delta \mathrm{N}-\mathrm{VP} 16-\mathrm{GR}$ activity is DEX-dependent. (D) BcatS33A $\triangle T A-V P 16-G R$-mediated secondary axis induction occurs independently of DEX-treatment. (E-F) Ventral overexpression of Tcf $3 \Delta C-G R$ and Tcf $\Delta H M G-G R$ results in the development of reduced dorso-anterior structures. (E) Tcf3 $\Delta \mathrm{C}$-GR-mediated ventralization is strongly enhanced by DEX-treatment. (F) Tcf $\triangle H M G-G R$ strongly induces ventralization phenotype independently of DEX.

Dorsal inhibition of Wnt/ 3 -Catenin signaling in Xenopus embryos suppresses the induction of the Spemann organizer and results in the formation of a ventralized phenotype. These embryos show reduced dorso-anterior structures, like cement gland and eye anlage (Figure 10B). In order to analyze activity and inducibility of predicted canonical Wnt signaling repressing GR-fusion constructs, mRNAs coding for these factors were injected marginally into both dorsal blastomeres of 4-cell stage embryos.Injected embryos were treated with DEX and cultivated until late tailbud stages for ventralization phenotype analysis (Figure $10 \mathrm{~B}$ ). All of these dorsally expressed GR-fusion constructs induced ventralization even without DEX treatment (Figure 10 E, F; Table 7). However, TCF3 $\triangle C-G R$ and EnR-Lef1-GR repress canonical Wht signaling in a dosedependent manner and protein activity was enhanced by addition of DEX (Figure $10 \mathrm{E}$; Table 7).

To confirm the data gained from axis duplication and ventralization assays, we tested signaling activity and inducibility of GR-fusion constructs in the Xenopus animal cap system. Stimulation or repression of canonical Wnt signaling can be monitored by expression analysis of direct Wnt/ $\beta$-Catenin target genes, such as Nodal-related 3 (Xnr3) or Siamois(Ghogomu et al., 2006).Embryos were injected animally with mRNAs coding for GR-fusion proteins and treated with DEX immediately after injection. At blastula stage, animal ectodermal tissue was dissected and cultivated until mid-gastrula stage for target gene expression analysis, using RT-PCR (Figure 11 A).Consistent with the data from axis duplication assays, Wnt/ß-Catenin target gene expression is induced by Lef1GR and BcatS33A $\triangle T A-V P 16-G R$. While Lef1-GR activity is induced by DEX, ßcatS33A $\triangle$ TA-VP16-GR promotes expression of $\mathrm{Xnr3}$ and siamois DEXindependently (Figure $11 \mathrm{~B}, \mathrm{D}$; Table 7). In order to analyze activity of Wnt/BCatenin repressing GR-fusion proteins, the corresponding constructs were 
coexpressed with canonical Wnt signaling stimulating factors, such as Dishevelled (Dvl) or $\beta$-Catenin (Figure $11 \mathrm{C}, \mathrm{D})$.Tcf3 $\Delta \mathrm{HMG}-\mathrm{GR}$ inhibited Dvlmediated target gene expression. However, as observed in the ventralization assay, Tcf3 $\Delta$ HMG-GR activity was not induced by DEX (Figure $11 \mathrm{C}$; Table 7). Surprisingly, 2 GR-fusion proteins, namely Lef $\triangle B D-G R$ and $\beta$ catS33A $\triangle T A-E n R-$ $\mathrm{GR}$, that were predicted to repress canonical Wnt signaling activity, were found to induce secondary axis formation and $\beta$-Catenin target gene expression (Figure $11 \mathrm{D}$; Table 7).

A

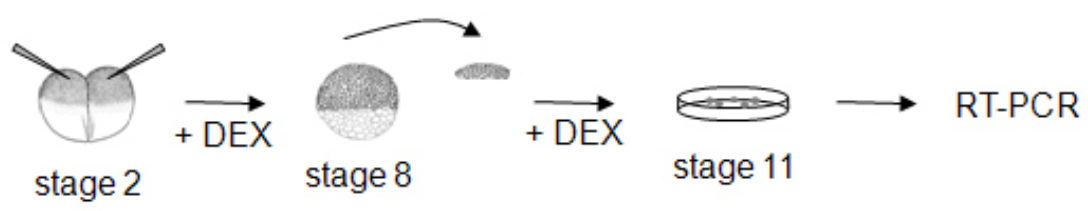

B

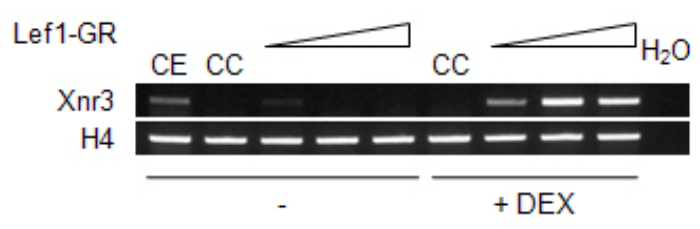

C

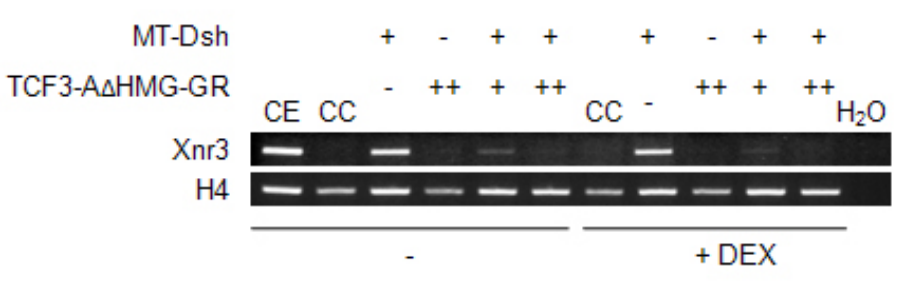

D

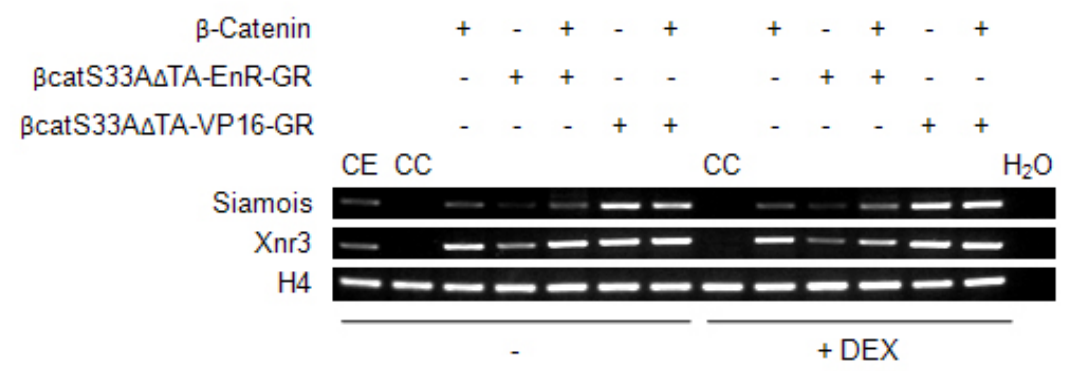

Figure 11. Activity and DEX-inducibilty of GR-fusion constructs as tested by gene expression analysis in animal cap explants.(A-D) Xenopus embryos were injected animally into both blastomeres at 2-cell-stage, ectodermal animal cap tissue was dissected at stage 8 and treated with Dexamethasone (DEX) until stage 11, when ectodermal explants were fixed for RT-PCR analysis. (B-D) Embryos were injected with 50 pg, 100 pg, or 150 pg Lef1-GR, 200 pg MT-Dsh, 50 pg or 100 pg TCF3-A $\Delta$ HMG-

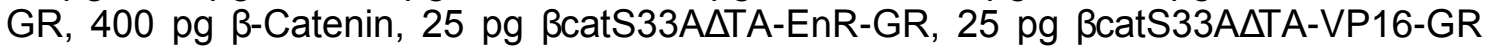
mRNA and treated with Dexamethasone, as indicated. RNA extracts were analysed for expression of Xnr3 (B-C) and Siamois (D). RT-PCR for histone H4 was included as loading control. (B) Lef1-GR induces Wnt/B-Catenin target gene expression dose- 
dependently upon activation with DEX. (C) TCF3-A $\triangle H M G-G R$ inhibits MT-Dshmediated target gene expression independently of DEX-treatment. (D) BcatS33A $\triangle \mathrm{TA}$ EnR-GR and $\beta$ catS33A $\triangle \mathrm{TA}-\mathrm{VP} 16-\mathrm{GR}$ both induce canonical Wnt target gene expression in the absence of DEX. CE - uninjected control embryo; CC - control animal cap tissue from uninjected embryos.

In summary,we have identified constructs that either inhibit or induce canonical Wnt signalingin a DEX dependent manner; these are: Lef1-GR and Lef $\Delta \mathrm{N}$ VP16-GR (activators) as well as TCF3 $\triangle$ C-GR and EnR-Lef1-GR (repressors).

Table 7.Summary of canonical Wnt signaling modulating activity and DEX inducibility of GR-fusion constructs used in this study.

\begin{tabular}{|c|c|c|c|c|c|}
\hline \multirow{2}{*}{ GR-fusion construct } & \multicolumn{2}{|c|}{ axis phenotype } & \multicolumn{2}{|c|}{ Target gene expression } & \multirow{2}{*}{$\begin{array}{c}\text { DEX } \\
\text { inducibility }\end{array}$} \\
\hline & $\begin{array}{c}\text { axis } \\
\text { duplication }\end{array}$ & ventralization & activation & repression & \\
\hline BcatS33A-GR & yes & n.d. & n.d. & n.d. & no \\
\hline GR-ßcatS33Y & yes & n.d. & n.d. & n.d. & no \\
\hline BcatS33A $\triangle T A-V P 16-G R$ & yes & n.d. & n.d. & n.d. & no \\
\hline Lef1-GR & yes & n.d. & yes & no & yes \\
\hline Lef $\Delta \mathrm{N}-\mathrm{VP} 16-\mathrm{GR}$ & yes & n.d. & yes & n.d. & yes \\
\hline Lef $\triangle B D-G R$ & yes & yes & yes & yes & yes \\
\hline TCF3 $\triangle \mathrm{C}-\mathrm{GR}$ & n.d. & yes & n.d. & n.d. & yes* \\
\hline EnR-Lef1-GR & n.d. & yes & n.d. & n.d. & yes* \\
\hline ßcatS33A $\triangle T A-E n R-G R$ & yes & yes & n.d. & n.d. & no \\
\hline GR-Tcf $3 \Delta \mathrm{N}$ & n.d. & yes & n.d. & n.d. & no \\
\hline GR-Tcf3 $\Delta H M G$ & n.d. & yes & n.d. & n.d. & no \\
\hline Tcf3 $\Delta H M G-G R$ & n.d. & yes & n.d. & yes & no \\
\hline GSK3ß-GR & n.d. & yes & n.d. & n.d. & no \\
\hline
\end{tabular}

\subsection{Modulation of canonical Wnt signaling activity interferes with pancreas specification and differentiation}

Previous studies in Xenopus as well as in other model systems had shown that canonical Wnt signaling plays important roles during patterning of the primitive gut tube, including aspects of specification, differentiation, and proliferation of endodermal cells. Different models for Wnt/ $\beta$-Catenin function during 
endodermal organ development have been proposed. While McLin and colleaguesdiscuss an anterior-posterior gradient of canonical Wnt signalingactivity within the gut tube, other studies suggested a model that is defined by temporal modulations $\beta$-Catenin stability in respect to the corresponding developmental phase(Damianitsch et al., 2009; Dessimoz et al., 2005; Heiser et al., 2006; McLin et al., 2007; Murtaugh et al., 2005).

In order to analyze the role of canonical Wnt signaling during pancreatic development, mRNAs coding for inducible canonical Wnt signaling activating or repressing GR-fusion proteins were injected into the vegetal pole of all 4 blastomeres of stage 3 Xenopus embryos. Embryos were treated with DEX either at stage 12, before the pancreatic anlage is specified, or at stage 30 , when pancreatic specification is completed, and cultivated until stage 40(Figure 12 A). Embryos were analyzed for expression of pancreatic protein disulfide isomerase (PDIp), which is an earlymarker for differentiation of the exocrine pancreatic cell lineage(Afelik et al., 2004).In the control situation, PDIp transcripts are detected strongly in the dorsal and ventral pancreatic bud and PDIp expression is not altered by DEX treatment (Figure $12 \mathrm{~B}, \mathrm{C}$ ).

As shown earlier, embryos injected with Lef1-GR are devoid of the dorsal pancreas both after early and late activation of the GR-fusion protein (Melchert, 2007). However, Lef $\Delta$ N-VP16-GR had no effect on PDIp expression (Figure 12 C). Early and late repression of canonical Wnt signaling using microinjection of Tcf3 $\triangle$ C-GR mRNA caused the loss of both ventral and dorsal pancreatic anlage. However, a similar phenotype was observed for embryos that were not treated with DEX (Figure $12 \mathrm{~B}, \mathrm{C}$ ). Therefore, reduced XPDIp expression in the dorsal and ventral pancreas upon Tcf3 $\triangle \mathrm{C}-\mathrm{GR}$ expression might also be a secondary effect caused by an impairment of earlier developmental events. However, this result is consistent with data from ventralization assays showing that Tcf3 $\triangle \mathrm{C}-\mathrm{GR}$ is active even in the absence of DEX (Figure $10 \mathrm{E}$; Table 7). While early repression of Wnt/ $\beta$-Catenin signaling using EnR-Lef1-GR caused reduced expression of PDIp in the dorsal pancreas, activation of the protein at stage 30 did not interefere with exocrine pancreatic development (Figure 12 B, C), (Forchmann, 2009). Furthermore, transcript levels of Insulin that is specifically expressed in the endocrine $\beta$-cells were neither early nor late altered by activation of EnR-Lef1-GR (Forchmann, 2009). 
These data show that both repression and hyperactivation of canonical Wnt signaling before and after specification of the dorsal pancreatic anlage can result in impaired exocrine pancreatic development. In contrast, development of the ventral pancreas was not influenced by increased Wnt/ $\beta$-catenin signaling. However, based on these data we cannot definitively conclude a requirement for Wnt signaling activity in the context of ventral pancreatic development.

A

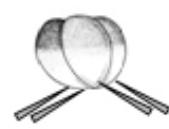

stage 3
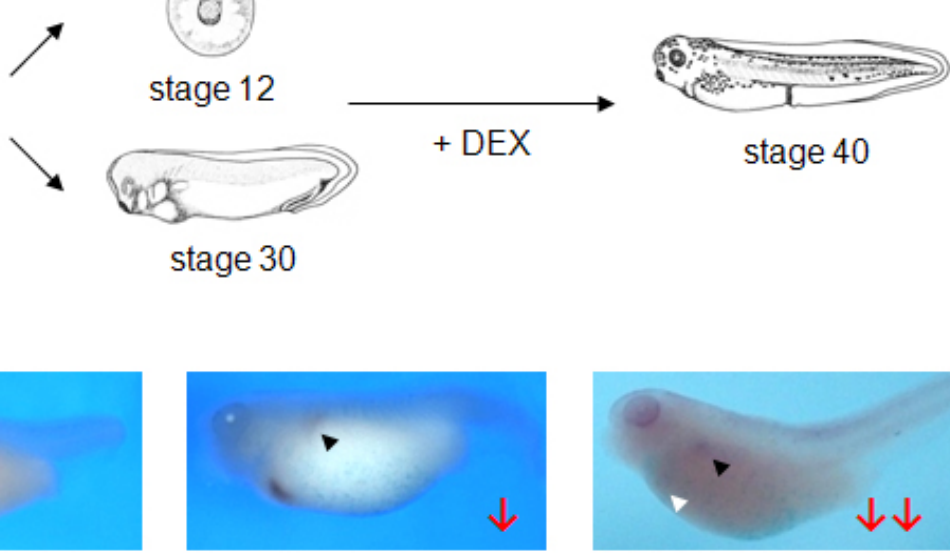

C

\begin{tabular}{|c|c|c|c|c|c|c|}
\hline \multirow{2}{*}{$\begin{array}{l}\text { GR-fusion } \\
\text { construct }\end{array}$} & \multicolumn{2}{|c|}{ - DEX } & \multicolumn{2}{|c|}{ DEX stage 12} & \multicolumn{2}{|c|}{ DEX stage 30} \\
\hline & phenotype & $\%(n)$ & phenotype & $\%(n)$ & phenotype & $\%(n)$ \\
\hline uninjected & none & $100 \%(22)$ & none & $100 \%(23)$ & none & $94 \%(17)$ \\
\hline Lef $\Delta N-V P 16-G R$ & none & $91 \%(22)$ & none & $93 \%(27)$ & none & $93 \%(27)$ \\
\hline Lef1-GR & none & $86 \%(22)$ & $\downarrow$ & $56 \%(25)$ & $\downarrow$ & $77 \%(26)$ \\
\hline TCF3 $\Delta \mathrm{C}$-GR & $\downarrow \downarrow$ & $94 \%$ (31) & $\downarrow \downarrow$ & $95 \%(43)$ & $\downarrow \downarrow$ & $84 \%(37)$ \\
\hline EnR-Lef1-GR & none & $65 \%(20)$ & $\downarrow$ & $88 \%(24)$ & none & $100 \%(23)$ \\
\hline
\end{tabular}

Figure 12. Stimulation and Inhibition of canonical Wnt signaling before and after pancreatic specification result in a reduced expression of the exocrine pancreatic marker XPDIp. (A) Xenopus embryos were injected into the vegetal pole of all 4 blastomeres at the 4-cell stage and cultivated either until stage 12 or stage 30 for Dexamethasone (DEX) treatment until stage 40. (B) Shown are representative embryos exhibiting either normal XPDIp expression (left panel) or reduced XPDIp expression only in the dorsal $(\downarrow)$ or in both dorsal and ventral $(\downarrow \downarrow)$ pancreatic anlage. XPDIp expression was determined using WMISH. Black arrow heads indicate reduced dorsal pancreas; white arrow head indicates reduced ventral pancreas. (C) Summary of phenotypes in the context of XPDIp expression observed upon activation (Lef1-GR, Lef $\Delta \mathrm{N}-\mathrm{VP} 16-\mathrm{GR}$ ) or repression (Tcf3 $\Delta \mathrm{C}-\mathrm{GR}$, EnR-Lef1-GR) of canonical Wnt signaling. Embryos were injected with 75 pg Lef1-GR, 300 pg Lef $\Delta$ N-VP16-GR, 100 pg Tcf $3 \Delta$ CGR, or 500 pg EnR-Lef1-GR mRNA and treated with DEX at stage 12 or at stage 30, as indicated. XPDIp expression was analyzed using WMISH and 2 phenotypes were observed: $\downarrow$ reduced dorsal pancreas; $\downarrow \downarrow$ reduced ventral and dorsal pancreas. Percentages of embryos showing the corresponding phenotype and numbers of analyzed embryos are indicated. Data shown for Lef1-GR injected embryos are taken 
from Melchert, 2007; data shown for EnR-Lef1-GR injected embryos are taken from Forchmann, 2009.

\subsection{Ectopic Fam132b induces formation of a secondary body axis in Xenopus embryos}

To identify novel regulators of $\mathrm{Wnt} / \mathrm{\beta}$-Catenin signaling, expression cloning was carried out, using primary body axis formation in Xenopus embryos as a read out system. A Xenopus tropicalis full-length cDNA library, containing more than 9000 individual cloneswas used(Gilchrist et al., 2004).

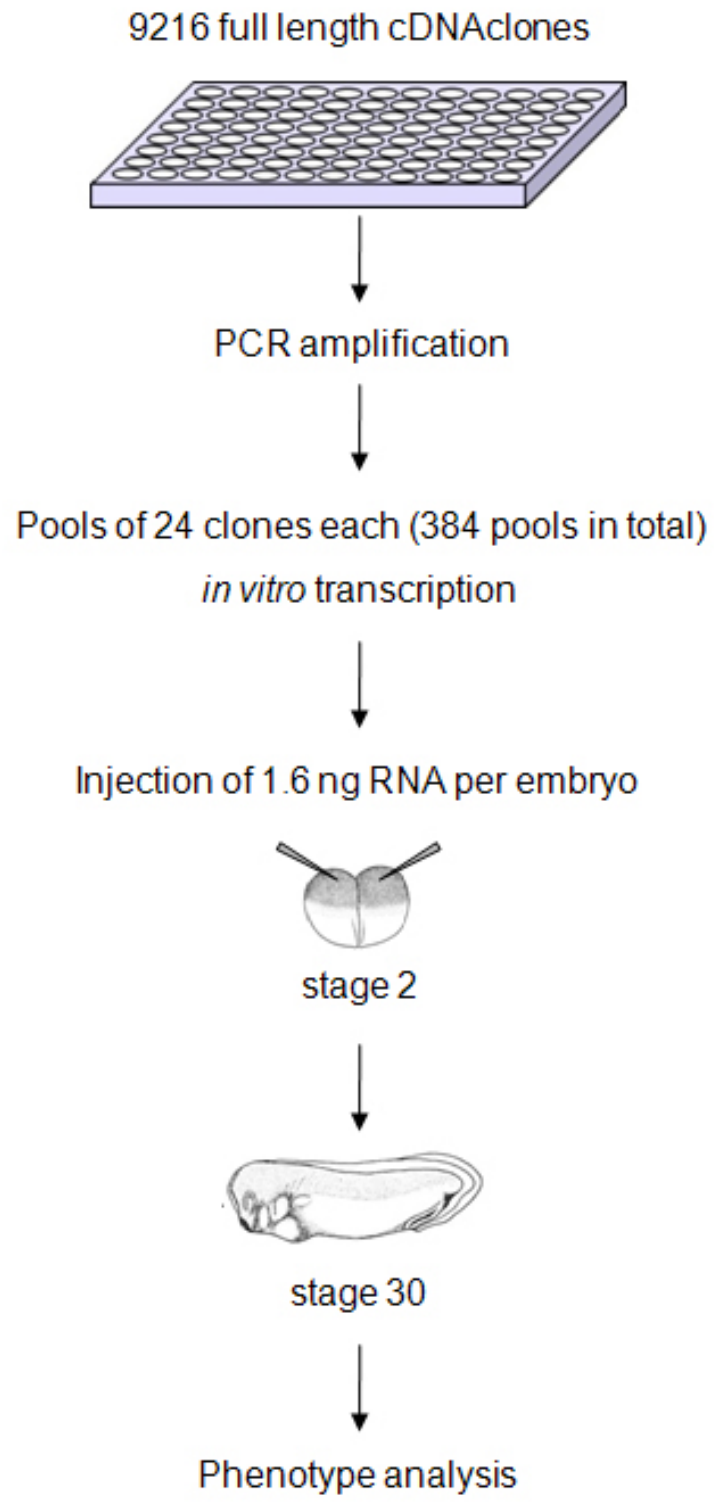

Figure 13. Schematic illustration of expression cloning. Bacteria containing Xenopus tropicalis full-length cDNA clones were cultured in 96-well plates. After DNA 
extraction cDNA clones were PCR amplified and pooled within rows. After in vitro synthesis, $1.6 \mathrm{ng}$ of mRNA pools were injected animally into both blastomeres of 2cell-stage Xenopus laevis embryos. Embryos were cultivated until stage 30 for phenotype analysis.

cDNA clones were amplified by PCR and pools of 24 cDNA clones each were transcribed in vitro(kindly provided by K. Henningfeld). Xenopus laevis embryos were injected with these pools of mRNAs animally into bothblastomeres at the 2-cell-stage and analyzed for axis formation defects at early tadpole stages (Figure 13). Embryos expressing one of these mRNA poolsexhibited a dorsalized phenotype (Figure $14 \mathrm{~A}$ ).

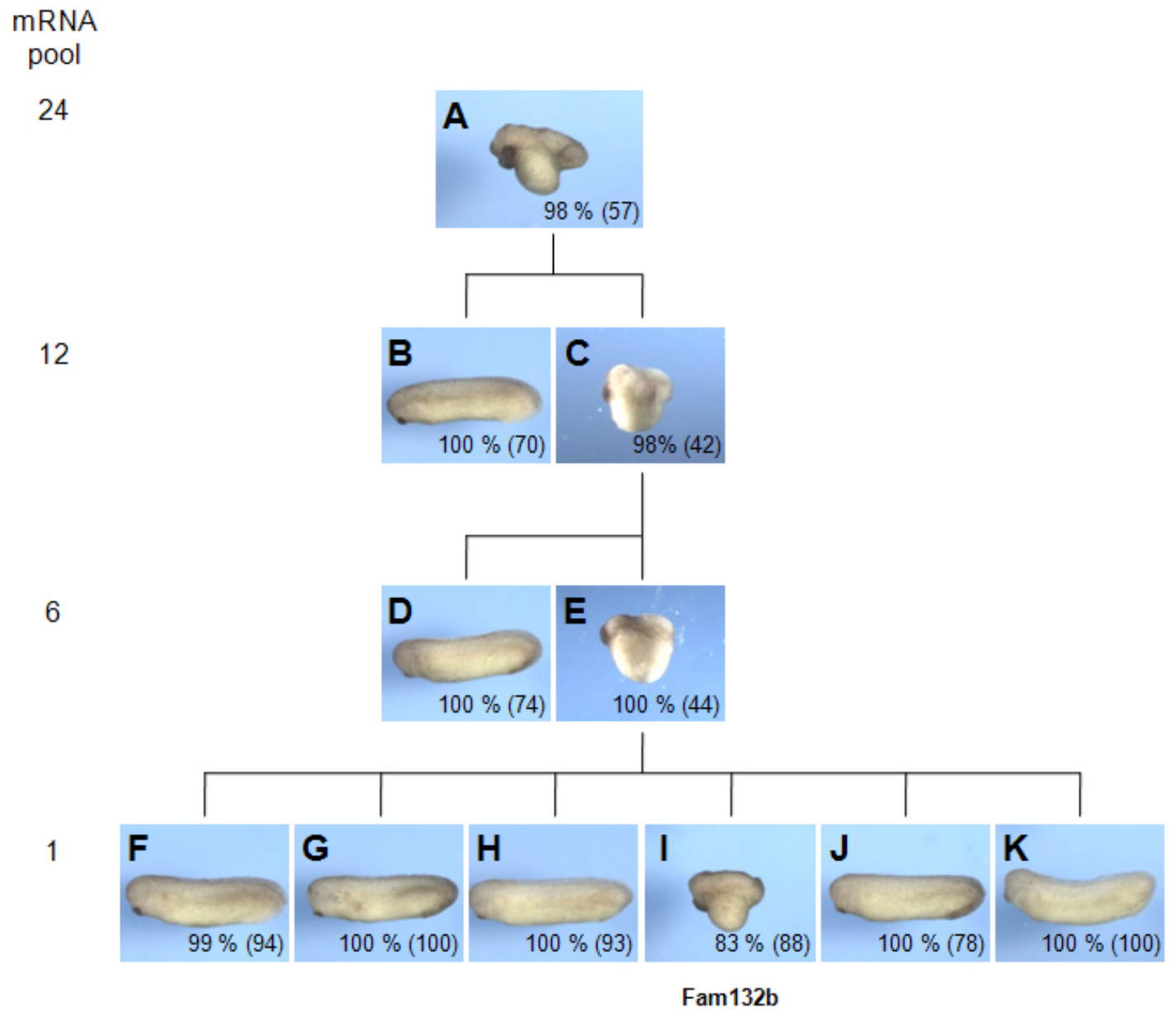

Figure 14. Expression cloning identifies Fam132b a dorsalizing factor. (A-K) Hierarchy of injected mRNA pools and observed phenotypes. mRNA mixtures derived from pools of $X$. tropicalis full-length cDNA clones were injected into both blastomeres at the 2-cell-stage. Embryos were cultivated to tailbud stage and screened for axis formation. $1.6 \mathrm{ng}(\mathrm{A}), 800 \mathrm{pg}(\mathrm{B}, \mathrm{C}), 500 \mathrm{pg}(\mathrm{D}, \mathrm{E})$ or $120 \mathrm{pg}(\mathrm{F}-\mathrm{K})$ of total mRNA were injected per embryo. Numbers of individual clones per injected mRNA pool are indicated at the left side. Embryos are depicted at lateral view with anterior to the left. 
Percentages of embryos exhibiting the shown phenotype in respect to the whole number of analyzed embryos is shown in the lower right hand corner of each panel.

This phenotype is defined by overrepresentation of very anterior structures, such as the cement gland, as well as by a shortened body axis (Figure 14 A, C, $\mathrm{E}, \mathrm{I})$. In order to identify the active clone, the dorsalization-positive pool was subdivided into pools of 12 , followed by subdivision into pools of 6individual clones. These mRNA pools were microinjected and embryos were analyzed, as described above (Figure 14 B-E). Ectopic expression of the 6 remaining individual clones lead to the identification of one clone as inducer of the observed dorsalized phenotype (Figure 14 F-K). Thisclone TTpA078f11 could be assigned to Xenopus tropicalisFam132b (AN: NM_001078919).

A

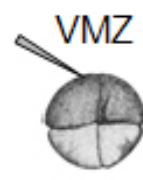

stage 3
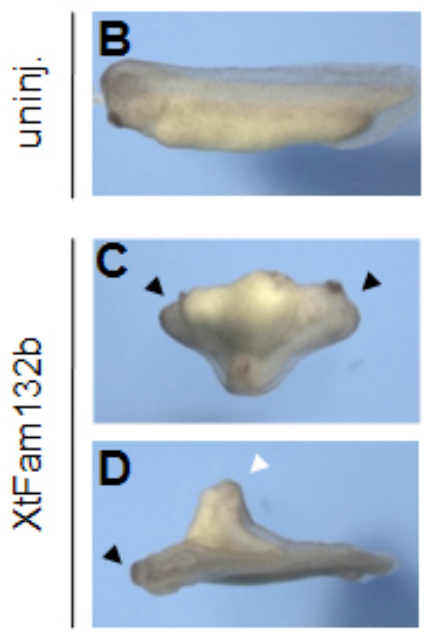

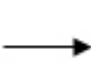

E

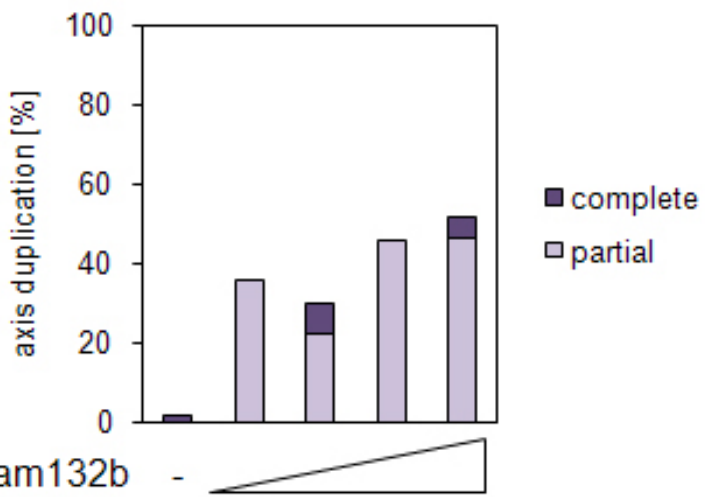

Figure 15. Fam132b induces secondary axis formation upon ventral overexpression.(A) Xenopus embryos were injected at the four-cell stage into the marginal zone of one ventral blastomere and cultivated until stage 28 for phenotype analysis. VMZ - ventral marginal zone. (B-E) Fam132b induces secondary axis formation. (B-D) Representative embryos showing partial or complete secondary axis formation and corresponding as indicated. Embryos are depicted in a lateral view with anterior to the left (B), in a lateral view with anterior to the top (C) or in a dorsal view with anterior to the left (D). Black arrows indicate the anterior tip of a complete body axis; white arrow head marks the anterior tip of a partial secondary body axis. (E) Quantification of embryos showing partial or complete secondary axis formation after ventral overexpression of increasing amounts of Fam132b, as indicated. 30 pg, 60 pg, $120 \mathrm{pg}$ or 250 of XtFam132b mRNA were injected per embryo. 
A dorsalized phenotype similar to that observed after expression of Fam132b mRNA could be caused by activation of Wnt/ $\beta$-Catenin signalingbut also by inhibition of BMP signaling in the early embryo(Oelgeschlager et al., 2003; Williams et al., 2005). Modulations of these signaling pathways, if restricted to the ventral marginal zone of the embryo, can induce secondary axis formation inXenopus embryos(Fagotto et al., 1997; Funayama et al., 1995; Graff et al., 1994; Suzuki et al., 1994).

To determine if Fam132b can induce axis duplication as well, Fam132b mRNA was injected marginally into 1 ventral blastomere at the 4-cell-stage. Indeed, Fam132b shows predominantly partial secondary axis inducing activity (Figure 15 A-C). These data suggest that Fam132b might be a protein with the potential to either stimulate $\mathrm{Wnt} / \beta-C a t e n i n$ signaling or negatively regulate BMP signaling.

\subsection{Fam132b does not activate Wnt/ $\beta$-Catenin signaling}

Since Fam132b exhibits secondary axis inducing activity, we asked ifFam132b could act as a Wnt/ $\beta$-Catenin signaling stimulating factor. For this purpose, Fam132b activity was analyzed in the Xenopus animal cap assay. Fam132b mRNA was injected into both blastomeres of 2-cell-stage embryos. At blastula stage animal ectodermal tissue (animal cap) was explanted and cultivated until sibling control embryos had reached gastrula stage.Animal caps, which do not show Wnt/ $\beta$-Catenin signaling activity, were analyzed for direct canonical target gene expression using RT-PCR (Figure 16 A). While Wnt8 strongly activates the expression of Xnr3, transcriptional induction of Xnr3 was not observed upon ectopic Fam132b expression (Figure 16B).

Furthermore, Fam132b activity was analyzed in the luciferase assay using a Wnt-responsive Siamois reporter construct. The siamois reporter construct, which contains the firefly luciferase gene under control of the siamois promoter, was injected together with a Renilla reporter construct into both blastomeres of a 2-cell-stage embryo (Brannon et al., 1997). Since Renilla reporter gene activation is independent of Wnt signaling activity, this construct was used for normalization of Siamois reporter gene activity. Embryos were cultivated until 
gastrula stage and analyzed for luciferase activity. While expression of Wnt8 mRNA dramatically increased Siamois reporter gene activity in the embryo, ectopic expression of Fam132b did not influence the level of endogenous canonical Wnt signaling (Figure $16 \mathrm{~A}, \mathrm{C}$ ).

To answer the question, if Fam132b might act as a Wnt/ $\beta$-Catenin signalingenhancing factor, Fam132b was coexpressed together with decreasing doses of Wnt8 mRNA in the ectodermal animal cap tissue, as described above. RT-PCR analysis revealed that Fam132b does not increase Wnt8 induced Xnr3 expression (Figure 16 A, D). Hence, a synergistic activity between Fam132b and Wnt8 can be excluded.

A

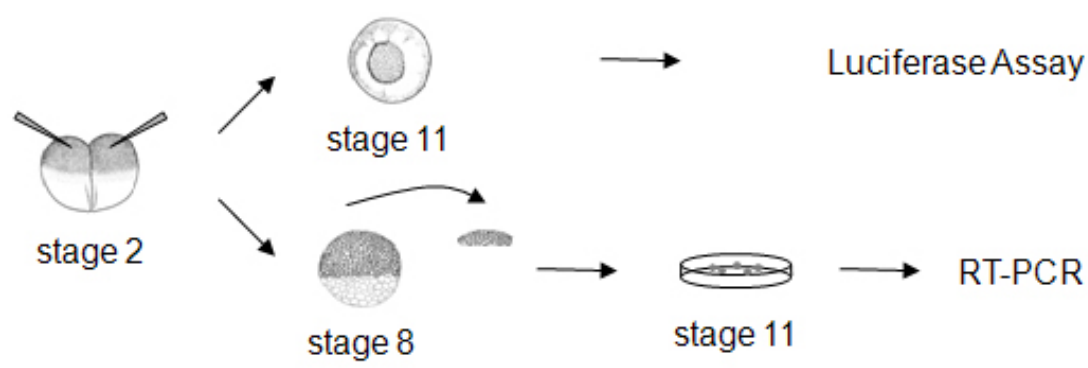

B

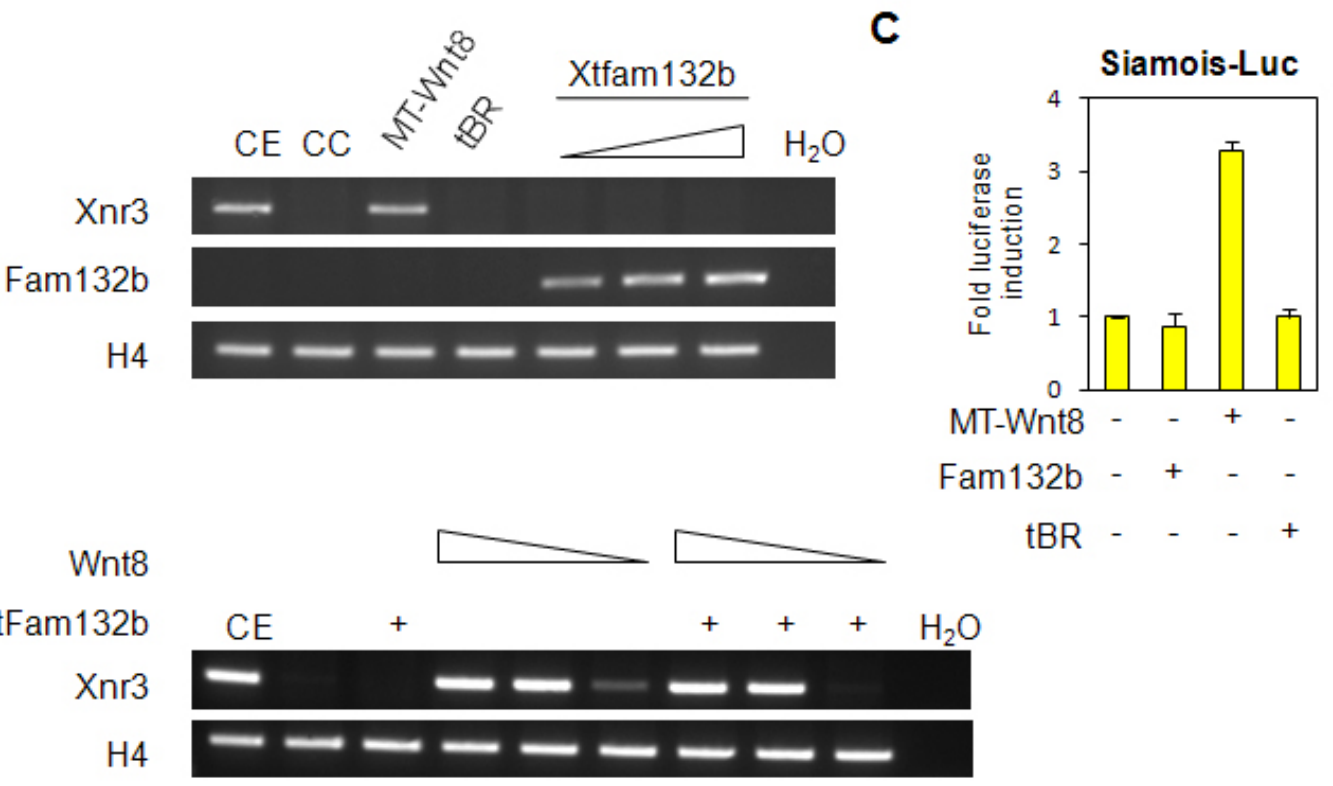

Figure 16. Overexpression of Fam132b does not modulate endogenous or ectopicaly activated canonical Wnt signaling activity. (A) Xenopus embryos were injected into both blastomeres at the 2-cell stage and cultivated either until stage 11 for luciferase assay or until stage 8 for dissection of the animal cap tissue. Ectodermal explants were cultivated until stage 11 and analyzed using RT-PCR. (B) Fam132b does not induce transcription of Xnr3 in animal cap cells. $30 \mathrm{pg}$ MT-Wnt8, $250 \mathrm{pg}$ tBR and $30 \mathrm{pg}, 60 \mathrm{pg}$ or $120 \mathrm{pg}$ of XtFam132b mRNA were injected per embryo. (C) Fam132b does not stimulate Siamois-Luc reporter gene activity. 10 pg MT-Wnt 8,120 
pg XtFam132b, and 250 pg tBR mRNA were injected per embryo and 3 samples containing 15 embryos each were analyzed. The graphs show the summary of 2 independent experiments; standard errors are indicated. Siamois-Luc reporter gene activity was normalized to Renilla reporter gene activity. Siamois-Luc reporter gene activity, induced by endogenous Wnt/B-Catenin signaling, was set to 1 . (D) MT-Wnt8mediated induction of Xnr3 transcription in animal cap explants is not enhanced by Fam132b coexpression. 40 pg, 4 pg or 0.4 pg MT-Wnt 8 and 120 pg XtFam132b mRNA were injected per embryo, as indicated.

In addition, expression of Fam132b in the axis duplication assay resulted in the formation of predominantly partial secondary body axis, lacking the very anterior structures, like cement gland or eye anlage (Figure 15). In contrast, ventral overexpression of $\mathrm{Wnt} / \beta$-Catenin signaling activating factors, such as Wnt8, induce the formation of complete secondary axis, exhibiting those anterior structures(Fagotto et al., 1997; Funayama et al., 1995). Taken together, these data show that ectopic Fam132b neither activates norenhances canonical Wnt signaling activity in Xenopus embryos.

\subsection{BMP signaling activity is repressed by ectopic Fam132b expression}

Apart from activation of canonical Wnt signaling, ventral inhibition of BMP signaling can induce secondary axis formation in Xenopus embryos(Graff et al., 1994; Suzuki et al., 1994). Therefore, we asked if Fam132b exhibits BMP antagonizing activity. To answer this question, we ectopically expressed Fam132b in animal cap cells, where BMP signaling is active. Xenopus embryos were injected with mRNA coding for Fam132b animally into both blastomeres at the 2-cell stage and animal caps were dissected at blastula stage (Figure 17 A).RT-PCR analysis of gastrula stage ectodermal explants revealed that transcriptional levels of direct BMP target genes, such as Vent1/2 or Msx1/2 are downregulated upon Fam132b expression, as observed for animal cap explants expressing the dominant negative truncated BMP receptor (tBR) or the secreted BMP antagonist Noggin (Figure17C). It has been shown, that repression of BMP signaling activity induces neural differentiation in embryonic ectodermal explants (Lamb et al., 1993; Sasai et al., 1995). Correspondingly, we found the neural cell adhesion molecule (N-CAM) to be upregulated in Fam132b expressing animal cap cells (Figure17 C). 
A

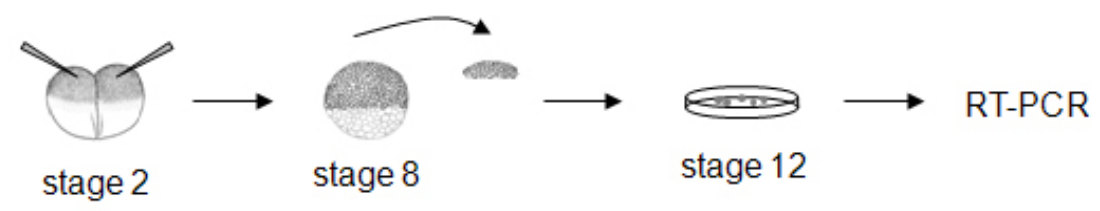

B

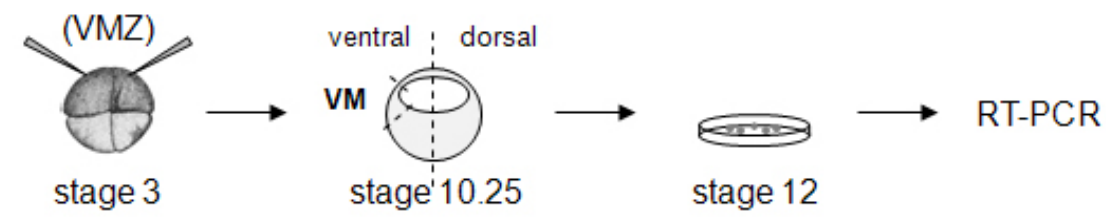

C

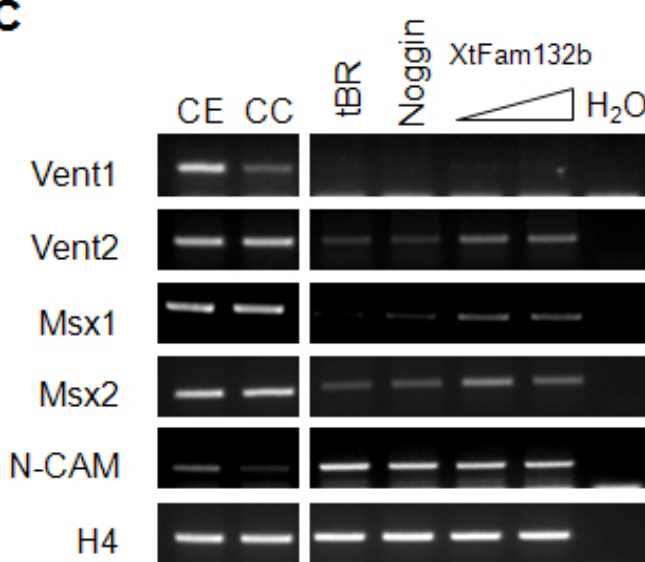

D

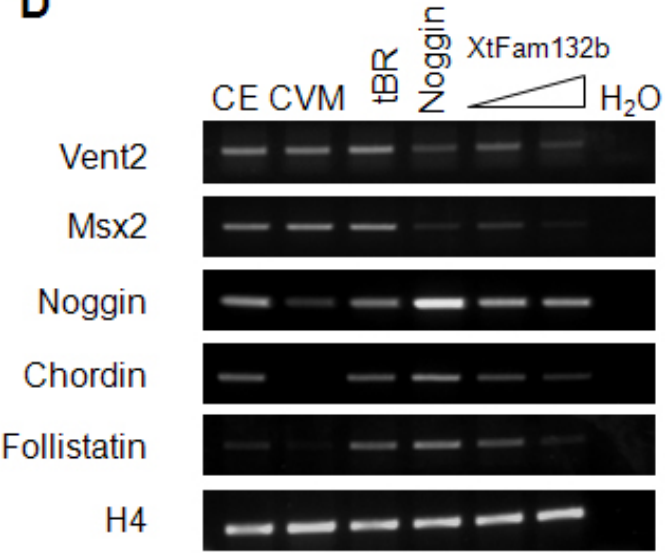

Figure 17. Overexpression of Fam132b antagonizes BMP-mediated target gene transcription (A) Both blastomeres of 2-cell-stage Xenopus embryos were injected animally, ectodermal animal cap tissue was dissected at stage 8 und cultivated until stage 12 for RT-PCR analysis. (B) Xenopus embryos were injected marginally into both ventral blastomeres at the 4-cell stage, ventral mesodermal tissue was explanted at stage 10.25 and cultivated until stage 12 for RT-PCR analysis. (C) Overexpression of Fam132b inhibits BMP target gene (Vent1/2, Msx1/2) expression and stimulates expression of the neural marker N-CAM in animal cap explants. (D) BMP target gene transcription is downregulated and expression of secreted BMP antagonists is stimulated upon overexpression of Fam132b in ventral mesodermal explants. (C-D) $300 \mathrm{pg}$ tBR, $100 \mathrm{pg}$ Noggin, 100 pg and $200 \mathrm{pg}$ (C) or $250 \mathrm{pg}$ and 500 pg (D) XtFam132b mRNA was injected per embryo, as indicated. RT-PCR for histone H4 was included as loading control. Overexpression of tBR and Noggin was included as control for BMP antagonizing activity. CE - uninjected control embryo; CC - control animal cap tissue from uninjected embryos; CVM - control ventral mesoderm from uninjected embryos.

Furthermore, we analyzed Fam132b activity in ventral mesodermal explants that highly express direct BMP target genes. For this pupose, Fam132b mRNA was injected marginally into both ventral blastomeres of 4-cell-stage Xenopus embryos. Ventral mesoderm was explanted at stage 10.25 and cultivated until gastrula stage for RT-PCR analysis (Figure $17 \mathrm{~B}$ ). As observed in the animal 
cap system, Fam132b as well as Noggin inhibits BMP target gene expression in ventral mesodermal explants (Fig 17 D). However, expression of tBR did not affect expression of Vent2 and Msx2.Inhibition of BMP signaling can induce the expression of organizer specific genes in the ventral mesoderm (Dosch and Niehrs, 2000). Similarly, Fam132b induces transcriptional activation of the organizer genes Noggin, Chordin, and Follistatin(Agius et al., 2000; Yamamoto et al., 2000), as observed previously upon expression of tBR (Figure 17 D).

A

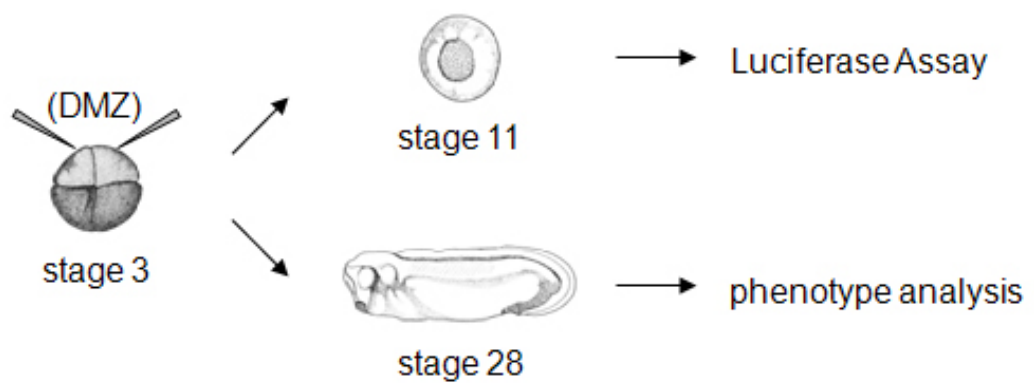

B

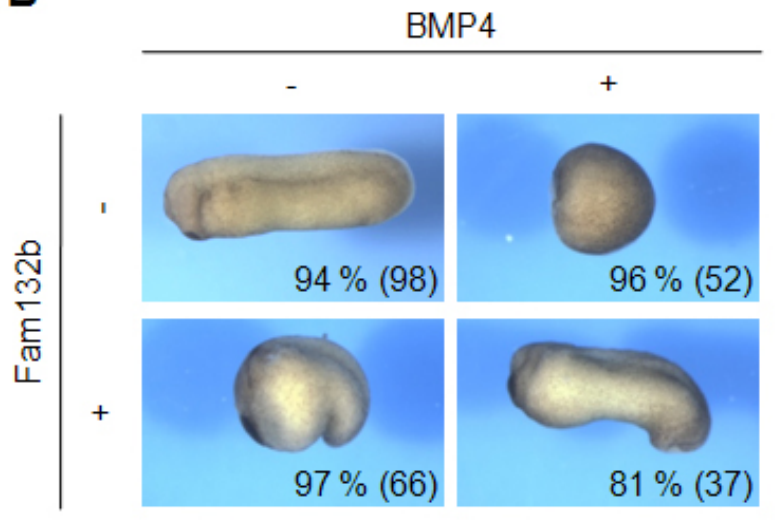

C

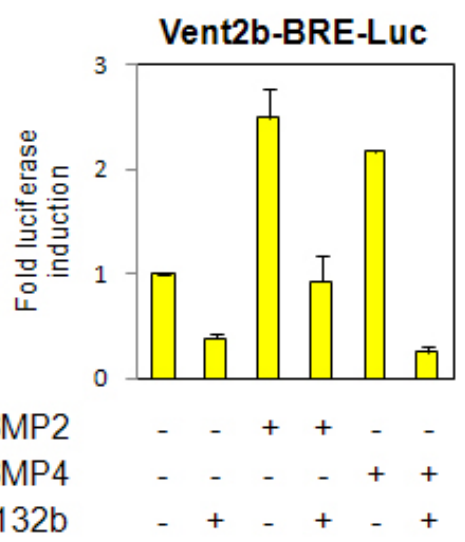

Figure 18. Fam132b represses BMP4- and BMP2-mediated BMP signaling activity. (A) Xenopus embryos were injected into both dorsal blastomeres at the 4-cell stage and cultivated either until stage 11 for luciferase assay or until stage 28 for phenotype analysis. (B) Coexpression of XtFam132b rescues the BMP4 induced ventralization phenotype. $1 \mathrm{ng}$ BMP4 and $100 \mathrm{pg}$ XtFam132b mRNA were injected per embryo, as indicated. (C) XtFam132b represses BMP4- and BMP2 stimulated Vent2bBRE-Luc reporter gene activity. $1 \mathrm{ng}$ BMP4, $1 \mathrm{ng}$ BMP2, and $100 \mathrm{pg}$ XtFam132b mRNA were injected per embryo and 3 samples containing 15 embryos each were analyzed per experiment. The graphs show the summary of 2 independent experiments; standard errors are inicated. Vent2b-BRE-Luc reporter gene activity was normalized to Renilla reporter gene activity. Vent2b-BRE-Luc reporter gene activity, induced by endogenous BMP signaling was set to 1 .

The RT-PCR experiments described above have shown that Fam132b inhibits endogenous BMP activity. In order to investigate if Fam132b could also 
antagonize ectopic BMP signaling, Fam123b mRNA was injected together with mRNA coding for BMP4 marginally into both dorsal blastomeres of 4-cell-stage embryos. These embryos were cultivated until late tailbud stages for phenotype analysis (Figure $18 \mathrm{~A}$ ). While expression of BMP4 by itself induces strong ventralization of Xenopus embryos, Fam132b expression results in the formation of a dorsalized phenotype, as described above. Coexpression of Fam132b together with BMP4 could partially rescue BMP4-mediated ventralization (Figure $18 \mathrm{~B}$ ).

Additionally, Fam132b activity was analyzed using the luciferase reporter assay. The Vent2b-BRE-Luc reporter construct(Henningfeld et al., 2000), containing the Firefly luciferase gene under control of the BMP responsive minimal Vent $2 b$ promoter, was injected together with the Renilla reporter construct into the dorsal marginal zone of 4-cell stage embryos. Embryos were cultivated until gastrula stage and analyzed for luciferase activity (Figure $18 \mathrm{~A}$ ). Endogenous BMP signaling activity is relatively low in the dorsal embryo, but reporter gene activity is significantly upregulated by overexpression of BMP2 and BMP4 mRNAs. Fam132b coexpression inhibits both, endogenous as well as BMP2and BMP4-mediated reporter gene activation (Figure $18 \mathrm{C}$ ). These data indicate that Fam132b antagonizes BMP signaling activity.

\subsection{Fam132b selectively inhibits BMP signaling}

Activity of the TGF- $\beta$ family of signalingpathways is tightly regulated during development and tissue homeostasis. Several factors are known to antagonize BMP, activin or Nodalsignaling. Some inhibitors are specific for the BMP signaling pathway, such as Noggin or Chordin(Sasai et al., 1994; Smith and Harland, 1992), while others antagonize more than one signaling pathway. BMP3, Follistatin, or BAMBI were shown to antagonize activin as well as BMP signal transduction pathways(Fainsod et al., 1997; Gamer et al., 2005; HemmatiBrivanlou et al., 1994; Onichtchouk et al., 1999). To elucidate if Fam132b is a BMP-specific inhibitor, we analyzed the effect of Fam132b on either eFGF-, activin, or BMP4 induced target gene expression. All these signaling molecules can activate the expression of the T-box gene Xbrachyury (Xbra) and the zinc 
finger transcription factor Early growth response protein 1 (egr-1) upon overexpression in animal cap explants(Panitz et al., 1998). Embryos were injected into both blastomeres at the 2-cell stage and cultivated until blastula stage for dissection of animal ectodermal tissue(Figure19 A). RT-PCR analysis reveals that target gene transcription induced via eFGF or activin signaling is not influenced by Fam132b, while BMP4-mediated target gene induction is completely repressed upon coexpression of Fam132b (Figure19B).These results suggest that the antagonizing activity of Fam $132 \mathrm{~b}$ is specific for the BMP-mediated signaling pathway.

A

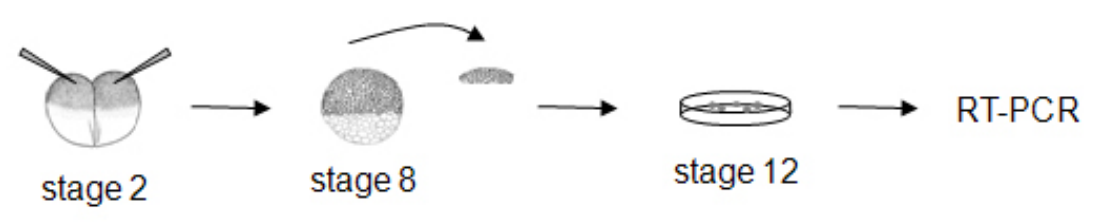

B

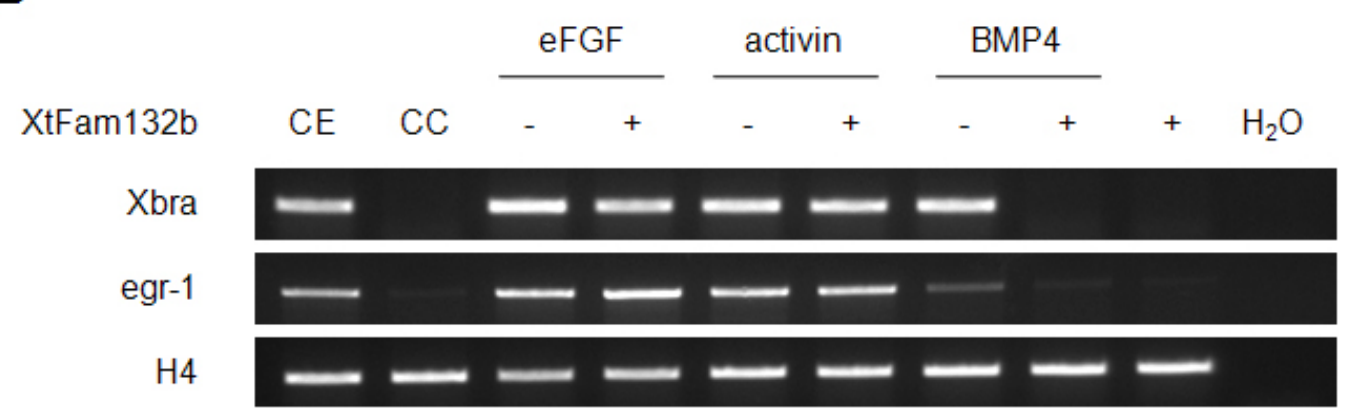

Figure 19. Fam132b selectively antagonizes BMP induced target gene transcription $(\mathrm{A})$ Xenopus embryos were injected animally into both blastomeres at the 2-cell-stage, ectodermal animal cap tissue was dissected at stage 8 und cultivated until stage 12 for RT-PCR analysis. (B) Fam132b interferes with BMP-induced target gene expression, while eFGF- and activin-mediated transcriptional induction is not influenced by Fam132b. 10 pg eFGF, 1 pg activin, 1 ng BMP4, and 100 pg XtFam132b mRNAs were injected per embryo, as indicated, and RNA extracts were analyzed for Xbra and egr-1 expression. RT-PCR for histone $\mathrm{H} 4$ was included as loading control. CE uninjected control embryo; CC - control animal cap tissue from uninjected embryos. 


\subsection{The BMP antagonizing activity of Fam132b is mediated on the extracellular level}

BMP signaling activity isregulated by multiple mechanisms, including intracellular and extracellular antagonism.Analysis of the predicted Xenopus tropicalis Fam132b protein sequence using SMART (Simple Modular Architecture Research Tool) reveals that it contains an N-terminal signal peptide of 33 amino acids, suggesting that this protein is a secreted factor (http://smart.embl-heidelberg.de/). To test this hypothesis hemagglutinin epitope (HA)-tagged Fam132b mRNA was injected vegetally into stage VI Xenopus laevis oocytes. Oocytes were cultivated for 24 hours, followed by Western Blot analysis of either oocyte or oocyte culture medium (OCM) protein extracts (Figure20 A).

A

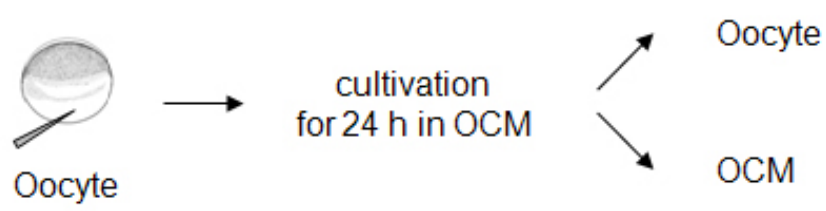

B

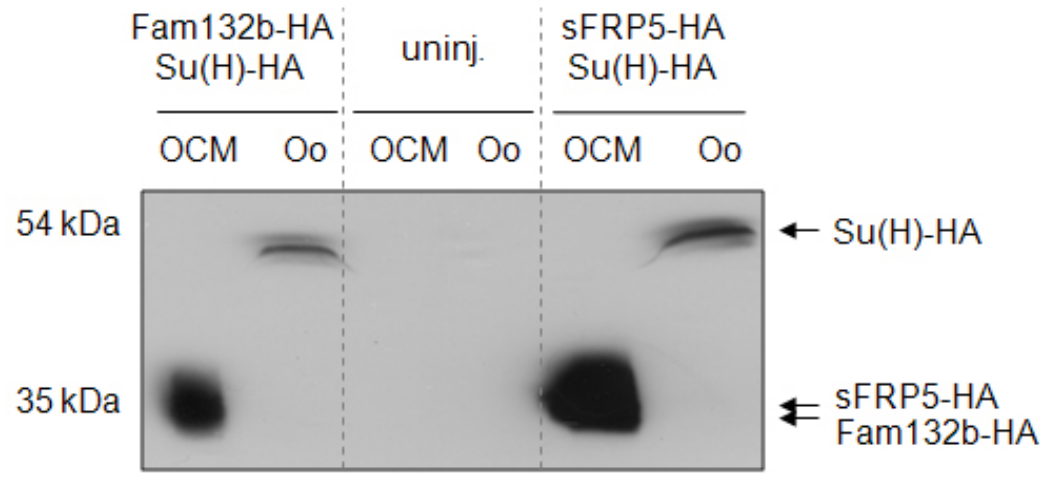

Figure 20. Fam132b is a secreted protein. (A) Stage $\mathrm{VI}$ oocytes were injected into the vegetal pole and cultivated for 24 hours. Oocytes (Oo) and Oocyte Culture Medium (OCM) were separated and protein extracts were prepared. (B) Fam132b-HA protein is secreted upon overexpression in Xenopus oocytes. $100 \mathrm{pg} \mathrm{Su}(\mathrm{H})-\mathrm{HA}$ was coinjected with either 150 pg Fam132b-HA or 150 pg sFRP5-HA mRNA. Su(H) and sFRP5 served as controls for non-secreted and secreted proteins, respectively. The expression of HAtagged proteins was analyzed by Western Blot.

An HA-fused version of the transcription factor Suppressor of Hairless $(\mathrm{Su}(\mathrm{H}))$ was coexpressed as internal control for non-secreted proteins. Within one day of cultivation,Xenopus oocytes efficiently translated injected mRNA into HA- 
tagged proteins. As expected, $\mathrm{Su}(\mathrm{H})-\mathrm{HA}$ protein was exclusively detected in the oocyte fraction, while the known secreted factor sFRP5-HA was found in the OCM (Figure20 B). Consistent with the finding that the Fam132b protein contains a signal peptide sequence, Fam132b-HA protein was similarly detected in the OCM, while being absent from the oocyte fraction (Figure20 B). These data indicate that Fam132b is a secreted factor, raising the possibility that Fam132b might antagonize BMP signaling activity on the extracellular level.

A

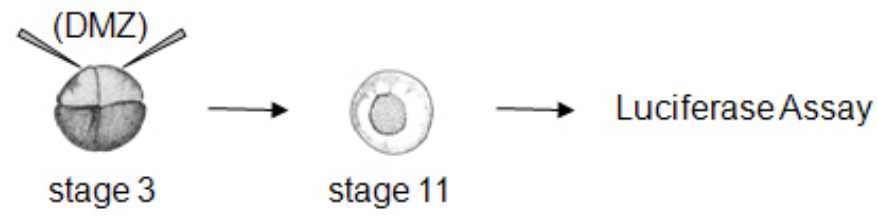

B

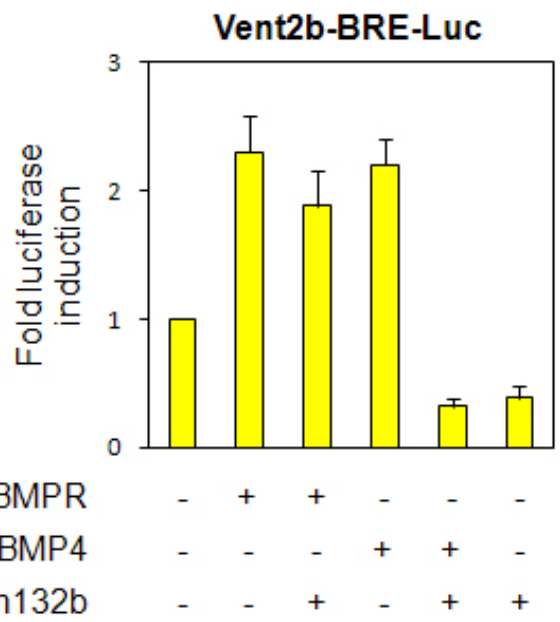

Figure 21. Fam132b inhibits BMP signaling activity on the extracellular level. (A) Xenopus embryos were injected at the 4-cell stage into the marginal zone of both dorsal blastomeres and cultivated until stage 11 for luciferase assay. DMZ - dorsal marginal zone. (B) Fam132b does not inhibit caBMPR induced reporter gene activation. The graphs summarize the results of three independent experiments; standard errors are indicated. Three samples containing 15 embryos each were analysed per experiment. 1 ng caBMPR, 1 ng BMP4 and 200 pg Fam132b mRNA per embryo were injected. Vent2b-BRE-Luc reporter gene activity was normalized to Renilla reporter gene activity. Vent2b-BRE-Luc Reporter gene activity induced by endogenous BMP signaling was set to 1.

To experimentally test this assumption, Fam132b was coexpressedwith either the constitutively active BMP receptor (caBMPR) or BMP4. Fam132b activity was analyzed in the luciferase assay at gastrula stage, using the reporter 
construct Vent2b-BRE-Luc (Henningfeld et al., 2000)and the BMP signaling independent Renilla luciferase reporter, as described above (Figure21 A, B). The caBMPR is a BMP type I receptor containing a mutation in the intracellular domain and it stimulates BMP signaling activity independently of the BMP protein(Candia et al., 1997). Reporter gene activity that is induced by caBMPR is antagonized exclusively by factors that function downstream of the receptor. As shown above, Fam132b efficiently inhibits reporter gene activity that was induced by BMP4, while caBMPR-stimulated reporter gene activity is not significantly affected (Figure21 B). These results show that the secreted protein Fam132b antagonizes BMP signaling activity on or upstream of the receptor level.

\subsection{Fam132b physically interacts with BMP specific type I receptors}

Previous studies identified a family of BMP antagonists, containing Noggin and Chordin,that function via direct binging to the BMP proteins and thereby blocking the interaction of BMPs with their receptors(Piccolo et al., 1996; Zimmerman et al., 1996). To investigate if Fam132b is a member of this family of BMP antagonistsco-immunoprecipitation (CoIP) experiments with Fam132b and BMP4 in Xenopus embryos were carried out. CoIP analysis using Noggin and BMP4 served as positive control. mRNAs coding for epitope-tagged versions of Fam132b, Noggin, and BMP4 were injected at the 2-cell stage and embryos were cultivated until gastrulation (Figure 22 A). Embryonic lysates were subjected to ColP analysis using antibodies against the HAepitope-tag. As expected, Noggin-MT strongly interacts with BMP4-HA.ColP of BMP4-HA andFam132b-MT-GR reveals that there is significant albeit weak binding between these proteins (Figure22 A, B).

Unlike BMP antagonists that regulate BMP availability, other factors, such as inhibin and BMP-3, have been identified as BMP receptor inhibitors(Gamer et al., 2005; Wiater and Vale, 2003). To test, if Fam132b interacts with BMP receptors, ColP experiments between epitope-tagged versions of the BMPspecific type I receptors Alk2 or Alk3 and Fam132b were carried out (Figure 22 A). Fam132b-MT was indeed co-immunoprecipitated with HA-tagged Alk2 and 
Alk3 (Figure22 C), but not with the human TGF $\beta$ type I receptor Alk4-HA, which is specific for TGF- $\beta$ ligands different from BMP proteins (data not shown), These data suggest that Fam132b antagonizes BMP signaling activity primarily via receptor binding. The direct binding to the BMP protein described abovecould be the result of trimeric complex formation including signal, receptor and antagonist.

A

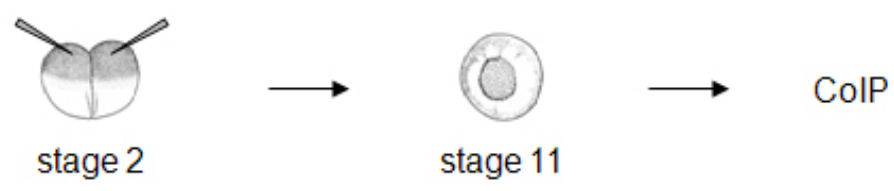

B

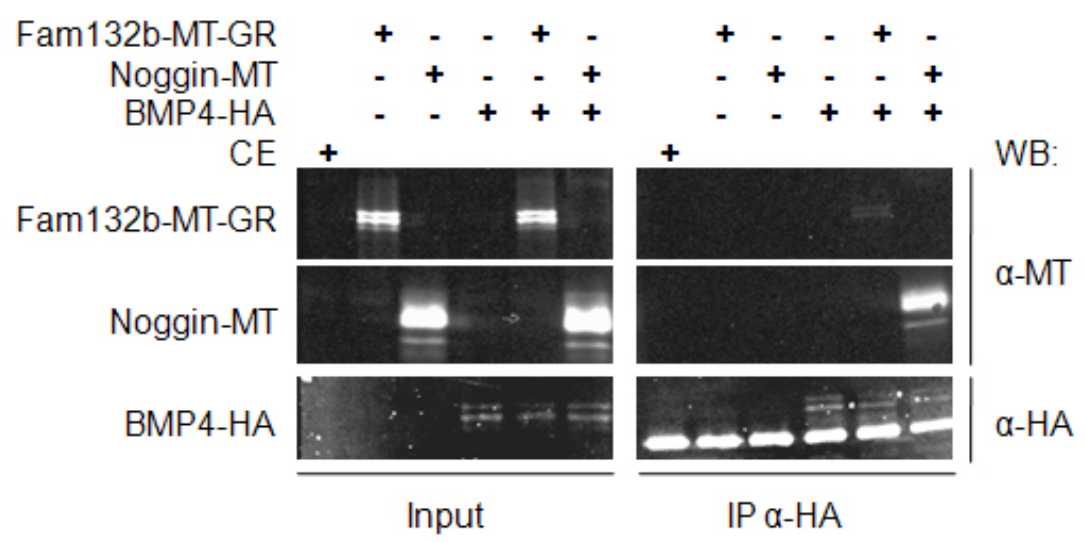

C

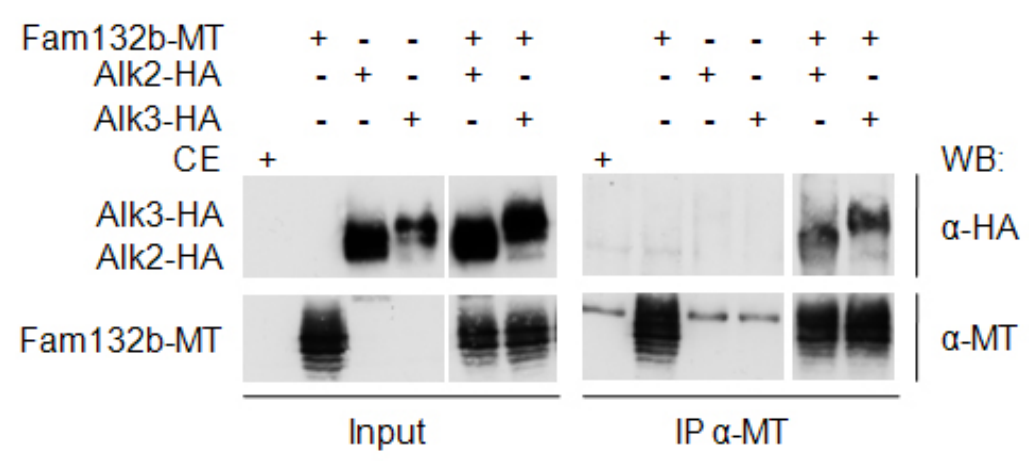

Figure 22. Fam132b strongly interacts with BMP type I receptors, and weakly with BMP4. (A) Xenopus embryos were injected animally into both cells at the 2-cell stage and lysed at stage 11 for ColP using anti-HA antibody (B) or anti-MT antibody (C). (B-C) ColP experiments showing Xenopus lysates used for ColP in the left panels and precipitated or co-precipitated proteins in the right panels. Embryo lysates and ColP samples were analyzed by Western Blot using anti-HA and anti-MT antibodies, as indicated. (B) Fam132b-MT-GR weakly co-precipitates with BMP4-HA. 200 pg Fam132b-MT, 200 pg Noggin-MT and 1 ng BMP4-HA mRNA were injected per embryo. (C) Fam132b-MT co-precipitates with BMP type I receptors Alk2-HA and Alk3HA. Embryos were injected with 200 pg Fam132b-MT, 500 pg Alk2-HA and 1 ng Alk3HA mRNA. 


\subsection{The conserved C1qTNF-like domain is dispensable for the BMP antagonizing activity of Fam132b}

Analysis of the predicted Xenopus tropicalis Fam132b protein sequence using NCBI protein BLAST revealed that it contains a conserved C-terminal C1q/TNFlike domain (http://blast.ncbi.nlm.nih.gov/Blast.cgi). This structure that is related to the globular head region of the complement $\mathrm{C} 1 \mathrm{q}$ protein is a highly conserved oligomerization motif and is known to bind to a variety of ligands(Carland and Gerwick, 2010; Kishore et al., 2004).

A

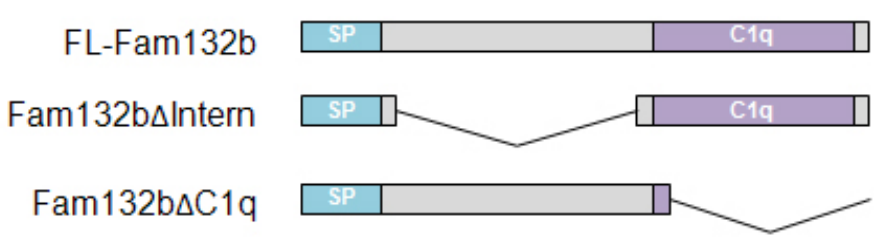

B

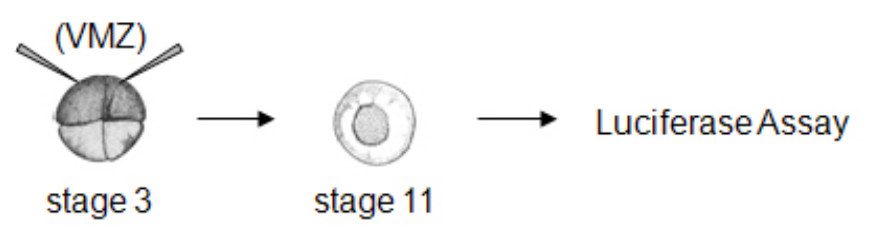

C

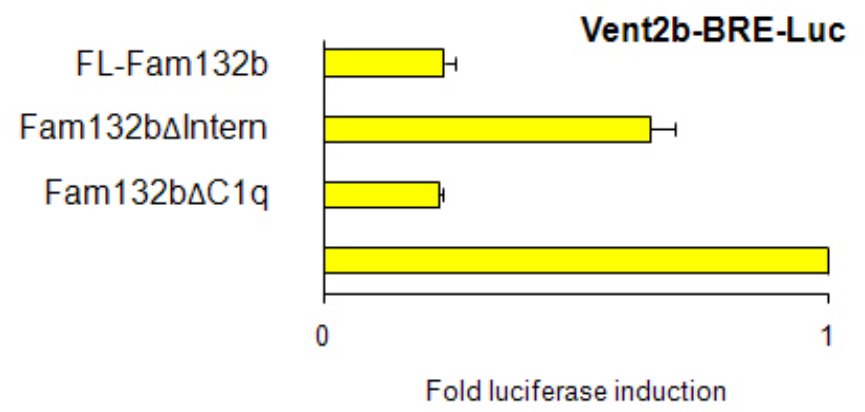

Figure 23. The Fam132b C1q domain is dispensable for Fam132b-mediated BMP antagonism. (A) Deletion mutants of XtFam132 lacking either the C1q domain or the internal region between signal peptide and C1q domaine were generated. (B) Xenopus embryos were injected at the 4-cell stage into the marginal zone of both ventral blastomeres and cultivated until stage 11 for luciferase assay. VMZ - ventral marginal zone. (C) Reporter gene activity stimulated by endogenous levels of BMP signaling is efficiently inhibited by FL-Fam132b and Fam 132b $\Delta C 1 \mathrm{q}$, but only moderately affected by expression of Fam $132 \mathrm{~b} \Delta$ ntern. The graphs summarize the results of 5 independent experiments; standard errors are indicated. Three samples containing 15 embryos each were analysed per experiment. $100 \mathrm{pg}$ of either FL-Fam132b, Fam132b $\Delta$ ntern, or Fam132b $\triangle C 1 \mathrm{q}$ mRNA were injected per embryo, as indicated. Vent2b-BRE-Luc reporter gene activity was normalized to Renilla reporter gene activity. Vent2b-BRELuc Reporter gene activity induced by endogenous BMP signaling was set to 1 . 
We asked if the BMP antagonizing function of Fam132b could be mediated via this protein domain. For this issue we generated Fam132b deletion mutants, lacking either the internal region or the C1q/TNF-like domain, and analyzed their activity in the luciferase assay (Figure $23 \mathrm{~A}$ ). mRNAs coding for full-length or mutant versions of Fam132b together with BMP-responsive Vent2b-BRE-Luc and BMP-independent CMV-Renilla reporter constructswere microinjected into both ventral blastomeres at the 4-cell-stage. Embryos were cultivated until gastrula stage and analyzed for luciferase activity (Figure 23B). Reporter gene activity, induced by endogenous BMP signaling, was efficiently blocked by injectionof either full-length Fam132b or Fam132b $\Delta \mathrm{C} 1 \mathrm{q}$, but only moderately upon injection of Fam132b $\Delta$ ntern (Figure 23C).

A

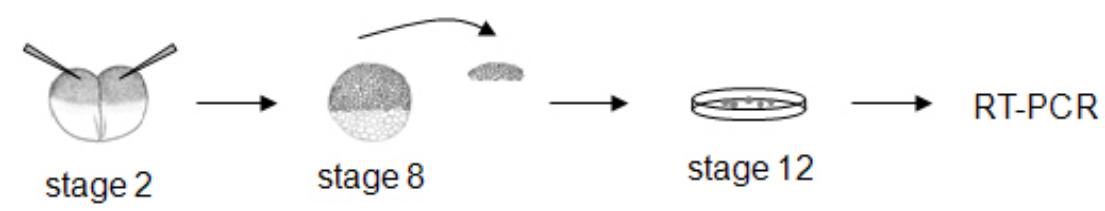

B

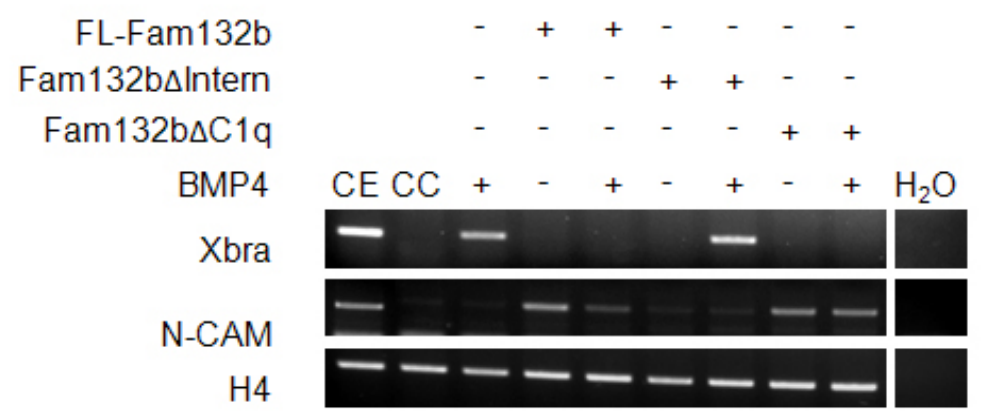

Figure 24. Fam132b amino-terminal domain is sufficient to block BMP signalingin animal cap cells. (A) Xenopus embryos were injected animally into both blastomeres at the 2-cell-stage, ectodermal animal cap tissue was dissected at stage 8 und cultivated until stage 12 for RT-PCR analysis. (B) FL-Fam132b and Fam132b $\Delta C 1 q$, but not Fam132b $\Delta$ ntern inhibit BMP4 induced Xbra expression and neuralize animal cap tissue. $1 \mathrm{ng}$ BMP4 and $100 \mathrm{pg}$ of either FL-Fam132b, Fam132b $\Delta$ ntern, or Fam132b $\triangle C 1 \mathrm{q}$ mRNA were injected per embryo, as indicated, and RNA extracts were analyzed by RT-PCR for Xbra and N-CAM expression. RT-PCR for histone H4 was included as loading control. CE - uninjected control embryo; CC - control animal cap tissue from uninjected embryos.

As a second assay, we analyzed the activity of the different Fam132b versions in respect to BMP4-mediated induction of Xbra expressionor endogenous BMP signaling activity in the animal cap system. Xenopus embryos were injected at 
the 2-cell stage with mRNAs coding for BMP4 and full-length or mutant versions of Fam132b. At blastula stage, animal ectodermal tissue was dissected and cultivated until gastrula stage for RT-PCR analysis (Figure 24A). Consistent with data from luciferase experiments, BMP4-mediated Xbra induction is repressed by expression of FL-Fam132b or Fam132b $\Delta C 1 q$. In addition, inhibition of endogenous and ectopic BMP signaling activity mediated by the same proteins results in activation of N-CAM expression. In contrast, expression of Fam132b $\Delta$ ntern does neither affect Xbra induction by BMP4 nor activate N-CAM expression (Figure 24B). These data suggest that the internal region of the Fam132b protein is sufficient to mediate its BMP antagonizing activity.

\subsection{The BMP antagonizing activity of Fam132b is not highly conserved}

The Fam132b protein is conserved within the vertebrate kingdom, according to information provided by $\mathrm{NCBI}$ database or Ensembl genome browser (http://www.ncbi.nlm.nih.gov/gquery/; http://www.ensembl.org).Thus, we asked if Fam132b protein function is also conserved in distantly related species. First we cloned Xenopus laevis Fam132b using 5'RACE and 3'RACE PCR. Sequence comparison between $X$. laevis and $X$. tropicalis Fam132b protein revealed that both proteins share $86 \%$ identity and therefore are highly conserved (Figure $25 \mathrm{C}$ ). For comparison of Xenopus Fam132b protein with those from other vertebrate species we used a multiple alignment, generated by DNASTAR Lasergene/MegAlign. General homology between these different vertebrate Fam132b proteins is low. However, conserved residues are moderately enriched in the C-terminal C1q/TNF-like domain. Seldin and colleagues described a motif of 6 collagenic repeats within the mouse myonectin/Fam132b protein (Seldin et al., 2012). This motif is highly conserved between human, rat, mouse, and zebrafish Fam132b proteins, but not the corresponding Xenopus sequence, where only two copies are present (Figure $25 \mathrm{~A})$.

Furthermore, we generated a phylogenetic tree and determined sequence identities to compare vertebrate Fam132b proteins (http://multalin. 
toulouse.inra.f/multalin/;http://imed.med.ucm.es/Tools/sias.html).General identities between Xenopus Fam132b proteins and those from other species did not exceed $30 \%$, while identity between mammalian proteins was higher than $70 \%$ (Figure $25 \mathrm{C}$ ). Correspondingly, a phylogenetic analysis illustrates that Xenopus Fam132b proteins are not closely related to Fam132b proteins derived from other vertebrate species (Figure $25 \mathrm{~B}$ ).

A

\begin{tabular}{|c|c|c|}
\hline & MDAEYKPI PLRCVLMAI SMAVLLI LLCAGPACTHKNRSF MF QDKA- VTVLPPQVI PRLTPPPEPLQRVPQLERPPWPPRD & \\
\hline X.pro & MDAEYKPI PLRCVLMTI SMGVLLI LF CAGPACTHKNRSF MF QVKP. VTVLPPLAI PRLTTPQESSEKVPRMERPPWPPKE & 79 \\
\hline Drpro & MKLRYGAFWALPALLLCLLLTT $\cdots$ CSTQDSEE $\cdots$ FTMERQEEN $\cdots \cdots \cdots \cdots$ STVSTESPDTVSSDI TPVSPHM & 61 \\
\hline Hs.pro & MAPARRPAGARLLLVYAGLLAAAAAGLGSPEPGAPSRSRARREPPPGNELPROPGESRAGPAARPPEPTAERAHSVDPRD & 80 \\
\hline Mm.pro & MASTRRPVGARTLLACASLLAA - MGL GVPESAEPVGTHARPQPP. GAELP....... APPANSPPEPTI AHAHSVDPRD & 70 \\
\hline Rn pro & MASTRSPGGARTLLACASLLAA- - MGL GVPESAEPVGT QARPQPP. GTELP $\cdots \cdots$ APPAHSPPEPTI AHAHSVDPRD & 70 \\
\hline tpro & SWL MLLKNSDRAPNSKKRQ - OEESLRPCRRGPI GSPAPAKQHSYN- PVLE - RKKLHHFLQLLSELLRRLNGERTEI SK & \\
\hline X.pro & SWL MLLKNSDRAPNGKKKS - OEESLRPCRRGPI GPPAPATHHSYS- PVLE- - RKKLHHFLQLLSELLRRLNGERTEMHK & \\
\hline Dr.pro & TW AF RDNYNKGGNKKPRQ - NKRLSKH JLPGPPGPPGPQGPPGPPGPLLPYHAEFI KDF OF KLKEMVG - ..... TYCV & \\
\hline Hs.pro & AVMLFVRQSDKGVNGKKRSRGKAKKLKF BLPGPPGPPGPQGPPGP. .1 | P. PEALLKEF OLLLKGAVRQRERAEPEPCT & \\
\hline Mm.pro & AWMLF VKQSOKGI NSKRRS - KARRLKL $3 L P G P P G P P G P Q G P P G P . \cdots$ F P. SEVLLKEF OLLLKGAVRQRESH. LEHCT & \\
\hline Rn.pro & AWMLFVKOSDKGI NSKKRSRTKARRLKL $\frac{\text { SLPGPPGPPGPQGPPGP. . . F P. SEVLLKEF OLLLKGAVRQRES. - TEHCT }}{6 \mathrm{Gly}-\mathrm{X}-\mathrm{Y}}$ & \\
\hline tepro & 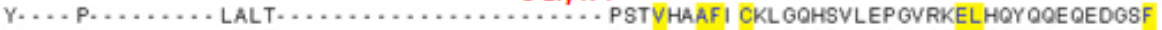 & \\
\hline X.pro & 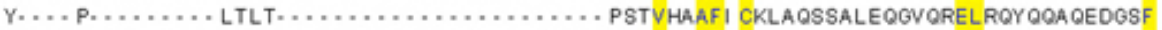 & \\
\hline Dr.pro & Y & \\
\hline Hs.pro & COPAGPVAASLAPVSATAGEDODDVVGDVLALLAAPLAPGPRAPRVEAAFLCRLRRDALVERRALHELGVYYLPDAEGAF & \\
\hline Mm.pro & ROLTTPASGSPSRVPAAOELDSQDP. GALLALLAATLAQGPRAPRVEAAF HCRLRROVQVDRRALLHELGI YYLPEVEGAF & 222 \\
\hline Rn pro & ROLTTPASGGPSRDPVTOELESQDQ- GAVLALLAATLAQSPRAPRVEAAFHCRLRRDV QVERRALHELGVYYLPEVEGAF & \\
\hline pro & & \\
\hline X.pro & N- RGAGLNLTI GRYTAPYSGL YAF NSRLNI GF OEHSPLDTTS - - GFLRAQVCI QSLCOKHLSLQOT SOI SGA & \\
\hline Drpro & HQRGQGF NI SSGRYTAPVSGFYQLSANLLLESNSESOKKAHGRQROSVRASI CI ESL CQSNVSLETVTGVSATGGVF SI L & 25 \\
\hline Hs.pro & R- RGPGLNLTSGQYRAPVAGFYALAATLHVALG- EPPRRGPPRPROHLRLLI CI QSRCQRNASLEAI MGLESSSELFTI S & \\
\hline Mm.pro & H. RGPGLNLTSGOYTAPVAGF YALAATLHVALT. EQPRKGPTRPRDRLRLLI CI OSLCOHNASLETVMOLENSSELFTI S & \\
\hline Rn.pro & R- RGPGLNLTSGQYTAPVAGF YALAATLHVALT- KQPRKGPPQPRDRLRLLI CI QSLCQHNASLETVMOLENSSELFTI \& & \\
\hline Xtpro & VHGVLYLQEGQ & \\
\hline XI.pro & VHOVLYLQEGQYVSVFLENRMSYPVVVEKGSEF SGVLLGOW & \\
\hline Dr.pro & LSGTLYLQAOEYVSI LI DNOT OSALTVLOOSLF SGI LI OV & \\
\hline Hs.pro & VNOVLYLQMOOWT SVF LDNASGCSLTVRSOSHF SAVLLGV & \\
\hline Mem.pro & VNGVLYLQAGHYTSVFLDNASGSSLTVRSGSHF SAI LLGL & \\
\hline Rn pro & VNOVLYLOT GHYTSVFLDNASGSSLTVRGGSHF SAI LLGL & \\
\hline
\end{tabular}

B

\section{C}
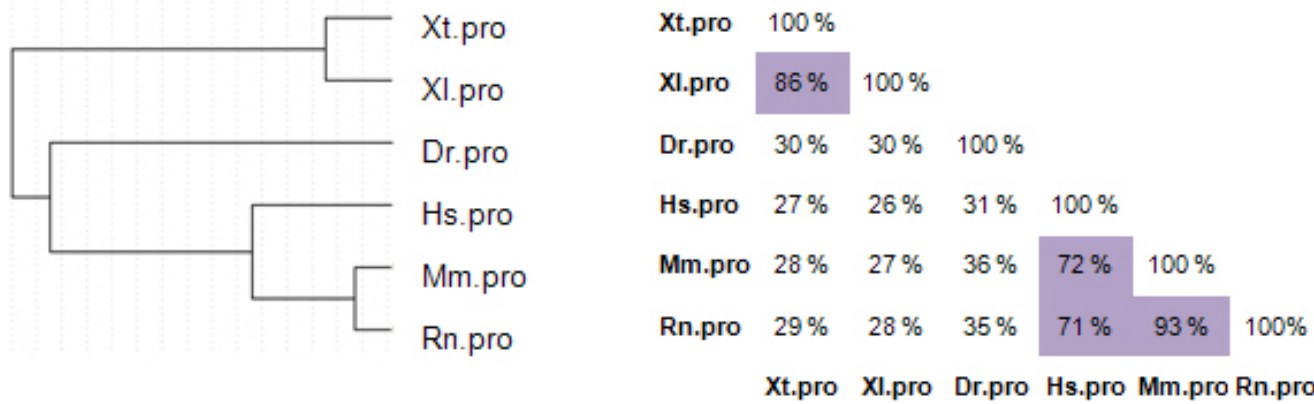

Figure 25. Sequence comparison of vertebrate Fam132b. (A) Sequence alignment of Fam132b protein sequences from Xenopus laevis, Xenopus tropicalis, zebrafish, human, mouse, and rat. The underlined C1q/TNF-like domain is moderately conserved in all species, whereas other regions of the protein are more divergent. Sequence alignment of putative Fam132b homologues was generated using ClustalW. Conserved residues are highlighted in yellow. The red box indicates the short collagen-like domain. (B-C) The Fam132b protein sequence is highly conserved between both Xenopus species, while highly divergent in comparison with other vertebrate species. (B) A phylogenetic tree of vertebrate Fam132b protein sequences was generated using MultAlign. (C) Overview of protein sequence identities between Fam132b proteins of 
different vertebrate species. Percentages were calculated using SIAS. High identity scores are highlighted in purple. Abbreviations and accession numbers of protein sequences: Xt.pro, Xenopus tropicalis (NP_001072387.1); XI.pro, Xenopus laevis; Dr.pro, Danio rerio (XP_002660750); Hs.pro, Homo sapiens (Q4G0M1.2); Mm.pro, Mus musculus (NP_775571); Rn.pro, Rattus norvegicus (XP_002727295).

In order to investigate if vertebrate Fam132b proteins are functionally related in respect to BMP antagonism, homologous Fam132b proteins were analyzed in the axis duplication assay. For this purpose, mRNAs coding for mouse, $X$. laevis, $X$. tropicalis or zebrafish Fam132b were injected marginally into 1 ventral blastomere at the 4-cell stage. At late tailbud stages embryos were scored for secondary axis formation (Figure 26 A). Expression of Xenopus Fam132b homologues strongly induces axis duplication, while neither zebrafish nor mouse Fam132b interfere with primary axis determination (Figure $26 \mathrm{~B}$ ).

Taken together, Fam132b protein sequence as well as protein function are only weakly conserved between Xenopus and other vertebrate species.

A

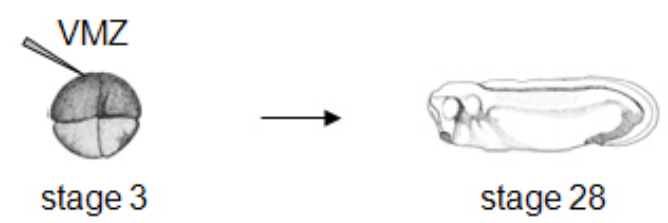

B

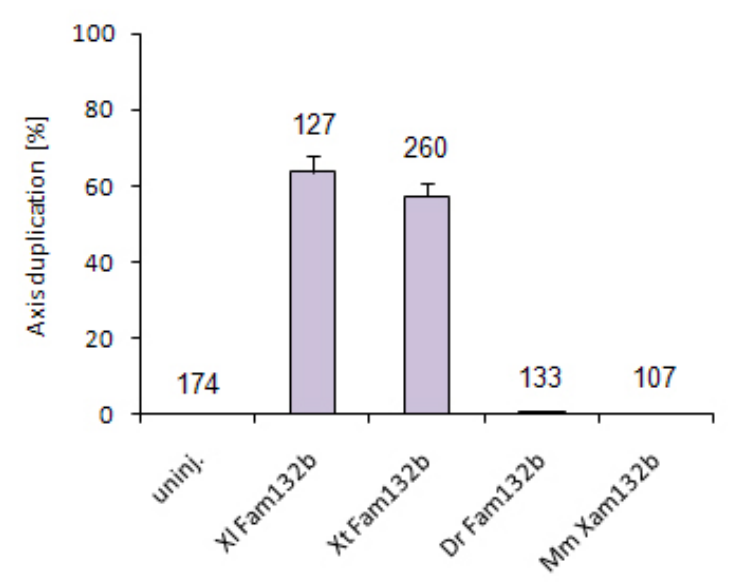

Figure 26. Xenopus but not mouse or zebrafish Fam123 can induce secondary axis formation. (A) Xenopus embryos were injected into the marginal zone of one ventral blastomere and cultivated until early tailbud stages. (B) Xenopus homologues of Fam132b induce a secondary body axis in Xenopus embryos. Quantification of embryos showing axis duplication phenotype. Graphs show the result of at least 2 independent experiments; standard errors are indicated. The number of analyzed 
embryos is indicated for each column. $50 \mathrm{pg}$ Xenopus laevis (XI) Fam132b, 50 pg Xenopus tropicalis (Xt) Fam132b, 500 pg Danio rerio (Dr) Fam132b and 500 pg Mus musculus $(\mathrm{Mm})$ Fam132b mRNA were injected per embryo.

\subsection{Fam132b is expressed in ventral blood islands and circulating blood cells}

Fam132b was isolated in from Xenopus tropicalis tadpole stage embryos, but a detailed analysis of the spatio-temporal expression pattern during Xenopus development had not been performed yet (Gilchrist et al., 2004). Therefore, we examined Fam132b expression in Xenopus laevis embryos at various developmental stages using whole-mount in situ hybridization (WMISH) andRTPCR.
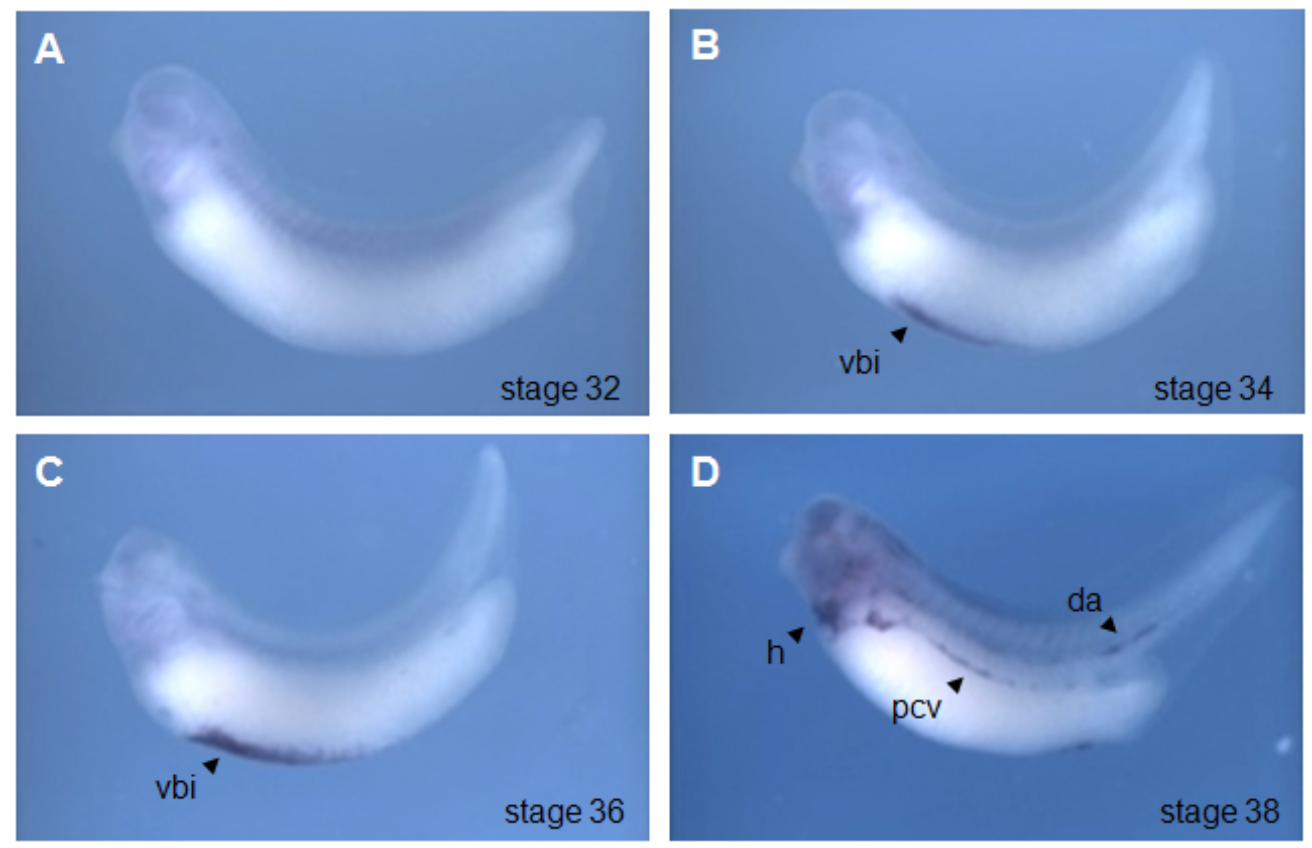

Figure 27. Fam132b is expressed in the VBI and in circulating blood cells.Transcripts of fam132bwere detected by Whole-mount in situ hybridization. Developmental stages of Xenopus laevis embryos are indicated at the lower right of each panel.Embryos are shown in a lateral view with anterior to the left. (A-B) fam132b transcripts are first detected at stage 34 in the ventral blood island (vbi). (D) The levels of fam132b in the VBI increase until stage 36. (E) By stage 38, Fam132b transcripts can be detected in circulating blood cells within the heart (h) and vascular structures such as the posterior cardinal vein (pcv) and the dorsal aorta (da).

Spatial expression of Fam132b was determined by WMISH. Fam132b transcripts were first detected at stage 34 in the anterior region of the ventral 
blood islands (VBI) (Fig 27 A, B). With further development this ventral expression domain expands towards the posterior portion of the ventral blood islands (Fig 27C). By stage 38 Fam132b transcripts are detected in circulating blood cells within the heart and the main vessels (Fig 27D).Expression of Fam132b in Xenopus laevis is consistent with that inXenopus tropicalis(data not shown).

A

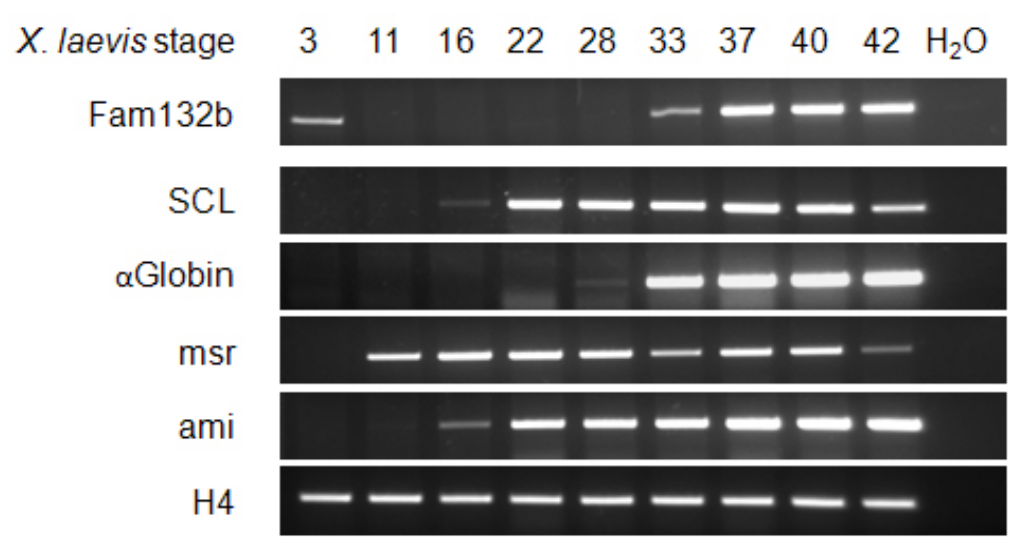

B
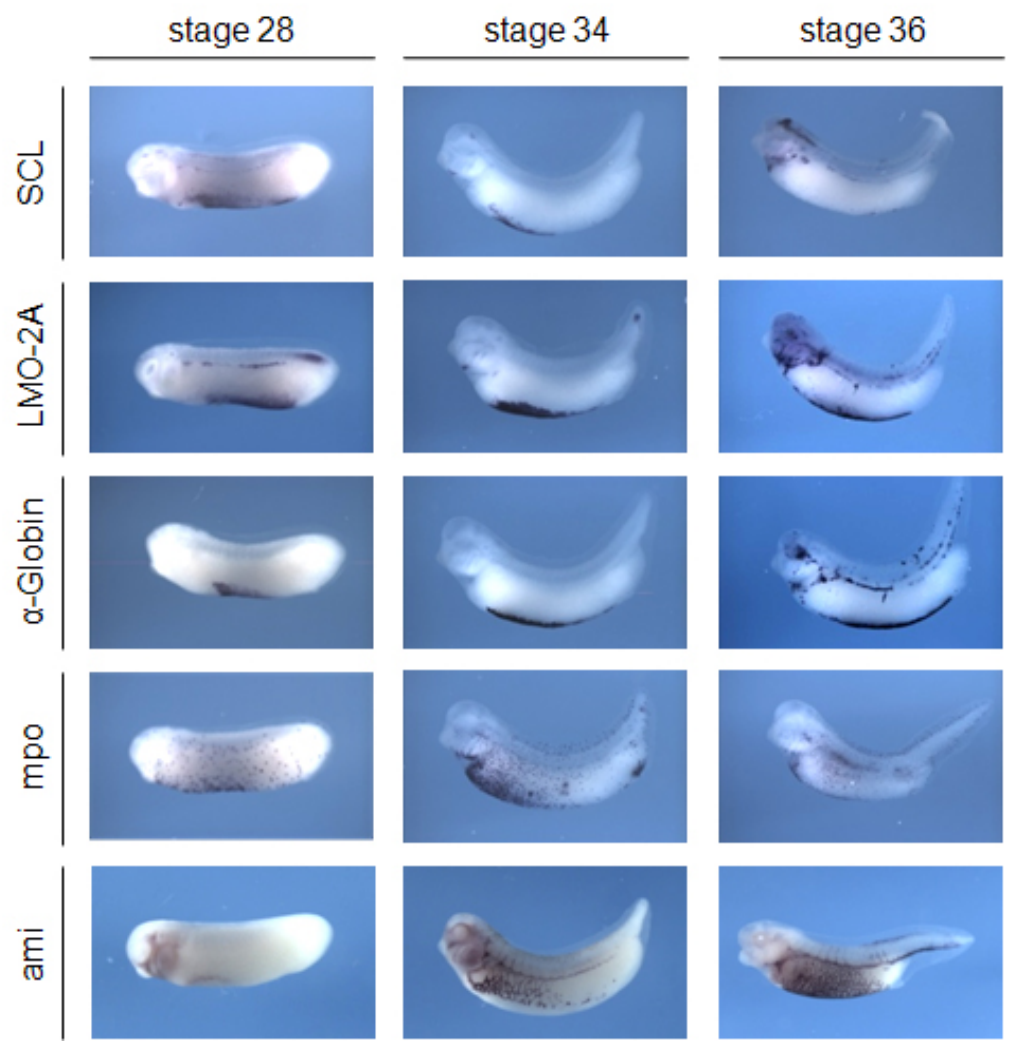

Figure 28. Fam132b is expressed in differentiated blood cells.(A) Fam132b is expressed maternally and later after the onset of aGlobin expression. RT-PCR analysis of the developmental stages indicated. Total RNA was harvested from staged embryos and subjected to RT-PCR using primer sets for Fam132b, the hematopoietic markers $\mathrm{SCL}$ and $\alpha$-Globin, and the vascular markers msr and ami, as indicated. RT-PCR for 
histone $\mathrm{H} 4$ was included as loading control. (B)Comparison of fam $132 b$ expression with that of hematopoietic and vascular marker genes indicates that Fam132b expression resembles the pattern of markers of the erythroid cell lineage, such as SCL, LMO2-A, and $a$-Globin. Fam132b expression is induced significantly later than that of a-Globin, indicating that fam $132 \mathrm{~b}$ is expressed in differentiated erythrocytes. Transcripts SCL, LMO2-A, $\alpha$-Globin,mpo and ami were detected by Whole-mount in situ hybridization, as indicated. Embryos are shown in lateral view with anterior to the left Developmental stages of Xenopus laevis embryos are indicated at the top of the panel.

RT-PCR revealed that Fam132b is expressed maternally. Zygotic transcripts are first detected at stage 33 and increase by stage 37 . Fam132b remains expressed until stage 42, the last stage tested in this experiment (Figure 28 A). Based on the finding that Fam132b is expressed in the VBI that represents the origin of embryonic blood and endothelial structures, we compared temporal expression of Fam132b with that of hematopoietic (SCL, $\alpha-$ Globin) and vascular (msr, ami) genes. We found that Fam132b is expressed shortly after hematopoietic and vascular differentiation marker gene expression, as shown by $a-G l o b i n$ and ami (Figure 28 A).Comparing the Fam132b expression pattern to those for known myeloid (mpo), erythroid (SCL, LMO2, $\alpha$-Globin) and vascular (ami) marker genes reveals that Fam132b expression resembles more the one of the erythroid rather than myeloid or vascular cell lineage (Fig 28 B). Taken together, these data reveal that Fam132b is expressed in differentiated, non-myeloid blood cells during Xenopus development.

\subsection{Etv2 induces Fam132b expression}

Etv2/er71 is a member of the ets-family of transcription factors. During Xenopus development it is mainly expressed in precursor cells of the hematopoietic and vascular lineage. Loss of function studies revealedthat Etv2/er71function is required for vasculogenesis, while being dispensable for hematopoiesis(Neuhaus et al., 2010; Salanga et al., 2010).Neuhaus and colleagues could show that Etv2/er71, overexpressed in Xenopus ectodermal explants, can induce the expression of both, hematopoietic and vascular marker genesfor specified and differentiated cells(Neuhaus et al., 2010). Fam132b expression was detected in the blood cell lineage, implicating a function for Fam132b during blood development in Xenopus (Figure 27 A-D). To 
investigate, if Fam132b is induced by Etv2/er71, we carried out RT-PCR analysis for Fam132b using cDNA from Etv2/er71 expressing animal cap explants of stage 14 and stage 36 (Figure 29 A). Indeed, Fam132b expression was induced by Etv2/er71 at stage 36, as observed for several other hematopoietic (SCL and $\alpha$-Globin) and vascular markers (msr and ami) markers (Figure29 B). Consistent with the data gained from the expression analysis, Fam132b is not expressed as early as the hematopoietic marker SCL (Fig 29 B). These data show that, like other factors that function during blood or vascular development, Fam132b is induced by Etv2/er71.

A

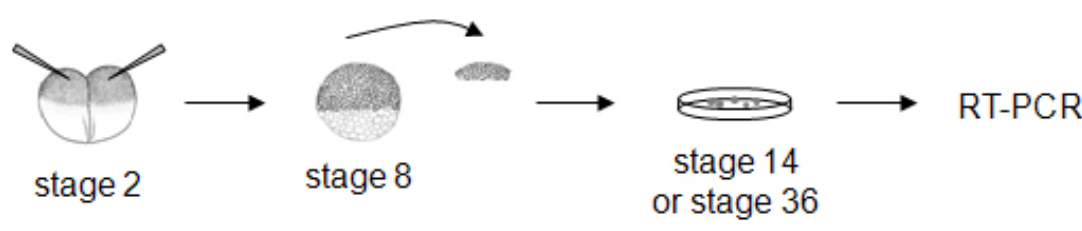

B

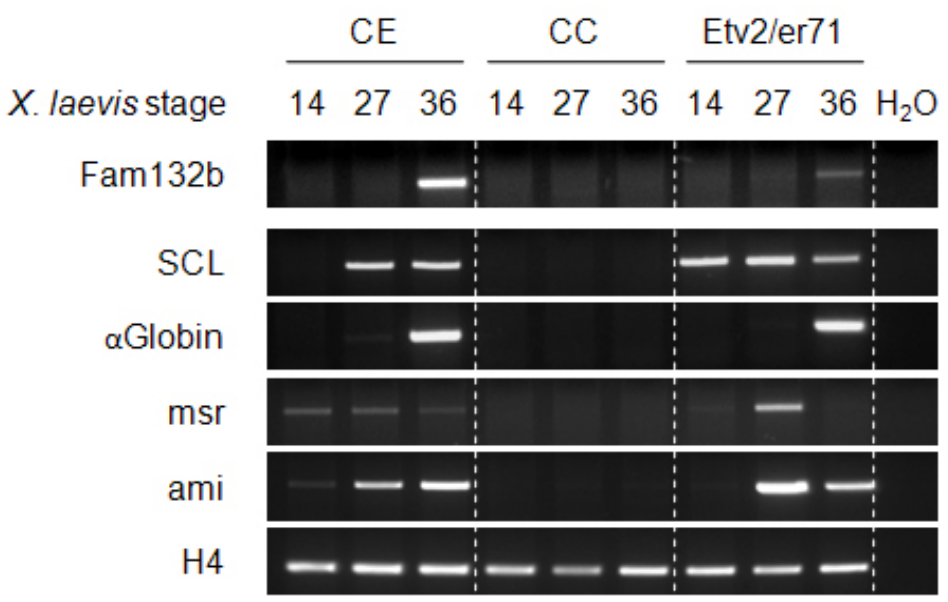

Figure 29. Overexpression of Etv2/er71 in animal caps induces expression of Fam132b. (A) Xenopus embryos were injected animally into both blastomeres at 2-cellstage, ectodermal animal cap tissue was dissected at stage 8 und cultivated until stage 14, 27 or 36 for RT-PCR analysis. (B) Expression of both hematopoietic (SCL and $\alpha$ Globin) and vascular (msr and ami) marker genes was induced by Er71/Etv2. Furthermore, Er71/Etv2 activates the transcription of Fam132b. 150 pg Er71/Etv2 mRNA was injected per embryo. RT-PCR for histone $\mathrm{H} 4$ was included as loading control. 


\subsection{Fam132b promotes vascular and suppresses hematopoietic development}

As shown above, Fam132b is expressed in the developing blood cell lineage of Xenopus embryos and is induced by Etv2/er71 in ectodermalXenopus explants (Figure 27 and Figure 29). These results seem to imply a function for Fam132b in the context of blood development. In order to test this further, we performed loss of function experiments. For this purpose, 2Fam132b antisense morpholino oligonucleotides were designed.These morpholinosare complementary to ashort sequences within the 5' untranslated region (UTR) or the coding sequence (CDS) of Fam132b mRNA, where they should bind and block Fam132b protein synthesis.

A

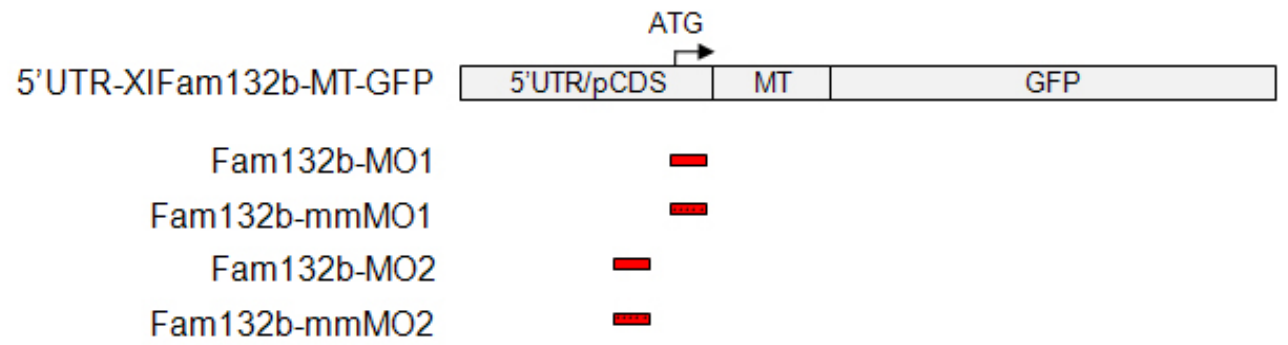

B

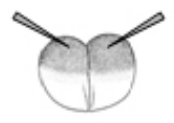

stage 2

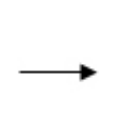

(1)

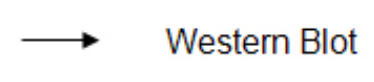

stage 11

C

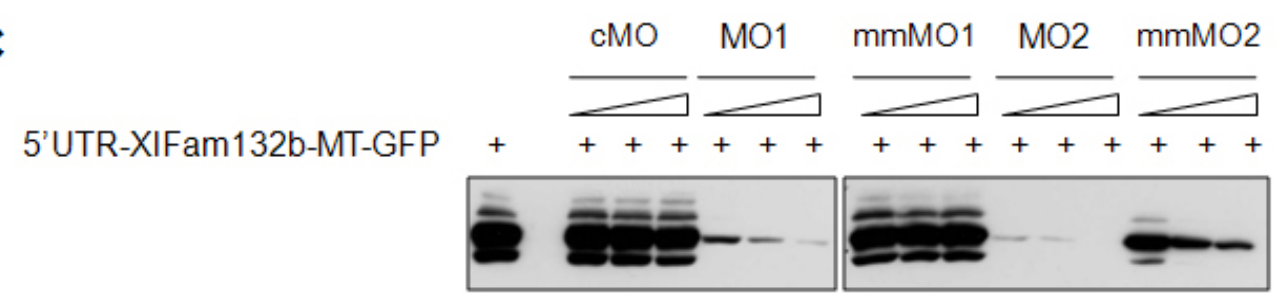

Figure 30. Fam132b MO1 and MO2 efficiently block reporter protein synthesis. (A) To test morpholino oligonucleotide (MO) activity, a reporter construct was generated, containing the Xenopus laevis Fam132b-5'untranslated region (UTR) anda part of the coding sequence (pCDS), fused to myc-epitope tag (MT) and GFP. Red bars indicate binding sites of the Fam132b MOs and mismatch (mm) MOs. (B) Xenopus embryos were injected animally into both blastomeres at the 2-cell-stage and cultivated until stage 11 for Western Blot analysis. (C) Both Fam132b MO1 and MO2 block translation of the reporter construct in a dose-dependent manner, while CMO and mmMO1 do not affect reporter protein synthesis. 200 pg 5'UTR-XIFam132b-MT-GFP mRNA was coinjected with $5 \mathrm{ng}, 10 \mathrm{ng}$, or $20 \mathrm{ng}$ morpholino per embryo, as indicated. Embryonic lysates were analyzed by Western Blot using antibodies anti MT. 
To ensure morpholino specificity, a contol morpholino (cMO) with irrelevant sequence or 5-base mismatch morpholinos (mmMO1/2) were used. These oligonucleotides should not bind and block translation of the corresponding target sequence. To test morpholino activity a reporter construct 5'UTRXIFam132b-MT-GFP was generated that contains morpholino binding sites, fused to myc-epitope tag (MT) and green fluorescent protein (GFP) (Figure 30 A). Reporter mRNA was injected together with different doses of morpholino oligonucleotides animally into both blastomeres of the 2-cell stage Xenopus embryo (Figure $30 \mathrm{~B}$ ). Western Blot analysis of injected gastrula stage embryos revealed that both Fam132b morpholino (MO) 1 and 2 efficiently block translation of the reporter protein in a dose-dependent manner, while cMO and mmMO1 do not affect protein synthesis (Figure $30 \mathrm{C}$ ). Although mmMO2 contained 5 mismatches, it still blocked reporter mRNA translation albeit at reduced efficiency(Figure $30 \mathrm{C}$ ). Additionally, we found MO1to block translation of a reporter constructthat lacks the morpholino binding sites,indicating that this morpholino unspecifically interfereswith protein synthesis (data not shown). Thus, MO1 and mmMO2 were not used for further Fam132b loss of function studies.

In order to test if Fam132b is needed for proper blood cell development, Fam132b MO2 and mmMO1 were injected ventrally and expression of the erythroid differentiation marker a-Globin was analyzed in whole embryos by WMISH at developmental stage 37/38. In this experiment, we did not observe any alteration in neither the level nor the distribution of $\alpha$-Globin transcripts (data not shown). However, morpholinos were injected at early cleavage stages while the onset of zygotic Fam132b expression does not occur before stage 33 (Figure 27). Thus, morpholino oligonucleotides might become toodiluted over time.

Therefore, we used a second assay for studying Fam132b activity during hematopoietic development and analyzed Fam132b loss of function as well as Fam132b gain of function in Etv2/er71 expressing animal cap explants. Correspondingly, Etv2/er71 mRNA was injected along with either Fam132b MO2 or mmMO1, or with Fam132b mRNA animally into both blastomeres of 2cell-stage Xenopus embryos. Animal cap tissue was explanted at stage 8 and ectodermal explants were cultivated until sibling control embryos reached stage 
37/38. After isolation of total RNA, gene expression was determined using Nanostring nCounter multiplex analysis (Figure $31 \mathrm{~A}$; for a complete list of genes analyzed see Appendix 6.1). In this process, individual mRNA transcripts are quantified without any amplification by hybridization with target-specific antisense RNA-probes, each labeled with a distinct code of fluorophores. Gene expression levels are determined by counting transcript-specific fluorescent signals (Geiss et al., 2008).

A

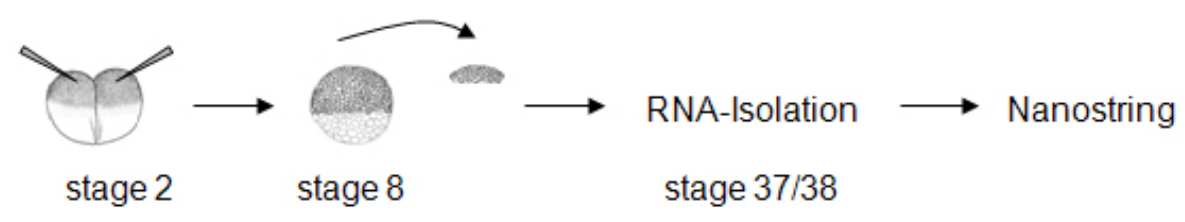

B

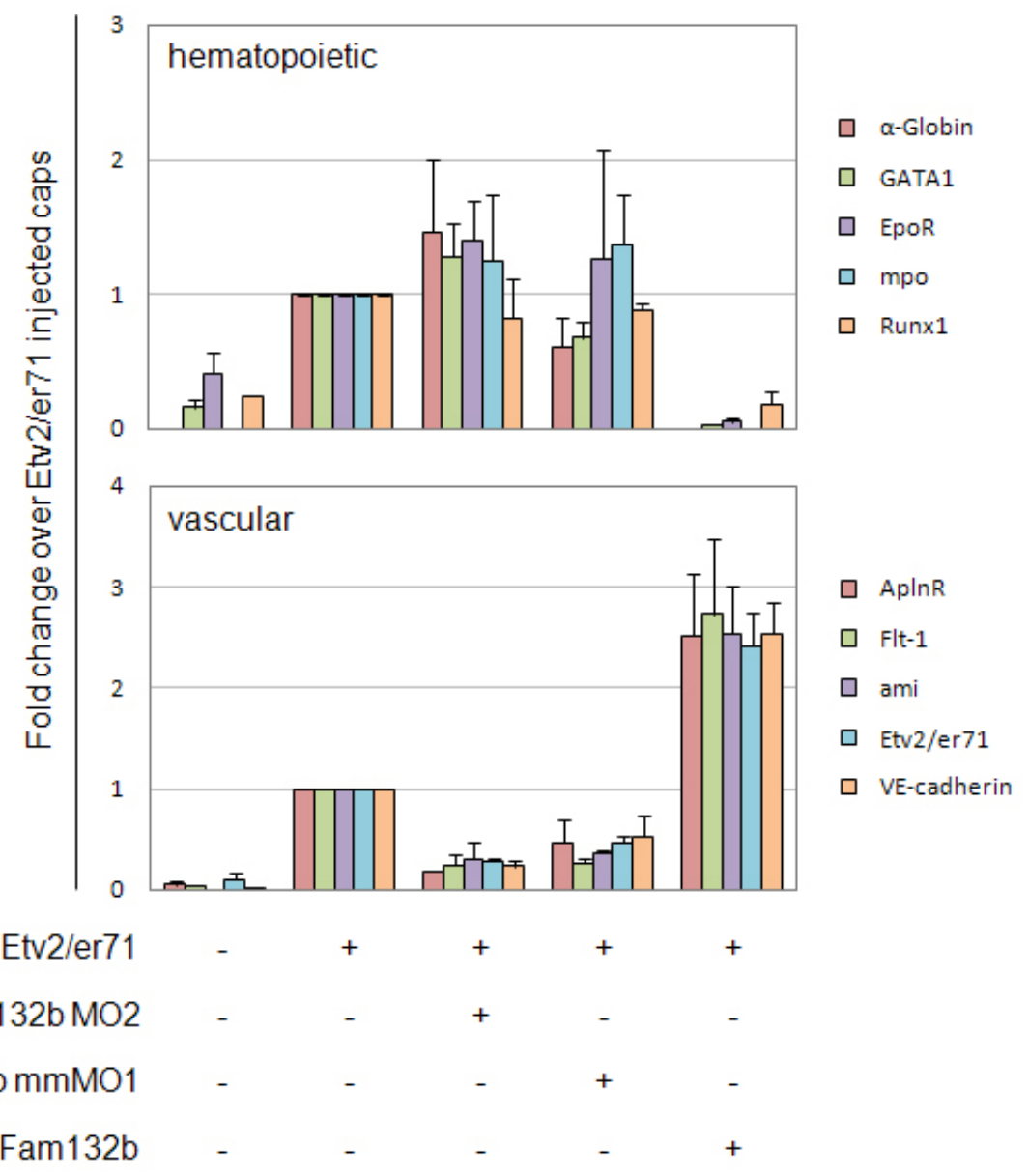

Figure 31. Fam132b enhances expression of vascular genes at the expense of blood markers. (A) Xenopus embryos were injected animally into both blastomeres at the 2-cell-stage, ectodermal animal cap tissue was dissected at stage 8 und cultivated until stage 37/38 for RNA isolation. Gene expression was analyzed using Nanostring nCounter analysis. (B-C) Shown are graphs of selected hematopoietic (B) and vascular (C) marker genes; for a full list see Appendix 6.3. The graphs show the averagedfold change over Etv2/er71 overexpressing caps from 2 independent experiments; standard 
errors are indicated.150 pg Er71/Etv2 and 150 pg Fam132b mRNA, and $10 \mathrm{ng}$ Fam132b MO2 or mmMO1 were injected, as indicated.

In this study, we analyzed the transcript levels of a set of genes which are expressed in differentiated blood or vascular cells (Figure 31 B and C). As described above, overexpression of Etv2/er71 inducesexpression of both hematopoietic and endothelial marker genes in animal cap cells (Figure 31 Aand B). Overexpression of Fam132b caused a strong decrease in expression of hematopoietic genes, such as a-Globin, Gata1, EpoR, mpo, and Runx1 (Figure 31 B). At the same time, vascular markers, such as Aplnr, Flt-1, ami, Etv2/er71, and VE-cadherin, were upregulated (Figure $31 \mathrm{C}$ ). In contrast, loss of Fam132b function using Fam132b MO2 caused a repression of Etv2/er71 inducedendothelial markers, while expression of hematopoietic genes was not significantly altered(Figure $31 \mathrm{~B}$ and $\mathrm{C}$ ). However, mmMO1 also affected vascular gene expression similar to $\mathrm{MO} 2$, at least partially.Taken together, our data suggest that Fam132b supports vascular development at the expense of the blood lineage. 


\section{Discussion}

\subsection{Modification of canonical Wnt signaling using GR-fusion constructs}

Previous studies have shown that canonical Wnt signaling activity has to be tightly regulated over time and space to allow proper organ development. For instance, we have shown that early inhibition of $\mathrm{Wnt} / \beta$-catenin signaling in the ventral pancreas is important to allow organ specification. In contrast, later during development proliferative stomach cells need high levels of canonical Wnt signaling (Damianitsch et al., 2009). These findings point to the importance of a tight temporal control of signaling modulations, if a specific developmental process has to be analyzed. For this reason, we generated a set of GR-fused putative Wnt/ $\beta$-Catenin signaling modulating factors and tested these for Dexamethosone inducibility as well as for their ability to activate or repress canonical Wnt signaling activity (Figure 9, Figure 10, and Figure 11). Surprisingly, we found that activity of only a small subset of these fusion proteins could be induced by Dexamethasone (Table 7). Multiple reports are available that describe the analysis of novel gene functions in the context of specific developmental processes using GR-fused proteins(De Rienzo et al., 2011; Domingos et al., 2001; Szeto et al., 2002; Tada et al., 1997). However, our data indicate that a careful functional analysis of GR-fusion protein inducibility in a well established and sensitive system is necessary to exclude unspecific protein activity.

To date, several studies have implicated canonical Wnt signaling in pancreatic development. Studies in mouse revealed that specification of pancreatic precursor cells needs low levels of nuclear $\beta$-catenin (Damianitsch et al., 2009; Heiser et al., 2006). Correspondingly, we found that early activation of canonical Wnt signaling causes a reduction of the dorsal pancreas, pointing to this inhibitory role of canonical Wnt signaling during pancreatic specification (Figure12), (Melchert, 2007). However, also late stimulation of Wnt signaling, that was discovered to enhance proliferation of the exocrine pancreatic 
compartment in the mouse, caused a loss of dorsal pancreas (Figure 12), (Heiser et al., 2006; Melchert, 2007; Murtaugh et al., 2005).

Additionally, McLin and colleagues postulated a model, in which Wnt/ 3 -Catenin signaling activity has to be low in the anterior and high in the posterior gut tube to allow specification of foregut and hindgut tissue, respectively (McLin et al., 2007). Correspondingly they could show that early ectopic activation of canonical Wnt signaling in the Xenopus anterior endoderm causes a repression of pancreatic marker gene expression in both dorsal and ventral pancreas. In contrast, repression of $\mathrm{Wnt} / \beta$-Catenin signaling in the posterior endoderm before neurulation induces ectopic expression of pancreatic genes in the hindgut (McLin et al., 2007). Contradictory to these data, we observed that early pan-endodermal repression of the Wnt signaling resulted in a reduction of the exocrine pancreatic compartment (Figure 12), (Forchmann, 2009). However, it is important to mention that we repressed Wnt signaling in the whole endoderm, resulting in the same level of signaling activity both anteriorly and posteriorly. In contrast, McLin and colleagues targeted Wnt repressors specifically to those blastomeres contributing to the posterior gut tissue only (McLin et al., 2007). Interestingly, Lyons and colleagues observed that both repression and hyperactivation of canonical Wnt signaling in the developing pronephros result in impaired pronephric tubulogenesis in Xenopus(Lyons et al., 2009).

Nevertheless, the observed phenotypes caused by overexpression of Wnt signaling modulating GR-fusion constructs were difficult to interpret, making it complicated to further analyze the role of canonical Wnt signaling in Xenopus endodermal development using these given tools.

\subsection{Fam132b, a novel BMP antagonist}

In this study, we have identified Fam132b as a novel antagonist of the BMP signaling pathway. To date, Fam132b has not been implicated in cell signaling and no function for Fam132b during development has been reported. Therefore, we are interested in investigating the mechanism by which Fam $132 \mathrm{~b}$ antagonizes BMP signaling activity. Multiple proteins are known to regulate BMP signaling by several different mechanisms, including those that affect the 
activity of either intracellular or extracellular mediators of the pathway (Ramel and Hill, 2012; Walsh et al., 2010).We could show that Fam132b is a secreted protein and that BMP signaling activity mediated by a constitutively active BMP type I receptor is not inhibited by Fam132b (Figure 20, Figure 21). Therefore, Fam132b most likely represents a novel extracellular BMP antagonist, rather than a pseudoreceptor or a cytoplasmic inhibitor of BMP signal transduction.

BMP signaling is initiated via formation of a heterohexameric complex between a BMP ligand dimer and BMP type I and type II receptors (Figure 32 A). To date, the most common extracellular mechanism of BMP inhibition is mediated by proteins such as Noggin, Chordin or members of the DAN family that directly bind to BMP ligands and thereby block BMP/receptor interaction (Gazzerro and Canalis, 2006; Piccolo et al., 1996; Smith and Harland, 1992). In this study, CoImmunoprecipitation experiments using epitope-tagged versions of Fam $132 \mathrm{~b}$ and BMP4 revealed that there is only weak interaction between these proteins, compared to the formation of the Noggin/BMP4 complex (Figure 22). Therefore, it remains unlikely that Noggin and Fam132b antagonize BMP signaling by the same mechanism.

A

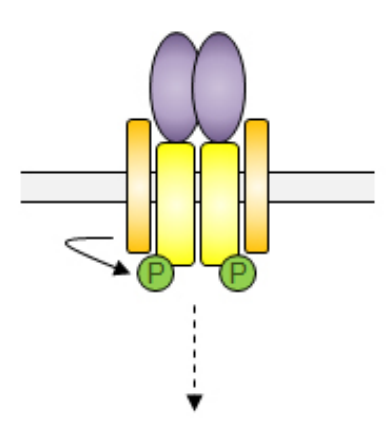

Target gene regulation
B C

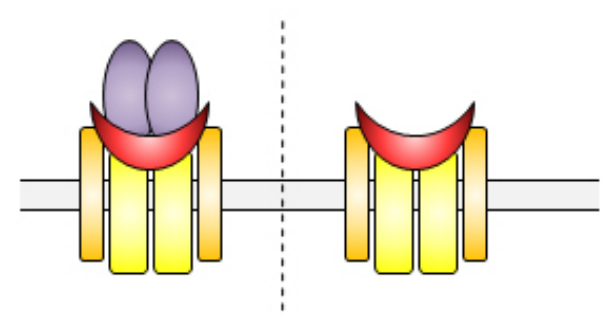

Figure 32. Model for Fam132b mediated BMP antagonism via receptor interaction. (A) Activation of the BMP signaling pathway. A BMP ligand dimer (purple) forms a heterohexameric complex with BMP type I (yellow) and type II receptors (orange) and autophosphorylation of the type I receptor is initiated. Activated type I receptors transduce the signal into the cell and trigger target gene regulation.(B-C) Fam132b (red) can bind to BMP type I receptors, suggesting different modes of action for Fam132b mediated BMP antagonism: (B) Fam132b binds the complex of BMP proteins and BMP receptors and inhibits signal transduction into the intracellular space. (C) Fam132b binds BMP receptors and blocks them from interacting with the BMP ligand. 
In contrast to those BMP binding proteins described above, Follistatin interacts directly with BMP but does not prevent BMP/receptor complex formation (lemura et al., 1998). Additionally, it was shown that Follistatin can interact with both type I and type II TGF- $\beta$ receptors (Thompson et al., 2005). We could show that Fam132b interacts with the BMP type I receptors Alk2 and Alk3, implying that Fam132b might inhibit the BMP pathway in a similar way as reported for Follistatin (Figure 22, Figure $32 \mathrm{~B}$ ).

However, ColP experiments revealed only weak interaction between BMP4 and Fam132b (Figure 22). Hence, we propose a mechanism for Fam132b antagonism in which Fam132b directly binds to the BMP receptor complex, blocking it from binding to the BMP ligand (Figure $32 \mathrm{C}$ ). A similar mode of action has already been described for other BMP antagonists, such as BMP-3 and inhibin. However, so far these proteins have been reported to interact with TGF- $\beta$ type II receptors (Gamer et al., 2005; Wiater and Vale, 2003). The question, if Fam132b interacts with BMP type II receptors as well, remains to be answered.

While Chordin and Noggin were shown to specifically antagonize BMP signaling activity, the majority of extracellular BMP antagonists, including BMP and receptorinteracting proteins, were shown to interfere with other pathways as well (Gamer et al., 2005; Gazzerro and Canalis, 2006; Harrison et al., 2006). Interestingly, we found that Fam132b neither inhibits activin nor FGF mediated signal transduction, indicating that this protein is a selective BMP antagonist (Figure 19).

\subsection{Fam132b, a member of the secreted C1q domain containing protein family}

Analysis of the Fam132b protein sequence revealed that Fam132b contains a C-terminal C1q/TNF-like domain (Figure 23). This structure is related to the Cterminal globular ligand binding domain of the complement factor C1q. The C1q protein is a key player in innate immunity and induces the classical pathway of the complement system by antigen binding via the globular $\mathrm{C} 1 \mathrm{q}$ domain. Subsequently, a cascade of proteolytic cleavages is induced, resulting in 
inflammatory response, phagocytosis or lysis of pathogenic cells (Janeway et al., 2001).

The globular C1q/TNF-like domain is not only found in the C1q protein itself, but also in C1q and TNF type protein families (Figure 33). This protein domain is characterized by the ability to fold into 5 pairs of anti-parallel $\beta$-strands forming a jelly roll beta barrel structure (Kishore et al., 2004). C1q- and TNF-like factors can be expressed as soluble plasma or membrane bound proteins and were shown to form oligomeric complexes with other members of the C1q/TNF-like superfamily (Schaffler and Buechler, 2012; Shapiro and Scherer, 1998). Members of this protein family exhibt a broad range of biological functions, including control of cell proliferation, apoptosis, energy homeostasis, and also inflammatory response.

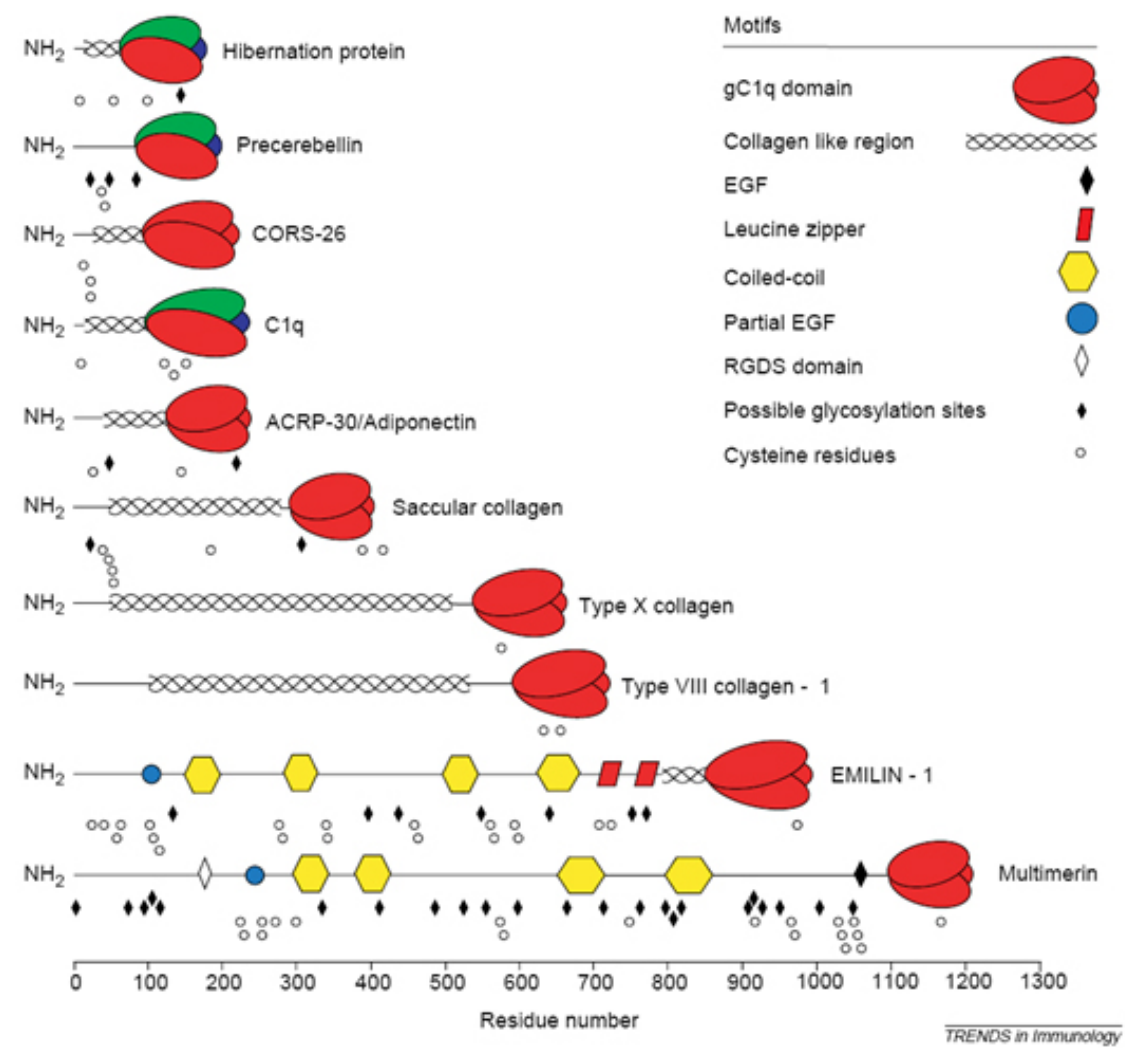

Figure 33. Cartoon depicting the structural motifs of the C1q family members. Proteins of the $\mathrm{C} 1 \mathrm{q}$ family have a C-terminal globular $\mathrm{C} 1 \mathrm{q}(\mathrm{gC} 1 \mathrm{q})$ domain and form homotrimeric (Adiponectin, Saccular collagen, Type VIII and X collagen, EMELIN-1 and multimerin) or heterotrimeric (Hibernation protein, Precerebellin and $\mathrm{C} 1 \mathrm{q}$ ) complexes. The majority of $\mathrm{C} 1 \mathrm{q}$-like proteins contain a collagen-like region, with the exception of precerebellin and multimerin. Elastin microfibril interface-located protein (EMELIN) contains two leucine zippers, while Multimerin has an RGDS motif. Both EMELIN-1 and Multimerin contain a partial epidermal growth factor (EGF)-like motif and are unique in 
forming coiled-coil structures. Many C1q-like proteins exhibit cysteine residues as well as possible glycosylation sites (from Kishore et al., 2004).

Furthermore, several members of these protein families have been implicated in cell signaling pathways, such as the MAPK pathway or NF-KB signaling(Kishore et al., 2004). However, a role for any of these factors in BMP antagonism, as observed for Xenopus Fam132b in the context of this study, has not been reportedso far. Interestingly, we found that the Fam132b C1q domain is dispensable for its BMP antagonizing function, suggesting that this structure might exhibit functions different from BMP inhibition (Figure 23, Figure 24).

Xenopus tropicalis Fam132b protein is predicted to share structural similarities with the secreted subfamily of $\mathrm{C} 1 \mathrm{q}$ domain containing proteins (sghC1q), such as Precerebellin (Figure 33). These are the $\mathrm{N}$-terminal signal peptide, the $\mathrm{C}$ terminal gC1q domain and the lack of an N-terminal collagen-like region (Figure 33), (Carland and Gerwick, 2010).Several studies in different fish species have described an increase in transcription of multiple sghc1q factors following an inflammatory stimulus (Carland and Gerwick, 2010; Gerwick et al., 2007; Gerwick et al., 2000; Nakamura et al., 2009).If Fam132b has a function during innate immune response was not analyzed.

Regarding database information, Fam132b homologues exist in different vertebrate species. But expression and function of this protein during development have not been described so far. However, a recent study delivered insight into the function of mouse Fam132b, termed myonectin/CTRP15, in tissue homeostasis. Seldin and colleagues found that the myokine myonectin is expressed and secreted predominantly by skeletal muscle of adult mice. The glycosylated protein can complex with other $\mathrm{C} 1 \mathrm{q}$ domain containing proteins and was shown to regulate fatty acid metabolism (Seldin et al., 2012). In Xenopus early embryonic development, Fam132b transcripts are not detected in myogenesis, and expression or function of Fam132b in the adult frog was not analyzed within this study.

Sequence comparison of Xenopus Fam132b with related proteins revealed that they share only moderate sequence identity, and the most considerable difference between these proteins was the presence of an amino-terminal collagen-like structure. Different from Xenopus Fam132b proteins, homologues from other species contained 5 to 6 repeats of the Gly-X-Y motif which form a 
collagen helix (Figure 25). Furthermore, both Xenopus laevis and Xenopus tropicalis Fam132b, but not homologues from mouse or zebrafish could induce secondary axis formation in Xenopus embryos (Figure 26). In conclusion, we do not expect the Xenopus Fam132b protein, analyzed in this study, to be the true functional homologue of mouse myonectin/Fam132b or the protein referred to as zebrafish Fam132b.

\subsection{The role of Fam132b during development of blood and vasculature}

BMP signaling has been shown to regulate hematopoiesis and development of the vascular system (Hartenstein, 2006; Lugus et al., 2005). In this study we identified Fam132b as a novel BMP antagonist which is expressed in the ventral blood islands and is induced by Etv2/er71, together with other markers of hematopoiesis and vasculogenesis (Figure 27, Figure 29). We found that coexpression of Fam132b with Etv2/er71 in animal cap explants caused a severe downregulation of Etv2/er71 induced hematopoietic genes (Figure 31 B). Interestingly, correlating observations have been made upon repression of endogenous or ectopic stimulation of BMP signaling activity in Xenopus embryos. While ectopic expression of BMP4 in animal cap explants induces stable expression of terminal erythroid differentiation markers, ventral mesodermal explants as a well as whole Xenopusembryos expressing a dominant negative BMP receptor loose the potential to activate the hematopoietic program (Maeno et al., 1994; Zhang and Evans, 1996). Initially, this loss of hematopoietic lineage was thought to be a result of impaired specification of ventral mesoderm, which is induced by high levels of BMP signaling and mainly contributes to the primitive erythroid compartment (Dale and Wardle, 1999; Dosch et al., 1997). However, using conditional inhibition of BMP signaling in Xenopus embryos Schmerer and Evans could show that BMP signaling is required for primitive erythroid cell differentiation, independent of any early requirement for cell specification (Schmerer and Evans, 2003).

In this study, we generated hemangioblast like cells by overexpression of Etv2/er71 in pluripotent Xenopus animal cap tissue. Given that Fam132b considerably antagonizes BMP signaling activity, we suggest a model in which 
ectopically expressed Fam132b interferes with the pro-hematopoietic activity of BMP signaling in the context of hemangioblast development into either endothelial or blood cells (Figure 34).

However, knockdown of Fam132b in Etv2/er71 expressing animal cap explants did not cause a significant upregulation of hematopoietic gene expression (Figure $31 \mathrm{~B}$ ). This result correlates with the finding that endogenous Fam132b is induced relatively late in Etv2/er71 expressing animal cap explants (Figure 29). In addition, Fam132b expression in the whole embryo was first detected after blood cell differentiation (Figure28), making it unlikely that regulation of hematopoietic or endothelial cell fate decision is indeed the endogenous function of Fam132b. Therefore, it would be interesting to analyze hematopoietic gene expression in Etv2/er71 expressing animal cap tissuetreated with recombinant Fam132b protein at later developmental stages.

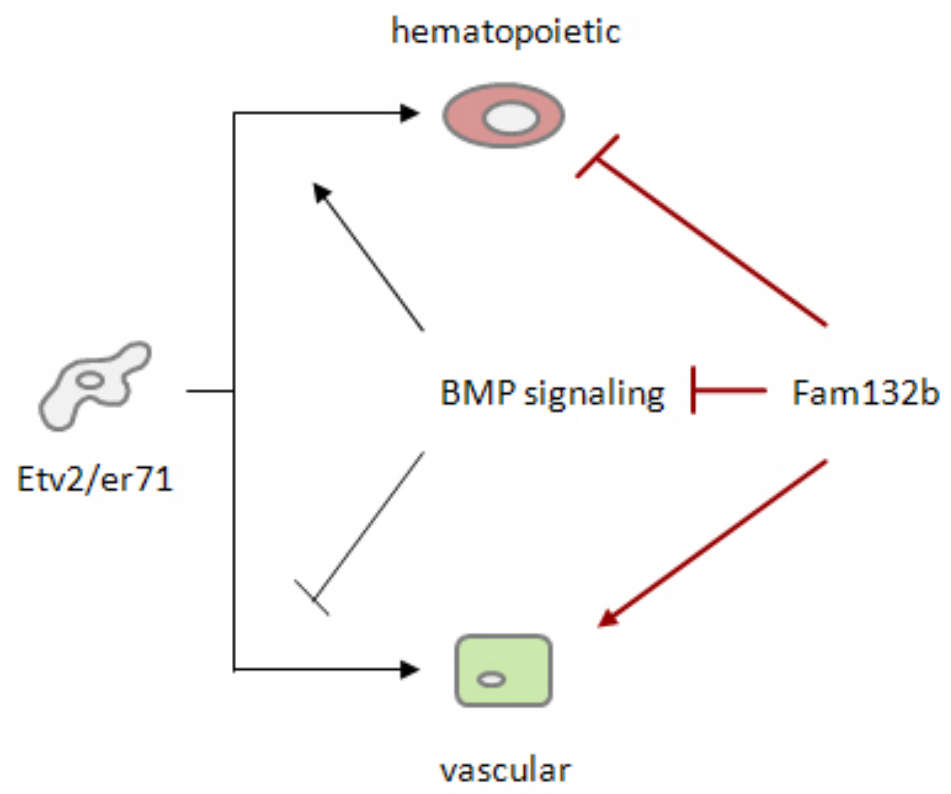

Figure 34. Model for Fam132b activity in the context of cell fate determination in Etv2/er71 expressing animal cap cells. Etv2/er71 induces either hematopoietic or vascular cell fate. Fam132b represses blood cell development while promoting vascular fate, possibly by inhibition of BMP signaling activity or by using an alternative mechanism.

BMP signaling activity does not only regulate the development of the hematopoietic cell lineage but is also relevant in the formation of endothelial structures. For instance, Walmsley and colleagues could show, that Xfli-1 expression was activated in the XenopusaVBI, but not maintained in the 
absence of BMP signaling activity (Walmsley et al., 2002). Consistant with these data,studies in mouse revealed that a loss ofthe BMP signal transducer Smad5 allows the formation of a primitive vascular plexus but a mature vascular network is not established(Chang et al., 1999; Yang et al., 1999). Furthermore, recent studies demonstrated that ectopic BMP signaling in endothelial cells inhibits the expression of apelin, a secreted factor that signals via its receptor $\mathrm{APJ} / \mathrm{Xmsr}$ and stimulates proliferation and migration of endothelial cells during angiogenesis (Ciais and Bailly, 2012; Larrivee et al., 2012; Poirier et al., 2012; Ricard et al., 2012). Taken together, these data suggest a biphasic role for BMP signaling during vascular development. While the pathway has to be downregulated within the early phase of vasculogenesis, BMP signaling activity is necessary for proper maturation of the vascular system.

We could show that Fam132b gain of function in Etv2/er71 expressing animal cap cells severely enhanced the expression of endothelial genes (Figure $31 \mathrm{C}$ ). We conclude that, in this experimental system, Fam132b promotes the development of the vascular compartment at the expense of the hematopoietic cell lineage and that this regulatory function could be mediated by its BMP antagonizing activity (Figure 34).

However, although Fam132b loss of function did not significantly alter hematopoietic gene expression, transcript levels of vascular markers were at least 2 fold decreased upon Fam132b morpholino injection (Figure 31). Given thatFam132b induction by Etv2/er71 in animal cap explantsoccurs long after endothelial cell specification (Figure 29), we suggest that Fam132b promotes endothelial development by a mechanism other than regulation of cell fate decision. For instance, Fam132b might be involved in regulation of endothelial cell fate maintenance.

Functional analysis of Fam132b in the context of blood and endothelial development was carried out in Etv2/er71 overexpressing animal cap explants which reflect an artificial system. However, it is reasonable to study protein activity in the whole embryo. But so far, loss of Fam132b function using microinjection of morpholino oligotides did not affect hematopoietic or vascular development in Xenopus embryos. The absence of a knockdown phenotype might be due to the late expression of Fam132b (Figure 27, Figure 28). Morpholino mediated knockdown of gene expression represents a satisfying 
tool for investigation of gene activity during early developmental processes. However, this system is limited, if late developmental processes are analyzed, since morpholinos are diluted with every cell cleavage. Alternatively, targeted gene disruption using engineered transcription activator-like effector nucleases (TALENs) was shown to be a very efficient tool for loss of function studies in rat and zebrafish, but also in Xenopus(Huang et al., 2011; Lei et al., 2012; Tesson et al., 2011). Therefore, TALENs approach will be used in future experiments to study the endogenous function of Fam132b in Xenopus development. 


\section{Conclusion}

In this study, $13 \mathrm{GR}$-fusion constructs were tested for their potential to modulate canonical Wnt signaling and for hormone-inducibility. However, only 4 of them showed the expected phenotype and were used for endodermal overexpression. Since both activation and repression of Wnt signaling caused the same reduction of exocrine pancreas we proceeded with expression cloning to investigate novel regulators of canonical Wnt signaling. Interestingly, in this screen we identified Fam132b as a novel extracellular BMP antagonist that selectively inhibits BMP signaling probably by binding to the BMP receptor. Previous studies have reported that regulation of BMP signaling activity is very important for development of the blood circulatory system. We found that Fam132b is expressed in the blood and vessel forming compartment during Xenopus development and that Fam132b regulates development of hematopoietic and endothelial cells in Xenopus tissue culture. Many studies have focused on early processes in the context of hematopoiesis and vasculogenesis, while later developmental events are only poorly characterized in Xenopus. We observed that Fam132b is expressed during this late developmental phase and it will be interesting to further investigate the function of this putative novel regulator in development of the blood circulatory system in Xenopus. 


\section{Bibliography}

Aberle, H., Bauer, A., Stappert, J., Kispert, A., Kemler, R., 1997. beta-catenin is a target for the ubiquitin-proteasome pathway. The EMBO journal 16, 3797-3804.

Afelik, S., Chen, Y., Pieler, T., 2004. Pancreatic protein disulfide isomerase (XPDIp) is an early marker for the exocrine lineage of the developing pancreas in Xenopus laevis embryos. Gene expression patterns : GEP 4, 71-76.

Agius, E., Oelgeschlager, M., Wessely, O., Kemp, C., De Robertis, E.M., 2000. Endodermal Nodal-related signals and mesoderm induction in Xenopus. Development 127, 1173-1183.

Amit, S., Hatzubai, A., Birman, Y., Andersen, J.S., Ben-Shushan, E., Mann, M., Ben-Neriah, Y., Alkalay, I., 2002. Axin-mediated CKI phosphorylation of beta-catenin at Ser 45: a molecular switch for the Wnt pathway. Genes \& development 16, 1066-1076.

Angers, S., Moon, R.T., 2009. Proximal events in Wnt signal transduction. Nature reviews. Molecular cell biology 10, 468-477.

Aramaki, T., Sasai, N., Yakura, R., Sasai, Y., 2010. Jiraiya attenuates BMP signaling by interfering with type II BMP receptors in neuroectodermal patterning. Developmental cell 19, 547-561.

Baker, N.E., 1987. Molecular cloning of sequences from wingless, a segment polarity gene in Drosophila: the spatial distribution of a transcript in embryos. The EMBO journal 6, 1765-1773.

Baron, M., 2001. Induction of embryonic hematopoietic and endothelial stem/progenitor cells by hedgehog-mediated signals. Differentiation; research in biological diversity 68, 175-185.

Behrens, J., von Kries, J.P., Kuhl, M., Bruhn, L., Wedlich, D., Grosschedl, R., Birchmeier, W., 1996. Functional interaction of beta-catenin with the transcription factor LEF-1. Nature 382, 638-642.

Bhanot, P., Brink, M., Samos, C.H., Hsieh, J.C., Wang, Y., Macke, J.P., Andrew, D., Nathans, J., Nusse, R., 1996. A new member of the frizzled family from Drosophila functions as a Wingless receptor. Nature 382, 225-230.

Bharathy, S., Xie, W., Yingling, J.M., Reiss, M., 2008. Cancer-associated transforming growth factor beta type II receptor gene mutant causes activation of bone morphogenic proteinSmads and invasive phenotype. Cancer research 68, 1656-1666.

Blitz, I.L., Cho, K.W., 2009. Finding partners: how BMPs select their targets. Developmental dynamics : an official publication of the American Association of Anatomists 238, 1321-1331.

Boisset, J.C., van Cappellen, W., Andrieu-Soler, C., Galjart, N., Dzierzak, E., Robin, C., 2010. In vivo imaging of haematopoietic cells emerging from the mouse aortic endothelium. Nature 464, 116-120.

Botchkarev, V.A., Sharov, A.A., 2004. BMP signaling in the control of skin development and hair follicle growth. Differentiation; research in biological diversity 72, 512-526.

Brack, A.S., Murphy-Seiler, F., Hanifi, J., Deka, J., Eyckerman, S., Keller, C., Aguet, M., Rando, T.A., 2009. BCL9 is an essential component of canonical Wnt signaling that mediates the differentiation of myogenic progenitors during muscle regeneration. Developmental biology 335, 93-105.

Bracken, C.M., Mizeracka, K., McLaughlin, K.A., 2008. Patterning the embryonic kidney: BMP signaling mediates the differentiation of the pronephric tubules and duct in Xenopus laevis. Developmental dynamics : an official publication of the American Association of Anatomists 237, 132-144.

Brannon, M., Gomperts, M., Sumoy, L., Moon, R.T., Kimelman, D., 1997. A beta-catenin/XTcf-3 complex binds to the siamois promoter to regulate dorsal axis specification in Xenopus. Genes \& development 11, 2359-2370.

Candia, A.F., Watabe, T., Hawley, S.H., Onichtchouk, D., Zhang, Y., Derynck, R., Niehrs, C., Cho, K.W., 1997. Cellular interpretation of multiple TGF-beta signals: intracellular antagonism between activin/BVg1 and BMP-2/4 signaling mediated by Smads. Development 124, 44674480 . 
Carland, T.M., Gerwick, L., 2010. The C1q domain containing proteins: Where do they come from and what do they do? Developmental and comparative immunology 34, 785-790.

Cavallo, R.A., Cox, R.T., Moline, M.M., Roose, J., Polevoy, G.A., Clevers, H., Peifer, M., Bejsovec, A., 1998. Drosophila Tcf and Groucho interact to repress Wingless signalling activity. Nature 395, 604-608.

Chang, H., Huylebroeck, D., Verschueren, K., Guo, Q., Matzuk, M.M., Zwijsen, A., 1999. Smad5 knockout mice die at mid-gestation due to multiple embryonic and extraembryonic defects. Development 126, 1631-1642.

Chen, D., Zhao, M., Mundy, G.R., 2004. Bone morphogenetic proteins. Growth factors 22, 233241.

Chen, G., Deng, C., Li, Y.P., 2012. TGF-beta and BMP signaling in osteoblast differentiation and bone formation. International journal of biological sciences 8, 272-288.

Chen, W., ten Berge, D., Brown, J., Ahn, S., Hu, L.A., Miller, W.E., Caron, M.G., Barak, L.S., Nusse, R., Lefkowitz, R.J., 2003. Dishevelled 2 recruits beta-arrestin 2 to mediate Wnt5Astimulated endocytosis of Frizzled 4. Science 301, 1391-1394.

Chen, X., Weisberg, E., Fridmacher, V., Watanabe, M., Naco, G., Whitman, M., 1997. Smad4 and FAST-1 in the assembly of activin-responsive factor. Nature 389, 85-89.

Choi, K., Kennedy, M., Kazarov, A., Papadimitriou, J.C., Keller, G., 1998. A common precursor for hematopoietic and endothelial cells. Development 125, 725-732.

Ciais, D., Bailly, S., 2012. BMPs go for apelin to regulate angiogenesis. Focus on "Inhibition of apelin expression by BMP signaling in endothelial cells". American journal of physiology. Cell physiology 303, C1127-1128.

Ciau-Uitz, A., Liu, F., Patient, R., 2010. Genetic control of hematopoietic development in Xenopus and zebrafish. The International journal of developmental biology 54, 1139-1149.

Ciau-Uitz, A., Walmsley, M., Patient, R., 2000. Distinct origins of adult and embryonic blood in Xenopus. Cell 102, 787-796.

Cleaver, O., Krieg, P.A., 1998. VEGF mediates angioblast migration during development of the dorsal aorta in Xenopus. Development 125, 3905-3914.

Clement, J.H., Fettes, P., Knochel, S., Lef, J., Knochel, W., 1995. Bone morphogenetic protein 2 in the early development of Xenopus laevis. Mechanisms of development 52, 357-370.

Clevers, H., Nusse, R., 2012. Wnt/beta-catenin signaling and disease. Cell 149, 1192-1205.

Constam, D.B., Robertson, E.J., 1999. Regulation of bone morphogenetic protein activity by pro domains and proprotein convertases. The Journal of cell biology 144, 139-149.

Costa, R.M., Soto, X., Chen, Y., Zorn, A.M., Amaya, E., 2008. spib is required for primitive myeloid development in Xenopus. Blood 112, 2287-2296.

Croce, J.C., McClay, D.R., 2008. Evolution of the Wnt pathways. Methods Mol Biol 469, 3-18.

Crosier, P.S., Kalev-Zylinska, M.L., Hall, C.J., Flores, M.V., Horsfield, J.A., Crosier, K.E., 2002. Pathways in blood and vessel development revealed through zebrafish genetics. The International journal of developmental biology 46, 493-502.

Cui, Y., Jean, F., Thomas, G., Christian, J.L., 1998. BMP-4 is proteolytically activated by furin and/or PC6 during vertebrate embryonic development. The EMBO journal 17, 4735-4743.

Dale, L., Wardle, F.C., 1999. A gradient of BMP activity specifies dorsal-ventral fates in early Xenopus embryos. Seminars in cell \& developmental biology 10, 319-326.

Daly, A.C., Randall, R.A., Hill, C.S., 2008. Transforming growth factor beta-induced Smad1/5 phosphorylation in epithelial cells is mediated by novel receptor complexes and is essential for anchorage-independent growth. Molecular and cellular biology 28, 6889-6902.

Damianitsch, K., 2008. Die Funktion des Wnt Antagonisten XsFRP5 während der frühembryonalen Musterbildung des Entoderms in Xenopus laevis. Doktorarbeit, Universität Göttingen, Göttingen.

Damianitsch, K., Melchert, J., Pieler, T., 2009. XsFRP5 modulates endodermal organogenesis in Xenopus laevis. Developmental biology 329, 327-337. 
Dann, C.E., Hsieh, J.C., Rattner, A., Sharma, D., Nathans, J., Leahy, D.J., 2001. Insights into Wnt binding and signalling from the structures of two Frizzled cysteine-rich domains. Nature 412, 86-90.

De Rienzo, G., Bishop, J.A., Mao, Y., Pan, L., Ma, T.P., Moens, C.B., Tsai, L.H., Sive, H., 2011. Disc1 regulates both beta-catenin-mediated and noncanonical Wnt signaling during vertebrate embryogenesis. FASEB journal : official publication of the Federation of American Societies for Experimental Biology 25, 4184-4197.

Denayer, T., Locker, M., Borday, C., Deroo, T., Janssens, S., Hecht, A., van Roy, F., Perron, M., Vleminckx, K., 2008. Canonical Wnt signaling controls proliferation of retinal stem/progenitor cells in postembryonic Xenopus eyes. Stem cells 26, 2063-2074.

Dessimoz, J., Bonnard, C., Huelsken, J., Grapin-Botton, A., 2005. Pancreas-specific deletion of beta-catenin reveals Wnt-dependent and Wnt-independent functions during development. Current biology : CB 15, 1677-1683.

Domingos, P.M., Itasaki, N., Jones, C.M., Mercurio, S., Sargent, M.G., Smith, J.C., Krumlauf, R., 2001. The Wnt/beta-catenin pathway posteriorizes neural tissue in Xenopus by an indirect mechanism requiring FGF signalling. Developmental biology 239, 148-160.

Dosch, R., Gawantka, V., Delius, H., Blumenstock, C., Niehrs, C., 1997. Bmp-4 acts as a morphogen in dorsoventral mesoderm patterning in Xenopus. Development 124, 2325-2334.

Dosch, R., Niehrs, C., 2000. Requirement for anti-dorsalizing morphogenetic protein in organizer patterning. Mechanisms of development 90, 195-203.

Ehrlich, M., Horbelt, D., Marom, B., Knaus, P., Henis, Y.I., 2011. Homomeric and heteromeric complexes among TGF-beta and BMP receptors and their roles in signaling. Cellular signalling 23, 1424-1432.

Fagotto, F., Guger, K., Gumbiner, B.M., 1997. Induction of the primary dorsalizing center in Xenopus by the Wnt/GSK/beta-catenin signaling pathway, but not by Vg1, Activin or Noggin. Development 124, 453-460.

Fainsod, A., Deissler, K., Yelin, R., Marom, K., Epstein, M., Pillemer, G., Steinbeisser, H., Blum, M., 1997. The dorsalizing and neural inducing gene follistatin is an antagonist of BMP-4. Mechanisms of development 63, 39-50.

Fiedler, M., Mendoza-Topaz, C., Rutherford, T.J., Mieszczanek, J., Bienz, M., 2011. Dishevelled interacts with the DIX domain polymerization interface of Axin to interfere with its function in down-regulating beta-catenin. Proceedings of the National Academy of Sciences of the United States of America 108, 1937-1942.

Forchmann, A.C.F., 2009. Bedeutung des $\beta$-Catenin abhängigen Wnt-Signalweges in der Musterbildung des primitiven Darmrohres in Xenopus laevis. . Bachelorarbeit, Universität Göttingen, Göttingen.

Funayama, N., Fagotto, F., McCrea, P., Gumbiner, B.M., 1995. Embryonic axis induction by the armadillo repeat domain of beta-catenin: evidence for intracellular signaling. The Journal of cell biology 128, 959-968.

Gamer, L.W., Nove, J., Levin, M., Rosen, V., 2005. BMP-3 is a novel inhibitor of both activin and BMP-4 signaling in Xenopus embryos. Developmental biology 285, 156-168.

Gazzerro, E., Canalis, E., 2006. Bone morphogenetic proteins and their antagonists. Reviews in endocrine \& metabolic disorders 7, 51-65.

Ge, G., Greenspan, D.S., 2006. Developmental roles of the BMP1/TLD metalloproteinases. Birth defects research. Part C, Embryo today : reviews 78, 47-68.

Ge, G., Hopkins, D.R., Ho, W.B., Greenspan, D.S., 2005. GDF11 forms a bone morphogenetic protein 1-activated latent complex that can modulate nerve growth factor-induced differentiation of PC12 cells. Molecular and cellular biology 25, 5846-5858.

Geiss, G.K., Bumgarner, R.E., Birditt, B., Dahl, T., Dowidar, N., Dunaway, D.L., Fell, H.P., Ferree, S., George, R.D., Grogan, T., James, J.J., Maysuria, M., Mitton, J.D., Oliveri, P., Osborn, J.L., Peng, T., Ratcliffe, A.L., Webster, P.J., Davidson, E.H., Hood, L., Dimitrov, K., 2008. Direct 
multiplexed measurement of gene expression with color-coded probe pairs. Nature biotechnology 26, 317-325.

Geng, Y., Dong, Y., Yu, M., Zhang, L., Yan, X., Sun, J., Qiao, L., Geng, H., Nakajima, M., Furuichi, T., Ikegawa, S., Gao, X., Chen, Y.G., Jiang, D., Ning, W., 2011. Follistatin-like 1 (Fstl1) is a bone morphogenetic protein (BMP) 4 signaling antagonist in controlling mouse lung development. Proceedings of the National Academy of Sciences of the United States of America 108, 70587063.

Gerwick, L., Corley-Smith, G., Bayne, C.J., 2007. Gene transcript changes in individual rainbow trout livers following an inflammatory stimulus. Fish \& shellfish immunology 22, 157-171.

Gerwick, L., Reynolds, W.S., Bayne, C.J., 2000. A precerebellin-like protein is part of the acute phase response in rainbow trout, Oncorhynchus mykiss. Developmental and comparative immunology 24, 597-607.

Ghogomu, S.M., van Venrooy, S., Ritthaler, M., Wedlich, D., Gradl, D., 2006. HIC-5 is a novel repressor of lymphoid enhancer factor/T-cell factor-driven transcription. The Journal of biological chemistry 281, 1755-1764.

Gilchrist, M.J., Zorn, A.M., Voigt, J., Smith, J.C., Papalopulu, N., Amaya, E., 2004. Defining a large set of full-length clones from a Xenopus tropicalis EST project. Developmental biology 271, 498-516.

Graff, J.M., Thies, R.S., Song, J.J., Celeste, A.J., Melton, D.A., 1994. Studies with a Xenopus BMP receptor suggest that ventral mesoderm-inducing signals override dorsal signals in vivo. Cell 79, 169-179.

Grammer, T.C., Liu, K.J., Mariani, F.V., Harland, R.M., 2000. Use of large-scale expression cloning screens in the Xenopus laevis tadpole to identify gene function. Developmental biology 228, 197-210.

Guo, X., Wang, X.F., 2009. Signaling cross-talk between TGF-beta/BMP and other pathways. Cell research 19, 71-88.

Habas, R., Dawid, I.B., 2005. Dishevelled and Wnt signaling: is the nucleus the final frontier? Journal of biology $4,2$.

Haramoto, Y., Tanegashima, K., Onuma, Y., Takahashi, S., Sekizaki, H., Asashima, M., 2004. Xenopus tropicalis nodal-related gene 3 regulates BMP signaling: an essential role for the proregion. Developmental biology 265, 155-168.

Harland, R.M., 1991. In situ hybridization: an improved whole-mount method for Xenopus embryos. Methods in cell biology 36, 685-695.

Harlow, E., Lane, D, 1988. Antibodies - A Laboratory Manual. Cold Spring Harbor Laboratory Press, New York.

Harrison, C.A., Chan, K.L., Robertson, D.M., 2006. Activin-A binds follistatin and type II receptors through overlapping binding sites: generation of mutants with isolated binding activities. Endocrinology 147, 2744-2753.

Hartenstein, V., 2006. Blood cells and blood cell development in the animal kingdom. Annual review of cell and developmental biology 22, 677-712.

Hata, A., Lagna, G., Massague, J., Hemmati-Brivanlou, A., 1998. Smad6 inhibits BMP/Smad1 signaling by specifically competing with the Smad4 tumor suppressor. Genes \& development 12, 186-197.

Hata, A., Seoane, J., Lagna, G., Montalvo, E., Hemmati-Brivanlou, A., Massague, J., 2000. OAZ uses distinct DNA- and protein-binding zinc fingers in separate BMP-Smad and Olf signaling pathways. Cell 100, 229-240.

Heiser, P.W., Lau, J., Taketo, M.M., Herrera, P.L., Hebrok, M., 2006. Stabilization of betacatenin impacts pancreas growth. Development 133, 2023-2032.

Hemmati-Brivanlou, A., Kelly, O.G., Melton, D.A., 1994. Follistatin, an antagonist of activin, is expressed in the Spemann organizer and displays direct neuralizing activity. Cell 77, 283-295. 
Henningfeld, K.A., Rastegar, S., Adler, G., Knochel, W., 2000. Smad1 and Smad4 are components of the bone morphogenetic protein-4 (BMP-4)-induced transcription complex of the Xvent-2B promoter. The Journal of biological chemistry 275, 21827-21835.

Hirschi, K.K., 2012. Hemogenic endothelium during development and beyond. Blood 119, 4823-4827.

Hollemann, T., Pieler, T., 1999. Xpitx-1: a homeobox gene expressed during pituitary and cement gland formation of Xenopus embryos. Mechanisms of development 88, 249-252.

Hsu, D.R., Economides, A.N., Wang, X., Eimon, P.M., Harland, R.M., 1998. The Xenopus dorsalizing factor Gremlin identifies a novel family of secreted proteins that antagonize BMP activities. Molecular cell 1, 673-683.

Huang, P., Xiao, A., Zhou, M., Zhu, Z., Lin, S., Zhang, B., 2011. Heritable gene targeting in zebrafish using customized TALENs. Nature biotechnology 29, 699-700.

Huber, T.L., Zon, L.I., 1998. Transcriptional regulation of blood formation during Xenopus development. Seminars in immunology 10, 103-109.

lemura, S., Yamamoto, T.S., Takagi, C., Uchiyama, H., Natsume, T., Shimasaki, S., Sugino, H., Ueno, N., 1998. Direct binding of follistatin to a complex of bone-morphogenetic protein and its receptor inhibits ventral and epidermal cell fates in early Xenopus embryo. Proceedings of the National Academy of Sciences of the United States of America 95, 9337-9342.

Imamura, T., Takase, M., Nishihara, A., Oeda, E., Hanai, J., Kawabata, M., Miyazono, K., 1997. Smad6 inhibits signalling by the TGF-beta superfamily. Nature 389, 622-626.

Inui, M., Asashima, M., 2006. A novel gene, Ami is expressed in vascular tissue in Xenopus laevis. Gene expression patterns : GEP 6, 613-619.

Isaacs, H.V., Pownall, M.E., Slack, J.M., 1994. eFGF regulates Xbra expression during Xenopus gastrulation. The EMBO journal 13, 4469-4481.

Janeway, C.A., Travers, P., Walport, M., 2001. Immunobiology: The Immune System in Health and Disease. New York: Garland Science 5th edition.

Jin, W., Yun, C., Kim, H.S., Kim, S.J., 2007. TrkC binds to the bone morphogenetic protein type II receptor to suppress bone morphogenetic protein signaling. Cancer research 67, 9869-9877.

Kau, C.L., Turpen, J.B., 1983. Dual contribution of embryonic ventral blood island and dorsal lateral plate mesoderm during ontogeny of hemopoietic cells in Xenopus laevis. Journal of immunology 131, 2262-2266.

Kavsak, P., Rasmussen, R.K., Causing, C.G., Bonni, S., Zhu, H., Thomsen, G.H., Wrana, J.L., 2000. Smad7 binds to Smurf2 to form an E3 ubiquitin ligase that targets the TGF beta receptor for degradation. Molecular cell 6, 1365-1375.

Kennedy, M., D'Souza, S.L., Lynch-Kattman, M., Schwantz, S., Keller, G., 2007. Development of the hemangioblast defines the onset of hematopoiesis in human ES cell differentiation cultures. Blood 109, 2679-2687.

Kim, R.H., Wang, D., Tsang, M., Martin, J., Huff, C., de Caestecker, M.P., Parks, W.T., Meng, X., Lechleider, R.J., Wang, T., Roberts, A.B., 2000. A novel smad nuclear interacting protein, SNIP1, suppresses p300-dependent TGF-beta signal transduction. Genes \& development 14, 16051616.

Kishore, U., Gaboriaud, C., Waters, P., Shrive, A.K., Greenhough, T.J., Reid, K.B., Sim, R.B., Arlaud, G.J., 2004. C1q and tumor necrosis factor superfamily: modularity and versatility. Trends in immunology 25, 551-561.

Kissa, K., Herbomel, P., 2010. Blood stem cells emerge from aortic endothelium by a novel type of cell transition. Nature 464, 112-115.

Kohn, A.D., Moon, R.T., 2005. Wnt and calcium signaling: beta-catenin-independent pathways. Cell calcium 38, 439-446.

Kumano, G., Belluzzi, L., Smith, W.C., 1999. Spatial and temporal properties of ventral blood island induction in Xenopus laevis. Development 126, 5327-5337.

Laemmli, U.K., 1970. Cleavage of structural proteins during the assembly of the head of bacteriophage T4. Nature 227, 680-685. 
Lamb, T.M., Knecht, A.K., Smith, W.C., Stachel, S.E., Economides, A.N., Stahl, N., Yancopolous, G.D., Harland, R.M., 1993. Neural induction by the secreted polypeptide noggin. Science 262, 713-718.

Larrivee, B., Prahst, C., Gordon, E., del Toro, R., Mathivet, T., Duarte, A., Simons, M., Eichmann, A., 2012. ALK1 signaling inhibits angiogenesis by cooperating with the Notch pathway. Developmental cell 22, 489-500.

Lee, H.X., Ambrosio, A.L., Reversade, B., De Robertis, E.M., 2006. Embryonic dorsal-ventral signaling: secreted frizzled-related proteins as inhibitors of tolloid proteinases. Cell 124, 147159.

Lee, M.K., Pardoux, C., Hall, M.C., Lee, P.S., Warburton, D., Qing, J., Smith, S.M., Derynck, R., 2007. TGF-beta activates Erk MAP kinase signalling through direct phosphorylation of ShcA. The EMBO journal 26, 3957-3967.

Lei, Y., Guo, X., Liu, Y., Cao, Y., Deng, Y., Chen, X., Cheng, C.H., Dawid, I.B., Chen, Y., Zhao, H., 2012. Efficient targeted gene disruption in Xenopus embryos using engineered transcription activator-like effector nucleases (TALENs). Proceedings of the National Academy of Sciences of the United States of America 109, 17484-17489.

Levine, A.J., Munoz-Sanjuan, I., Bell, E., North, A.J., Brivanlou, A.H., 2003. Fluorescent labeling of endothelial cells allows in vivo, continuous characterization of the vascular development of Xenopus laevis. Developmental biology 254, 50-67.

Li, V.S., Ng, S.S., Boersema, P.J., Low, T.Y., Karthaus, W.R., Gerlach, J.P., Mohammed, S., Heck, A.J., Maurice, M.M., Mahmoudi, T., Clevers, H., 2012. Wnt signaling through inhibition of betacatenin degradation in an intact Axin1 complex. Cell 149, 1245-1256.

Liu, C., Li, Y., Semenov, M., Han, C., Baeg, G.H., Tan, Y., Zhang, Z., Lin, X., He, X., 2002. Control of beta-catenin phosphorylation/degradation by a dual-kinase mechanism. Cell 108, 837-847.

Liu, F., Pouponnot, C., Massague, J., 1997. Dual role of the Smad4/DPC4 tumor suppressor in TGFbeta-inducible transcriptional complexes. Genes \& development 11, 3157-3167.

Liu, I.M., Schilling, S.H., Knouse, K.A., Choy, L., Derynck, R., Wang, X.F., 2009. TGFbetastimulated Smad1/5 phosphorylation requires the ALK5 L45 loop and mediates the promigratory TGFbeta switch. The EMBO journal 28, 88-98.

Liu, X., Wang, L., Zhao, K., Thompson, P.R., Hwang, Y., Marmorstein, R., Cole, P.A., 2008. The structural basis of protein acetylation by the p300/CBP transcriptional coactivator. Nature 451, 846-850.

Lugus, J.J., Park, C., Choi, K., 2005. Developmental relationship between hematopoietic and endothelial cells. Immunologic research 32, 57-74.

Lyons, J.P., Miller, R.K., Zhou, X., Weidinger, G., Deroo, T., Denayer, T., Park, J.I., Ji, H., Hong, J.Y., Li, A., Moon, R.T., Jones, E.A., Vleminckx, K., Vize, P.D., McCrea, P.D., 2009. Requirement of $\mathrm{Wnt} /$ beta-catenin signaling in pronephric kidney development. Mechanisms of development 126, 142-159.

MacDonald, B.T., Tamai, K., He, X., 2009. Wnt/beta-catenin signaling: components, mechanisms, and diseases. Developmental cell 17, 9-26.

Maeno, M., Komiyama, K., Matsuzaki, Y., Hosoya, J., Kurihara, S., Sakata, H., Izutsu, Y., 2012. Distinct mechanisms control the timing of differentiation of two myeloid populations in Xenopus ventral blood islands. Development, growth \& differentiation 54, 187-201.

Maeno, M., Ong, R.C., Suzuki, A., Ueno, N., Kung, H.F., 1994. A truncated bone morphogenetic protein 4 receptor alters the fate of ventral mesoderm to dorsal mesoderm: roles of animal pole tissue in the development of ventral mesoderm. Proceedings of the National Academy of Sciences of the United States of America 91, 10260-10264.

Mao, J., Wang, J., Liu, B., Pan, W., Farr, G.H., 3rd, Flynn, C., Yuan, H., Takada, S., Kimelman, D., $\mathrm{Li}, \mathrm{L} ., \mathrm{Wu}, \mathrm{D} ., 2001$. Low-density lipoprotein receptor-related protein-5 binds to Axin and regulates the canonical Wnt signaling pathway. Molecular cell 7, 801-809.

Martin, C.S., Moriyama, A., Zon, L.I., 2011. Hematopoietic stem cells, hematopoiesis and disease: lessons from the zebrafish model. Genome medicine 3, 83. 
Massague, J., 1998. TGF-beta signal transduction. Annual review of biochemistry 67, 753-791. Massague, J., Seoane, J., Wotton, D., 2005. Smad transcription factors. Genes \& development 19, 2783-2810.

McLin, V.A., Rankin, S.A., Zorn, A.M., 2007. Repression of Wnt/beta-catenin signaling in the anterior endoderm is essential for liver and pancreas development. Development 134, 22072217.

Mead, P.E., Deconinck, A.E., Huber, T.L., Orkin, S.H., Zon, L.I., 2001. Primitive erythropoiesis in the Xenopus embryo: the synergistic role of LMO-2, SCL and GATA-binding proteins. Development 128, 2301-2308.

Melchert, J., 2007. Die Rolle der kanonischen Wnt Signaltransduktion bei der Differenzierung des Gastrointestinaltrakts in Xenopus laevis. Diplomarbeit, Universität Göttingen, Göttingen.

Misra, K., Matise, M.P., 2010. A critical role for sFRP proteins in maintaining caudal neural tube closure in mice via inhibition of BMP signaling. Developmental biology 337, 74-83.

Miyazono, K., Kamiya, Y., Morikawa, M., 2010. Bone morphogenetic protein receptors and signal transduction. Journal of biochemistry 147, 35-51.

Molenaar, M., van de Wetering, M., Oosterwegel, M., Peterson-Maduro, J., Godsave, S., Korinek, V., Roose, J., Destree, O., Clevers, H., 1996. XTcf-3 transcription factor mediates betacatenin-induced axis formation in Xenopus embryos. Cell 86, 391-399.

Morin, P.J., Sparks, A.B., Korinek, V., Barker, N., Clevers, H., Vogelstein, B., Kinzler, K.W., 1997. Activation of beta-catenin-Tcf signaling in colon cancer by mutations in beta-catenin or APC. Science 275, 1787-1790.

Moustakas, A., Heldin, C.H., 2009. The regulation of TGFbeta signal transduction. Development 136, 3699-3714.

Muraoka, O., Shimizu, T., Yabe, T., Nojima, H., Bae, Y.K., Hashimoto, H., Hibi, M., 2006. Sizzled controls dorso-ventral polarity by repressing cleavage of the Chordin protein. Nature cell biology 8, 329-338.

Murray, P., 1932. The development in vitro of the blood of early chick embryo. Proc. Roy. Soc. London 11, 497-521.

Murtaugh, L.C., Law, A.C., Dor, Y., Melton, D.A., 2005. Beta-catenin is essential for pancreatic acinar but not islet development. Development 132, 4663-4674.

Nakamura, O., Wada, Y., Namai, F., Saito, E., Araki, K., Yamamoto, A., Tsutsui, S., 2009. A novel C1q family member with fucose-binding activity from surfperch, Neoditrema ransonnetii (Perciformes, Embiotocidae). Fish \& shellfish immunology 27, 714-720.

Neuhaus, H., Muller, F., Hollemann, T., 2010. Xenopus er71 is involved in vascular development. Developmental dynamics : an official publication of the American Association of Anatomists 239, 3436-3445.

Nishihara, A., Hanai, J., Imamura, T., Miyazono, K., Kawabata, M., 1999. E1A inhibits transforming growth factor-beta signaling through binding to Smad proteins. The Journal of biological chemistry 274, 28716-28723.

Nishimatsu, S., Suzuki, A., Shoda, A., Murakami, K., Ueno, N., 1992. Genes for bone morphogenetic proteins are differentially transcribed in early amphibian embryos. Biochemical and biophysical research communications 186, 1487-1495.

Nusse, R., Varmus, H.E., 1982. Many tumors induced by the mouse mammary tumor virus contain a provirus integrated in the same region of the host genome. Cell 31, 99-109.

Oelgeschlager, M., Kuroda, H., Reversade, B., De Robertis, E.M., 2003. Chordin is required for the Spemann organizer transplantation phenomenon in Xenopus embryos. Developmental cell 4, 219-230.

Oelgeschlager, M., Larrain, J., Geissert, D., De Robertis, E.M., 2000. The evolutionarily conserved BMP-binding protein Twisted gastrulation promotes BMP signalling. Nature 405, 757-763.

Onichtchouk, D., Chen, Y.G., Dosch, R., Gawantka, V., Delius, H., Massague, J., Niehrs, C., 1999. Silencing of TGF-beta signalling by the pseudoreceptor BAMBI. Nature 401, 480-485. 
Panitz, F., Krain, B., Hollemann, T., Nordheim, A., Pieler, T., 1998. The Spemann organizerexpressed zinc finger gene Xegr-1 responds to the MAP kinase/Ets-SRF signal transduction pathway. The EMBO journal 17, 4414-4425.

Pardali, E., Goumans, M.J., ten Dijke, P., 2010. Signaling by members of the TGF-beta family in vascular morphogenesis and disease. Trends in cell biology 20, 556-567.

Piccolo, S., Sasai, Y., Lu, B., De Robertis, E.M., 1996. Dorsoventral patterning in Xenopus: inhibition of ventral signals by direct binding of chordin to BMP-4. Cell 86, 589-598.

Pinson, K.I., Brennan, J., Monkley, S., Avery, B.J., Skarnes, W.C., 2000. An LDL-receptor-related protein mediates Wnt signalling in mice. Nature 407, 535-538.

Ploper, D., Lee, H.X., De Robertis, E.M., 2011. Dorsal-ventral patterning: Crescent is a dorsally secreted Frizzled-related protein that competitively inhibits Tolloid proteases. Developmental biology 352, 317-328.

Plouhinec, J.L., Zakin, L., De Robertis, E.M., 2011. Systems control of BMP morphogen flow in vertebrate embryos. Current opinion in genetics \& development 21, 696-703.

Poirier, O., Ciumas, M., Eyries, M., Montagne, K., Nadaud, S., Soubrier, F., 2012. Inhibition of apelin expression by BMP signaling in endothelial cells. American journal of physiology. Cell physiology 303, C1139-1145.

Pouponnot, C., Jayaraman, L., Massague, J., 1998. Physical and functional interaction of SMADs and $\mathrm{p300/CBP.} \mathrm{The} \mathrm{Journal} \mathrm{of} \mathrm{biological} \mathrm{chemistry} \mathrm{273,} \mathrm{22865-22868.}$

Pukrop, T., Gradl, D., Henningfeld, K.A., Knochel, W., Wedlich, D., Kuhl, M., 2001. Identification of two regulatory elements within the high mobility group box transcription factor XTCF-4. The Journal of biological chemistry 276, 8968-8978.

Qin, B.Y., Chacko, B.M., Lam, S.S., de Caestecker, M.P., Correia, J.J., Lin, K., 2001. Structural basis of Smad1 activation by receptor kinase phosphorylation. Molecular cell 8, 1303-1312.

Ramel, M.C., Hill, C.S., 2012. Spatial regulation of BMP activity. FEBS letters 586, 1929-1941.

Ricard, N., Ciais, D., Levet, S., Subileau, M., Mallet, C., Zimmers, T.A., Lee, S.J., Bidart, M., Feige, J.J., Bailly, S., 2012. BMP9 and BMP10 are critical for postnatal retinal vascular remodeling. Blood 119, 6162-6171.

Rijsewijk, F., Schuermann, M., Wagenaar, E., Parren, P., Weigel, D., Nusse, R., 1987. The Drosophila homolog of the mouse mammary oncogene int-1 is identical to the segment polarity gene wingless. Cell 50, 649-657.

Risau, W., 1995. Differentiation of endothelium. FASEB journal : official publication of the Federation of American Societies for Experimental Biology 9, 926-933.

Robb, L., Lyons, I., Li, R., Hartley, L., Kontgen, F., Harvey, R.P., Metcalf, D., Begley, C.G., 1995. Absence of yolk sac hematopoiesis from mice with a targeted disruption of the scl gene. Proceedings of the National Academy of Sciences of the United States of America 92, 70757079.

Rogers, C.D., Moody, S.A., Casey, E.S., 2009. Neural induction and factors that stabilize a neural fate. Birth defects research. Part C, Embryo today : reviews 87, 249-262.

Roose, J., Molenaar, M., Peterson, J., Hurenkamp, J., Brantjes, H., Moerer, P., van de Wetering, M., Destree, O., Clevers, H., 1998. The Xenopus Wnt effector XTcf-3 interacts with Grouchorelated transcriptional repressors. Nature 395, 608-612.

Rubenstein, A., Merriam, J., Klymkowsky, M.W., 1997. Localizing the adhesive and signaling functions of plakoglobin. Developmental genetics 20, 91-102.

Rupp, R.A., Snider, L., Weintraub, H., 1994. Xenopus embryos regulate the nuclear localization of XMyoD. Genes \& development 8, 1311-1323.

Sabin, F.R., 2002. Preliminary note on the differentiation of angioblasts and the method by which they produce blood-vessels, blood-plasma and red blood-cells as seen in the living chick. 1917. Journal of hematotherapy \& stem cell research 11, 5-7.

Sadlon, T.J., Lewis, I.D., D'Andrea, R.J., 2004. BMP4: its role in development of the hematopoietic system and potential as a hematopoietic growth factor. Stem cells 22, 457-474. 
Salanga, M.C., Meadows, S.M., Myers, C.T., Krieg, P.A., 2010. ETS family protein ETV2 is required for initiation of the endothelial lineage but not the hematopoietic lineage in the Xenopus embryo. Developmental dynamics : an official publication of the American Association of Anatomists 239, 1178-1187.

Sambrook, J.u.R., D. W., 2001. Molecular Cloning: A Laboratory Manual. Cold Spring Harbor Laboratory Press, New York.

Sammar, M., Stricker, S., Schwabe, G.C., Sieber, C., Hartung, A., Hanke, M., Oishi, I., Pohl, J., Minami, Y., Sebald, W., Mundlos, S., Knaus, P., 2004. Modulation of GDF5/BRI-b signalling through interaction with the tyrosine kinase receptor Ror2. Genes to cells : devoted to molecular \& cellular mechanisms 9, 1227-1238.

Sasai, Y., Lu, B., Steinbeisser, H., De Robertis, E.M., 1995. Regulation of neural induction by the Chd and Bmp-4 antagonistic patterning signals in Xenopus. Nature 376, 333-336.

Sasai, Y., Lu, B., Steinbeisser, H., Geissert, D., Gont, L.K., De Robertis, E.M., 1994. Xenopus chordin: a novel dorsalizing factor activated by organizer-specific homeobox genes. Cell 79, 779-790.

Schaffler, A., Buechler, C., 2012. CTRP family: linking immunity to metabolism. Trends in endocrinology and metabolism: TEM 23, 194-204.

Schmerer, M., Evans, T., 2003. Primitive erythropoiesis is regulated by Smad-dependent signaling in postgastrulation mesoderm. Blood 102, 3196-3205.

Schmierer, B., Hill, C.S., 2007. TGFbeta-SMAD signal transduction: molecular specificity and functional flexibility. Nature reviews. Molecular cell biology 8, 970-982.

Schwab, K.R., Patterson, L.T., Hartman, H.A., Song, N., Lang, R.A., Lin, X., Potter, S.S., 2007. Pygo1 and Pygo2 roles in Wnt signaling in mammalian kidney development. BMC biology 5, 15. Schwappacher, R., Weiske, J., Heining, E., Ezerski, V., Marom, B., Henis, Y.I., Huber, O., Knaus, P., 2009. Novel crosstalk to BMP signalling: CGMP-dependent kinase I modulates BMP receptor and Smad activity. The EMBO journal 28, 1537-1550.

Seifert, J.R., Mlodzik, M., 2007. Frizzled/PCP signalling: a conserved mechanism regulating cell polarity and directed motility. Nature reviews. Genetics 8, 126-138.

Seldin, M.M., Peterson, J.M., Byerly, M.S., Wei, Z., Wong, G.W., 2012. Myonectin (CTRP15), a novel myokine that links skeletal muscle to systemic lipid homeostasis. The Journal of biological chemistry 287, 11968-11980.

Semenov, M.V., Habas, R., Macdonald, B.T., He, X., 2007. SnapShot: Noncanonical Wnt Signaling Pathways. Cell 131, 1378.

Shalaby, F., Rossant, J., Yamaguchi, T.P., Gertsenstein, M., Wu, X.F., Breitman, M.L., Schuh, A.C., 1995. Failure of blood-island formation and vasculogenesis in Flk-1-deficient mice. Nature 376, 62-66.

Shapiro, L., Scherer, P.E., 1998. The crystal structure of a complement-1q family protein suggests an evolutionary link to tumor necrosis factor. Current biology : CB 8, 335-338.

Sharma, R.P., Chopra, V.L., 1976. Effect of the Wingless (wg1) mutation on wing and haltere development in Drosophila melanogaster. Developmental biology 48, 461-465.

Sharp, P.A., Sugden, B., Sambrook, J., 1973. Detection of two restriction endonuclease activities in Haemophilus parainfluenzae using analytical agarose--ethidium bromide electrophoresis. Biochemistry 12, 3055-3063.

Shi, Y., Sawada, J., Sui, G., Affar el, B., Whetstine, J.R., Lan, F., Ogawa, H., Luke, M.P., Nakatani, Y., Shi, Y., 2003. Coordinated histone modifications mediated by a CtBP co-repressor complex. Nature 422, 735-738.

Smith, S.J., Kotecha, S., Towers, N., Latinkic, B.V., Mohun, T.J., 2002. XPOX2-peroxidase expression and the XLURP-1 promoter reveal the site of embryonic myeloid cell development in Xenopus. Mechanisms of development 117, 173-186.

Smith, W.C., Harland, R.M., 1991. Injected Xwnt-8 RNA acts early in Xenopus embryos to promote formation of a vegetal dorsalizing center. Cell 67, 753-765. 
Smith, W.C., Harland, R.M., 1992. Expression cloning of noggin, a new dorsalizing factor localized to the Spemann organizer in Xenopus embryos. Cell 70, 829-840.

Sokol, S.Y., 1996. Analysis of Dishevelled signalling pathways during Xenopus development. Current biology : CB 6, 1456-1467.

Souchelnytskyi, S., Nakayama, T., Nakao, A., Moren, A., Heldin, C.H., Christian, J.L., ten Dijke, P., 1998. Physical and functional interaction of murine and Xenopus Smad7 with bone morphogenetic protein receptors and transforming growth factor-beta receptors. The Journal of biological chemistry $273,25364-25370$.

Stadeli, R., Hoffmans, R., Basler, K., 2006. Transcription under the control of nuclear Arm/betacatenin. Current biology : CB 16, R378-385.

Suzuki, A., Thies, R.S., Yamaji, N., Song, J.J., Wozney, J.M., Murakami, K., Ueno, N., 1994. A truncated bone morphogenetic protein receptor affects dorsal-ventral patterning in the early Xenopus embryo. Proceedings of the National Academy of Sciences of the United States of America 91, 10255-10259.

Szeto, D.P., Griffin, K.J., Kimelman, D., 2002. HrT is required for cardiovascular development in zebrafish. Development 129, 5093-5101.

Tada, M., O'Reilly, M.A., Smith, J.C., 1997. Analysis of competence and of Brachyury autoinduction by use of hormone-inducible Xbra. Development 124, 2225-2234.

Tamai, K., Semenov, M., Kato, Y., Spokony, R., Liu, C., Katsuyama, Y., Hess, F., Saint-Jeannet, J.P., He, X., 2000. LDL-receptor-related proteins in Wnt signal transduction. Nature 407, 530535.

Tashiro, S., Sedohara, A., Asashima, M., Izutsu, Y., Maeno, M., 2006. Characterization of myeloid cells derived from the anterior ventral mesoderm in the Xenopus laevis embryo. Development, growth \& differentiation 48, 499-512.

Tesson, L., Usal, C., Menoret, S., Leung, E., Niles, B.J., Remy, S., Santiago, Y., Vincent, A.I., Meng, X., Zhang, L., Gregory, P.D., Anegon, I., Cost, G.J., 2011. Knockout rats generated by embryo microinjection of TALENs. Nature biotechnology 29, 695-696.

Thesleff, I., 2003. Epithelial-mesenchymal signalling regulating tooth morphogenesis. Journal of cell science 116, 1647-1648.

Thompson, T.B., Lerch, T.F., Cook, R.W., Woodruff, T.K., Jardetzky, T.S., 2005. The structure of the follistatin:activin complex reveals antagonism of both type I and type II receptor binding. Developmental cell 9, 535-543.

Tracey, W.D., Jr., Pepling, M.E., Horb, M.E., Thomsen, G.H., Gergen, J.P., 1998. A Xenopus homologue of aml-1 reveals unexpected patterning mechanisms leading to the formation of embryonic blood. Development 125, 1371-1380.

Tsiftsoglou, A.S., Vizirianakis, I.S., Strouboulis, J., 2009. Erythropoiesis: model systems, molecular regulators, and developmental programs. IUBMB life 61, 800-830.

Umulis, D., O'Connor, M.B., Blair, S.S., 2009. The extracellular regulation of bone morphogenetic protein signaling. Development 136, 3715-3728.

Urist, M.R., 1965. Bone: formation by autoinduction. Science 150, 893-899.

van Ooyen, A., Nusse, R., 1984. Structure and nucleotide sequence of the putative mammary oncogene int-1; proviral insertions leave the protein-encoding domain intact. Cell 39, 233-240.

Visvader, J.E., Fujiwara, Y., Orkin, S.H., 1998. Unsuspected role for the T-cell leukemia protein $\mathrm{SCL} /$ tal-1 in vascular development. Genes \& development 12, 473-479.

Walmsley, M., Ciau-Uitz, A., Patient, R., 2002. Adult and embryonic blood and endothelium derive from distinct precursor populations which are differentially programmed by BMP in Xenopus. Development 129, 5683-5695.

Walsh, D.W., Godson, C., Brazil, D.P., Martin, F., 2010. Extracellular BMP-antagonist regulation in development and disease: tied up in knots. Trends in cell biology 20, 244-256.

Wang, H., Noulet, F., Edom-Vovard, F., Tozer, S., Le Grand, F., Duprez, D., 2010. Bmp signaling at the tips of skeletal muscles regulates the number of fetal muscle progenitors and satellite cells during development. Developmental cell 18, 643-654. 
Wiater, E., Vale, W., 2003. Inhibin is an antagonist of bone morphogenetic protein signaling. The Journal of biological chemistry 278, 7934-7941.

Wilkinson, L., Kolle, G., Wen, D., Piper, M., Scott, J., Little, M., 2003. CRIM1 regulates the rate of processing and delivery of bone morphogenetic proteins to the cell surface. The Journal of biological chemistry 278, 34181-34188.

Williams, D.S., Atilla, G.E., Bregman, H., Arzoumanian, A., Klein, P.S., Meggers, E., 2005. Switching on a signaling pathway with an organoruthenium complex. Angewandte Chemie 44, 1984-1987.

Wittbrodt, J., Rosa, F.M., 1994. Disruption of mesoderm and axis formation in fish by ectopic expression of activin variants: the role of maternal activin. Genes \& development 8, 14481462.

Wrighton, K.H., Lin, X., Feng, X.H., 2009. Phospho-control of TGF-beta superfamily signaling. Cell research 19, 8-20.

Yabe, T., Shimizu, T., Muraoka, O., Bae, Y.K., Hirata, T., Nojima, H., Kawakami, A., Hirano, T., $\mathrm{Hibi}, \mathrm{M}$., 2003. Ogon/Secreted Frizzled functions as a negative feedback regulator of Bmp signaling. Development 130, 2705-2716.

Yamamoto, T.S., lemura, S., Takagi, C., Shimasaki, S., Ueno, N., 2000. Characterization of follistatin isoforms in early Xenopus embryogenesis. The International journal of developmental biology 44, 341-348.

Yanagawa, S., Matsuda, Y., Lee, J.S., Matsubayashi, H., Sese, S., Kadowaki, T., Ishimoto, A., 2002. Casein kinase I phosphorylates the Armadillo protein and induces its degradation in Drosophila. The EMBO journal 21, 1733-1742.

Yang, X., Castilla, L.H., Xu, X., Li, C., Gotay, J., Weinstein, M., Liu, P.P., Deng, C.X., 1999. Angiogenesis defects and mesenchymal apoptosis in mice lacking SMAD5. Development 126, 1571-1580.

Yost, C., Torres, M., Miller, J.R., Huang, E., Kimelman, D., Moon, R.T., 1996. The axis-inducing activity, stability, and subcellular distribution of beta-catenin is regulated in Xenopus embryos by glycogen synthase kinase 3 . Genes \& development 10, 1443-1454.

Zhang, C., Evans, T., 1996. BMP-like signals are required after the midblastula transition for blood cell development. Developmental genetics 18, 267-278.

Zhu, H., Kavsak, P., Abdollah, S., Wrana, J.L., Thomsen, G.H., 1999. A SMAD ubiquitin ligase targets the BMP pathway and affects embryonic pattern formation. Nature 400, 687-693.

Zimmerman, L.B., De Jesus-Escobar, J.M., Harland, R.M., 1996. The Spemann organizer signal noggin binds and inactivates bone morphogenetic protein 4. Cell 86, 599-606.

Zon, L.I., 1995. Developmental biology of hematopoiesis. Blood 86, 2876-2891.

Zovein, A.C., Hofmann, J.J., Lynch, M., French, W.J., Turlo, K.A., Yang, Y., Becker, M.S., Zanetta, L., Dejana, E., Gasson, J.C., Tallquist, M.D., Iruela-Arispe, M.L., 2008. Fate tracing reveals the endothelial origin of hematopoietic stem cells. Cell stem cell 3, 625-636. 


\section{Appendix}

\subsection{Genes analyzed by Nanostring nCounter}

The nCounter gene expression Code set was purchased from nanoString ${ }^{\circledR}$

TECHNOLOGIES (Seattle, USA). Genes analyzed by Nanostring nCounter are

shown in Table 8.

Table 8. Summary of Gene symbols, Accession numbers, Target regions and Target sequences for all genes analyzed by Nanostring nCounter.

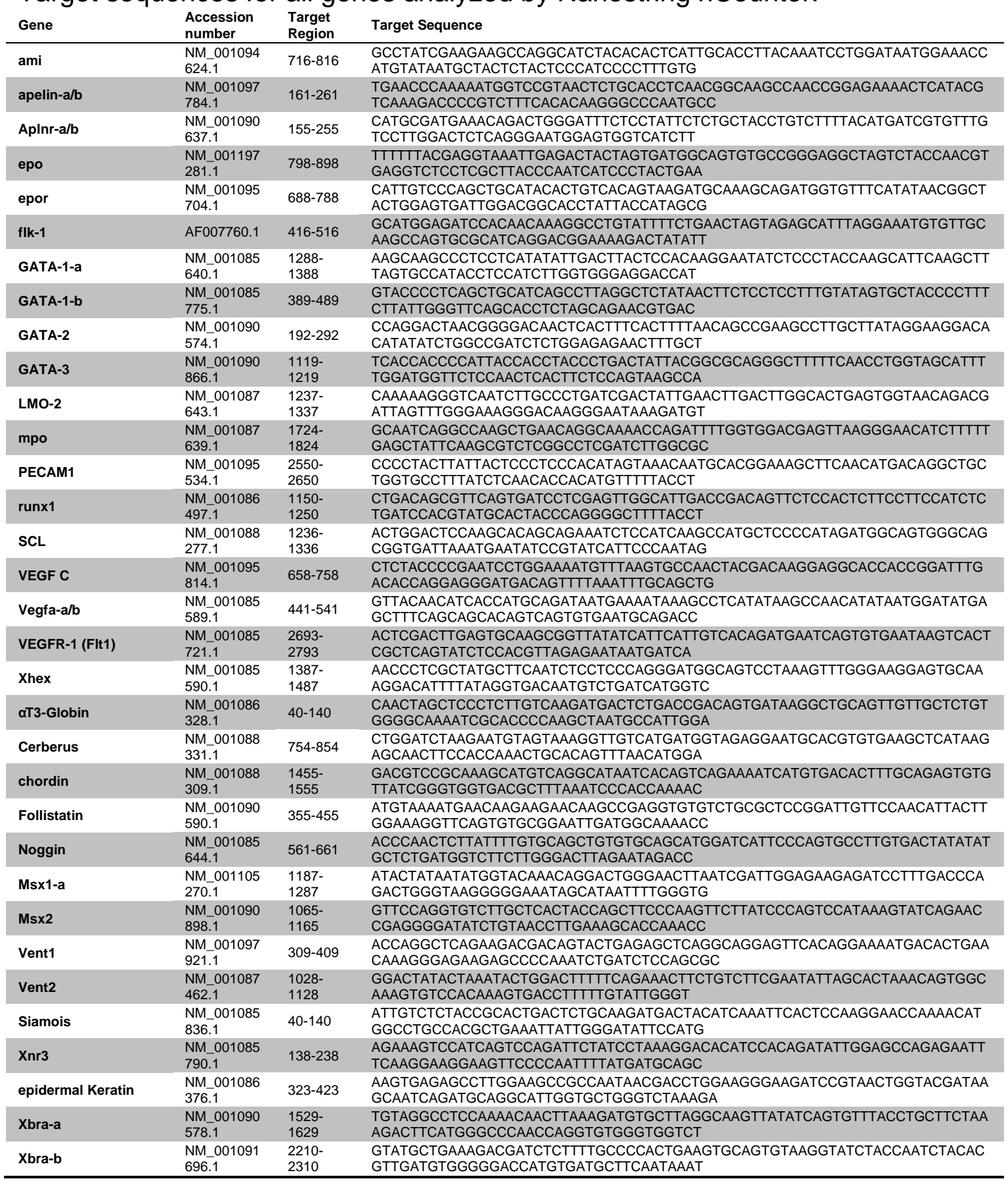




\begin{tabular}{|c|c|c|c|}
\hline Gene & $\begin{array}{l}\text { Accession } \\
\text { number }\end{array}$ & $\begin{array}{l}\text { Target } \\
\text { Region }\end{array}$ & Target Sequence \\
\hline NCAMa/b & $\begin{array}{l}\text { NM_001087 } \\
827.1\end{array}$ & $44-144$ & $\begin{array}{l}\text { CATCTGGACTTTATATTTCATAGGAACTGCAGTGGCGTTGGAAGTGAACATTGTTCCAGATCAAG } \\
\text { GAGAAATAAGCCTTGGGGAGTCCAAATTCTTCCTG }\end{array}$ \\
\hline Sox2 & $\begin{array}{l}\text { NM_001088 } \\
222.1\end{array}$ & $901-1001$ & $\begin{array}{l}\text { CCGGGCATGTCTCTGGGATCCATGGGCTCGGTAGTCAAGTCGGAATCCAGCTCCAGTCCACCTG } \\
\text { TAGTCACCTCTTCTTCCCATTCGCGGGCTCCGTGCC }\end{array}$ \\
\hline Sox3 & $\begin{array}{l}\text { NM_001090 } \\
679.1\end{array}$ & $998-1098$ & $\begin{array}{l}\text { GCTCACTCACATATAACACTTTGTGCCCTTTGCTAAAGACGCTTTACTTGCCTGCTGGCAACTATC } \\
\text { AGACTGCCGCATAAAACATTTAAAAAAAAAAATC }\end{array}$ \\
\hline МyT1 & $\begin{array}{l}\text { NM_001088 } \\
192.1\end{array}$ & $684-784$ & $\begin{array}{l}\text { GAGCTAAACAATGAAAAGCCAACTTCAGTAAAGTCGGGTCAAGCGGAAATAGAACAACTTATGGT } \\
\text { AGAAGAGGCGTGTGAGAAAGAAATCATCATCCAGA }\end{array}$ \\
\hline activin B & $\begin{array}{l}\text { NM_001090 } \\
586.1\end{array}$ & $\begin{array}{l}1299- \\
1399\end{array}$ & $\begin{array}{l}\text { TTGAGAGCAGTGGGGTCTGTGTGTCTCCCATCGCAGACTTGTTCCAATACCTAAATAATAATATC } \\
\text { TCATGGGACTGTCAGTGTCAGTAGCCACCTTGGCG }\end{array}$ \\
\hline BMP7.1 & $\begin{array}{l}\text { NM_001087 } \\
397.1\end{array}$ & 289-389 & $\begin{array}{l}\text { CAGGTTCTGTTCTCCTTTGGACATACTTCTTGTGGAGGATCATCCTGGCTGACTTCACCTTGGAC } \\
\text { AATGAGGTGCACTCTAGCTTTATCCAGAGGAGGTT }\end{array}$ \\
\hline FGF4a & $\begin{array}{l}\text { NM_001085 } \\
823.1\end{array}$ & 89-189 & $\begin{array}{l}\text { TCCAGAGAAACGACACCGTGGAACGGCGATGGGAGACCCTCTTTTCCAGGTCCATGGGGGAAA } \\
\text { AAAAGGATACGAGTCGGGACAGTGACTATTTGCTGGG }\end{array}$ \\
\hline FGF4b & $\begin{array}{l}\text { NM_001085 } \\
824.1\end{array}$ & $92-192$ & $\begin{array}{l}\text { CCCAGAGAAATGACACCCTGGAACGGAGATGGGAGACCCTCTTTTCCAGGTCCATGGCCAGGAT } \\
\text { CCCGGGGGAAAAAAAGGATATGAGTCGGGAAAGTGA }\end{array}$ \\
\hline TGF $\beta-1$ & $\begin{array}{l}\text { NM_001087 } \\
861.1\end{array}$ & $\begin{array}{l}1455- \\
1555\end{array}$ & $\begin{array}{l}\text { GTCCTTACATCTGGAGCATGGATACTCAGTACAGCAAGGTGCTATCACTTTATAATCAGAACAAT } \\
\text { CCCGGTGCATCTATATCTCCCTGCTGTGTTCCTGA }\end{array}$ \\
\hline egr1-a/b & $\begin{array}{l}\text { NM_001090 } \\
393.1\end{array}$ & $\begin{array}{l}2326- \\
2426\end{array}$ & $\begin{array}{l}\text { AGTCTCAGTAACTTGGTGCCTTTTTTGTGAAGCCTTGCTGATGTCTCGACACGTGTATCTGCGTG } \\
\text { ACCTGATGCGTTGCATCTAGCCTTAAGGTAAAAGG }\end{array}$ \\
\hline Mix2 & X58772.1 & $62-162$ & $\begin{array}{l}\text { CTGCGCCCCTTTACTCACCGCAATGTCTTCTCCCAGGAGGATCAAAGAGGATTTAAGCTCGGAT } \\
\text { GAAGAGGGCCAAGTGCACCCTACGCTCTCCCCATCT }\end{array}$ \\
\hline angiopoitin (angpt1) & $\begin{array}{l}\text { NM_001092 } \\
334.1\end{array}$ & $\begin{array}{l}1644- \\
1744\end{array}$ & $\begin{array}{l}\text { GAATGGAATAAAGTGGCATTACTTCAAAGGCCCTAGTTACTCCTTACGTGCAACAACAATGATGA } \\
\text { TCCGGCCCTTGGAGTTCTAATTCAGCGAGAACCAG }\end{array}$ \\
\hline er71/etv2 & $\begin{array}{l}\text { NM_001096 } \\
131.1\end{array}$ & $182-282$ & $\begin{array}{l}\text { CAAGTCGCGAAATTCAGCTGTCCAGGGATTCAAAAACTCCTTGAGAGAAGAGATCAGAGATTTGG } \\
\text { TGCAAGCAGAGCCTGTCGCGAAATTCAGCAAGATG }\end{array}$ \\
\hline erg-a (v-ets) & $\begin{array}{l}\text { NM_001085 } \\
840.1\end{array}$ & $96-196$ & $\begin{array}{l}\text { TAAAATCAGCTAACTGGACCACATCATTTGATTTATCTTCTGACCCGGAGTAGCCAGAAAAACAA } \\
\text { GAGATTTGCTACTAAGGAAGCTGATTGTTTTCTCG }\end{array}$ \\
\hline erg-b & $\begin{array}{l}\text { NM_001085 } \\
841.1\end{array}$ & $5-105$ & $\begin{array}{l}\text { TAGCCACTCACTCACACGAAGAGATTACACATTCAGACTGGCTGCTGCTCCTGCTGGAGTCACC } \\
\text { ACAACATTCAGTCCAGCCTCCTTCTATCCACCCTCC }\end{array}$ \\
\hline nr2f2 (COUP.TFII) & $\begin{array}{l}\text { NM_001094 } \\
481.1\end{array}$ & $\begin{array}{l}1567- \\
1667\end{array}$ & $\begin{array}{l}\text { TTGGCCTTACATGCCCATCCAATGCTCCTAGGGAGCCGCCTTGGGACTCTCACTTGGACCTCATT } \\
\text { TGGCCACACAGCTCTAATGATGCTAGGCTTAATTA }\end{array}$ \\
\hline vegf $D$ (figf) & $\begin{array}{l}\text { NM_001127 } \\
797.1\end{array}$ & $293-393$ & $\begin{array}{l}\text { TTCTCTTACTCACCATGTCCATTAAAATGGGCATTGGCAGCTGTATCCTCTCTAGTGTTTAACGGC } \\
\text { TGGCAACGCGCTCTACCAATATGATTAGACCGTG }\end{array}$ \\
\hline SPIB-a & FJ644945.1 & $\begin{array}{l}1074- \\
1174\end{array}$ & $\begin{array}{l}\text { TGTGAGCTCCTCAGAAAGAGGAAAGTGACGGAACTTAAATGATGTGGTAGTGATGTTGGTAGAAA } \\
\text { ACCGTAGATTAGGAGTTTAGAGAATGAAGAGGAGA }\end{array}$ \\
\hline SPIB-b & FJ644946.1 & $985-1085$ & $\begin{array}{l}\text { AATCTTGGCCTAAATTTGCACTGAAGACCTTGGAAAGGAGCTTGCACAAAGGACAAGAGTCAAGA } \\
\text { AGGCATCAAATCATTCATCATCAATGGACCCGTGT }\end{array}$ \\
\hline numb & $\begin{array}{l}\text { GQ214766. } \\
1\end{array}$ & $625-725$ & $\begin{array}{l}\text { AGGCGATGGATCTGTCACTGCTTCATGACTGTTAAAGATACGGGAGAGAGGCTCAGCCATGCTG } \\
\text { TTGGATGTGCATTTGCCGCTTGTCTGGAGAGGAAGC }\end{array}$ \\
\hline lipase endothelial & $\begin{array}{l}\text { NM_001090 } \\
061.1\end{array}$ & 298-398 & $\begin{array}{l}\text { GCTTTCGGACGAAAACGATGTTGTGCCAGAAACGCATCCCCATGTCAAGTTTAACGCCCACTTCT } \\
\text { CCAAACATGACCGTGGGTGCTTTCTATTTCCTGGC }\end{array}$ \\
\hline bmper & $\begin{array}{l}\text { NM_001095 } \\
672.1\end{array}$ & 208-308 & $\begin{array}{l}\text { TCCTTGTACCTCTTGTGTGTGCCTGAACAAAGAAGTTACCTGCAAACGAGAGAAGTGCCCAATAC } \\
\text { TGTCCAAGGATTGCGCTTTGGTTATAAAGCAGAGA }\end{array}$ \\
\hline pdgf-a & $\begin{array}{l}\text { NM_001087 } \\
835.1\end{array}$ & $725-825$ & $\begin{array}{l}\text { GAACTGTTATATACGAGATACCTCGTAGCCAAATTGATCCAACATCTGCCAATTTTCTGATCTGGC } \\
\text { CTCCATGCGTGGAGGTGAAACGATGCACGGGATG }\end{array}$ \\
\hline STAT-5 & $\begin{array}{l}\text { NM_001090 } \\
421.1\end{array}$ & $844-944$ & $\begin{array}{l}\text { GACTTGTTGCAGACATGGTGTGAAAAGCTTGCGGACATCATCTGGCAGAATCGGCAGCAAATCA } \\
\text { GACGAGCTGAGCACCTTTGTCAGCAGTTCCGCATCC }\end{array}$ \\
\hline Castor & EF666978.1 & $3-103$ & $\begin{array}{l}\text { AAACACACATTTTCCTTTACTTGGAAAGTCACCCAAAGCAGTCCAAGTGCAGAGATTCCAAAAATC } \\
\text { AATCCAATAAAACAAAGATAAGAAGAAAGAACAT }\end{array}$ \\
\hline hand1 & $\begin{array}{l}\text { NM_001085 } \\
659.1\end{array}$ & $107-207$ & $\begin{array}{l}\text { TGATTGTGGTGCTTCCCTGAGGAGTGATTGCAGAGTAGCTGAGGATGTTCTGATGCCATATCTAA } \\
\text { TGGCTTCCCACTGAGGAGGTGCCAGAAGTTGTTTT }\end{array}$ \\
\hline hand2-a & $\begin{array}{l}\text { NM_001085 } \\
639.1\end{array}$ & $401-501$ & $\begin{array}{l}\text { TTATTTATGGAGAGCCAGTGATAACCTATTGAACACACGACACCAGCACTGTCTGTTTATACATAG } \\
\text { ATTGTCAGCAGGAGGACAAGAAGCGCCCAGACAA }\end{array}$ \\
\hline$n k x 2.5$ & $\begin{array}{l}\text { NM_001086 } \\
721.1\end{array}$ & $\begin{array}{l}1110- \\
1210\end{array}$ & $\begin{array}{l}\text { AAATGTTCTGCACTCGCTCAGTGCTAGGAGTACAGCCCATTAGAGCTACAGTTGGGTGTGTGTG } \\
\text { GTTAATATGGCAATATGCGACGGTCAGATGTCTACT }\end{array}$ \\
\hline wnt11 & $\begin{array}{l}\text { NM_001093 } \\
610.1\end{array}$ & $229-329$ & $\begin{array}{l}\text { AAAGGACTTATCAGGATATTTACTGGAAAAGTTACCGGGGGATTCACGCAGCATAATGGCACGTT } \\
\text { GCTTACGGCCATAACCCTAAAGGATTAATTTCAAC }\end{array}$ \\
\hline Gli2 & AF109923.1 & $\begin{array}{l}3003- \\
3103\end{array}$ & $\begin{array}{l}\text { GGAGGCACCAAAGCAAAACCTACCAATTGAGTACAACAGTCCAGCACGGAATCTACAAAGCAGC } \\
\text { ATAAAACCTTTCCATCACAACACACCACACAGGGCT }\end{array}$ \\
\hline Gli3 & $\begin{array}{l}\text { NM_001087 } \\
971.1\end{array}$ & $\begin{array}{l}1289- \\
1389\end{array}$ & $\begin{array}{l}\text { GCTCTTATGGGCACCTAGCAGCCAGTGCCATCAGTCCAGCTTTGAATTTTGCATACCAGCCTACC } \\
\text { CCAGTGTCTCTTCAGCAAATGCATCAACAGATTAT }\end{array}$ \\
\hline Gli4 & U42462.1 & $\begin{array}{l}3019- \\
3119\end{array}$ & $\begin{array}{l}\text { GCCCCAGAGCAAAACCTACAGACGGAGTACAGCAGTCCAGCCCGGAATCTACAAAGCAACACAA } \\
\text { AATCTTTCCATAACAATACACCAGAACAACCCAGGG }\end{array}$ \\
\hline patched1 & $\begin{array}{l}\text { NM_001088 } \\
613.1\end{array}$ & $\begin{array}{l}3586- \\
3686\end{array}$ & $\begin{array}{l}\text { CTGAGCATCCTAGACCGACACAAAATGGGTCGGATTCCTCAGATTCCGAATATAGTTCTCAAACC } \\
\text { TCTGTATCGGGAATCAGTGAAGAGCTCCACCAATA }\end{array}$ \\
\hline patched2 & AB037688.1 & $\begin{array}{l}1469- \\
1569\end{array}$ & $\begin{array}{l}\text { CAAAGAAAGTTTGTAGAGCAAGCACAACAGTCCGTCCCACAGAACTCATCCCAGGACATCCATG } \\
\text { CTTTTTCTACCACCACACTTAATGACATCATGAAGT }\end{array}$ \\
\hline smoothend & AF302766.1 & $\begin{array}{l}1824- \\
1924\end{array}$ & $\begin{array}{l}\text { GATGTCTCGGTAACACCTGTAGCAACTCCAGTTCCACCAGAAGAAAGGGACCAGTGGTTTATTGA } \\
\text { AGGAGATATACCTCAGGGGATGGTTAAGAAAATGT }\end{array}$ \\
\hline sonic hedgehog & $\begin{array}{l}\text { NM_001088 } \\
313.1\end{array}$ & $152-252$ & $\begin{array}{l}\text { GCGAAGGAGAACATCCTCTGAGCCTTTGATGTAATTGGCTTCGCTCGGACGAGATGCTGGTTGC } \\
\text { GAACTCGAATCTCTGTTGGCTGCTGAGCTTCATCTG }\end{array}$ \\
\hline $\begin{array}{l}\text { indian hedgehog } \\
\text { (bhh) }\end{array}$ & $\begin{array}{l}\text { NM_001085 } \\
793.1\end{array}$ & $932-1032$ & $\begin{array}{l}\text { AGTAAGGTCAGTAAATACGCAGACAAACTATGGGGCTTATGCTCCTCTAACTCAGCATGGGACAC } \\
\text { TCGTGGTAGATGATGTGGTTGTGTCCTGTTTTGCC }\end{array}$ \\
\hline egln1 (PHD2) & $\begin{array}{l}\text { NM_001094 } \\
234.1\end{array}$ & $\begin{array}{l}1443- \\
1543\end{array}$ & $\begin{array}{l}\text { CTTAACTATATGAGTGACGTCGAGGCTGGAGGAGCAACAGTATTTCCTGACTTTGGGGCAGCAA } \\
\text { TTTGGCCCAGAAAGGGTACTGCTGTATTCTGGTATA }\end{array}$ \\
\hline egln2 (PHD1) & $\begin{array}{l}\text { NM_001090 } \\
537.1\end{array}$ & $\begin{array}{l}2180- \\
2280\end{array}$ & $\begin{array}{l}\text { TCCTGGCTGGAGCCTGTGACCCATCCTCCAAAAATGCAAATTAACATTTTCTCTGGACAGGAGGA } \\
\text { GGTTTTCAGTAGAATCTGCTTGATTTGTGAAGCAT }\end{array}$ \\
\hline egln3 (PHD3) & $\begin{array}{l}\text { NM_001112 } \\
854.1\end{array}$ & $\begin{array}{l}1970- \\
2070\end{array}$ & $\begin{array}{l}\text { TAAGTGTAAAGCTGTGCTGCTGTAATGATTGACATGTTGTGACTCATGGGGAGCCGTGTAATTTG } \\
\text { GCCTCCTGTGCAGGTGGTGAGATTGTCCTGATCTG }\end{array}$ \\
\hline HIF-1a & $\begin{array}{l}\text { NM_001086 } \\
980.1\end{array}$ & 86-186 & $\begin{array}{l}\text { TCGTACGGTCGGATTAAACCGGAGGGATTGCGTCGTAAAATATTCCCTGCCGGGGTTGCCGGAG } \\
\text { AGATCTGACCTTGCCAACGAATCGTCTTTCGCGTGT }\end{array}$ \\
\hline HIF-2a (epas1) & $\begin{array}{l}\text { NM_001092 } \\
249.1\end{array}$ & $\begin{array}{l}1935- \\
2035\end{array}$ & $\begin{array}{l}\text { GCATTTGCTCGCTCTTCCAGCCGACGACCCCGTCTCCCCAGAATCAATTTCTTCAGCAGAACATC } \\
\text { CTTCAACCGACCGCAGCTAAAAACAATAATGGCAG }\end{array}$ \\
\hline Prox-1 & $\begin{array}{l}\text { NM_001090 } \\
703.1\end{array}$ & $\begin{array}{l}2035- \\
2135\end{array}$ & $\begin{array}{l}\text { AGGTTCCGGAGAGATTCCTAGAAGTGGCTCAGATCACGTTACGAGAGTTTTTCAATGCCATTATC } \\
\text { GCAGGCAAAGACGTTGATCCTTCTTGGAAGAACGC }\end{array}$ \\
\hline ctroponin & $\begin{array}{l}\text { NM_001090 } \\
295.1\end{array}$ & $\begin{array}{l}1225- \\
1325\end{array}$ & $\begin{array}{l}\text { ATGTAAAAAGCCTTACTCCTGACATTAACCCATTCATGGCTGAAGAGTTCAGAAGAAGTACAATAC } \\
\text { TAAATGCAAGTGTTACAGTGGTCCGGACAAGTGC }\end{array}$ \\
\hline myosin light chain 1 & $\begin{array}{l}\text { NM_001086 } \\
783.1\end{array}$ & $920-1020$ & $\begin{array}{l}\text { GGAGCACTGTAAAAAATAAAAAAAAGACATGTCAATAAACACCTTTGCTAATTTGGTGGCTACCAA } \\
\text { GTCTATTTATTTCATCTGCCAAAGGCTTTGGGCC }\end{array}$ \\
\hline notch-1 & $\begin{array}{l}\text { NM_001087 } \\
605.1\end{array}$ & $468-568$ & $\begin{array}{l}\text { ACTGGGGTGTGCCTATGCGGTAATTTGTATTTCGGTGAAAGGTGCCAGTTCCCCAATCCCTGCA } \\
\text { CCATAAAGAATCAGTGTATGAACTTTGGAACCTGCG }\end{array}$ \\
\hline
\end{tabular}




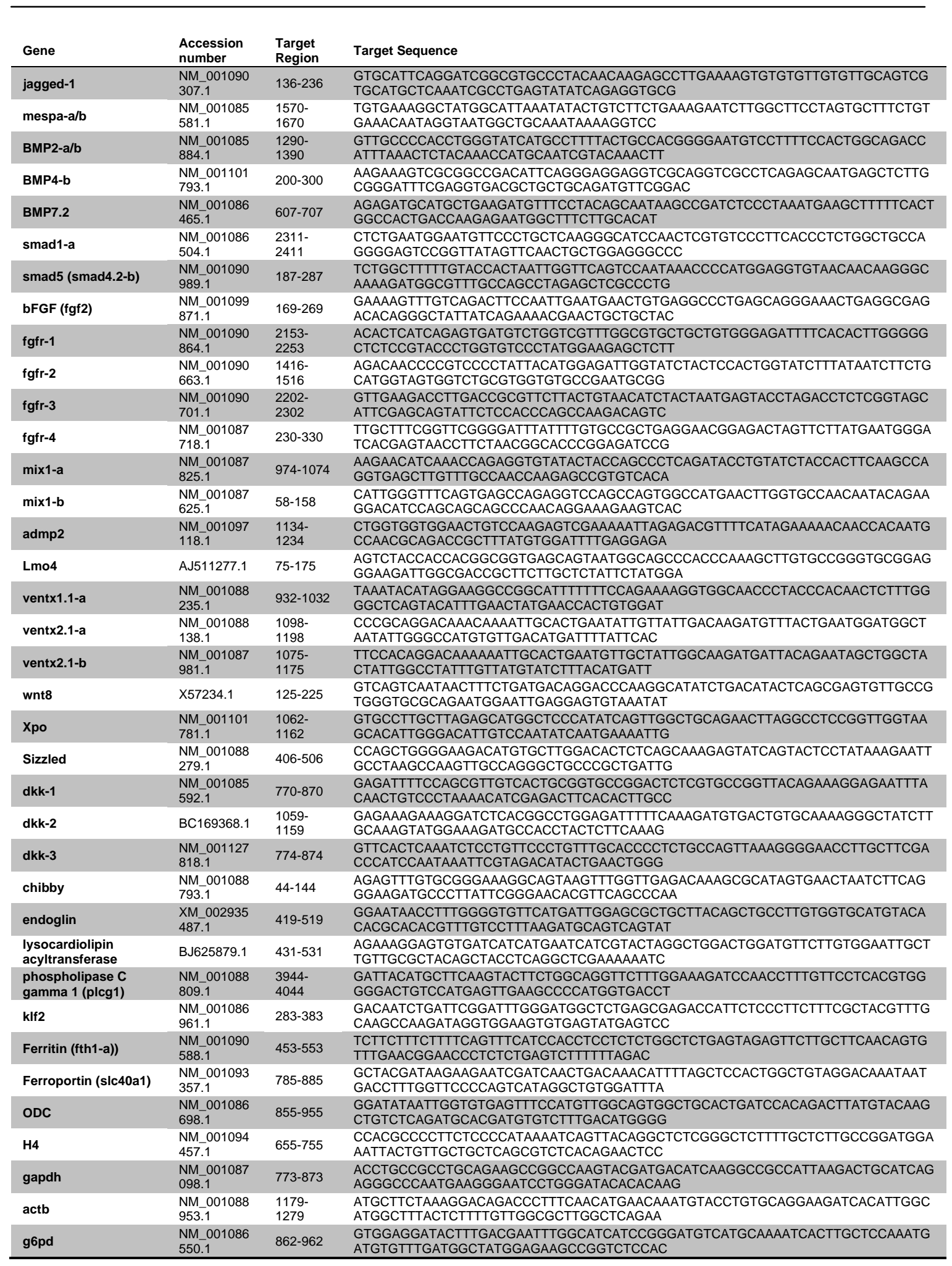

\subsection{Primary gene expression data}

Primary gene expression data from Nanostring nCounter analysis are shown for two independent experiments in Table 9 and Table 10. 
Table 9.Primary gene expression data from Nanostring nCounter analysis for experiment 1.

\begin{tabular}{|c|c|c|c|c|c|c|}
\hline \multirow[t]{2}{*}{ Gene } & \multicolumn{6}{|c|}{ experiment 1} \\
\hline & CE & $\mathrm{CC}$ & Etv2 & Etv2/ MO2 & Etv2 /mmMO1 & Etv2 /Fam132b \\
\hline AT3-Globin & 29920 & 16 & 2326 & 5449 & 1568 & 3 \\
\hline Aplnr-a/b & 1161 & 38 & 1266 & 282 & 269 & 2309 \\
\hline BMP2-a/b & 553 & 203 & 261 & 302 & 245 & 64 \\
\hline BMP4-b & 115 & 244 & 170 & 70 & 104 & 59 \\
\hline BMP7.1 & 1051 & 448 & 349 & 286 & 244 & 190 \\
\hline BMP7.2 & 11 & 2 & 5 & 6 & 1 & 1 \\
\hline Castor & 275 & 43 & 54 & 40 & 23 & 69 \\
\hline Cerberus & 20 & 16 & 15 & 6 & 2 & 4 \\
\hline FGF4b & 18 & 4 & 8 & 9 & 6 & 1 \\
\hline Fam32B & 59 & 4 & 7 & 13 & 5 & 2532 \\
\hline Ferritin (fth1-a)) & 21740 & 25564 & 17750 & 19039 & 29781 & 12265 \\
\hline Ferroportin (slc40a1) & 2642 & 3226 & 1887 & 1761 & 1810 & 528 \\
\hline Follistatin & 842 & 18 & 82 & 9 & 4 & 191 \\
\hline Foxc1a & 639 & 52 & 40 & 22 & 26 & 36 \\
\hline GATA-1-a & 127 & 11 & 36 & 58 & 22 & 2 \\
\hline GATA-2 & 284 & 147 & 142 & 208 & 167 & 147 \\
\hline GATA-3 & 647 & 686 & 371 & 347 & 362 & 196 \\
\hline Gli2 & 509 & 144 & 82 & 76 & 60 & 144 \\
\hline Gli3 & 321 & 81 & 50 & 48 & 50 & 74 \\
\hline Gli4 & 348 & 34 & 27 & 19 & 26 & 85 \\
\hline H4 & 18 & 26 & 33 & 21 & 14 & 5 \\
\hline HIF-1a & 1151 & 742 & 703 & 702 & 603 & 437 \\
\hline HIF-2a (epas1) & 499 & 1314 & 549 & 574 & 533 & 217 \\
\hline LMO-2 & 413 & 1 & 235 & 242 & 134 & 103 \\
\hline Lmo4 & 441 & 77 & 132 & 112 & 56 & 109 \\
\hline Mix2 & 446 & 1689 & 854 & 848 & 796 & 176 \\
\hline Msx2 & 1544 & 2893 & 1610 & 1216 & 1308 & 682 \\
\hline Мут1 & 1448 & 79 & 54 & 60 & 43 & 307 \\
\hline NCAMa/b & 1891 & 3 & 72 & 3 & 1 & 364 \\
\hline Noggin & 267 & 22 & 41 & 14 & 15 & 58 \\
\hline ODC & 28270 & 8876 & 6882 & 8066 & 5611 & 6591 \\
\hline PECAM1 & 26 & 1 & 13 & 8 & 2 & 17 \\
\hline Prox-1 & 664 & 14 & 50 & 42 & 34 & 30 \\
\hline SCL & 387 & 4 & 106 & 147 & 64 & 97 \\
\hline SPIB-a & 150 & 34 & 696 & 1836 & 1599 & 42 \\
\hline STAT-5 & 758 & 1661 & 572 & 648 & 660 & 113 \\
\hline Siamois & 8 & 7 & 4 & 1 & 4 & 2 \\
\hline Sizzled & 91 & 75 & 84 & 130 & 102 & 33 \\
\hline Sox2 & 2630 & 48 & 141 & 62 & 66 & 713 \\
\hline Sox3 & 852 & 45 & 48 & 22 & 26 & 246 \\
\hline TGFB-1 & 702 & 54 & 139 & 157 & 100 & 139 \\
\hline VEGF C & 254 & 18 & 35 & 42 & 33 & 24 \\
\hline VEGFR-1 (FIt1) & 88 & 3 & 31 & 16 & 9 & 49 \\
\hline
\end{tabular}


Appendix

\begin{tabular}{|c|c|c|c|c|c|c|}
\hline \multirow[t]{2}{*}{ Gene } & \multicolumn{6}{|c|}{ experiment 1} \\
\hline & CE & CC & Etv2 & Etv2/ MO2 & Etv2 /mmMO1 & Etv2 IFam132b \\
\hline Vegfa-a/b & 527 & 69 & 60 & 65 & 54 & 40 \\
\hline Vent1 & 28 & 14 & 21 & 30 & 15 & 4 \\
\hline Vent2 & 17 & 13 & 16 & 14 & 8 & 4 \\
\hline Xbra-a & 41 & 5 & 5 & 6 & 5 & 7 \\
\hline Xbra-b & 128 & 5 & 5 & 1 & 1 & 1 \\
\hline Xhex & 160 & 8 & 327 & 299 & 228 & 216 \\
\hline Xnr3 & 9 & 8 & 8 & 8 & 6 & 3 \\
\hline Xpo & 985 & 1104 & 613 & 671 & 544 & 217 \\
\hline actb & 164684 & 137150 & 102995 & 127872 & 121969 & 51702 \\
\hline activin $B$ & 205 & 32 & 18 & 14 & 18 & 46 \\
\hline admp2 & 9 & 8 & 9 & 7 & 4 & 4 \\
\hline ami & 2896 & 8 & 5234 & 2924 & 1640 & 10477 \\
\hline angiopoitin (angpt1) & 190 & 5 & 7 & 2 & 1 & 15 \\
\hline apelin-a/b & 306 & 19 & 29 & 19 & 11 & 24 \\
\hline bFGF (fgf2) & 172 & 20 & 20 & 19 & 16 & 20 \\
\hline bmper & 431 & 53 & 92 & 72 & 47 & 91 \\
\hline chibby & 8 & 8 & 9 & 8 & 10 & 2 \\
\hline chordin & 59 & 1 & 9 & 3 & 5 & 7 \\
\hline ctroponin & 144 & 2 & 1 & 4 & 2 & 6 \\
\hline dkk-1 & 131 & 84 & 93 & 60 & 68 & 8 \\
\hline dkk-2 & 38 & 8 & 12 & 4 & 7 & 1 \\
\hline dkk-3 & 297 & 59 & 47 & 31 & 26 & 183 \\
\hline egln1 (PHD2) & 719 & 581 & 355 & 196 & 218 & 131 \\
\hline egln2 (PHD1) & 29698 & 40733 & 23368 & 23224 & 22558 & 6741 \\
\hline egln3 (PHD3) & 88 & 45 & 40 & 51 & 49 & 48 \\
\hline egr1-a/b & 168 & 827 & 477 & 508 & 674 & 349 \\
\hline endoglin & 87 & 1 & 72 & 42 & 42 & 94 \\
\hline epidermal Keratin & 30825 & 74729 & 42790 & 59999 & 40719 & 16295 \\
\hline epo & 21 & 5 & 18 & 11 & 4 & 5 \\
\hline epor & 114 & 15 & 18 & 28 & 22 & 1 \\
\hline er71/etv2 & 87 & 25 & 310 & 102 & 99 & 612 \\
\hline erg-a (v-ets) & 263 & 2 & 97 & 89 & 56 & 68 \\
\hline fgfr-1 & 245 & 52 & 51 & 22 & 24 & 48 \\
\hline fgfr-2 & 909 & 398 & 258 & 279 & 218 & 154 \\
\hline fgfr-3 & 358 & 38 & 41 & 18 & 14 & 62 \\
\hline fgfr-4 & 876 & 54 & 135 & 109 & 70 & 161 \\
\hline flk-1 & 85 & 8 & 125 & 51 & 30 & 145 \\
\hline g6pd & 904 & 417 & 452 & 1104 & 1385 & 208 \\
\hline gapdh & 8710 & 16699 & 8935 & 4007 & 5957 & 463 \\
\hline hand1 & 398 & 3 & 12 & 10 & 5 & 2 \\
\hline hand2-a & 995 & 119 & 72 & 97 & 64 & 52 \\
\hline indian hedgehog (bhh) & 46 & 3 & 9 & 6 & 3 & 2 \\
\hline jagged-1 & 1068 & 154 & 166 & 99 & 90 & 209 \\
\hline klf2 & 76 & 31 & 102 & 33 & 64 & 152 \\
\hline
\end{tabular}


Appendix

\begin{tabular}{|c|c|c|c|c|c|c|}
\hline \multirow[t]{2}{*}{ Gene } & \multicolumn{6}{|c|}{ experiment 1} \\
\hline & CE & CC & Etv2 & Etv2/ MO2 & Etv2 ImmMO1 & Etv2 /Fam132b \\
\hline lipase endothelial & 66 & 30 & 47 & 37 & 30 & 9 \\
\hline lysocardiolipin acyltransferase & 1015 & 964 & 552 & 596 & 521 & 233 \\
\hline mespa-a/b & 4 & 2 & 1 & 2 & 1 & 1 \\
\hline mix1-b & 6 & 7 & 1 & 9 & 2 & 2 \\
\hline mpo & 3911 & 20 & 9012 & 18394 & 12802 & 22 \\
\hline myosin light chain 1 & 20118 & 9 & 255 & 7 & 1 & 10 \\
\hline$n k x 2.5$ & 171 & 13 & 10 & 21 & 13 & 39 \\
\hline notch-1 & 1396 & 140 & 235 & 169 & 147 & 459 \\
\hline nr2f2 (COUP.TFII) & 514 & 22 & 35 & 11 & 11 & 119 \\
\hline numb & 397 & 605 & 363 & 360 & 298 & 124 \\
\hline patched1 & 572 & 46 & 53 & 17 & 20 & 66 \\
\hline patched2 & 2314 & 7 & 141 & 24 & 24 & 169 \\
\hline pdgf-a & 185 & 19 & 22 & 11 & 15 & 30 \\
\hline phospholipase C gamma 1 (plcg1) & 246 & 60 & 85 & 28 & 35 & 87 \\
\hline runx1 & 127 & 128 & 390 & 503 & 292 & 105 \\
\hline smad1-a & 1176 & 575 & 429 & 401 & 355 & 263 \\
\hline smad5 (smad4.2-b) & 57 & 59 & 37 & 21 & 24 & 27 \\
\hline smoothend & 478 & 67 & 79 & 45 & 31 & 87 \\
\hline sonic hedgehog & 239 & 7 & 16 & 7 & 2 & 8 \\
\hline ve-cadherin & 745 & 10 & 669 & 232 & 170 & 1414 \\
\hline vegf D (figf) & 51 & 16 & 22 & 18 & 10 & 6 \\
\hline ventx1.1-a & 11 & 4 & 9 & 10 & 4 & 1 \\
\hline ventx2.1-b & 45 & 2 & 13 & 14 & 7 & 2 \\
\hline wnt11 & 213 & 8 & 11 & 1 & 1 & 21 \\
\hline wnt8 & 8 & 3 & 2 & 2 & 8 & 2 \\
\hline NEG_A & 3 & 3 & 6 & 3 & 1 & 1 \\
\hline NEG_B & 6 & 3 & 3 & 4 & 3 & 1 \\
\hline NEG_C & 1 & 5 & 5 & 1 & 1 & 1 \\
\hline NEG_D & 4 & 4 & 3 & 5 & 4 & 1 \\
\hline NEG_E & 2 & 1 & 4 & 1 & 2 & 1 \\
\hline NEG_F & 4 & 2 & 3 & 2 & 1 & 4 \\
\hline NEG_G & 3 & 1 & 3 & 1 & 1 & 1 \\
\hline NEG_H & 4 & 4 & 7 & 2 & 2 & 1 \\
\hline POS_A & 8097 & 9727 & 11049 & 6552 & 5888 & 6252 \\
\hline POS_B & 4452 & 4739 & 5128 & 3583 & 3148 & 3313 \\
\hline POS_C & 1233 & 1317 & 1489 & 1032 & 887 & 872 \\
\hline POS_D & 256 & 251 & 323 & 186 & 175 & 165 \\
\hline POS_E & 58 & 63 & 64 & 55 & 46 & 31 \\
\hline POS_F & 20 & 21 & 18 & 8 & 13 & 17 \\
\hline
\end{tabular}


Table 10.Primary gene expression data from Nanostring nCounter analysis for experiment 2.

\begin{tabular}{|c|c|c|c|c|c|c|}
\hline \multirow{2}{*}{ Gene } & \multicolumn{6}{|c|}{ experiment 2} \\
\hline & CE & CC & Etv2 & Etv2/ MO2 & Etv2 /mmMO1 & Etv2 /Fam132b \\
\hline AT3-Globin & 24226 & 11 & 6300 & 6879 & 2375 & 8 \\
\hline Aplnr-a/b & 965 & 49 & 465 & 109 & 313 & 2587 \\
\hline BMP2-a/b & 517 & 362 & 568 & 505 & 349 & 138 \\
\hline BMP4-b & 124 & 282 & 161 & 155 & 255 & 102 \\
\hline BMP7.1 & 952 & 611 & 591 & 638 & 652 & 510 \\
\hline BMP7.2 & 12 & 7 & 3 & 1 & 3 & 4 \\
\hline Castor & 244 & 27 & 38 & 32 & 26 & 31 \\
\hline Cerberus & 19 & 10 & 11 & 16 & 13 & 10 \\
\hline FGF4b & 10 & 6 & 13 & 6 & 4 & 4 \\
\hline Fam32B & 39 & 11 & 11 & 13 & 5 & 591 \\
\hline Ferritin (fth1-a)) & 24714 & 23290 & 27188 & 20539 & 29594 & 37435 \\
\hline Ferroportin (slc40a1) & 1913 & 3788 & 3117 & 2904 & 2619 & 1475 \\
\hline Follistatin & 878 & 13 & 25 & 14 & 14 & 307 \\
\hline Foxc1a & 426 & 41 & 41 & 24 & 68 & 73 \\
\hline GATA-1-a & 95 & 22 & 73 & 87 & 41 & 10 \\
\hline GATA-2 & 323 & 324 & 387 & 411 & 240 & 117 \\
\hline GATA-3 & 672 & 873 & 651 & 646 & 659 & 660 \\
\hline Gli2 & 479 & 316 & 169 & 192 & 177 & 303 \\
\hline Gli3 & 218 & 82 & 42 & 56 & 54 & 140 \\
\hline Gli4 & 338 & 86 & 66 & 64 & 58 & 196 \\
\hline $\mathrm{H} 4$ & 12 & 25 & 23 & 23 & 24 & 13 \\
\hline HIF-1a & 1042 & 634 & 655 & 655 & 553 & 672 \\
\hline HIF-2a (epas1) & 725 & 1334 & 725 & 685 & 570 & 504 \\
\hline LMO-2 & 280 & 3 & 325 & 277 & 222 & 69 \\
\hline Lmo4 & 351 & 67 & 114 & 119 & 132 & 118 \\
\hline Mix2 & 470 & 2454 & 1579 & 1654 & 1596 & 594 \\
\hline Msx2 & 1089 & 4572 & 2372 & 2155 & 2325 & 1603 \\
\hline MyT1 & 1292 & 55 & 35 & 46 & 48 & 720 \\
\hline NCAMa/b & 1698 & 5 & 3 & 9 & 5 & 754 \\
\hline Noggin & 228 & 25 & 34 & 25 & 32 & 278 \\
\hline ODC & 30707 & 12170 & 11049 & 13103 & 10819 & 19765 \\
\hline PECAM1 & 15 & 3 & 11 & 8 & 11 & 35 \\
\hline Prox-1 & 582 & 11 & 66 & 52 & 57 & 31 \\
\hline $\mathrm{SCL}$ & 280 & 1 & 158 & 178 & 76 & 106 \\
\hline SPIB-a & 148 & 54 & 1469 & 1009 & 1256 & 89 \\
\hline STAT-5 & 637 & 1762 & 986 & 997 & 1546 & 397 \\
\hline Siamois & 5 & 7 & 4 & 11 & 5 & 6 \\
\hline Sizzled & 92 & 112 & 299 & 209 & 222 & 75 \\
\hline Sox2 & 2661 & 45 & 76 & 85 & 98 & 2559 \\
\hline Sox3 & 684 & 26 & 22 & 19 & 36 & 537 \\
\hline TGFB-1 & 627 & 43 & 159 & 146 & 85 & 218 \\
\hline VEGF C & 208 & 42 & 62 & 45 & 39 & 72 \\
\hline
\end{tabular}


Appendix

\begin{tabular}{|c|c|c|c|c|c|c|}
\hline \multirow{2}{*}{ Gene } & \multicolumn{6}{|c|}{ experiment 2} \\
\hline & CE & CC & Etv2 & Etv2/ MO2 & Etv2 /mmMO1 & Etv2 /Fam132b \\
\hline VEGFR-1 (Flt1) & 97 & 7 & 25 & 7 & 8 & 135 \\
\hline Vegfa-a/b & 519 & 75 & 78 & 47 & 54 & 103 \\
\hline Vent1 & 30 & 19 & 29 & 25 & 37 & 6 \\
\hline Vent2 & 23 & 13 & 39 & 20 & 35 & 27 \\
\hline Xbra-a & 37 & 5 & 7 & 3 & 4 & 7 \\
\hline Xbra-b & 44 & 3 & 1 & 2 & 1 & 1 \\
\hline Xhex & 135 & 15 & 278 & 186 & 300 & 151 \\
\hline Xnr3 & 8 & 8 & 9 & 4 & 9 & 3 \\
\hline Xpo & 1782 & 1097 & 1063 & 863 & 1336 & 863 \\
\hline actb & 145623 & 211552 & 179180 & 172366 & 194719 & 128701 \\
\hline activin B & 198 & 24 & 36 & 26 & 20 & 114 \\
\hline admp2 & 9 & 7 & 7 & 9 & 8 & 9 \\
\hline ami & 2403 & 4 & 2431 & 401 & 801 & 13017 \\
\hline angiopoitin (angpt1) & 143 & 5 & 12 & 4 & 1 & 28 \\
\hline apelin-a/b & 322 & 6 & 38 & 15 & 30 & 47 \\
\hline bFGF (fgf2) & 156 & 22 & 19 & 12 & 24 & 68 \\
\hline bmper & 377 & 101 & 127 & 96 & 153 & 198 \\
\hline chibby & 8 & 7 & 9 & 6 & 6 & 2 \\
\hline chordin & 37 & 2 & 1 & 3 & 4 & 11 \\
\hline ctroponin & 147 & 11 & 3 & 11 & 5 & 7 \\
\hline dkk-1 & 115 & 39 & 99 & 94 & 87 & 53 \\
\hline $\mathrm{dkk}-2$ & 43 & 15 & 6 & 15 & 10 & 16 \\
\hline dkk-3 & 232 & 92 & 59 & 53 & 49 & 369 \\
\hline egln1 (PHD2) & 532 & 1026 & 345 & 274 & 473 & 165 \\
\hline egln2 (PHD1) & 26112 & 35713 & 30931 & 33722 & 27580 & 26829 \\
\hline egln3 (PHD3) & 58 & 54 & 74 & 63 & 57 & 60 \\
\hline egr1-a/b & 508 & 2098 & 1196 & 1636 & 1081 & 622 \\
\hline endoglin & 84 & 5 & 57 & 30 & 67 & 102 \\
\hline epidermal Keratin & 31658 & 112133 & 100861 & 104344 & 84504 & 68498 \\
\hline еро & 16 & 11 & 3 & 7 & 9 & 15 \\
\hline epor & 112 & 15 & 35 & 44 & 17 & 7 \\
\hline er71/etv2 & 37 & 15 & 53 & 22 & 29 & 246 \\
\hline erg-a (v-ets) & 276 & 7 & 113 & 61 & 65 & 158 \\
\hline fgfr-1 & 244 & 45 & 29 & 26 & 49 & 101 \\
\hline fgfr-2 & 768 & 587 & 392 & 466 & 385 & 294 \\
\hline fgfr-3 & 285 & 51 & 34 & 29 & 23 & 90 \\
\hline fgfr-4 & 706 & 89 & 187 & 162 & 153 & 256 \\
\hline flk-1 & 78 & 5 & 54 & 16 & 36 & 170 \\
\hline g6pd & 719 & 361 & 822 & 702 & 701 & 608 \\
\hline gapdh & 8700 & 7347 & 4923 & 5341 & 9563 & 886 \\
\hline hand1 & 274 & 7 & 9 & 15 & 3 & 4 \\
\hline hand2-a & 753 & 251 & 142 & 164 & 141 & 130 \\
\hline indian hedgehog (bhh) & 65 & 5 & 5 & 3 & 5 & 4 \\
\hline jagged-1 & 925 & 164 & 188 & 139 & 227 & 445 \\
\hline
\end{tabular}


Appendix

\begin{tabular}{|c|c|c|c|c|c|c|}
\hline \multirow{2}{*}{ Gene } & \multicolumn{6}{|c|}{ experiment 2} \\
\hline & CE & CC & Etv2 & Etv2/ MO2 & Etv2 /mmMO1 & Etv2 /Fam132b \\
\hline klf2 & 153 & 35 & 85 & 41 & 71 & 144 \\
\hline lipase endothelial & 92 & 77 & 48 & 67 & 51 & 23 \\
\hline lysocardiolipin acyltransferase & 1096 & 1277 & 969 & 1052 & 1263 & 618 \\
\hline mespa-a/b & 2 & 1 & 3 & 2 & 1 & 1 \\
\hline $\operatorname{mix1-b}$ & 3 & 6 & 6 & 7 & 1 & 2 \\
\hline mpo & 3680 & 2 & 15121 & 13637 & 14872 & 8 \\
\hline myosin light chain 1 & 7045 & 2 & 2 & 3 & 1 & 4 \\
\hline$n k x 2.5$ & 116 & 25 & 30 & 43 & 31 & 249 \\
\hline notch-1 & 1329 & 192 & 211 & 165 & 235 & 668 \\
\hline nr2f2 (COUP.TFII) & 569 & 22 & 23 & 13 & 14 & 136 \\
\hline numb & 335 & 553 & 415 & 438 & 596 & 245 \\
\hline patched1 & 489 & 41 & 24 & 27 & 22 & 78 \\
\hline patched2 & 1635 & 14 & 47 & 24 & 39 & 109 \\
\hline pdgf-a & 150 & 30 & 17 & 21 & 21 & 69 \\
\hline phospholipase C gamma 1 (plcg1) & 197 & 108 & 74 & 48 & 92 & 105 \\
\hline runx1 & 97 & 179 & 639 & 416 & 530 & 106 \\
\hline smad1-a & 808 & 594 & 491 & 454 & 601 & 491 \\
\hline smad5 (smad4.2-b) & 58 & 75 & 25 & 28 & 32 & 31 \\
\hline smoothend & 464 & 123 & 78 & 66 & 68 & 163 \\
\hline sonic hedgehog & 173 & 2 & 7 & 5 & 10 & 4 \\
\hline ve-cadherin & 670 & 14 & 298 & 67 & 216 & 1499 \\
\hline vegf $D$ (figf) & 91 & 23 & 28 & 20 & 27 & 11 \\
\hline ventx1.1-a & 8 & 17 & 13 & 15 & 14 & 1 \\
\hline ventx2.1-b & 64 & 21 & 56 & 35 & 50 & 32 \\
\hline wnt11 & 201 & 3 & 2 & 1 & 2 & 59 \\
\hline wnt8 & 10 & 4 & 3 & 7 & 6 & 6 \\
\hline NEG_A & 1 & 4 & 3 & 2 & 4 & 2 \\
\hline NEG_B & 2 & 1 & 1 & 1 & 2 & 1 \\
\hline NEG_C & 4 & 4 & 1 & 2 & 2 & 4 \\
\hline NEG_D & 1 & 5 & 5 & 4 & 3 & 4 \\
\hline NEG_E & 2 & 1 & 3 & 2 & 1 & 1 \\
\hline NEG_F & 2 & 4 & 3 & 2 & 1 & 3 \\
\hline NEG_G & 2 & 3 & 2 & 1 & 2 & 2 \\
\hline NEG_H & 6 & 5 & 4 & 3 & 2 & 3 \\
\hline POS_A & 7135 & 8574 & 5711 & 6265 & 7757 & 6373 \\
\hline POS_B & 3824 & 4561 & 3125 & 3602 & 3900 & 3954 \\
\hline POS_C & 1034 & 1246 & 884 & 974 & 1095 & 1094 \\
\hline POS_D & 200 & 255 & 143 & 177 & 207 & 210 \\
\hline POS_E & 52 & 48 & 39 & 46 & 47 & 27 \\
\hline POS_F & 26 & 29 & 18 & 14 & 20 & 17 \\
\hline
\end{tabular}




\subsection{Processed data from Nanostring nCounter analysis}

Fold Changes over Etv2 for experiment 1 and experiment 2 were calculated. Averaged Fold Changes over Etv2 and standard errors for each sample and gene are shown in Table 11 and Table 12.

Table 11.Averaged fold changes over Etv2 of two independent experiments.

\begin{tabular}{|c|c|c|c|c|c|}
\hline \multirow{2}{*}{ Gene } & \multicolumn{5}{|c|}{ averaged Fold Change over Etv2 } \\
\hline & $\mathrm{CC}$ & Etv2 & Etv2/ MO2 & Etv2 ImmMO1 & Etv2 IFam132b \\
\hline AT3-Globin & 0,00 & 1 & 1,46 & 0,61 & 0,00 \\
\hline Aplnr-a/b & 0,05 & 1 & 0,19 & 0,47 & 2,52 \\
\hline BMP2-a/b & 0,59 & 1 & 0,87 & 0,90 & 0,19 \\
\hline BMP4-b & 1,36 & 1 & 0,57 & 1,20 & 0,35 \\
\hline BMP7.1 & 0,97 & 1 & 0,81 & 1,00 & 0,52 \\
\hline BMP7.2 & 1,17 & 1 & 1,00 & 1,00 & 1,00 \\
\hline Castor & 0,58 & 1 & 0,66 & 0,61 & 0,93 \\
\hline Cerberus & 0,72 & 1 & 0,83 & 0,82 & 0,18 \\
\hline FGF4b & 0,45 & 1 & 1,28 & 1,60 & 0,45 \\
\hline Fam32B & 0,86 & 1 & 3,89 & 1,39 & 1452,73 \\
\hline Ferritin (fth1-a)) & 0,95 & 1 & 0,78 & 1,59 & 0,75 \\
\hline Ferroportin (slc40a1) & 1,22 & 1 & 0,79 & 1,02 & 0,28 \\
\hline Follistatin & 0,22 & 1 & 0,22 & 0,27 & 5,38 \\
\hline Foxc1a & 0,96 & 1 & 0,44 & 1,33 & 1,02 \\
\hline GATA-1-a & 0,16 & 1 & 1,27 & 0,68 & 0,03 \\
\hline GATA-2 & 0,78 & 1 & 1,09 & 1,06 & 0,64 \\
\hline GATA-3 & 1,33 & 1 & 0,82 & 1,12 & 0,56 \\
\hline Gli2 & 1,56 & 1 & 0,88 & 1,00 & 1,48 \\
\hline Gli3 & 1,59 & 1 & 1,00 & 1,36 & 1,85 \\
\hline Gli4 & 1,11 & 1 & 0,69 & 1,15 & 2,98 \\
\hline $\mathrm{H} 4$ & 0,75 & 1 & 0,68 & 0,83 & 0,13 \\
\hline HIF-1a & 0,85 & 1 & 0,85 & 0,96 & 0,61 \\
\hline HIF-2a (epas1) & 1,77 & 1 & 0,85 & 1,00 & 0,40 \\
\hline LMO-2 & 0,00 & 1 & 0,80 & 0,70 & 0,28 \\
\hline Lmo4 & 0,47 & 1 & 0,80 & 0,86 & 0,72 \\
\hline Mix2 & 1,48 & 1 & 0,87 & 1,09 & 0,21 \\
\hline Msx2 & 1,57 & 1 & 0,71 & 1,00 & 0,41 \\
\hline MyT1 & 1,32 & 1 & 1,07 & 1,27 & 9,89 \\
\hline NCAMa/b & 0,51 & 1 & 2,68 & 1,13 & 262,77 \\
\hline Noggin & 0,47 & 1 & 0,40 & 0,71 & 3,40 \\
\hline ODC & 1,00 & 1 & 1,00 & 1,00 & 1,00 \\
\hline PECAM1 & 0,14 & 1 & 0,41 & 0,68 & 2,37 \\
\hline Prox-1 & 0,10 & 1 & 0,69 & 0,89 & 0,43 \\
\hline $\mathrm{SCL}$ & 0,01 & 1 & 1,09 & 0,62 & 0,67 \\
\hline SPIB-a & 0,03 & 1 & 1,42 & 1,86 & 0,05 \\
\hline STAT-5 & 1,95 & 1 & 0,91 & 1,52 & 0,21 \\
\hline
\end{tabular}


Appendix

\begin{tabular}{|c|c|c|c|c|c|}
\hline \multirow{2}{*}{ Gene } & \multicolumn{5}{|c|}{ averaged Fold Change over Etv2 } \\
\hline & CC & Etv2 & Etv2/ MO2 & Etv2 ImmMO1 & Etv2 /Fam132b \\
\hline Siamois & 1,17 & 1 & 4,22 & 1,72 & 1,00 \\
\hline Sizzled & 0,51 & 1 & 0,98 & 1,17 & 0,27 \\
\hline Sox2 & 0,37 & 1 & 0,66 & 0,96 & 12,73 \\
\hline Sox3 & 0,88 & 1 & 0,53 & 1,29 & 11,52 \\
\hline TGFB-1 & 0,25 & 1 & 0,88 & 0,72 & 0,92 \\
\hline VEGF C & 0,44 & 1 & 0,85 & 0,97 & 0,70 \\
\hline VEGFR-1 (FIt1) & 0,05 & 1 & 0,24 & 0,27 & 2,73 \\
\hline Vegfa-a/b & 0,88 & 1 & 0,72 & 0,94 & 0,73 \\
\hline Vent1 & 0,44 & 1 & 1,09 & 1,22 & 0,05 \\
\hline Vent2 & 0,35 & 1 & 0,58 & 0,80 & 0,21 \\
\hline Xbra-a & 0,66 & 1 & 0,66 & 1,41 & 2,36 \\
\hline Xbra-b & 1,00 & 1 & 1,00 & 1,00 & 1,00 \\
\hline Xhex & 0,02 & 1 & 0,67 & 0,98 & 0,49 \\
\hline Xnr3 & 0,62 & 1 & 0,89 & 2,19 & 0,49 \\
\hline Xpo & 1,17 & 1 & 0,81 & 1,19 & 0,41 \\
\hline actb & 1,05 & 1 & 0,94 & 1,28 & 0,46 \\
\hline activin B & 1,13 & 1 & 0,61 & 1,09 & 2,96 \\
\hline admp2 & 0,43 & 1 & 1,07 & 1,21 & 0,44 \\
\hline ami & 0,00 & 1 & 0,31 & 0,36 & 2,54 \\
\hline angiopoitin (angpt1) & 0,55 & 1 & 0,55 & 0,55 & 7,50 \\
\hline apelin-a/b & 0,22 & 1 & 0,39 & 0,63 & 0,83 \\
\hline bFGF (fgf2) & 0,89 & 1 & 0,66 & 1,33 & 1,84 \\
\hline bmper & 0,56 & 1 & 0,65 & 0,94 & 0,97 \\
\hline chibby & 0,33 & 1 & 0,62 & 2,28 & 0,30 \\
\hline chordin & 0,72 & 1 & 0,72 & 1,04 & 2,33 \\
\hline ctroponin & 3,43 & 1 & 4,22 & 1,63 & 2,14 \\
\hline dkk-1 & 0,51 & 1 & 0,67 & 0,91 & 0,17 \\
\hline dkk-2 & 2,76 & 1 & 3,08 & 2,68 & 1,70 \\
\hline dkk-3 & 1,22 & 1 & 0,65 & 0,78 & 4,19 \\
\hline egln1 (PHD2) & 2,00 & 1 & 0,57 & 1,08 & 0,32 \\
\hline egln2 (PHD1) & 1,20 & 1 & 0,88 & 1,05 & 0,39 \\
\hline egln3 (PHD3) & 0,76 & 1 & 0,94 & 1,24 & 0,92 \\
\hline egr1-a/b & 1,47 & 1 & 1,03 & 1,34 & 0,53 \\
\hline endoglin & 0,01 & 1 & 0,45 & 0,99 & 1,23 \\
\hline epidermal Keratin & 1,18 & 1 & 1,03 & 1,01 & 0,39 \\
\hline еро & 2,97 & 1 & 1,82 & 3,72 & 2,86 \\
\hline epor & 0,42 & 1 & 1,40 & 1,27 & 0,05 \\
\hline er71/etv2 & 0,11 & 1 & 0,29 & 0,46 & 2,42 \\
\hline erg-a (v-ets) & 0,01 & 1 & 0,62 & 0,65 & 0,76 \\
\hline fgfr-1 & 1,12 & 1 & 0,54 & 1,24 & 1,60 \\
\hline fgfr-2 & 1,28 & 1 & 0,97 & 1,03 & 0,52 \\
\hline fgfr-3 & 1,05 & 1 & 0,51 & 0,54 & 1,69 \\
\hline fgfr-4 & 0,35 & 1 & 0,71 & 0,74 & 1,02 \\
\hline flk-1 & 0,01 & 1 & 0,27 & 0,48 & 1,55 \\
\hline
\end{tabular}


Appendix

\begin{tabular}{|c|c|c|c|c|c|}
\hline \multirow{2}{*}{ Gene } & \multicolumn{5}{|c|}{ averaged Fold Change over Etv2 } \\
\hline & CC & Etv2 & Etv2/ MO2 & Etv2 /mmMO1 & Etv2 /Fam132b \\
\hline g6pd & 0,55 & 1 & 1,41 & 2,34 & 0,45 \\
\hline gapdh & 1,40 & 1 & 0,65 & 1,40 & 0,08 \\
\hline hand1 & 0,21 & 1 & 1,37 & 0,31 & 0,18 \\
\hline hand2-a & 1,48 & 1 & 1,09 & 1,08 & 0,64 \\
\hline indian hedgehog (bhh) & 0,72 & 1 & 0,72 & 1,34 & 0,72 \\
\hline jagged-1 & 0,75 & 1 & 0,56 & 0,96 & 1,34 \\
\hline klf2 & 0,26 & 1 & 0,32 & 0,82 & 1,29 \\
\hline lipase endothelial & 0,96 & 1 & 0,94 & 0,97 & 0,18 \\
\hline lysocardiolipin acyltransferase & 1,28 & 1 & 0,92 & 1,25 & 0,40 \\
\hline mespa-a/b & 1,00 & 1 & 1,00 & 1,00 & 1,00 \\
\hline $\operatorname{mix} 1-b$ & 0,76 & 1 & 2,29 & 0,76 & 0,76 \\
\hline mpo & 0,00 & 1 & 1,25 & 1,37 & 0,00 \\
\hline myosin light chain 1 & 0,50 & 1 & 0,50 & 0,50 & 0,51 \\
\hline$n k x 2.5$ & 1,09 & 1 & 2,70 & 2,48 & 8,61 \\
\hline notch-1 & 0,64 & 1 & 0,63 & 0,96 & 1,94 \\
\hline nr2f2 (COUP.TFII) & 0,60 & 1 & 0,28 & 0,47 & 4,09 \\
\hline numb & 1,26 & 1 & 0,87 & 1,25 & 0,34 \\
\hline patched1 & 1,15 & 1 & 0,60 & 0,71 & 1,73 \\
\hline patched2 & 0,09 & 1 & 0,26 & 0,52 & 1,32 \\
\hline pdgf-a & 1,18 & 1 & 0,72 & 1,20 & 2,31 \\
\hline phospholipase C gamma 1 (plcg1) & 0,93 & 1 & 0,39 & 0,90 & 0,95 \\
\hline runx1 & 0,25 & 1 & 0,83 & 0,89 & 0,18 \\
\hline smad1-a & 1,07 & 1 & 0,79 & 1,14 & 0,60 \\
\hline smad5 (smad4.2-b) & 2,20 & 1 & 0,71 & 1,14 & 0,74 \\
\hline smoothend & 1,05 & 1 & 0,59 & 0,69 & 1,20 \\
\hline sonic hedgehog & 0,21 & 1 & 0,23 & 1,40 & 0,44 \\
\hline ve-cadherin & 0,01 & 1 & 0,24 & 0,52 & 2,53 \\
\hline vegf $D$ (figf) & 0,56 & 1 & 0,63 & 0,79 & 0,15 \\
\hline ventx1.1-a & 0,81 & 1 & 1,38 & 0,90 & 0,26 \\
\hline ventx2.1-b & 0,21 & 1 & 0,82 & 0,85 & 0,21 \\
\hline wnt11 & 0,61 & 1 & 0,61 & 0,61 & 20,33 \\
\hline wnt8 & 1,00 & 1 & 2,12 & 5,00 & 1,00 \\
\hline
\end{tabular}

Table 12. Standard errors of the fold change over Etv2 shown in Table 11.

\begin{tabular}{l|crrrr}
\hline \multirow{2}{*}{ Gene } & \multicolumn{5}{c}{ standard error } \\
\cline { 2 - 6 } & CC & Etv2 & Etv2/ MO2 & Etv2 /mmMO1 & Etv2 /Fam132b \\
\hline AT3-Globin & 0,00 & 0 & 0,54 & 0,22 & 0,00 \\
Aplnr-a/b & 0,03 & 0 & 0,00 & 0,21 & 0,61 \\
BMP2-a/b & 0,01 & 0 & 0,12 & 0,27 & 0,06 \\
BMP4-b & 0,24 & 0 & 0,24 & 0,44 & 0,01 \\
BMP7.1 & 0,03 & 0 & 0,11 & 0,13 & 0,05 \\
BMP7.2 & 0,17 & 0 & 0,00 & 0,00 & 0,00 \\
Castor & 0,01 & 0 & 0,04 & 0,09 & 0,53 \\
Cerberus & 0,14 & 0 & 0,72 & 0,70 & 0,07 \\
\hline & & & & & 124
\end{tabular}


Appendix

\begin{tabular}{|c|c|c|c|c|c|}
\hline \multirow{2}{*}{ Gene } & \multicolumn{5}{|c|}{ standard error } \\
\hline & CC & Etv2 & Etv2/ MO2 & Etv2 /mmMO1 & Etv2 /Fam132b \\
\hline FGF4b & 0,36 & 0 & 1,07 & 1,50 & 0,36 \\
\hline Fam32B & 0,14 & 0 & 2,72 & 1,11 & 1402,95 \\
\hline Ferritin (fth1-a)) & 0,17 & 0 & 0,14 & 0,47 & 0,02 \\
\hline Ferroportin (slc40a1) & 0,11 & 0 & 0,01 & 0,16 & 0,01 \\
\hline Follistatin & 0,10 & 0 & 0,19 & 0,26 & 2,77 \\
\hline Foxc1a & 0,09 & 0 & 0,02 & 0,48 & 0,01 \\
\hline GATA-1-a & 0,05 & 0 & 0,25 & 0,12 & 0,00 \\
\hline GATA-2 & 0,02 & 0 & 0,19 & 0,43 & 0,48 \\
\hline GATA-3 & 0,11 & 0 & 0,02 & 0,09 & 0,01 \\
\hline Gli2 & 0,15 & 0 & 0,08 & 0,07 & 0,48 \\
\hline Gli3 & 0,25 & 0 & 0,17 & 0,02 & 0,13 \\
\hline Gli4 & 0,07 & 0 & 0,13 & 0,24 & 1,26 \\
\hline $\mathrm{H} 4$ & 0,19 & 0 & 0,19 & 0,32 & 0,05 \\
\hline HIF-1a & 0,03 & 0 & 0,00 & 0,10 & 0,04 \\
\hline HIF-2a (epas1) & 0,10 & 0 & 0,05 & 0,20 & 0,01 \\
\hline LMO-2 & 0,00 & 0 & 0,08 & 0,00 & 0,17 \\
\hline Lmo4 & 0,04 & 0 & 0,08 & 0,34 & 0,16 \\
\hline Mix2 & 0,06 & 0 & 0,02 & 0,06 & 0,00 \\
\hline Msx2 & 0,18 & 0 & 0,06 & 0,00 & 0,03 \\
\hline МуТ1 & 0,14 & 0 & 0,09 & 0,23 & 3,16 \\
\hline NCAMa/b & 0,49 & 0 & 2,66 & 1,12 & 256,98 \\
\hline Noggin & 0,12 & 0 & 0,20 & 0,28 & 1,72 \\
\hline ODC & 0,00 & 0 & 0,00 & 0,00 & 0,00 \\
\hline PECAM1 & 0,01 & 0 & 0,11 & 0,53 & 0,01 \\
\hline Prox-1 & 0,03 & 0 & 0,03 & 0,01 & 0,22 \\
\hline $\mathrm{SCL}$ & 0,00 & 0 & 0,13 & 0,13 & 0,31 \\
\hline SPIB-a & 0,00 & 0 & 0,84 & 0,98 & 0,01 \\
\hline STAT-5 & 0,32 & 0 & 0,06 & 0,09 & 0,01 \\
\hline Siamois & 0,17 & 0 & 3,22 & 0,53 & 0,00 \\
\hline Sizzled & 0,18 & 0 & 0,39 & 0,41 & 0,14 \\
\hline Sox2 & 0,13 & 0 & 0,30 & 0,39 & 7,20 \\
\hline Sox3 & 0,16 & 0 & 0,19 & 0,61 & 5,36 \\
\hline TGFB-1 & 0,03 & 0 & 0,10 & 0,18 & 0,16 \\
\hline VEGF C & 0,13 & 0 & 0,25 & 0,33 & 0,07 \\
\hline VEGFR-1 (Flt1) & 0,01 & 0 & 0,12 & 0,03 & 0,75 \\
\hline Vegfa-a/b & 0,03 & 0 & 0,23 & 0,23 & 0,00 \\
\hline Vent1 & 0,05 & 0 & 0,37 & 0,19 & 0,02 \\
\hline Vent2 & 0,16 & 0 & 0,18 & 0,14 & 0,11 \\
\hline Xbra-a & 0,34 & 0 & 0,34 & 1,09 & 2,04 \\
\hline Xbra-b & 0,00 & 0 & 0,00 & 0,00 & 0,00 \\
\hline Xhex & 0,01 & 0 & 0,11 & 0,12 & 0,20 \\
\hline Xnr3 & 0,19 & 0 & 0,72 & 0,90 & 0,32 \\
\hline Хро & 0,23 & 0 & 0,13 & 0,10 & 0,04 \\
\hline actb & 0,02 & 0 & 0,12 & 0,17 & 0,06 \\
\hline
\end{tabular}


Appendix

\begin{tabular}{|c|c|c|c|c|c|}
\hline \multirow{2}{*}{ Gene } & \multicolumn{5}{|c|}{ standard error } \\
\hline & CC & Etv2 & Etv2/ MO2 & Etv2 /mmMO1 & Etv2 IFam132b \\
\hline activin B & 0,61 & 0 & 0,02 & 0,55 & 1,06 \\
\hline admp2 & 0,01 & 0 & 0,61 & 0,70 & 0,01 \\
\hline ami & 0,00 & 0 & 0,17 & 0,02 & 0,45 \\
\hline angiopoitin (angpt1) & 0,45 & 0 & 0,45 & 0,45 & 5,95 \\
\hline apelin-a/b & 0,20 & 0 & 0,11 & 0,19 & 0,16 \\
\hline bFGF (fgf2) & 0,12 & 0 & 0,19 & 0,13 & 0,50 \\
\hline bmper & 0,14 & 0 & 0,01 & 0,31 & 0,10 \\
\hline chibby & 0,10 & 0 & 0,24 & 1,66 & 0,13 \\
\hline chordin & 0,28 & 0 & 0,28 & 0,04 & 0,43 \\
\hline ctroponin & 2,43 & 0 & 3,22 & 0,63 & 1,14 \\
\hline dkk-1 & 0,19 & 0 & 0,13 & 0,01 & 0,11 \\
\hline $\mathrm{dkk}-2$ & 2,58 & 0 & 2,90 & 1,75 & 1,52 \\
\hline dkk-3 & 0,21 & 0 & 0,11 & 0,08 & 0,49 \\
\hline egln1 (PHD2) & 0,72 & 0 & 0,10 & 0,33 & 0,06 \\
\hline egln2 (PHD1) & 0,15 & 0 & 0,04 & 0,14 & 0,09 \\
\hline egln3 (PHD3) & 0,13 & 0 & 0,22 & 0,45 & 0,49 \\
\hline egr1-a/b & 0,12 & 0 & 0,12 & 0,41 & 0,24 \\
\hline endoglin & 0,00 & 0 & 0,03 & 0,25 & 0,22 \\
\hline epidermal Keratin & 0,17 & 0 & 0,16 & 0,16 & 0,01 \\
\hline еро & 2,89 & 0 & 1,42 & 3,62 & 2,69 \\
\hline epor & 0,15 & 0 & 0,30 & 0,81 & 0,03 \\
\hline er71/etv2 & 0,06 & 0 & 0,02 & 0,08 & 0,33 \\
\hline erg-a (v-ets) & 0,00 & 0 & 0,17 & 0,07 & 0,01 \\
\hline fgfr-1 & 0,33 & 0 & 0,22 & 0,66 & 0,54 \\
\hline fgfr-2 & 0,08 & 0 & 0,04 & 0,02 & 0,11 \\
\hline fgfr-3 & 0,34 & 0 & 0,21 & 0,15 & 0,12 \\
\hline fgfr-4 & 0,06 & 0 & 0,02 & 0,10 & 0,26 \\
\hline flk-1 & 0,00 & 0 & 0,06 & 0,20 & 0,29 \\
\hline g6pd & 0,16 & 0 & 0,69 & 1,47 & 0,03 \\
\hline gapdh & 0,05 & 0 & 0,27 & 0,58 & 0,02 \\
\hline hand1 & 0,03 & 0 & 0,68 & 0,14 & 0,00 \\
\hline hand2-a & 0,14 & 0 & 0,11 & 0,06 & 0,14 \\
\hline indian hedgehog (bhh) & 0,28 & 0 & 0,28 & 0,91 & 0,28 \\
\hline jagged-1 & 0,03 & 0 & 0,06 & 0,29 & 0,01 \\
\hline klf2 & 0,07 & 0 & 0,07 & 0,04 & 0,34 \\
\hline lipase endothelial & 0,52 & 0 & 0,28 & 0,15 & 0,03 \\
\hline lysocardiolipin acyltransferase & 0,08 & 0 & 0,00 & 0,08 & 0,04 \\
\hline mespa-a/b & 0,00 & 0 & 0,00 & 0,00 & 0,00 \\
\hline $\operatorname{mix} 1-b$ & 0,24 & 0 & 0,62 & 0,24 & 0,24 \\
\hline mpo & 0,00 & 0 & 0,49 & 0,37 & 0,00 \\
\hline myosin light chain 1 & 0,50 & 0 & 0,50 & 0,50 & 0,49 \\
\hline$n k x 2.5$ & 0,41 & 0 & 1,41 & 1,37 & 3,32 \\
\hline notch-1 & 0,18 & 0 & 0,02 & 0,19 & 0,15 \\
\hline nr2f2 (COUP.TFII) & 0,19 & 0 & 0,13 & 0,12 & 0,21 \\
\hline
\end{tabular}


Appendix

\begin{tabular}{l|ccccr}
\hline \multirow{2}{*}{ Gene } & \multicolumn{5}{c}{ standard error } \\
\cline { 2 - 6 } & CC & Etv2 & Etv2/ MO2 & Etv2 ImmMO1 & Etv2 /Fam132b \\
\hline numb & 0,05 & 0 & 0,02 & 0,23 & 0,02 \\
patched1 & 0,49 & 0 & 0,39 & 0,27 & 0,30 \\
patched2 & 0,08 & 0 & 0,14 & 0,33 & 0,02 \\
\hline pdgf-a & 0,56 & 0 & 0,43 & 0,24 & 0,45 \\
phospholipase C gamma 1 (plcg1) & 0,40 & 0 & 0,15 & 0,40 & 0,17 \\
runx1 & 0,00 & 0 & 0,28 & 0,04 & 0,10 \\
smad1-a & 0,03 & 0 & 0,01 & 0,12 & 0,04 \\
\hline smad5 (smad4.2-b) & 0,86 & 0 & 0,28 & 0,29 & 0,09 \\
smoothend & 0,40 & 0 & 0,12 & 0,21 & 0,01 \\
\hline sonic hedgehog & 0,11 & 0 & 0,13 & 1,30 & 0,12 \\
ve-cadherin & 0,01 & 0 & 0,06 & 0,22 & 0,31 \\
\hline vegf D (figf) & 0,10 & 0 & 0,05 & 0,24 & 0,05 \\
ventx1.1-a & 0,38 & 0 & 0,28 & 0,39 & 0,17 \\
\hline ventx2.1-b & 0,06 & 0 & 0,31 & 0,07 & 0,06 \\
wnt11 & 0,39 & 0 & 0,39 & 0,39 & 15,83 \\
wnt8 & 0,00 & 0 & 1,12 & 1,48 & 0,00 \\
\hline
\end{tabular}




\section{Curriculum Vitae}

Name: Juliane Melchert

Date of Birth: $\quad 22.07 .1982$

Place of Birth: Neubrandenburg, Germany

Address: $\quad$ Robert-Koch-Str. 1, 37075 Göttingen, Germany

Email: $\quad$ jmelche1@gwdg.de

\section{Education:}

01.2008 - 12.2013 Doctoral studies: "Expression screen for Wnt signaling-like phenotypes identifies Fam132b as anovel inhibitor of BMP signaling in Xenopus"

Dept. of Developmental Biochemistry, University of Göttingen, Germany. Advisor: Prof. Dr. T. Pieler.

28.12.2007

Diploma, Georg-August University, Göttingen Germany

Diploma studies: "Die Rolle der kanonischen Wnt

Signaltransduktion bei der Differenzierung des

Gastrointestinaltrakts in Xenopus laevis".

Dept. of Developmental Biochemistry, University of

Göttingen, Germany. Advisor: Prof. Dr. T. Pieler.

$2004-2007$ Biology studies, Georg-August University, Göttingen Germany

19.10.2004 Vordiplom, Georg-August University, Göttingen Germany

$2002-2004 \quad$ Biology studies, Georg-August University, Göttingen Germany

21.06 .2002

Abitur, Curie-Gymnasium Neubrandenburg, Germany

\section{Publications:}

Damianitsch K, Melchert J, Pieler T (2009). XsFRP5 modulates endodermal organogenesis in Xenopus laevis. Dev Biol. 329(2): 327-37. 